\title{
Siutakahe'ahoafā: \\ Navigating the Kingdom of Tonga's national development priorities under international aid.
}

$B Y$

Faka'iloatonga Taumoefolau

A thesis

submitted to the Victoria University of Wellington in fulfilment of the requirements for the degree of Doctor of Philosophy

Victoria University of Wellington

2020 


\section{Abstract}

The title of this thesis - Siutaka he 'aho afā - is interpreted as 'Day storm voyager'. This title encapsulates the journeys undertaken by the Kingdom of Tonga as it navigates the ocean of international development and the frequent challenges or 'storms' it encounters. This research seeks to understand better how Tonga articulates and pursues its national development priorities in the context of international aid. It focuses in particular on Country Programmable Aid to Tonga from Australia and New Zealand in the years 2013-17 and how the Paris Declaration on Aid Effectiveness Principles are applied to Tonga. The main research question addressed is: 'To what extent are the national development priorities of Tonga shaped or supported by international aid?'

The research is qualitative in approach and is composed of two sources of data: from in-depth interviews with a range of both Tongan and donor officials; and analysis of key aid and development documents. It examines the political and administrative context of Tonga, highlighting the political environment, changing leadership and the direction set by its strategic goals for development. It then looks in detail at the aid activities of, respectively, Australia and New Zealand, and analyses their various priorities and ways of operating.

The research uses the five Paris Declaration principles for aid effectiveness as a framework to analyse the way aid relationships and interactions occurred in Tonga over the period. There was generally high-level support for the Paris principles and these supported the idea that the Government of Tonga should 'own' its development, by drafting and implementing its development priorities and strategies. This was supported by agreement to abide by the principles of alignment with Tongan systems and Harmonisation amongst donors as well as pursuing practices which enhanced results-based management and accountability. However, in the details of daily interactions and practices, we also saw how these high-level agreements were often diluted or confused. Although Tonga had its own set of priorities, donors continued to choose which of these they would fund, according to their own strategic goals and concerns. Furthermore, given significant issues of capacity to operate effectively in the aid environment, with much onus on Tongan officials and agencies to provide data, report on progress, consult with the public and engage closely with donors, we saw how Tonga often struggled to exert strong and consistent leadership and control of aid-supported development.

In drawing broader conclusions, the Paris Declaration is found to be a step in the right direction for improving the effectiveness of foreign aid to Tonga. However, what determines the likelihood of effectiveness is multifaceted, and dependent on will, need, and, perhaps most importantly, on Tonga's 
leadership. It is found that the most fundamental factor for Tonga - both a unique challenge and a strength - is the enduring resilience of our culture together with our leadership code. 


\section{Dedication}

This PhD is dedicated to my mother Heleni Taiana Tapealava (1962 - 2005) from Mo'unga'one, Ha'apai and Kolomotu'a/Ha'avakatolo, Tongatapu.

You endured being a single mother who believed in her children.

You taught us how to survive but more importantly you raised me to be the man I am today. Rest in love and know I will always strive to make you proud.

To my father Siutakahe'ahoafā Taumoefolau from Hunga, Vava'u.

You continue to teach me every day about being content with what I have and to respect my ambitions.

To my siblings Kitefakalau-e-maama my tehina you are a better man of character than I am, Tinalasa our tuofefine you embody the beautiful strength of our mother, Siosiua Matangi you have so much potential, and my son Siutakahe'ahoafā you continue to give us hope as the bedrock of our little family. Thank you for being patient with your brother/father. I love you all.

"Ko e anga mo'ui 'oku fakalakalaka ki mu'a”

"Life is about progress"

To my mentor and an inspiration to the country, Dr Netatua Prescott Taufatofua, who sadly passed away during my studies. A formidable woman and internationally recognized environmental scientist who dedicated her life to serving communities. 


\section{Acknowledgement}

Ko e 'Otua 'oku 'o'ona 'a e lāngilangi. Representation is important to me as a Tongan and as a researcher. I know I am the fruition of many sacrifices, dedication to duty, family, and responsibility for which generations before me laid the foundation. I acknowledge this foundation for I am immensely proud of my linage with each thread on my paternal and maternal bloodline inspiring the values for which I myself aim to live up to in character and in conduct. There is a saying in Tongan 'oua e mo'ui ngalo which means do not forget who you are and where you came from, as in your heritage, your family, and your fatongia. This academic milestone is no doubt an important achievement but what is even more meaningful is how I honour this foundation for who I am today with who I will be tomorrow for the next generation.

Taumoefolau/Vaonukonuka. I acknowledge my Taumoefolau bloodline from Hunga, Vava'u and have taken inspiration from the children of my paternal great grandfather 'Eneasitangiholakeituai. Taunaholo, son of Pāpani, and Malakai, son of Fä'one, who revered and respected their paternal uncles; Sailosi Fä'one the eldest; Kalisi 'Ovava and Hepisipa who were highly respected by their brothers; Rev. Tu'ipulotu Toutaiolepo the leader; Siua the gentle soul; Simione Faka'iloatonga (my grandfather for which I have taken his middle name) a man of stature; Manu-siu-mo-'eva-he-fisi'inaua the strongest and feared but cared most to ensure success of the next generation; Tupoutu'a with her strength to endure; and Tu'ifua who was destined for more. Each have contributed to the betterment of our culture particularly in music, faith, education, and demonstrated an ethos for serving others without expectations. I appreciate better the principles of loto fakatōkilalo, uouongataha, and faka'apa'apa with my own journey in learning about them and hopefully add my contribution to the legacy they forged for the Taumoefolau bloodline.

Tapealava/Kali-o-Pau. I acknowledge my maternal Tapealava bloodline from Mo'unga'one, Ha'apai who have moulded and shaped me to embrace my responsibility. With the mantra of 'we serve to fulfil our responsibilities', I think a lot of the sacrifice my great grandfather Siosaia Tapealava made when he heeded the call by the Church (Siasi Tonga Hou'eiki) to serve at the Fua'amotu congregation. He built a boat and sailed with all his children from Mo'unga'one to Tongatapu. Education was and continues to be a hallmark for the family. A special place in my heart, given he is an alumnus, is for my great uncle Tafokitau Tapealava who is a Maamaloa Loumaile (the Honour Board with distinction) and Dux 1946 of Tupou College when it was still located at Nafualu. Toakase Fe'ao, Mele Fe'ofa'aki, and Hu'aniu as sisters all led their siblings from Makineti, Nehasi Moi, Malakai, Longo, and the twins Siosi and Sauni through school and in life. On the other side of this multifaceted family, to great uncle 
Muli ki Ofolanga Tu'anaki, Sione Tu'anaki, 'Isileli together with great aunts 'Oliva, Meliana, Puli ki Vaiola, Sofaia and Uila (children of Siale) and siblings of my mother Sateki, Valenisia, loane, 'Ilai, and Taufia I remember and acknowledge the love you showed my mother. The dedication to fatongia, $a k o$, lotu, and ngāue mālohi motivated me growing up and to continue striving for a brighter future.

Prescott/Sia ko Veiongo. Grandpa and Grandma, Viliami Vea 'o loto Neiafu Prescott (Vanaa) and Mele Fe'ofa'aki Prescott (née Tapealava) who embodied the qualities and spirit to succeed. Vea was a man steadfast and unwavering in his expectations of us when it came to education. Rightly so, for I am disciplined enough to embrace the challenges in life because of his akonaki (teachings). Mele Fe'ofa'aki always pushing us to be better in life. To Dr Lesieli Tongati'o who exemplifies diligence; 'Ikani Latu, a measured man who reminds us to lead with our heart; Kolopeaua always ready for the needs of our family; Dr Netatua Prescott the most courageous woman I know and Mavae who gives supports unequivocally, thank you. I learnt a lot from 'Ana Tu'iano a woman skilled in rhetoric who nurtured my confidence to engage in our cultural oratory at my mother's funeral. The values that guide my work ethic and placing weight on integrity is because you have raised me to understand mamahi'i me'a, fua kavenga, and loto to'a.

Uhi/Sia ko Veiongo. My mother is a great grandniece of Uhi Sione Latu (also known as Uhi Sitauni) through his sister. Part of my upbringing was growing up in Kolomotu'a with uncles and great uncles on my maternal side who had a huge impact on my life. Most notably Lopeti Uhi with a work ethic second to none in my view. I am indebted to the many experiences joining Lopeti at the siaine (banana), ma'ala 'ufi (yam), talo (taro) and lesi (pawpaw) plantations. On these plantation fields I learned immeasurable lessons about toil which I have applied later in life. 'Olive Uhi who personified patience and Hopoi Uhi, a staunch Tonga College alumnus and proud Hala 'Alipate local, taught me how to be fearless. Tevita Uhi who is a hard case but somehow unites the family. This reality is not a given and my Uhi family have shown me what mateaki and matengata'a means for the right reasons.

Naitoko/Vai ko Hiva. I acknowledge the family of my biological grandfather, Lopeti Vikatoa Naitoko, whom my mother is his youngest child after 'Ana, Lu'isa, 'Ifalemi, Siunipa, Heikolo 'Ofa ki Nasinu, and Fotuika Laviena. Uhi Sione Latu had three sisters Akesa, Lesieli Pupumoahi (married George Prescott), and Siosi (married Joshua Cocker). Akesa the eldest child married 'Etueni (Siuta) Malanga of Ha'avakatolo. Their children were Sione 'Osaiasi Naitoko (my great grandfather), Hāmala, Seinihuihui and Pinomi. Sione 'Osaiasi Naitoko married Heikolo Hafoka daughter of Rev. Sione Hafoka and Niufo'ou Kavapalu. Named by the King's daughter, Salote Mafile'o Pilolevu, Heikolo (Hē-'i-Koro) means 
exiled in Koro (Fiji) for she was born 1888 when the schism between the Siasi Tonga (Free Church of Tonga) and Siasi Fakaongo (now the Free Wesleyan Church of Tonga) occurred and members of the latter were exiled to Fiji. Rev. Sione Hafoka went to Sāmoa in 1896 and is buried at Piula Theological College Lufilufi. I have learned that my grandfather, Vikatoa Naitoko left school early to help his mother take care of his siblings after the premature death of his father. For this and more, I have the utmost respect for my Naitoko bloodline in feilaulau and mo'ui lōtolu, setting us grandchildren examples of what matters most in life.

Throughout my life different family and friends have left an indefinable imprint that has inspired me. To Fotu 'a ika ta'ane, Dowager Lady Fielakepa Tunakaimanu and Temaleti Manakovimomoho, thank you for anchoring this nomadic soul to grow and serve with all the other generations at Fale Tonga. Mei he 'otu mu'omu'a Nomuka, Ha'apai pea mo Hihifo, Niuatoputapu my paternal grandma Tinalasa Taumoefolau (née Makasini), daughter of Supiesi Makasini and Pakile Finau, your calm devotion and commitment to our family through your faith reminds us all there is more than today. Isileli and Manakovi Tupou (née Taumoefolau) I have valued your insight and encouragement for me to continue independently, finding my own path but knowing your thoughtful admiration, is humbling. Masela and children, all that you have done is still counted. Ki he Afo e Teau Rev. Vaokotone Teaupa his wife Seini Kauvaka Teaupa and children Sione, Siaosi, Rev. Nafetalai, Otolose, Olo'imoana, Elizabeth, and Samisoni. As Seini would say "Ha feitu'u pe te tau 'alu ki ai, 'oua pe na'a ngalo ko e afo pe taha na'a tau tupu hake ai." During my years at Tupou College you counted me as your own and I hold that dear with gratitude.

Thank you to the Canada High Commission in Wellington for trusting me to be the Canada Fund for Local Initiatives (CFLI) Coordinator for Fiji, Kiribati, Sāmoa, Tonga and Tuvalu throughout my time as a PhD student. Always making sure I wore my ta'ovala on visits, I count my blessings to be reminded by our people across Oceania of our spirit to persevere. There is a sense of poetic resonance that just like the voyaging of our seafaring people in the past this thesis remembers those ancient linkages for Tonga because I wrote it on the islands of Savai'i, Upolu, and Manono in Sāmoa; Vanua Levu (Labasa) and Viti Levu (Nadi, and Suva) in Fiji; Tongatapu, 'Eua, and Vava'u in Tonga; and Tarawa in Kiribati.

My supervisor Prof. John Overton (Director of Development Studies) you have been incredibly generous with your guidance and ensuring my identity is reflected in this thesis. You are a humble and good soul, fakamālō lahi atu mo e hounga'ia Prof. John. I acknowledge the Ministry of Foreign Affairs and Trade of New Zealand for this PhD scholarship that enables me to fulfil my promise to my late 
mother. My friends and colleagues at the School of Geography, Environment and Earth Sciences DEVE and Post Graduate Student Association (as a former Executive Member) I will cherish the friendships knowing more awaits us in the world. Wellingtonians Alison, Nela, and Martin keep being determined in all you do.

Lastly, I reflect on my life and my humble background. From joining my mother and father in the fruit picking fields near Robinvale in Victoria Australia as immigrants to being raised by our single mother in Tonga. Days when a PhD would be as far as the stars at night, I would look up and only dream. Truly, my heart aches knowing my mother, Heleni Taiana Tapealava, is not here to see what I have become despite the trials. She made sure I knew a dream begins with an unyielding resilient will and hard work. As I complete this chapter another destination has appeared on the horizon. One that maybe is what life has prepared me for intuitively.

'Oku tu'a hoku sino, ka 'oku 'eiki hoku fekau. 


\section{Acronyms}

AAP

ADB

ADC

AusAID

CEDAW

CPA

DAC

DFA

DFAT

ERP

GOT

GPEDC

GroFED

HLC

HLF

IMF

ISDF

JCfD

JPRM

MDG

MFAT

MoE

MoFNP

$\mathrm{MoH}$

NCD

NIIP

NSPAO

NZAid

NNUP

NZD

NZAP

ODA

OECC
Australia Aid Program

Asian Development Bank

Tonga Aid Development Committee

Australia Aid Program

Convention on the Elimination of all Forms of Discrimination Against Women

Country Programmable Aid

OECD Development Assistance Committee

Direct Funding Agreement

Australia Department of Foreign Affairs and Trade

European Recovery Program

Government of Tonga

Global Partnerships for Effective Development Co-operation

Tonga Growers Federation

High Level Consultations

High Level Forum

International Monetary Fund

Interim Skills Development Facility

Joint Commitment for Development

Joint Policy for Reform Matrix

Millennium Development Goals

New Zealand Ministry of Foreign Affairs and Trade

Tonga Ministry of Education

Tonga Ministry of Finance and National Planning

Tonga Ministry of Health

Non-Communicable Diseases

National Infrastructure Investment Plan

National Spatial Planning Authority Office

New Zealand Aid Programme

Nuku'alofa Network Upgrade Project

New Zealand Dollar

New Zealand Aid Programme

Official Development Assistance

Organisation for Economic Co-operation and Development 


\begin{tabular}{ll} 
OECD & Organisation for Economic Co-operation and Development \\
OIREP & Outer Island Renewable Energy Project \\
PACER Plus & The Pacific Agreement on Closer Economic Relations \\
PFM & Public Financial Management \\
PHAMA & Pacific Horticulture and Agriculture Market Access \\
PIFS & Pacific Islands Forum Secretariat \\
PPP & Public Private Partnership \\
PSDI & Private Sector Development Initiative \\
SAMOA & Small Island Developing States Accelerated Modalities of Action Pathway \\
SAP & Structural Adjustment Program \\
SDG & Sustainable Development Goals \\
SOE & State Owned Enterprise \\
TERM & Tonga Energy Road Map \\
TERM-IU & Tonga Energy Road Map Implementation Unit \\
TOP & Tongan Pa'anga \\
TSDF I & Tonga Strategic Development Framework Phase I \\
TSDF II & Tonga Strategic Development Framework Phase II \\
TVET & Tonga Technical and Vocational Education and Training \\
UN & United Nations \\
USA & United States of America \\
USD & United States Dollar \\
US & United States of America \\
WB & World Bank \\
\hline
\end{tabular}




\section{Glossary}

This glossary is to provide explanations of the Tongan words or phrases that appear in this thesis. This is more than just direct literal translations but include interpretations of the idiom, meaning, and context the researcher perceives is important to detail. The translation of some words are incorporated here directly from the source material such as the writings of Thaman (2003) and the Tonga National Leadership Code.

'Ata ki tu'a

'Eiki

Fa'a Kataki

Faitotonu

Faka'apa'apa

Fakafe'iloaki

Fakamaau'anga

Fakatapu

Fakatōkilalo

Falala'anga

Fale Alea

Fatongia

Founga Fakamuli

$\mathrm{Hau}$

Heliaki

Hou'eiki

\section{Transparency}

An aristocrat. Usual English translation for Chief.

Patience

Literal translation means 'do the right thing'. Here it means honesty.

A form of respect.

The process and protocol to introduce oneself and finding the connection you have with an audience. This is usually by knowing ties of family history, legacies, and lineage.

Judiciary or Court

Form of acknowledgement that is respectful and seeks the permission to speak using honorific language.

Humility

Integrity or trustworthy

Parliament or Legislative Assembly

Obligation/responsibility/social duties. When fulfilling the fatongia it is done in the spirit of serving and selflessness, not expecting something in return.

Foreign method

Political/temporal ruler by strength, ability, prowess and lineage. In some contexts, it is used to describe someone who is the apex.

Metaphorical language and meaning

This is the plural form of the word 'eiki and can also mean aristocracy 
Kakala

Kali-o-Pau

Kāinga

Loto Fakatōkilalo

Luva
Garland but also inclusive of the process of producing it in Tongan culture

Metaphorical name for the island of Mo'unga'one, Ha'apai

Extended families linked by heritage and bloodline

Humility

Gift or giving one's all

Makatu'unga Fakataki Fakafonua 'o Tonga Tonga National Leadership Code

Mamahi'i Me'a

Matāpule

Mateaki

Me'a Vale

Mo'ui Faka-e-'Otua

Mo'ui Lelei Faka-e-sino

Mo'ui Visione

Ngāue mālohi

'Ofa

Pule'anga

Sia-ko-Veiongo

Siutakahe'ahoafō

Talanoa

Tali Ui

Tamahā

Ta'ovala
Commitment

Commonly translated as Orator Chief but the word is also inclusive of rank below Hou'eiki, higher than tu'a, and carries functional social duties

Loyalty

Ignorant Ones

Pius

Physical Health

Vision (a translation used by the Tonga National Leadership Code)

Hard work ethic

Love

Government

Metaphorical name for the village of Kolomotu'a, Tongatapu Literal translation is 'voyage day storm' or Day Storm Voyager Engage in calm and constructive discussion through storytelling

Accountability

Highest rank in Tongan society before the 1875 Constitution. Not a title bestowed but a rank in and of itself.

Formal traditional woven mat that comes in different forms depending on rank, function, ceremony, and purpose. It is worn around the body. 
Tauhi Vā

Taula'eiki

Toka'i

Toli

$T u^{\prime} a$

Tui

Tu'i Ha'atakalaua

Tu'i Kanokupolu

Tu'i Tonga

Uouongataha

Vahevahe Taau

Vai-ko-Hiva

Vaonukonuka
Reciprocal relationship that includes mutual duty and responsibilities

Before Christianity was adopted as the religion in Tonga, Tonga had its own religion. Taula'eiki translated literally means anchor of a god. Modern connotation of the word is used interchangeably with the more colloquial word in Tongan for Reverend, Faifekau.

Reverence and manifestation of respect

This word takes on the meaning under the context Thaman (2003) used to describe the process of making the kakala which is to 'select' or 'choose'. It is important to recognize this because on it's on the word can mean pick or pluck.

Commoner rank

Refer to the stages for making the kakala garland Thaman (2003) has used together with the words luva and toli. In this context tui means to thread.

Title and royal dynasty establish by Tu'i Tonga Kau'ulufonua Fekai by bestowing it upon his younger brother Mo'ungamotu'a

Title of the current royal dynasty of monarchs. Established by the sixth Tu'i Ha'atakalaua Mo'unga 'o Tonga upon his son. In 1875 the new Constitution was promulgated and the $19^{\text {th }}$ Tu'i Kanokupolu King Tupou I began his reign as a Constitutional Monarchy after consolidating his power and abolishing the other two royal dynastic titles.

Title of the ancient monarchs of Tonga who ruled across Oceania

Collective, working collectively

Equity

Metaphorical name for the village of Ha'avakatolo, Tongatapu

Metaphorical name for the island of Hunga, Vava'u. 


\section{Table of Contents}

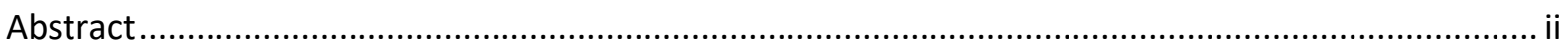

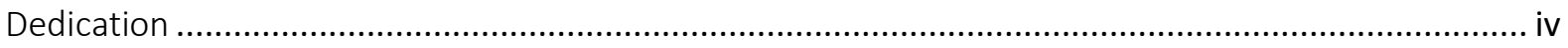

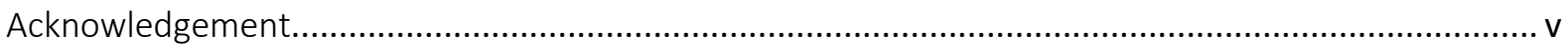

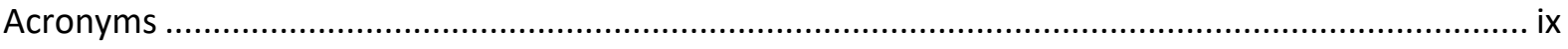

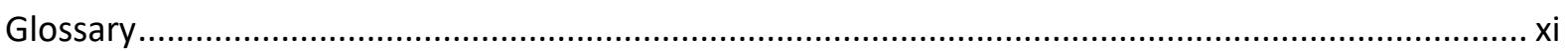

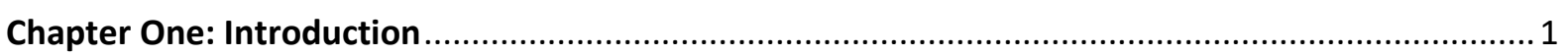

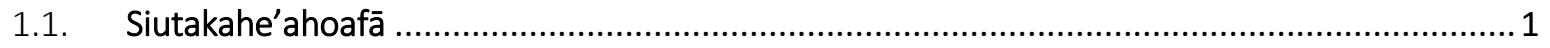

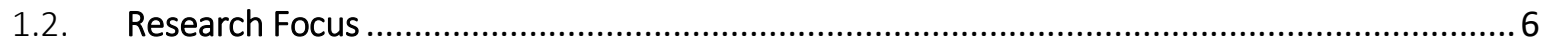

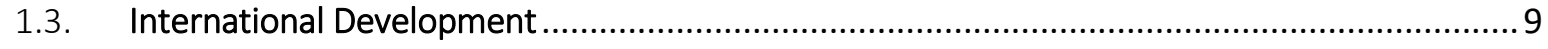

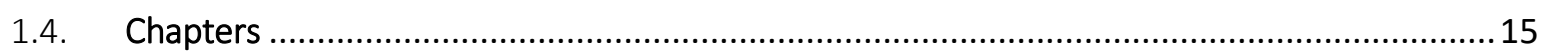

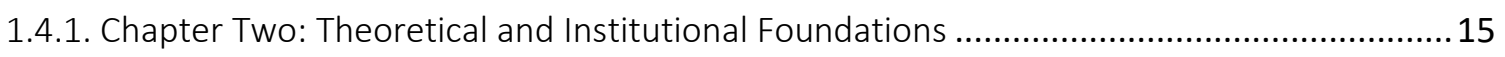

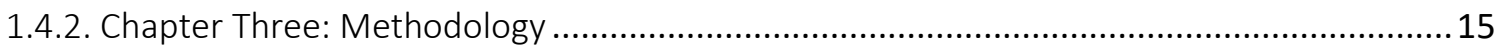

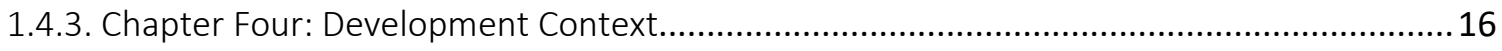

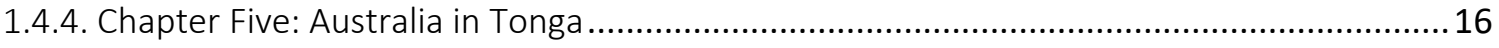

1.4.5. Chapter Six: New Zealand Country Programmable Aid ...................................................... 16

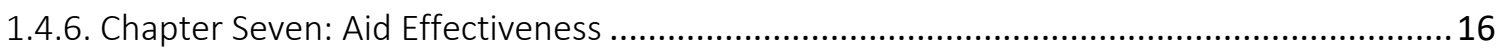

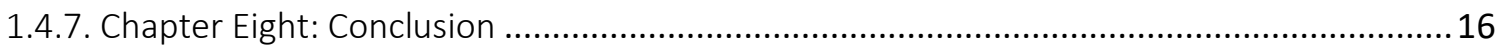

Chapter Two: Theoretical and Institutional Foundations ....................................................... 17

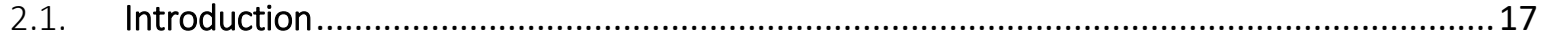

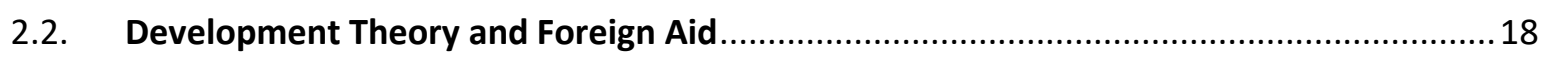

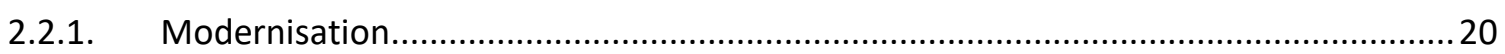

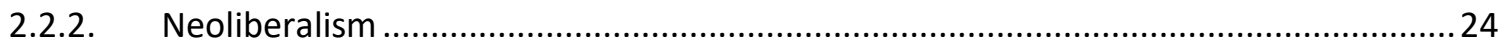

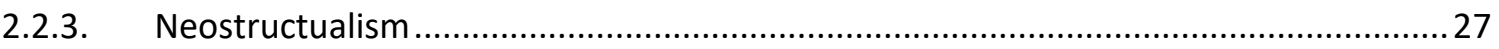

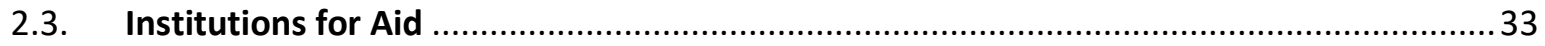

2.3.1. European Recovery Program and the OECC institution.............................................. 34

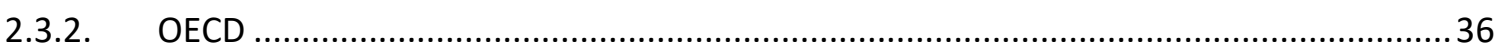

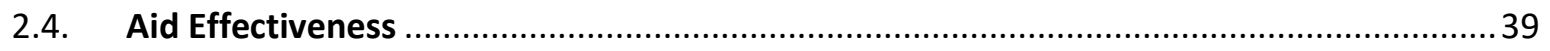

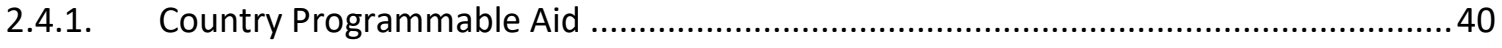

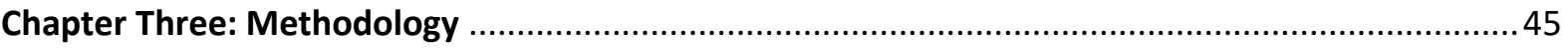

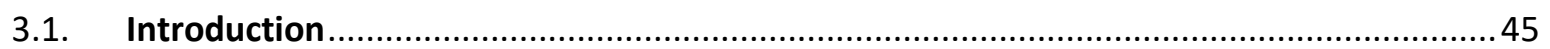

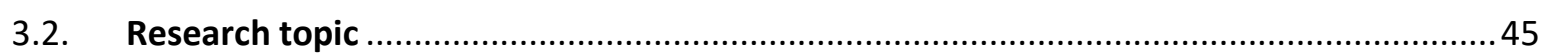

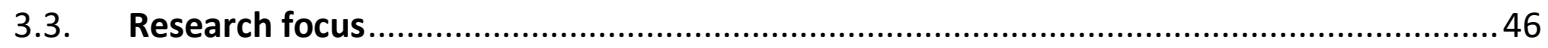

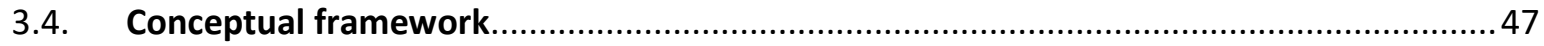

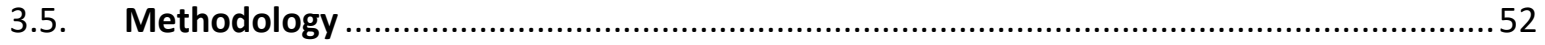

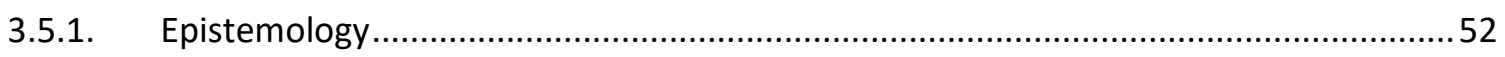

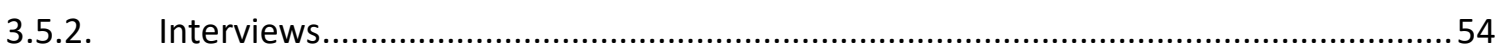




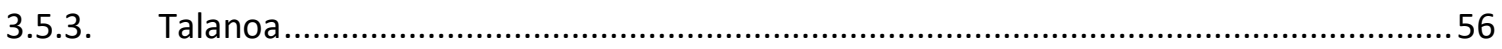

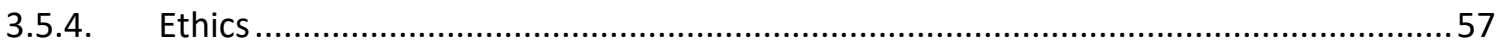

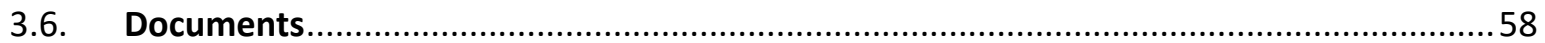

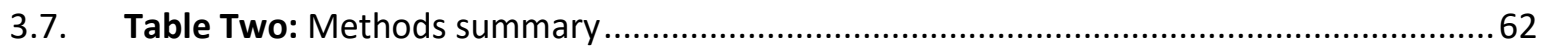

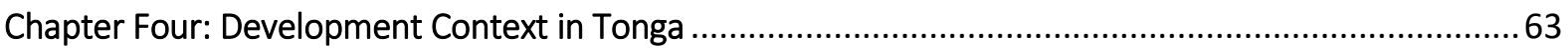

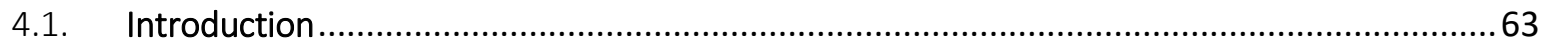

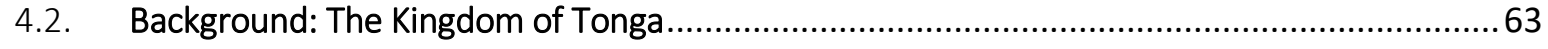

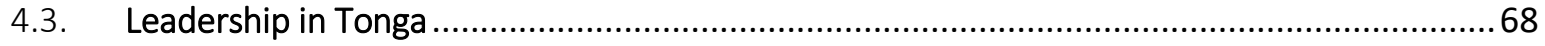

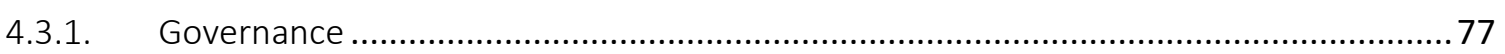

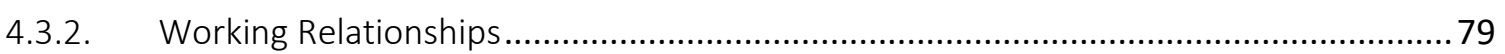

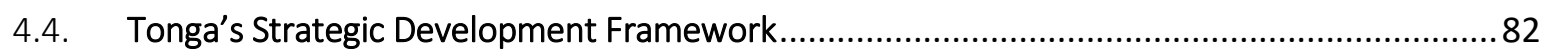

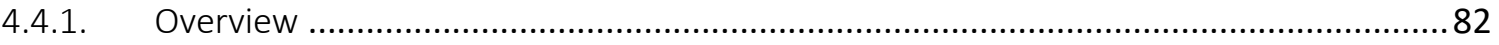

4.4.2. Nature of Official Development Assistance to Tonga .................................................... 85

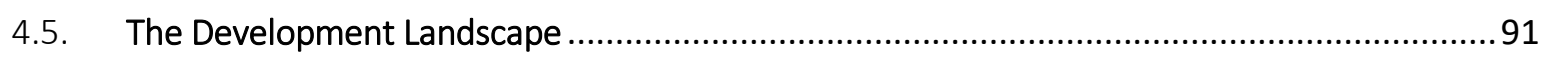

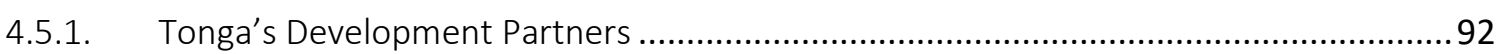

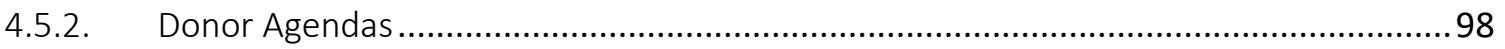

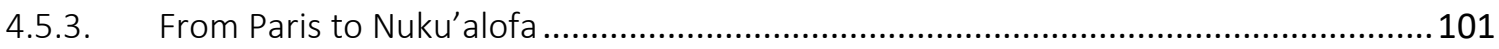

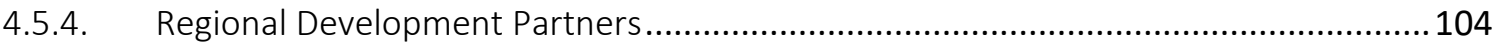

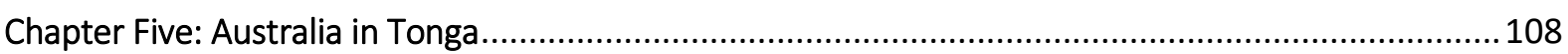

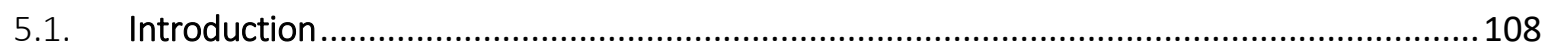

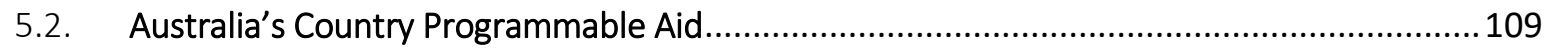

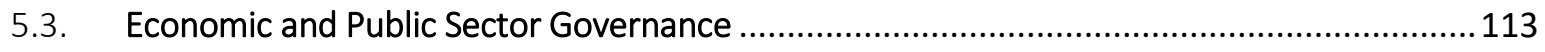

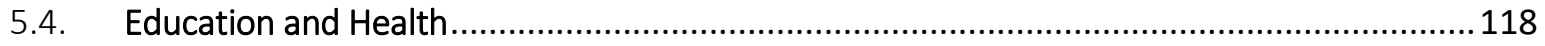

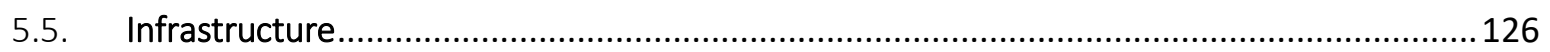

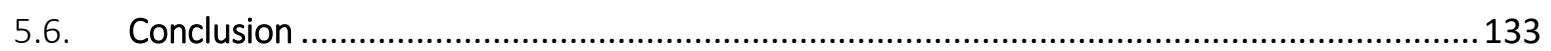

Chapter Six: New Zealand Country Programmable Aid to Tonga ..................................................136

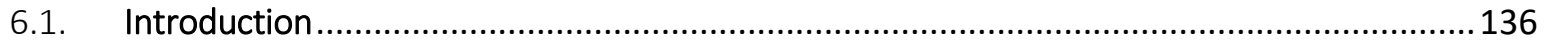

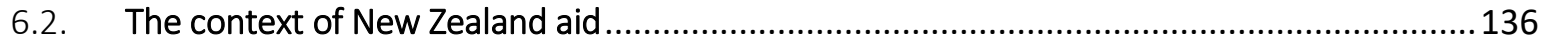

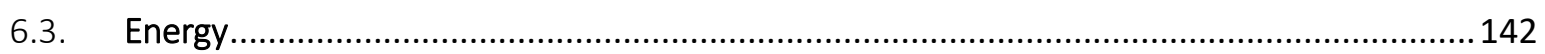

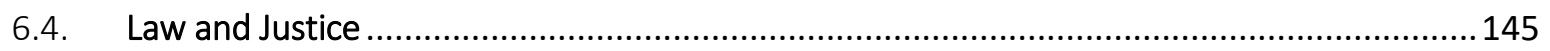

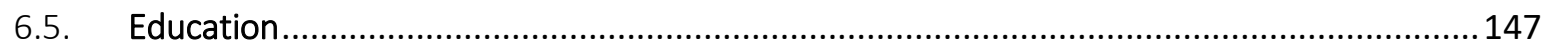

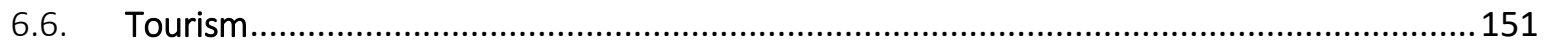

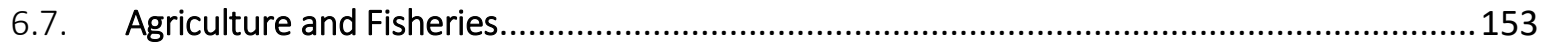

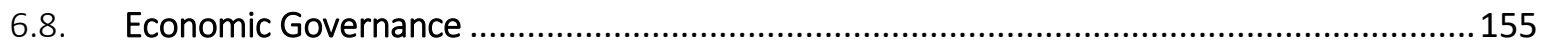

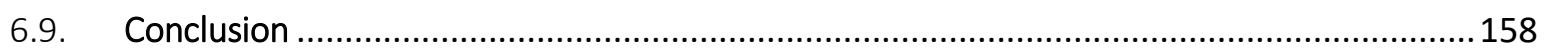

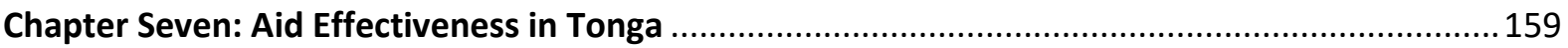

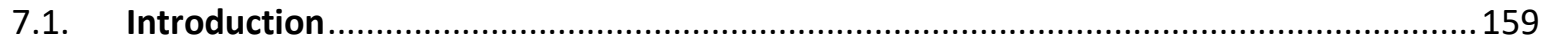

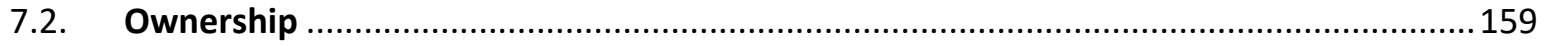




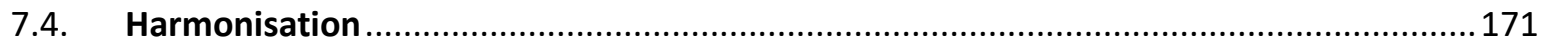

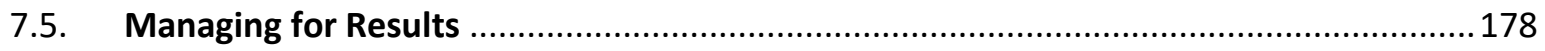

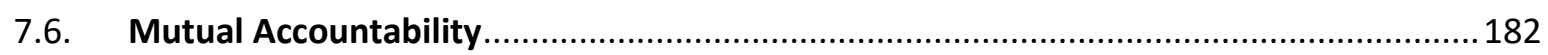

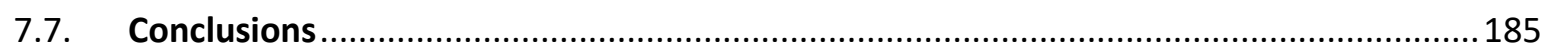

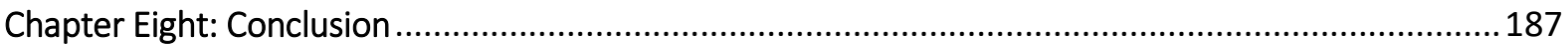

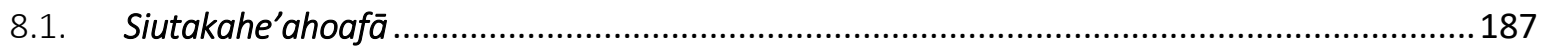

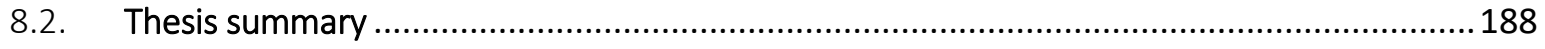

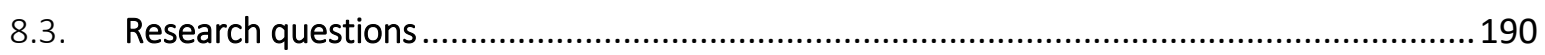

8.3.1. How does Tonga develop and articulate its development priorities? and how do donor priorities and systems help shape the way Tonga articulates its own priorities?....

8.3.2 What is the external aid environment and to what extent does it align or not with these priorities?

8.3.3. What analytical tools do donors (and Tongan agencies) use in the aid relationship?193

8.3.4. How do these systems and relationships deal with the dynamics of aid (changes in policies and personnel on each side)?.

8.3.5. How do the relationships within aid systems in Tonga accommodate differences in the

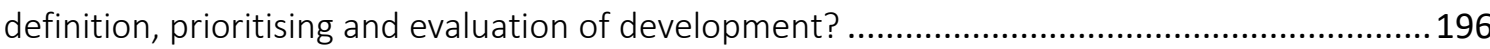

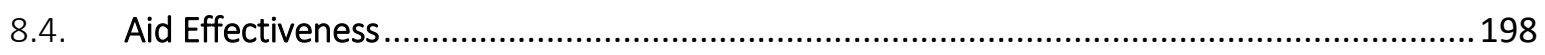

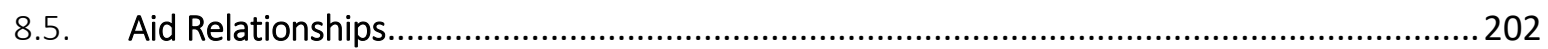

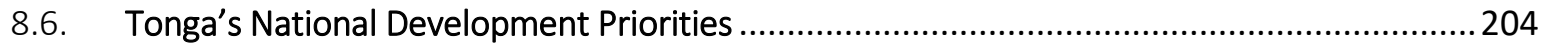

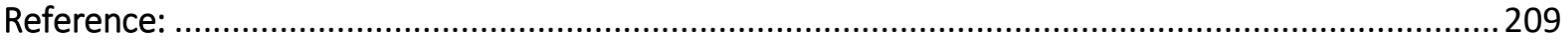

Appendix One:

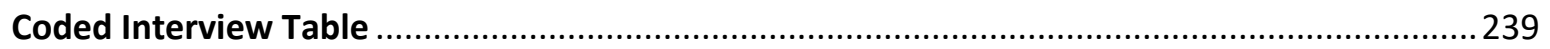

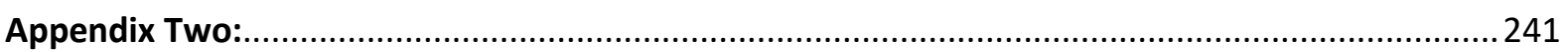

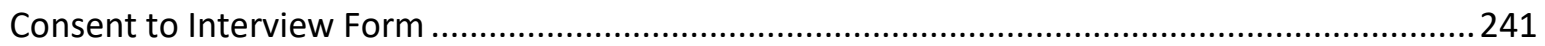

Appendix Three:

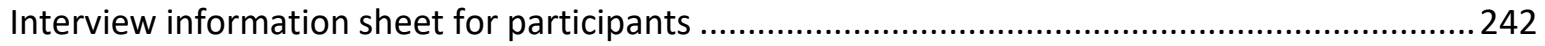

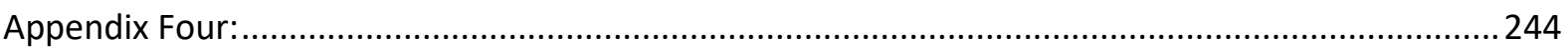

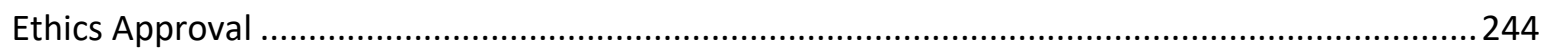

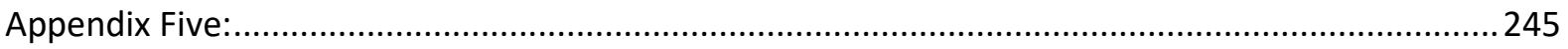

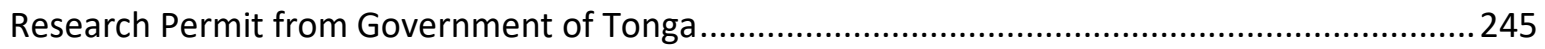




\section{Chapter One: Introduction}

\subsection{Siutakahe'ahoafā}

As Tongans, our practices and protocols in the Tongan culture are important to incorporate in research. This culture enriches research and broadens an understanding of being Tongan. In Tongan culture, knowledge of your paternal and maternal lineage is sacred. We are able to not only navigate within our hierarchical society with confidence but acknowledge linkages. Another key aspect is our background and experiences pertaining to the focus, in this case the research and the subject matter. In this research I will weave in areas of our Tongan culture so that both non-Tongans and Tongans are assured of the integrity of that knowledge. The aim here is to do justice to the Tongan identity, the respect it deserves in academia, and acknowledgement of knowledge being collective.

To begin with, there are two concepts that are important - Fakatapu and Fakafe'iloaki. Fakatapu is when a person asks for permission, be that in a speech or, in this medium, research. Fakatapu is composed by request but also by acknowledgement of the history and lore of the land and our people. The individual who is acknowledging follows a format beginning with a deity then onto the Ruler, chiefs, sacred land then those according to rank or occasion. Tu'ipulotu (2013) explains that there is a "sincere reverence to the authorities following the society's social order [and this] ... address of reverence is called fakatapu as a ngofua ke lea pe malanga (a permission to speak or preach)" (p.2).

This concept Fakatapu as an action of reverence, permission, and acknowledgement is demonstrated further in the opening given by Thaman in her paper "Decolonizing Pacific studies: Indigenous perspectives, knowledge, and wisdom in higher education" (Thaman 2003):

“Fakatapu mo e tangata'i fonua 'o Hawai'i kae 'uma 'a 'a kimoutolu katoa ka e 'ata kia teau ke hoko atu 'a e katoanga lea 'o e 'aho ni. I wish to acknowledge the presence of". (p.1)

The language used by the speaker is honorific and takes skill to carry it out with precision and eloquence without the meaning being lost in jargon. Despite the influx of western ideas and concepts, Fakatapu has remained steadfast in the psyche of Tongans. Fakatapu encapsulates our continued reverence to our values of respect and humility.

Fakafe'iloaki is where one introduces themselves in a way that is relatable to the collective. For example, using metaphorical language a person acknowledges the villages pertaining to both their paternal and maternal bloodline. The purpose of Fakafe'iloaki for the reader is that they can trace 
potential linkages, if they themselves know their own genealogy and linkage. Linkage for Tongans is important because as a society, we are a collective. Fakafe'iloaki is strongly interconnected with the concept Tauhi Vā which Ka'ili (2008:vi) defines as:

"The art of creating and maintaining beautiful sociospatial relations ( $v a)$ through the mutual performance of social duties (fatongia)"

Hence, the concept of Fakafe'iloaki holds like the concept Fakatapu multi-dimensional elements that are combined to provide a more holistic understanding. Fakafe'iloaki incorporates maintaining sociospatial relations and a sense of duty. In this research, I have not created the knowledge pertaining to Tongan culture and identity, but I am treating it as sacred. I am an avatar on behalf of my linage. For the purposes of this research, Fakafe'iloaki is used not only with regard to my lineage but in a pragmatic way regarding the background in work experience, knowledge of being a Tongan, and academic qualifications.

Following that understanding of the concept of Fakatapu:

Tapu mo e 'Afio 'a e 'Otua Mafimafi 'i hotau lotolotonga ni

Tapu mo e Hau 'o e Fonua

Tapu mo e Hou'eiki

Tapu mo e kakai tu'ufonua 'o Aotealoa

Tapu mo e mātu'a Tauhi Fonua mo ha Taula'eiki

Tapu mo ha Matāpule

Tapu mo kimoutolu maamaloa he mala'e 'ako

Pea hüfanga 'i he ngaahi tala fakatapu hono kotoa kae atā mo e motu'a ni ke fakahoko atu 'a e 'ako fakatotolo ni.

I acknowledge the presence of God

I acknowledge our Sovereign

I acknowledge the Aristocracy

I acknowledge the indigenous people of Aotearoa

I acknowledge the Custodians of the Land, the Spirit anchors, and the Orator Chiefs

I acknowledge those who have paved the way in academia

Under this acknowledgement and more, may I humbly present this research. 
I have chosen to acknowledge the Māori of Aotearoa because this is where I am located, and it is a recognition of their ownership of the land. The Fakatapu for me is used at the first instance because in my view I am the messenger pertaining to our Tongan culture. I am asking permission with acknowledgement of my rank - I am a $T u^{\prime} a /$ commoner - to interpret our culture. However, this acknowledgement is also to make it clear I am not the authority. Nor should other Tongans in academia be viewed in such light (unless they are of rank): their definitions of our concepts should be read with caution. Our culture belongs to each and every one of us.

Fakafe'iloaki on my paternal bloodline is that my last name is Taumoefolau and my heritage derives from Vaonukonuka. My maternal bloodline, Tapealava, Naitoko, and Prescott, hail from Kali o Pau, Vai Ko Hiva, and Sia Ko Veiongo, representing how interwoven is the background of my mother and her heritage with these villages. I am the eldest of four and my education began in Australia and New Zealand. I attended Tupou College for five years and have continued from then on to tertiary studies at the University of the South Pacific in Tonga and Fiji, the Australia National University in Australia, and now Victoria University of Wellington, New Zealand. Whilst my legacy is only beginning, Fakafe'iloaki allows me to introduce myself and in doing so open others to an understanding of this research. As a concept in Tongan culture, Fakafe'iloaki is stating that you are representing others, you are strengthening the connections, and you recognise that our knowledge is collective. This is the purpose the concept of Fakafe'iloaki serves at the offset, to introduce myself in an understanding according to Tongan culture.

The title of this thesis - Siutaka he 'aho afā - is interpreted as 'Day storm voyager'. As a researcher, and here as a Tongan, heritage is important. This importance derives from the identity of being a Tongan and the cultural values innate with that identity. As such, the title aims to be a heliaki or metaphor that represents the reality this research observes and also provides a Tongan perspective. The perspective provided are on many of the subject areas this research will cover. Taufe'ulungaki (2009) makes the proposition that 'a community's values are important for re-thinking education' ( $p$. 127). However, what is insightful to me about Taufe'ulungaki's approach is her use of reflection and storytelling to make her point regarding values. I wish to utilize the same approach here - reflection, storytelling, and the use of heliaki - with the title of the thesis, Siutakahe'ahoafā. For a Tongan, the use of a metaphor is important and is part of 'an indigenous approach to reading and writing the word/world, but may also exist as a culturally relevant strategy for conducting critique' (Smith and 'Otunuku, 2015, p. 99). 
I, as a Tongan, am on a research voyage navigating the vast ocean of international development in academia with storms at times on the horizon. This matches what I am studying at the national level. The Kingdom of Tonga is on a voyage navigating the vast ocean of international development that often encounters unique challenges or 'storms'. Under that conceptual parameter, the title here is not a prescribed existing framework in the traditional sense. It is rather the researcher's interpretation, through reflection on heritage, storytelling, and heliaki, of the dynamics involved within the nature of navigating international development.

I openly acknowledge that within the Tongan culture I do not hold any rank or title. This distinction is important because to Tongans our oral traditions are maintained by social classes, socio-political units, and families (Lātūkefu, 1968, p. 135). Even if I was to apply myself at the smallest socio-political unit within the Tongan culture, kāinga, I still hold little sway. However, there is a duality and contradiction. We should embrace our culture with the values of faka'apa'apa and toka'i rather than treat it as an absolute cardinal rule. What I mean here is that Lātūkefu (1968) himself acknowledges that in our culture, knowledge is retained to a select few of the socio-political make-up, but openly contradicts it by collecting and interpreting it. Hence, my position agrees with arguments Lātūkefu (1968) makes, namely that language and knowledge of local culture should be seen in research as an advantage (1968, pp. 136-137). As Tu'itahi argues:

'Incorporating Pacific knowledge in its original vernacular into mainstream language and academic literature has mutual benefits for all languages and culture' $(2010, p$. 134)

The value I wish to add to this accepted practice, in agreement with the elements and actions expressed by Lātūkefu and Tu'itahi, that as a Tongan part of incorporating our culture into research is also acknowledging who you are within our society. Simply being fluent in the Tongan language and understanding the culture should not be taken at first glance as indicating that one is an authority. More clarity is provided later in this thesis on, what should be, common knowledge amongst Tongans. Ultimately, there is a collective knowledge that dates back thousands of years and a more compelling sense of responsibility by Tongans should be shown toward acknowledgement of, engaging with, the culture, and the likely challenges in doing so.

My research also comes with a sense of responsibility due to my Tongan identity and culture. What I find most fascinating here as a researcher is that very few Tongan academics address the point of view, at least to me, that unless you are of Hou'eiki, and to a lesser extent, Matāpule rank, then you are not the authorized distinguisher of Tongan culture or identity. In other words, what makes you a 
Tongan? And, pivotal in my view because of how I understand being a Tongan, what authority do you or I have to interpret and explain the/our Tongan culture? Hau'ofa (2008) gives some context into where my starting point is coming from in that "the term for commoners is me'a vale, "the ignorant ones", which is a survival from an era when the aristocracy controlled all important knowledge in the society" (p. 28). I would agree more with the term Taufa (1993) used, tu'a (p. 39), which literally translated means "outside", not as being from a foreign land but outside of the aristocratic rank, instead of me'a vale. Tongan culture, and by extension society, is still rigid in hierarchy (Lātūkefu, 1980) but different from western class categorization.

I suspect accompanying challenges associated with this perspective is why it is hard to find it in literature. From a Tongan legal perspective, what made you Tongan, as in an identity, has not been straightforward as one would assume. For example, prior to the Tonga Nationality (Amendment) Act 2007 (Tonga Nationality Act, 2016), the definition of being a Tongan national was limited to:

a) any person born in Tonga whose father is a Tongan;

b) any person born abroad of a Tongan father who was born in Tonga;

c) any person born out of wedlock in Tonga whose mother is a Tongan;

d) any alien woman who marries a Tongan provided that within 12 months from the date of her marriage she -

i. lodges with the Minister of Police a written declaration that she wishes to assume Tongan nationality;

ii. and takes the oath of allegiance prescribed by this Act;

e) any person naturalized under this Act. (Tonga Nationality Act, 1959)

Of course, this did not stop nor discourage Tongans who did not fall under this legal definition identifying themselves as Tongan, but it is one example of the inherent sensitivity to finding an answer to the fundamental question of, what is it that makes you a Tongan?

Historical events are important as well with understanding the Tongan culture. Prior to the 1875 Constitution most Tongans in and under the rank of $t u^{\prime} a$ had no rights. This all changed with the Emancipation Edict of 1862 which gave commoners rights and took away from Chiefs absolute authority (Lātūkefu, 1975a, pp. 33-34). An important aspect to that feat which should and is still revered by all Tongans is that this was an achievement honoured by the Hau (Taumoefolau, 1996), King Taufa'ahau Tupou I. This gives insight in that legitimacy, authority, and change in Tongan society ultimately comes from the consent of the top, rather than as it is in western democracies from the 
people. Moving forward to contemporary reality, the Tongan culture has indeed morphed and changed a great deal. Most evidently it is seen in the opportunities afforded to Tongans of commoner status in areas of education and living abroad, arguably a direct result of the rights inherited in the Constitution of 1875 . However, it is very important, especially for Tongans, to know and appreciate your heritage and where you stand relative to what the English language would term family, clan, and nation.

Some caution should be exercised but mindful of each of our journey in identifying as a Tongan. Being afforded a platform does not automatically qualify someone to speak on the Tongan culture nor interpret it to the outside world. An example here is when a Tongan who may identify themselves as a Tongan and works on an aid programme for a donor but comes from a background where they did not grow up in Tonga, they have no experience working in Tonga, and do not fully understand the socio-economic and political environment in Tonga, finds themselves designing, managing, and appraising the funding for the donor. Being a Tongan is a question of legitimacy and integrity under the Tongan cultural framework, which is not written, but is a living phenomenon.

Relevance is an important factor when interpreting the many concepts explored and examined in this research. Many of the concepts are derived from a western perspective. For example, drawing from the discipline of international relations - and quoting Wendt (1992, p.395) 'Anarchy is what states make of it' - we can argue that there is no 'central authority' in the international system and that states are driven by their own self-interest. Wendt (1992) offers an understanding of the world and subsequently international relations according to a predominant western perspective. As a Tongan, there is a natural inclination to find relevance of this claim to the Kingdom. What does this mean for the Kingdom of Tonga? How does Tonga navigate these norms and institutions? These are questions asked here by myself in my identity as a Tongan with regard to interpretations in the academic field of international development and foreign aid. As a practitioner with almost a decade of experience in international development and a researcher in the subject, I felt there is a need for a deeper understanding that would enrich the discipline further. Being the introduction to my research this chapter serves as a window into navigating what this thesis is about and the structure.

\subsection{Research Focus}

This research seeks to understand better how Tonga articulates and pursues its development in the context of international aid. I ask and examine the applicability of theories of development, engage with the literature and highlight what has changed, what has not changed, in perception concerning development both in Tonga and abroad. Fakafe'iloaki instils an added level of integrity to be able and perceive the focus area as how a Tongan would in research. Narrowing it down further, my research 
topic is the national development priority of Tonga and I ask six sub-questions guided by the Paris Aid Effectiveness Principles (Organisation for Economic Co-operation and Development, 2005).

Research on Tonga with a focus on aid effectiveness and the dynamic relationship between foreign aid and national development priorities is limited and sporadic. Campbell (2001) and Needs (1988) are examples offering historical accounts on the manner and issues of foreign aid to Tonga, particularly on the nature of the donors' interests, but there has been little consideration towards the Tongan perspective. They are important to the dialogue and research on international development because they, especially Needs (1988), touch theories of development. Others, such as Hau'ofa (1993), Lātūkefu (1975 and 1980), Taumoefolau (1996), and Thaman (2009) provide a valuable contribution and insight within their respective academic fields - education, linguistics, politics, and history. These insights enrich our understanding of their fields and propel forward Tongan views on the subject matter, though they do not focus specifically on aid and development. The research focus aims to bridge the perspectives of westerners and the understandings of Tongans pertaining to international development. We build off the threads championed by those aforementioned but equally important, I, as a Tongan, offer an insight.

Research about how Country Programmable Aid and the Paris Declaration on Aid Effectiveness Principles are applied to Tonga are few and far between. Concern in this thesis is from 2013 to 2017 and the ways Australia and New Zealand made bilateral commitments to support Tonga's national development priorities in different thematic areas and sectors. Between 2013 to 2017 the national development priorities of Tonga have been articulated via different mechanisms and forums. The Tonga Strategic Development Frameworks (Tonga Ministry of Finance and National Planning, 2011 and 2015b) and the High Level Bilateral meeting with Australia and New Zealand producing important outcome documents, for example. Expanding on the Tonga Strategic Development Frameworks, they exist as guiding documents. However, they are more than just documents and there is a whole process and personnel that were, and continue to be, involved. I will attempt to collate international development concepts - national development priorities of Tonga, Country Programmable Aid of Australia and New Zealand, and the Aid Effectiveness Principles in the Paris Declaration, into one focused area. Using the concept of Fakafe'iloaki, where one introduces their background, this research is also offering a Tongan perspective to guide analysis.

This research takes a particular interest in the OECD's Paris Declaration of 2005 on aid effectiveness. This declaration represented at the time, an international consensus (involving both donors and recipients) regarding what was good practice in international development aid. It articulated five key 
principles that should be followed if aid was to be more effective in meeting broad development oObjectives. The five principles were Ownership, Alignment, Harmonisation, Mutual Accountability, and Managing for Results (Organisation for Economic Co-operation and Development, 2005). More analysis is given later regarding the mechanisms and the different driving forces that created these principles. Throughout this research we will examine and explore how these principles have existed in practice with Country Programmable Aid in Tonga. In particular, I am concerned with the way Tonga 'owns' or leads its own development in an environment where aid is such a significant part of its economic and political situation and where aid donors play a major role.

Design of a research question would take into account navigating, or Siutakahe'ahoafā, the many interconnected and multi-layered concepts of international development. The construction of the question is guided by how it defines the investigation, sets boundaries, acts as a frame of reference, and, perhaps most importantly, gives a sense of direction (O'Leary, 2010, p.47).

The main research question is:

To what extent are the national development priorities of Tonga shaped or supported by international aid?

The six sub-questions that are designed and centred around the five principles are outline below, in no particular order -

1. How does Tonga develop and articulate its development priorities?

2. What is the external aid environment and to what extent does it align or not with Tonga's development priorities?

3. How do donor priorities and systems help shape the way Tonga articulates its own priorities?

4. What analytical tools do donors and Tongan agencies use in the aid relationship?

5. How do these systems and relationships deal with the dynamics of aid (changes in policies and personnel on each side)?

6. How do the relationships within aid systems in Tonga accommodate differences in the definition, prioritising, and evaluation of development?

The key here is to both address the questions in a manner a Tongan would better understand but also ask how it is relevant to the Kingdom of Tonga. Some of the concepts are well established globally, for example the Paris Declaration on Aid Effectiveness stipulates what the principles are intended to mean. However, when they are applied to the Country Programmable Aid of the two development 
partners and what the principle of ownership may mean in terms of Tonga's national development priorities, those meanings are not completely adhered to, as will be seen, for several reasons. As a Tongan researcher with the cultural lens being used, I am metaphorically navigating a day storm Siutakahe'ahoafā. This involves the act of navigating a capricious diversity of foreign ideas in the discipline of international development but having to search for a grounded point of reference and understanding.

The focus of this research will examine four broad areas. Each area will be examined, analysed, contextualised, and defined in later chapters. The areas are international development, national development priorities, aid effectiveness principles, and Country Programmable Aid. For each area, this research has chosen Australia, New Zealand, and Tonga as the countries of interest. The analytical lens being applied are concentrated on the dynamic interaction the three different actors - Australia, New Zealand, and Tonga - had between 2013 to 2017 and the context they operated or practiced under the Paris Aid Effectiveness Principles. The international development context for this research is now briefly defined before we set the course for the thesis with an outline of the chapters to follow.

\subsection{International Development}

For the purposes of this research it is meaningful to briefly expand on focus areas we will cover. Firstly, International development and foreign aid are two different but inextricably linked concepts that are highly contested in definition, meaning, and understanding. Cowen and Shenton (1996) in their book 'Doctrines of Development' allude to this challenge in trying to ascertain a definition for the concept of 'development'. If we summarize what literature exists, the spectrum ranges from multiple definitions versus how definitions appear to be subjective (Cowen and Shenton, 1996, p.2). They suggest that 'development' is both a widespread, unregulated and largely chaotic process of creative destruction, as a result of the spread and integration of markets, and a set of deliberate interventions by agencies to achieve a form of order and pursue defined and progressive social and economic goals. Tracking the modern iteration of the concept of development, we can see a demarcation from development meant before and after the Second World War. This signpost was established by President Harry S Truman in his 1949 inauguration address (Rist, 1997, p.73). In a nutshell, it was not so much that President Truman created a new concept, but he used the adjective 'underdeveloped' and in doing so gave 'development a transitive meaning', claims Rist (1997, p.73). It is a transitive meaning that questionably better reflected the geopolitical shift towards self-determination by former colonies and the transition of the colonized into newly-formed and independent sovereign states. Development, then, can be regarded as a largely 'modern' phenomenon dating from the end of the Second World War. 
The Marshall Plan, or formally known as the European Recovery Program launched in 1948, is the progenitor of international assistance program. The European Recovery Program is understood today in the 'form' of foreign aid for international development. Prior to this the international system had been arranged according to a different paradigm altogether, with a hierarchy of colonizer and colonized. The new international system, which the Marshall Plan entered, involved 'the new developed and underdeveloped dichotomy [and] proposed a different relationship' between states (Rist, 1997, p.73). Since then, many theories have focused on international development. For example, proponents of modernisation theory, Rostow (1960) and Lewis (1955), saw that industrialisation, Keynesian economics, delivery of aid, land reform, and support for state budgets would lead former colonies to become 'developed' states. Although many schools of development theory have since appeared, many sharply critical of this line of thinking, this modernist view of development - and the role of international aid in it - has permeated much development policy and practice through to the present.

As a program, the European Recovery Program thus acts as the first blueprint international development and subsequently one that foreign aid can use. This is important because it offers a window into the line of thought towards programming foreign aid and to where we are now. From the beginning, foreign aid as a means to achieve international development involved continual evolution and change.

In general, there has been a broad debate concerning the ability of aid to promote development or not. Critics from the right, such as Bauer (1976), have argued that aid has been ineffective, largely due to its distorting effects on recipient economies. Critics have also come from the left of the political spectrum with authors such as Hayter (1971) suggesting that aid is a mechanism whereby powerful donors exert control over recipient states as a new form of imperialism. Aid - international development assistance - has been the subject of much academic investigation over past decades with critics and proponents. Modern-day critics have included Moyo (2010) and Easterly (2006) and they have pointed to the failure of aid to reach intended beneficiaries. For the Pacific region, the Australian economist Helen Hughes has been particularly critical and has claimed that aid has 'failed' (2003). However, a large body of work, has countered that aid can and does work, albeit with an acknowledgement that it can have adverse effects and there have been numerous examples of poor practice (Cassen 1994, Sachs 2005, Dollar and Pritchett 1998, Collier and Dollar 2002, Riddell 2007). With this international context in mind, this thesis then seeks to explore aid relationships in Tonga by 
focusing on three key national 'players': Tonga itself and two of the leading donors, Australia and New Zealand. Each will be examined with regard to its strategies, policies and practices of aid.

Australia and New Zealand are members of the OECD Development Assistance Committee (DAC) and within this aid environment, structured monetary assistance is a key way international aid is understood in this research. I am seeking to explore and explain how these two donors understand the concepts of aid and development. By doing this, I would enable myself to appreciate the ebb and flow of how their aid seeks to achieve development goals. Linked to this is how Tonga understands the concept and how in turn the definitions overlap and interact, manifesting ways in how aid shapes the national development priorities of Tonga.

How international development and foreign aid are understood is important. The different threads of understanding contextualise not only the historical 'why' of development - tracing back to its European post-war origins and rebuilding a war torn continent - but also the 'how' - through various forms of international aid. The predominately financial instrument to accelerate and achieve development was, and still arguably is, international aid, and it, at least in its modern iteration, began with the Organisation for European Economic Cooperation or OECC, an organisation that was conceived to manage the US-financed Marshall Plan (Organisation for Economic Co-operation and Development, 2007b.).

Over the following years, the OEEC transformed into the Organisation for Economic Co-operation and Development (OECD) and within the OECD is a Development Assistance Committee (DAC). DAC 'is a unique international forum of many of the largest funders of aid' (Organisation for Economic Cooperation and Development, n.d.). The DAC acts as a secretariat for the major Western donors, gathering data, sharing information, providing policy advice and conducting peer reviews of aid programmes.

Furthermore, DAC has played a key role in defining what 'aid' means and what can be officially counted as aid. DAC has defined Official Development Assistance (ODA) as:

"those flows to countries and territories on the DAC List of ODA Recipients and to multilateral institutions which are:

1. provided by official agencies, including state and local governments, or by their executive agencies; and 
2. each transaction of which:

a. is administered with the promotion of the economic development and welfare of developing countries as its main objective; and

b. is concessional in character and conveys a grant element of at least 25 per cent (calculated at a rate of discount of 10 per cent)." (Organisation for Economic Cooperation and Development, n.d.)

Some donors have taken this definition and embedded it within their own understandings and systems. For example, the Ministry of Foreign Affairs and Trade of New Zealand uses two criteria to define the concept of 'aid': financial means and the definition of Official Development Assistance by the OECD DAC. It is "Financial or other assistance that qualifies as Official Development Assistance as defined by the OECD Development Assistance Committee (DAC)" (New Zealand Ministry of Foreign Affairs and Trade, 2017b, p.17). The definition has evolved slightly. For example, New Zealand MFAT define ODA under the Partnerships for International Development Guideline as:

"International aid. A grant or loan from the government with the promotion of economic development and welfare of developing countries as its main objective" (New Zealand Ministry of Foreign Affairs and Trade, 2017b, p. 20)

Similarly, the Australian Department of Foreign Affairs and Trade does consider aid along the same lines, but also takes into account other forms of assistance (trade, investment etc) as "aid represents an increasingly small proportion of development finance" (Australia Department of Foreign Affairs and Trade, 2014a, p. 5).

When reference in this research is made to both Australian and New Zealand aid, unless specifically detailed otherwise, I am referring to their respective Country Programmable Aid or CPA. Under the Organisation for Economic Co-operation and Development, CPAs were introduced in 2007 and defined as:

"CPA reflects the amount of aid that is subjected to multi-year planning at country/regional level, and is defined through exclusions, by subtracting from total gross bilateral Official Development Aid that is:

- unpredictable by nature (humanitarian aid and debt relief); 
- entails no cross-border flows (administrative costs, imputed student costs, promotion of development awareness, and research and refugees in donor countries);

- does not form part of co-operation agreements between governments (food aid and aid from local governments);

- is not country programmable by the donor (core funding of NGOs)" (Organisation for Economic Co-operation and Development, 2007a)

This refinement is important because ODA internationally has been observed to now include significant volumes of 'assistance' that are spent largely within donor countries (refugee resettlement costs, student scholarships etc) or in subsidising the business operations of donor companies in developing countries (Murray and Overton, 2011b). By this adoption of CPA this research narrows the scope on which aspect of foreign aid to focus on and more importantly the purpose CPAs serve aligns with what this research examines, with the crucial words "CPA tracks the proportion of ODA over which recipient countries have, or could have significant say" (Organisation for Economic Co-operation and Development, 2007a). We can assume that foreign aid is the (1) contribution by Government agency; (2) economic development and welfare as the main objective; (3) and a grant element of at least 25 percent (Ludwig, 2005, pp. 7-8).

Australia and New Zealand apply CPA according to the definition mentioned above but equally important is the way aid is framed to Oceania. Ratuva (2019) touches on how aid is an extension of the foreign policy of Australia and New Zealand (pp. 56 -59). This framing of foreign aid acknowledges the broader international role it holds and how it is applied within the region. That is, foreign aid from the donors' perspective and how their foreign policy interests are applied via this mechanism. This research provides a link because it acknowledges that donor perspective but focuses on how it is viewed and framed at the national level. In this case I looks at Tonga's view and how Tonga navigates the nature of aid, the different ways it is framed, and how it is applied through different processes.

Aid as a concept and definition is important to consider, not only from these wider international frameworks, but more importantly for this research from the perspective of the Tongan Government. Combing through documents by the Government of Tonga, aid is not explicitly defined but referenced interchangeably with words such as 'cash', 'grant', 'funds', and 'loans' (Tonga Ministry of Finance and National Planning, Tonga, n.d.). This sheds light on how aid is not only still predominately seen as financial but different types of financial mechanisms.

Consider also the different dimensions of aid: aid as a foreign policy tool, a form of development assistance, or a humanitarian response to a natural disaster. There are competing understandings of 
aid such as it being for economic development, thereby supposedly advancing the welfare of the recipient (Fuhrer, 1994), or that it has an impact on institutions, such as education, it is supposed to strengthen (Sanga and Taufe'ulungaki, 2005). As part of the main research question, understanding the different dimensions of aid give insight into how national development priorities are shaped or supported. Brech and Potrafke (2014) provides a detailed mapping of the different types of aid ranging from need-driven and interest-based to recipient characteristics on aid flows.

For Tonga, bilateral foreign aid began with a loan from Britain worth $£ 514,000$ to initiate building of Queen Salote wharf in 1965 (Campbell, 1992, p.66). Campbell (1992) highlights historically foreign aid schemes for Oceania, including Tonga, began with the Canberra Pact between Australia and New Zealand: the two countries agreeing on security and development interests (p. 65). The first Five Year Development Plan for Tonga was in 1965 prioritising agriculture, health, and education (Campbell, 1992, p.67). There was a Second Development Plan in 1970, and subsequently a Third in 1975 (Campbell, 1992, p.67). As an observation, this familiar key institutional context and format is still adhered by Tonga today: there is a bilateral agreement document, with a key implementing partner (in the case of bilateral aid), and a national development document that articulates priorities.

The Tonga Strategic Development Framework I and II (Tonga Ministry of Finance and National Planning, 2011 and 2015b) in this research is the main policy document for the Kingdom of Tonga pertaining to national development priorities. There are some main points to keep in mind when we are examining the different elements of such a policy document. Firstly, it is not an action plan (Tonga Ministry of Finance and National Planning, 2015b, p.48). This is made clear in that -

'It is not a national plan with detailed priorities. It is a ten-year framework within which government, and other organisations in the Kingdom, can plan in a more consistent and integrated manner' (Tonga Ministry of Finance and National Planning, 2015b, p.48)

The research here subsequently treats these two important documents accordingly. The reason for this is because it is important to examine these two documents as critical sources of data on aid and development in Tonga but also recognise them for what they are - broad frameworks - and not detailed development plans. Another point to keep in mind is that there two documents differ in style and, to some extent, content. This difference, and areas where the status quo has been maintained or improved, is highlighted further on in the later chapters. Suffice to say here that as an overarching 
framework, Tonga has a foundation to build on and provide clarity. This acts as a starting point or the connecting point where international aid meets national aspirations.

With these contextual points in mind, we can now outline the structure of the thesis to follow.

\subsection{Chapters}

Each chapter for this research adheres to a consistent format. Firstly, the main arguments with caveats are introduced and the main body of the chapter expands on the argument further. Explanations are given if there are deviations from this format with subtle differences between them. For example, Chapter Five 'Australia in Tonga' and Chapter Six 'New Zealand Country Programmable Aid' differ in approach with presenting the argument, data, and analysis of the data. The impetus to this is data driven and requires the analysis to be also.

\subsubsection{Chapter Two: Theoretical and Institutional Foundations}

In this chapter I will explore literature that touches on the constructs and concepts covered in this research. The objective of this exercise is to give an overarching view on the contextual landscape concepts such as development, foreign aid, and national development priorities exist. Important points on this journey to consider are the historical background the concepts arise from (Ridley, 2012, p.24) pertaining to the OECD aid principles. Analysing the history is divided into three components. Firstly, the history of the Organisation for Economic Co-operation and Development as an organisation is examined. The intention here is to establish a point of reference for legitimacy of the Organisation for Economic Co-operation and Development as a forum and the implications this has on operationalizing foreign aid. Secondly, I explore what development means for Tonga and the Aid Effectiveness principles by exploring the constructs or versions of concepts pertaining to national development priorities and to what extent are they shaped or supported by foreign aid from Australia and New Zealand. Lastly, we will explore the theories of development and the conceptual frameworks they offer, unpacking the foundations and assumptions of these frameworks and whether they are applicable.

\subsubsection{Chapter Three: Methodology}

In this chapter I explain why I chose this specific research topic, what I focus on, and what guided my focus. I outline how I designed my research, how the design was managed, and the challenges to the design. This looks at the conceptual framework, interview design and purpose, and techniques and approaches that acknowledges documentation as a research method. The key feature of this chapter

is how I went about conducting my research and what tools, in the form of interviews and 
documentation, I used to do so. The form of this chapter is laid out in a narrative with a minor visual representation in the construction of a methodological matrix.

\subsubsection{Chapter Four: Development Context}

Chapter Four looks at the development context in the Kingdom of Tonga. The focus is on the political and institutional aspects of the development context. What are the key mechanisms? Who manages foreign aid in Tonga? What is the key aid development policy document? How are the aid effectiveness principles applied in Tonga?

\subsubsection{Chapter Five: Australia in Tonga}

In this chapter we cover the Country Programmable Aid component of the Australia Aid Programme to Tonga between 2013 to 2017. Here we look at how the Country Programmable Aid is structured and where possible some of the fundamental factors that shape it.

\subsubsection{Chapter Six: New Zealand Country Programmable Aid}

This Chapter we analyse New Zealand's Country Programmable Aid. In this chapter we look at these sectors the Country Programmable Aid prioritized relative to Tonga's Strategic Development Framework Phase I and Phase II. This begins with the high level agreement that New Zealand enters with the Government of Tonga. Behind this high level agreement is a rich source of data to unpack and analyse. Are there patterns that emerge in terms of consistency of emphasis and focus, with exploration toward thematic priorities.

\subsubsection{Chapter Seven: Aid Effectiveness}

In this chapter the objective is to use the six sub-questions as an analytical framework and better understand the two aid programmes under the Paris Declaration on aid effectiveness. Here we explore what the data informs us about how foreign aid is applied, the nuances behind it, the national development priorities of Tonga, and more importantly focus on the aid effectiveness principles.

\subsubsection{Chapter Eight: Conclusion}

Building on from the different chapters and under the OECD Aid Effectiveness principles, I address the key question of whether or not foreign aid does shape and support Tonga's national development priorities. 


\section{Chapter Two: Theoretical and Institutional Foundations}

\subsection{Introduction}

As part of this research being Siutakahe'ahoafā - navigating the vast ocean of international development in academia and its challenges - we engage in this chapter with literature to better understand the relationship of development concepts to Tonga. The chapter will explore literature that touches on several, but not all, constructs and concepts of international development. The purpose is firstly to establish the key foundations in development theories for international aid and secondly to illuminate the main institutional structure at a global level for international development assistance.

Literature of three prominent theories of development - modernisation, neoliberalism, and neostructualism - are approached here based on the chronological order they developed. We start with modernisation theory with origins shortly after the Second World War and into the Cold War era. Historically, as the first body of theory to garner mainstream attention, modernisation articulated arguments through the stages of economic growth by Rostow (1960) in the 1960s, how 'development' become a policy objective (Escobar, 1995; Rist, 1997), what type of market to adopt (Przeworski, 1996; Bernstein, 1971) and the interventionist role states take in achieving development. Next is the theory of neoliberalism and at its core is economic development with the market as the key driver through privatisation and deregulation. Development under neoliberalism looks at reducing market-distorting interventions (Nederveen Pieterse, 2002, p. 6). Lastly, neostructualism as a theory of development focuses on poverty alleviation with the state taking a more active role (Murray and Overton, 2016). Global agreements such as the Millennium Development Goals and the Paris Declaration on Aid Effectiveness are at the forefront of neostructualism.

Evident in the general literature on aid, many have examined issues relating to development policies (e.g. Nallari, Yusuf, Griffith, and Bhattacharya, 2011), modalities (e.g. Furukawa and Takahata, 2017) and measurement (e.g. Griffith, 2011). In relation to Oceania, the conclusions of Dornan and Pryke (2017) on the delivery of foreign aid to the Pacific highlight the finding that "aid volatility and predictability remain problematic in Pacific island countries" (p.401). Of relevance to this thesis, they conducted a comparative examination of Official Development Assistance, which includes Australia, New Zealand, plus Tonga, and offer a bird's eye view on monetary figures, expenditure, and allocations whilst trying to interpret trends they observe. Over two decades ago, Campbell (1992) examined the topics of aid and dependency with Tonga as an example. He gives us a historical look into the past with 
eerie familiar undertones to contemporary issues we still encounter concerning foreign aid and Tonga's national development.

This literature review is to give an overarching understanding on the contextual landscape concepts such as development, foreign aid, and national development priorities exist. The historical background the concepts arise from (Ridley, 2012, p.24) and the dominance of the western perspective on the concepts and themes are also helpful starting points (Banivanua-Mar, 2016; Va'ai and Casimira, 2017). Understanding these individual elements of each theory at a global level assists in how aid programmes were applied in Oceania and eventually the Kingdom of Tonga. The chapter then turns to exploring how these broad paradigms of aid, particularly neostructuralism, have been embedded in global aid and development institutions. The key role of the OECD in mobilising and articulating broad aid strategies, definitions and measurements of aid is examined before turning to the specific aid effectiveness agenda it promoted. This, notably through the 2005 Paris Declaration, became a cornerstone of the neostructural approach to aid.

\subsection{Development Theory and Foreign Aid}

All three theories - modernisation, neoliberalism, and neostructualism - have been the dominant theoretical paradigms informing development policy since 1945. Linked to this is how foreign aid is applied, that is the development theories are the framework by which the purpose of foreign aid is articulated. Table One below seeks to provide a summary of the intricate interaction between the theories of development we cover and how foreign aid is applied. This table is donor-focused and helps us understand better how Australia and New Zealand have approached aid to Tonga over the past four and more decades.

Table One: Changing Development Paradigms for Aid

\begin{tabular}{lllll}
\hline Decade & Donor Plan & Donor ideology & Donor focus & Types of aid \\
\hline 1980s & Colombo Plan & Modernisation and early & Development & Some budget \\
& & Neoliberalism & through state & support \\
& \multirow{2}{*}{ Jackson Review for } & & agencies then a & Projects for \\
& Australia & shift to market- & welfare (education \\
& & orientation and & \& health) and \\
& & deregulation & economic sectors
\end{tabular}


South Pacific Aid

Programme for New

Zealand

1990s

Australia's Simons
Report
New Zealand 1992
ODA Principles
promote sustainable
economic and social
progress

2000s

Millennium
Development Goals
OECD Paris Principles
on Aid Effectiveness

2010s

$$
\text { Country }
$$

Programmable Aid
Neoliberalism

Neo-Structuralism

Retroliberalism

Sustainable

economic

development (agriculture,

infrastructure)

$\begin{array}{ll}\begin{array}{ll}\text { Aid cuts to force } \\ \text { public sector }\end{array} & \begin{array}{l}\text { Structural } \\ \text { adjustment }\end{array} \\ \text { reform } & \text { programmes } \\ \text { orientation } & \text { Move to projects: } \\ \text { Sector focused } & \text { civil society } \\ \text { such as education, } & \text { focused } \\ \text { water, agriculture } & \end{array}$

Poverty alleviation Budget support

and sector-wide

programmes.

High level

agreements for

govt. to govt.

relationships

Donor aid for

private sector

partnership

Source: adapted from Overton, Murray, Prinsen, Ulu, and Wrighton (2019, pp.31-32).

Table One offers an understanding of the different high-level aid regimes, modalities, and policies followed by aid donors in the Pacific region. As Overton et al. (2019) point out when offering such overviews: 
"Even though these are presented chronologically, once again it is important to state that reality is more complex than this - elements of each regime can persist at any given time and vary between places" (p. 30)

Nonetheless, the framework gives an overview and basic understanding of how foreign aid slowly progressed to how it is understood today and, more importantly for this research, the context for the years 2013 to 2017. The sections which follow outline the key elements and policy approaches to aid within each of the three paradigms.

\subsubsection{Modernisation}

Modernisation theories of development originated shortly after the Second World War, during a period of decolonisation, and into the Cold War era. As a theory of development, modernisation is centred on the sociological assumption that to be 'developed' is to become like the 'West' (Peet and Hartwick, 2009, p. 104). It pointed to the stages of economic growth by Rostow (1960) in the 1960s and positioned the way 'development' become a policy objective (Escobar, 1995; Rist, 1997). The definition of development for the theory of modernisation varies but the main features is how closely aligned a country to the ideal of the modern industrial society, particularly the capitalist market and western democracies (Przeworski, 1996; Bernstein, 1971). It proposed a linear transition, through a process of development, from 'traditional' and 'underdeveloped' to 'modern' and 'developed'. This would be akin to saying Australia and New Zealand are the advanced countries and Tonga is the developing country that should aspire to reach their status. As an era, this covers the years between 1945 to the 1980 s.

Modernisation is a theory of social and economic change that uses a model that dichotomizes society from a traditional society and a capitalist market-oriented society, the latter being what constitutes 'modern' (Bernstein, 1971). It suggests the historical trajectory of 'western' countries such as the United States, United Kingdom, and France, for example, are to be emulated but arguably only applies a selective approach to the traits that makes these countries 'modern'. It also assumes that such emulation is possible, forgetting the colonial basis to, and exploitation inherent within, much Western economic growth prior to 1945. By application the most influential version of modernisation theory is Rostow and his stages of economic growth (1960). Rostow (1960) argued that to go from the traditional to the modern society takes five economic stages - (1) traditional society which is basically a society that relies on agriculture for subsistence and lacking the rationalism philosophy of man's ability to "control the world through thought, logic, and calculation" (Peet and Hartwick, 2009, p. 107); the pre-conditions of take-off, meaning the application of "modern science began to be translated 
into new production functions in both agriculture and industry" (1960, p.6); the take-off stage when economic growth becomes the normal condition (1960, p.7); the drive to maturity turns into spill over growth of the whole economy going from "entrepreneurial skills to produce not everything, but anything that it choose to produce" (1960, p. 10); and the age of high mass-consumption (1960, p.4).

Highlighting social change comes about because of philosophies such as naturalism. This suggests that just as in nature there are 'natural laws' that govern so to, as the argument supposes, are natural laws applied to human societies (Spencer, 1882 cited by Peet and Hartwick, 2009, pp. 106-107). Hence there was version of social Darwinism to modernisation: countries would supposedly evolve over time from more 'primitive' communal forms to stronger more vibrant individual and secular societies.

Modernization is also about 'conceptualising the modern' (Bernstein, 1971, p.44) or in other words for someone like me who is not from a western society, it is about foreign concepts and experiences westerners went through that led them to where they are modern now. In mind here, Bernstein is talking about where the social, economic, and political change began and where did it reach its destination (1971, p. 44). The interpretation taken by me as a Tongan researcher is that external understanding of allocated concepts have been assigned to describe this experience. If we were to go through the five stages of Rostow, the changes within the 'stages of economic growth' include different roles for the market and state. Let us assume the 'traditional society' (Rostow, 1960, p.4). In the traditional society the challenges to development into the modern are:

"a ceiling existed on the level of attainable output per head. This ceiling resulted from the fact that the potentialities which flow from modern science and technology were either not available or not regularly and systematically applied" (Rostow, 1960, p.4).

Perhaps the most obvious challenge for Tonga in trying to accommodate this assumption is its development and therefore its economic progress is arguably different to that of Australia and New Zealand. It has a fundamentally different culture, social priorities, and history but some similar aspirations with common interests.

Needs (1988) interprets modernisation and states:

"The problem for modernisation theorists and policy-makers was to identify structural and cultural properties which would encourage such development. This involved an analysis of the 'lack of progress' as well as an analysis of 'progress' itself" (p.5). 
Foreign aid under modernisation began through the European Recovery Program (Woodward, 2009, pp. 13-14) which aimed to help Europe recover from the ruins of the Second World War. Delivery and implementation of the ERP resulted in the origin of the Organisation for European Economic Cooperation. With the ERP and the establishment of the OECC we begin to see what became constituted as the normative legitimacy of global institutions relating to development cooperation (Buchanan and Keohane, 2006). The OECC was the institution set up to manage and coordinate the foreign aid from the United States and achieve its development objectives. The objectives in turn exhibit familiar conceptual underpinnings to how we understand the 'why' aspects of foreign aid today. These centred on the interests of the donors (principally USA at the time), fostering development cooperation, and, under the political context of the time, serving the geopolitical foreign policy interests of donors but at a global level (Woodward, 2009, p. 14). It was also contingent on states devising and implementing their own blueprint for recovery. Keynes' influence on economics was evident in this early approach to aid: "the market was to be fostered and encouraged, yet the state maintained both a regulatory oversight and the ability to intervene directly, as in infrastructure, when the private sector was seen as incapable." (Overton et. al., 2019, p. 37). As a development program the ERP was the blueprint of modernisation theory of development: state-centred with a strong emphasis on infrastructure and industrialisation.

In the context of Oceania and Tonga this paradigm continued under a policy focusing on infrastructure development. In the case of Tonga, its first bilateral aid agreement was with the United Kingdom for a loan of $f 514,000$ to begin the building of the Queen Salote Wharf (Campbell, 1992, p.66) and subsequently development projects were articulated through national five year plans. The 'Five Year Plans' afterwards not only prioritized education as a development need but incorporated elements derived from the modernisation paradigm, health and agriculture included. However, as 'Utoikamanu argues, when the Five Year Plans are examined more closely, they can be seen to have only been successful to a limited extent (1980, p. 430). Tonga encountered some challenges associated with the development plans, namely inadequate resources, deficiencies in the plans, and "unanticipated dislocations to domestic economic activity” ('Utoikamanu, 1980, p. 431). We can infer here perhaps early traces of the ownership principle to an extent with the five year plans and subsequently development priorities for Tonga.

Decolonisation shaped the way foreign aid started for the Kingdom of Tonga as it did for many countries in Oceania. At the time of its first bilateral aid agreement Tonga was still a protectorate of 
the United Kingdom. This does not appear to have hindered Tonga in terms of the familiar institutional elements associated with foreign aid under modernisation but with a local context. Interestingly, between 1945 to the 1960s Tonga paid its own way with "budget surplus and balance of trade surplus" (Campbell, 1992, p. 66). The first experience Tonga had with foreign aid, different from bilateral, is a sanitation scheme in 1957 with the World Health Organisation (Campbell, 1992, p. 66). The state was the main driver for the delivery of foreign aid and managed it (Campbell, 1992) but under the cultural power structures that existed (Lātūkefu, 1975b and 1980). In turn Tonga's five year plans as national development policy documents mimic to an extent the global approaches that began with the ERP in Europe regarding the delivery, purpose, and management of foreign aid.

Australia and New Zealand did not establish official bilateral ties with Tonga until the 1970s and even then their aid programmes were small. Nonetheless, the Canberra Pact of 1944 to which Australia and New Zealand agreed on security and development interests (Campbell, 1992: Needs, 1988), the Colombo Plan of the 1950s, which aimed at regional security in South East-Asia and economic development, and the establishment of the South Pacific Commission (Needs, 1988, p. 6) are all institutional elements and policies that were underpinned by modernisation theory. Thus, the theory of modernisation offers a conceptual framework and subsequently analytical tools for societies to be like the 'west'. What modernisation offers strongly mimics the perspective implemented by the Marshall Plan - Keynesian economics whereby the state implements short-term fiscal policies to drive the economy and remove barriers that hinders economic progress. To achieve development under modernisation theory, from this comprehension, is to economically, politically, and socially progressive to the stage of being modern like the 'west'.

Modernisation theory has been strongly criticised, for example with the rise of dependency theory in the late 1960s. Rather than pointing to internal barriers to development, such as social conservatism and a lack of skills and resources, dependency theory rightly pointed to the way 'underdevelopment' was created through processes of colonialism and capitalist exploitation of societies in Africa, Latin America and Asia. Similarly, today it is easy to highlight the deficiencies of modernisation theory with regard to its naïve dismissal of 'traditional' societies and cultures as having little or no value. However, it is still important to appreciate the thinking behind modernisation theory for it informed both the origins of international development assistance in the 1950s and 1960s and many of its basic elements, such as the emphasis on economic integration and growth, the call for social and political change, and the assumption of the desirability of western lifestyles, remain key features of aid and development models today. It is also important to note that modernisation thinking persisted in 
Oceania and in aid activities there well into the 1980 s before being challenged and replaced by strict neoliberal ideas and practices.

\subsubsection{Neoliberalism}

As a theory of development, neoliberalism argues the 'market' will achieve economic development. It was a theory that countries, such as the United States of America under Reagan, the United Kingdom under Margaret Thatcher and New Zealand with the Lange Labour Government after 1984, adopted (Overton et al., 2019, p. 40). In terms of aid practices, it was given much impetus by the end of the Cold War. The key aspects of neoliberalism theory are "structural reform, deregulation, liberalisation, privatization - all of which are to roll back government and reduce market-distorting interventions" (Nederveen Pieterse, 2002, p. 6). The economics of neoliberalism - monetarism, deregulation, and market-based reforms - adopted theoretical models championed by Friedman and Hayek for example (Jones, 2014, pp. 1-5). In comparison to modernisation theory, where the state intervenes to alleviate economic downturn, for neoliberalism, development should be left to the invisible hand of the market and the state should take austerity measures to reduce its role in the economy. Thus, it was seen that development was not held back by a lack of finance for investment but rather poor policies and governance (Dollar and Svensson, 1998).

From a global perspective, debt is what seems to be the catalyst for the theory to spread into practice globally. By this I mean the debt crisis of the 1980s in Latin America and other developing countries led to Structural Adjustment Programs (SAPs) to the later part of the decade (Pastor, 1989: Kelly 2008 : Kay, 1993). Donors and international agencies, such as the IMF and World Bank, were able to exploit the desperate economic situation many indebted countries found themselves in by insisting on radical reform of the state (through SAPs) as a condition of debt relief. In doing so this elevated the theory into mainstream. As Kay (1993) denotes, SAPs were the central strategy of neoliberalism:

"neoliberal structural changes entail drastically rolling back the state by radically reducing government expenditure (especially welfare expenditure), privatising state enterprises, eliminating subsidies and protectionism, and liberalising markets" ( $p$. 693).

Basically, this suggests that countries should let the private sector lead development and the market drive it. As a concept, neoliberalism has some issues in programming foreign aid. Most prominent is that it is a top-down model with a seemingly uniform unilateral approach. Furthermore, there was to 
be a major shift in the role of aid, from a modernisation-inspired mechanism to support state provision of infrastructure and welfare, to a situation where reductions in aid starved recipient governments so that they had to severely reduce their economic roles and the leadership of development strategies.

The neoliberal development paradigm under the form of Structural Adjustment Programs reached the Global South including Oceania around the 1980s and 1990s (Overton et al., 2019, p. 40). Both the ideology and general aim, in the guise of conditionalities, affected the development of countries (Emeagwali, 2011; World Bank, 1999; and Gudikunst et al., 2010). The imposed approaches included, but were not limited to:

"domestic currency, privatization of the ownership of industries, liberalization of trade, and the removal of subsidies on health, education and social services" (Emeagwali, 2011, p. 3).

These structural approaches are indicative of how donors perceived development under neoliberalism and subsequently linking that with aid programs, particularly the SAPs of the World Bank and the International Monetary Fund, which had mixed results. For example, a study by Forster et al. (2019) found that "overall, policy reforms mandated by the IMF increased income inequality in borrowing countries" (p. 83). Whilst Oliver (2006) found:

"countries that have maintained more dynamic public social and health programming while applying SAPs have been better able to protect the health of the most vulnerable sectors of society" (p. 217)

The highlight here is the continuing evolution of the top-down donor aid environment. The radical shift in aid that neoliberalism brought was entirely donor-driven but questionable. The ideology of neoliberalism, through SAPs, largely produced the intended development results, namely a significant shift away from states as leading agents of development. States and state agencies came to be regarded by donors as inefficient, bloated and incapable of delivering effective development.

By the time neoliberalism dominated development thought between late 1980s to the late 1990s, Tonga had reached its sixth Five Year Development Plan in 1991. The Sixth Five Year Development plan ran from 1991 to 1995 and was the first to include 'natural resource planning' (Takau, 2020). Takau highlights that the sixth five year plan held an overall vision of "sustainable economic growth 
conducive to a higher per capita income" and Government aiming toward environmental planning, resource management, and reduction in spending (2020, p. 42). In the same period, Storey and Murray (2001) examine the political economy of the Tonga agro-export sector. They highlight that development under the neoliberal paradigm for countries in Oceania, and a case study of Tonga, posed an 'evolving dilemma' between environmental conservation and economic development (Storey and Murray, 2001).

The model of programming foreign aid that neoliberalism appears to follow is still featured. In 2009 for example, the Asian Development Bank implemented the Pacific Private Sector Development Initiative Phase II co-financed with, at the time, AusAID. This was USD\$3 million from ADB and USD\$9 million from AusAID amounting to a USD\$12 million project that aimed at:

"three key reform areas: (i) state-owned enterprise (SOE) reform and public-private partnerships (PPPs); (ii) financial sector reform to promote access to financial services; and (iii) reform of the legal and business regulatory environment" (Asian Development Bank, 2009)

The PSDI Phase II was a regional project meaning it was implemented into Sāmoa, Fiji, Kiribati, and Tonga for example and had two outputs being Policy Advisor - that advocated, researched, and communicated technical advice and capacity development - and Transactions support in feasibility studies, due diligence and initial assessments (Asian Development Bank, 2009).

Neoliberalism as a theory provides development, and subsequently foreign aid, a lens where four main themes are the focus areas - structural reform, deregulation, liberalisation, and privatization (Nederveen Pieterse, 2002). These areas are brought to the forefront because of the reactions to the development environment - how poor policies for example are why development was held back (Dollar and Svensson, 1998); challenges to who the driver for development is, that is the state or the market; what model of development is a template; and the debt crisis in Latin America and other developing countries (Pastor, 1989: Kelly 2008: Kay, 1993).

As development has progressed so too have the approaches neoliberalism presents. One emphasized here, under the premises of the delivery of foreign aid, is Structural Adjustment Programs. The SAPS in the 1980s and 1990s were championed by organisations such as the World Bank, International Monetary Fund, and up to today in aid programmes by the Asian Development Bank. Countries were 
to adhere to conditions whereby foreign aid was provided, dominated in the ideology of structural reform, deregulation, liberalisation, and privatization. SAPs produced mixed results, as mentioned earlier. It is worth noting as well that this paradigm of understanding development through SAPs effectively decreased the role and power of the state. The assumption of neoliberalism is underpinned by believing a strong private sector would emerge as it was 'liberated'.

As a theory of development and as a result of the lacklustre performance of the results from aid delivery, neoliberalism offers us insight into the evolution of how aid effectiveness slowly gained prominence globally. It demonstrated how donors were capable of both a sharp change of aid policy, driven by ideological shifts, and of instigating a strongly imposed development model, one that sought to 'discipline' recipient states and challenge their power to oversee development. This aspect of neoliberalism has strong implications for this thesis and its main research question because it shows that aid donors are indeed willing and able at times not only to shape but also dictate the national development priorities of countries such as Tonga.

\subsubsection{Neostructualism}

From a chronological standpoint, neostructualism arose in a similar manner to neoliberalism, reacting to what came before but drawing on new global ideas about development. It held sway in particular from 2000 to about 2010 but has remained very influential in many parts of the aid world, including Tonga, through to the present.

Development thinking appeared to have shifted due to a change on the ground, around the late 1990s. Neoliberalism together with the policies it championed began to be portrayed rather differently and in a much more critical light. As Overton et al. (2019) explain:

"Voices from the Pacific were not alone in its dislike of the institutional and social disruption and often misery of neoliberal policies" (p. 44) (Emphasis added)

According to Levia, neostructualism is a development framework that arose in the 1990s in Latin America out of:

“Neoliberalism's failure to deliver high rates of economic growth and its role in causing widespread popular discontent and massive mobilizations, along with 
electoral victories by center-left coalitions, point to the decline in the hegemony of neoliberal economic ideas" (2008, p. 1)

There was strong resistance to neoliberal policies in the form of the Structural Adjustment Programs and how that dominated policy and society and this came from both popular movements in many countries and from academia. The elements of development that were brought to the forefront were poverty reduction, inequality, and debt (Overton et al., 2019, pp. 44-45). As a theory, neostructualism offers patterns for us to understand just as neoliberalism does. What are the drivers of development? What causes the lack of development? What policies should be in place? For example, neoliberalism looks at the market to drive economic development whilst neostructualism propels forward the role of the State to tackle poverty. Development under neostructualism is:

"development oriented in terms of resource allocation and State intervention, universalist in the social field and conservationist on the environment" (Bielschowsky, 2008, p. 172)

By way of definition, Levia also adds that neostructualism is:

"simultaneously an alternative vision to neoliberal dogmatism, a comprehensive development strategy, an integrated policy framework, and a grand narrative about the path toward modernity that the twenty-first century allegedly offers to Latin American and Caribbean societies. To reduce it to just one of these dimensions is to misrepresent and underestimate it." (2008, p. 3)

At a global level, neo-structuralism is the alternative to the perceived, and arguably real, shortfalls of neoliberal economic development policies (Kirby, 2009, p. 137). International institutions such as the International Monetary Fund and the World Bank championed these policies. It is the assumption that development is achieved by market forces exclusively. Ramirez (1993) summarizes the issues to this assumption well:

"the governments of the region [Latin America] need to formulate stabilisation programs that address the socioeconomic constraints and realities of countries in the process of development - not those of economists working at the IMF and World Bank who are, by and large, trained in monetarist theoretical constructs that preclude them from devising sensible macro-economic programs for the region" (p.1025) 
Ramirez (1993) argues here that development requires not only the input of the state, but the state also has a role in advancing social justice. Neo-structuralism offers to us at the global level the idea that because of the way the international system is set up from an economic point of view, there exists a 'centre-periphery system' facet to development. Early on, Prebisch (1949) led this argument, that development is hard to achieve if the 'centre' followed a different economic pattern to the contemporary reality of 'periphery' developing countries. In the example of Latin America, this means entering the global economic system at an unequal footing relative to North America or Europe.

Neostructualism impacted the way foreign aid was perceived, especially on the grounds of how a greater role was given to the state. There was growing recognition in the 1990s, even within the World Bank, that structural adjustment had weakened states to such an extent that not only could they not function effectively in fields such as law and order but also weak states and growing poverty were threats to continued economic growth. Development models were being reconceived in ways which reconstructed a development role for states, alongside the market. In this aspect we better understand the shift toward recipient countries owning a larger input in delivering foreign aid. This context is where the Paris Declaration on Aid Effectiveness arose.

Before that, however, there were also growing demands to tackle poverty, something which was seen to have worsened as a result of neoliberal restructuring. The launch of the Millennium Development Goals (MDGs) by the United Nations in 2000 provided a new global development mission, away from neoliberal rolling back of the state, towards an explicit set of goals to alleviate poverty at a global scale (United Nations, 2000). The eight goals the MDGs defined what the priorities were to be in terms of poverty reduction and asked donors to agree to commit substantially more aid resources to address these priorities.

Whilst the MDGs defined the poverty alleviation goals of this new neostructural approach, the OECD worked on a global agreement on how to best use aid to meet the goals. These resulted in the aid effectiveness principles adopted by the Paris Declaration of 2005 and they were further endorsed and slightly modified in subsequent high level forums on aid effectiveness in Accra in 2008 and Busan in 2011.

Under neostructualism the Paris Aid Effectiveness principles are used as guiding tools and a conceptual framework with their own distinct features. For example, the role the state holds and plays in development is significant, whereby the state tackles social justice but in the context of a globalized 
economy that remains open. Poverty and inequality are seen as consequences of the market but are accepted as responsibilities of the state (Murray and Overton, 2016, p.247). What characterizes neostructualism is not only the shift in emphasis - poverty alleviation as opposed to the liberal market, but also this assumed sense of maturity of development as a concept. The Paris Declaration to a degree captures this maturity of development understanding through its five principles towards aid effectiveness. They represent a set of generally accepted good practices for aid delivery. They will be discussed further in later sections of this chapter.

Neostructuralism was firmly established through the MDGs and the Paris Declaration as the dominant approach to aid in the first decade of the new millennium. Some writers (Harmon and Williams, 2014: Murray and Overton, 2016: Mawdsley et al., 2018) have suggested that this approach has itself been superseded in the past decade, largely the result of the Global Financial Crisis of 2007-08 and subsequent changes in global politics. This, they suggest, has been associated with a move away from the poverty focus of aid to a primary goal of promoting economic growth, a much greater role for the private sector alongside the state, and more explicit pursuit of donors' self interest in the form of economic, trade and diplomatic objectives. Some have even suggested that this represents a completely new aid 'regime, termed 'retroliberalism' (Murray and Overton 2016). However, although some aspects of this shift can be seen in Tonga (such as the already noted re-integration of Australia's and New Zealand's aid agencies back into wider foreign affairs and trade ministries), for this research, I have not adopted the retroliberal concept. This is because, for the aid environment in Tonga in 201317 , it is apparent that neostructural understandings and ways of working were still dominant. Although both donors may have made changes to their aid programmes elsewhere, on the ground in Tonga it seems that the neostructural model continued, particularly as it affected relationships between the three governments.

As a theoretical framework for Oceania what neostructualism characterised can be summed up in two key main points, focus and the modality. The focus being under the overarching umbrella of poverty eradication, derived just as much from the global agenda - the MDGs (Dabelstein and Michael, 2012, p. 24) - and the shift in delivery of aid under the structure of separating it from foreign policy. With regard to the latter, the most obvious result was the establishment of the semi-autonomous aid agencies of Australia and New Zealand, colloquially 'Aus Aid' (1995) and 'NZAid' (2001) respectively. Under neostructualism these two foreign aid agencies were separate from the wider ministries of foreign affairs and trade and they had their own primary mission of poverty alleviation. They have since both been absorbed into their respective Ministry and rebranded as the Australia Aid Program 
or AAP and the New Zealand Aid Programme or NZAP. Davis (2011) sketches an interesting point that illustrates why this may came about. To begin with he explores the:

“institutional nature of Australia's official aid structures and organisations, including the processes whereby they formulate and provide development assistance programmes, and the political interpretations of 'recipient' countries that are embedded in, and by, these processes" (Davis, 2011, p. 390)

Davis (2011) argues that several narratives exist in the post-war history of Australian aid and there exists competition between "foreign policy demands that aid must serve the national interest and increasing cognisance that effective 'development' may be stymied by these demands" (p. 402). In other words, for Australia their foreign aid is still challenging to balance competing development and foreign policy demands. This competition in demand is still on-going and links up with the other main point of neostructualism, poverty eradication, in definition and measurement. In the neostructural environment, poverty alleviation took precedence (at least in the rhetoric of aid mission statements) in aid policies in Australia and New Zealand over the donor's over-riding foreign policy interests.

With regard to Oceania, neo-structuralism requires scrutiny. Neostructuralism, as with neoliberalism, puts emphasis on continued globalisation alongside its poverty-reducing goals. Firstly, for nations in Oceania, poverty is a contestable issue. Mainstream indicators, such as Gross National Income and Gini coefficients, are open to criticism as they do not portray a complete picture of wellbeing or poverty in the region. They do not, for example, count for access to communally-held and non-market access to key resources such as garden land and fishing grounds which have provided Pacific people with adequate food sources for centuries, despite apparently low per capita monetary incomes. Furthermore, it is important to question the merits of globalisation for Oceania. How have small island states entered the global economic international system and how has development fared for these countries by adopting capitalism and global free trade? The answer appears to be that such a development model delivers poor results given small-scale economies, relatively non-existent elements for industrialization or the ability to compete with more technologically advanced and distant markets. These arguments have been complemented - and sometimes contradicted - by Pacific academics such as Hau'ofa (1993). Hau'ofa (1993) certainly was not addressing the merits or limitations of neo-structuralism but offered a re-conceptualization of Western perceptions and by extension ideas of what development for the Oceania region, including Tonga, embody. He rejected notions of smallness, isolation and vulnerability and saw some hopeful and positive aspects to global 
engagement, yet it is also possible to suggest that his critiques would also reject grand notions of 'poverty' inherent within neostructuralism.

For Tonga the experience with neostructualism is captured through the national development plans and broader policy initiatives associated with the Paris Declaration on aid effectiveness. By the early 2000s Tonga had moved from the five year plans, characteristic of the modernisation and neoliberal models, into what they termed 'Strategic Development Plans' (Takau, 2020, p. 42). Plans such as these conform to calls for recipient states to articulate their own development strategies, often in the form of Poverty Reduction Strategy Papers (PRSPs) which are required by many donors. Strategic Development Plan Seven covered the years 2001 to 2004 and Strategic Development Plan Eight went from 2006 to 2009. We can attest to the elements that are familiar with neostructualism in the 'strategic development plans' with the incorporation of the Millennium Development Goals and a heavy focus on 11 social goals (Takau, 2020, pp. 42-43). In early 2005, 'Utoikamanu as the Minister of Finance initiated what could be analysed as four policy forums but centred on the principle of harmonisation ('Utoikamanu and Rodger, 2010). The four policy forums were - Efficient machinery of government that looked at streamlining donor processes particularly community consultations; Bringing donors into the budget process to be a more transparent and efficient mechanism for development; Balancing emergency response to basic (financial) needs; and Involving civil society and donors in governance ('Utoikamanu and Rodger, 2010, pp. 12 -13). The Tonga Strategic Development Framework I (2011 to 2014) is the next document after Strategic Development Plan Eight.

Harmonisation has interesting features about it as a principle in theory and in practice. Eyben (2007) informs us that this principle is challenged by prescriptive agendas being channelled indirectly via a global programme, adherence to arguably different set of 'rules' by donors and recipients, and the assumption that this principle discourages innovation towards addressing 'local problems' (p. 644). That should not be seen as harmonisation not working despite its paradoxical nature but that the principle acts as a clue to how adaptive recipients are no matter the level of complexity imposed. From a chronological analysis the Organisation for Economic Co-operation and Development principles of Aid Effectiveness agreed to in 2005 are observed in this research focus to determine their existence between 2013 to 2017.

Neostructualism also highlights a key fundamental way of perceiving foreign aid and shift in attitude by those providing it and by those receiving it. As Murray and Overton (2011b) put it eloquently, neostructualism places emphasis for the state to forge: 
"a successful economy also dependent on the creation of a democratic participatory society where harmony and cohesion are paramount" (p. 311)

Hence in that regard the state is "a body that facilitates belonging, often around shared identity based on rights and freedoms" (Murray and Overton, 2011b, p. 311). This is an important facet that applies to both the donor giving foreign aid and the recipient receiving it. Hence this is why the principles of ownership and mutual accountability matter. Ownership encourages a donor to trust the capability and self-determination of the recipient, whilst mutual accountability implicitly advances responsibility onto the conduct of the latter.

Modernisation, neoliberalism, and neostructualism are different conceptual frameworks and analytical tools that the field of development has offered. Each have their own strengths and weaknesses which is important to not only understand but appreciate. At the same time, they are a window in how to interpret and look at the world. However, the theories should not be treated as dogma or treated zealously as 'the' explanation. Instead, they are to be utilized strategically heeding the insight offered by Thaman in that "it is essential to challenge the dominance of western philosophy, content, and pedagogy" (2003, p.1). Balancing between finding the use of western interpretation and articulating the indigenous perspective is simultaneously important and complex.

\subsection{Institutions for Aid}

Having traced the overall theoretical basis for the changing global aid environment over the past 75 years, it is now necessary to examine the institutional framework for aid on a global level. In this section we explore the history behind the establishment of the Organisation for Economic Cooperation, otherwise now known as the Organisation for Economic Co-operation and Development, the Development Assistance Committee (OECD DAC), and the Paris Principles on Aid Effectiveness (Organisation for Economic Co-operation and Development, 2005). This establishes a global context and for foreign aid has transitioned into neostructualism. Gauging with the history of the OECD offers us an insight into how attempts are made at the global level to find a collective cohesive definition of Official Development Assistance. The by-product of this is countries - solely donors at first and then recipients later - agreeing on a whole range of matters pertaining to ODA. This includes aid effectiveness and how countries understand development cooperation.

What the literature informs us so far with the different theories is that at the global level the understanding of development assistance and cooperation has gone through different stages. 
Beginning with the modernisation theory era, development is led by Keynesian economics and state intervention (Przeworski, 1996; Bernstein, 1971). Foreign aid under this context of decolonisation and the Cold War is bilateral, development policies are shaped by recovery and economic cooperation, and global institutions shaped by security interests. Development and foreign aid for Oceania, including Tonga, is heavily shaped by these elements. Under neoliberalism and neostructualism development adjusts to the shifting geo-political context. Firstly, the debt crises countries fell to required structural adjustment programs of the World Bank and International Monetary Fund, and then with the latter a change of focus to poverty alleviation set about by the United Nations Millennium Development Goals in the early 2000s. The evolution of the OECC into the OECD presented here is a helpful example of weaving together theory and practice. That is to understand the different stages development cooperation has gone through at a global, regional, and national level, together with how it has arrived at the Paris Declaration on Aid Effectiveness principles.

\subsubsection{European Recovery Program and the OECC institution}

After the Second World War, Europe was in a state of ruin and, rather than repeating the inadequate policies adopted after the First World War the United States initiated the European Recovery Program or ERP, otherwise known as the Marshall Plan (Woodward, 2009, pp. 13-14). The ERP total aid amounted to USD\$13.2 billion (Magid, 2012, p.4). The objective of the ERP was twofold for the United States: one was to 'sustain economic prosperity;' and two was to advance in a strategic way one doctrine over the other, capitalism versus communism (Woodward, 2009, p. 14). Three main conditions were also set by the United States for the European countries with regards to the ERP package. The recipients were to disassemble any obstacles to trade between each other, apply a cooperative consensus on requirements, and employ a multilateral approach to implementation of the Plan (Bainbridge, 2000, p. 111).

In 1948 seventeen countries and one territory (Free Territory of Trieste) formally signed the intergovernmental arrangement under the Convention establishing the Organisation for European Economic Cooperation or OECC (Woodward, 2009, p.15). The countries were - Austria, Belgium, Denmark, France, Greece, Iceland, the Republic of Ireland, Italy, Luxembourg, the Netherlands, Norway, Portugal, Sweden, Switzerland, Turkey, the United Kingdom, and West Germany. The Convention is symbolic being intra-European in focus and economically concentrated to the geographical location. Placed within the context of recovery and reconstruction for Europe, foreign aid in the form of the European Recovery Program to the sixteen European countries implies a heritage 
of multilateralism, features of ownership, and conditionality. The speech General Marshall gave at Harvard University that led to the creation of the European Recovery Plan alludes to this:

"It would be neither fitting nor efficacious for this Government to undertake to draw up unilaterally a program designed to place Europe on its feet economically. This is the business of the Europeans. The initiative, I think, must come from Europe." (Organisation for Economic Co-operation and Development, 2007b).

Note here the acknowledgement by Marshall of Europe as a continent as opposed to signalling out one country. This implies the collective institution as opposed to a unilateral or bilateral one.

Inferred is the principle of ownership, it being afforded to the Europeans to come up with the recovery and reconstruction plan of the ERP but agreed to by the United States. Ownership was not to be at the expense of a collective outcome. In these circumstances:

"The Marshall Plan was more than aid to separate countries; it was the beginning of the attempt to jump start the cooperative effort of European economies and end the malaise of restrictive, bilateral trade. Throughout the process the role that the OEEC played was crucial in the recovery programme's successful implementation." (Barbezat, 1997, p.33)

This is reflected in the language of the Economic Cooperation Act of $1948 \mathrm{s.102}$ (US), (note the emphasis of ownership in italics and conditionality underlined):

"The restoration or maintenance in European countries of principles of individual liberty, free institutions, and genuine independence rests largely upon ... the achievement by the countries of Europe of a healthy economy independent of extraordinary outside assistance ...The accomplishment of these objectives calls for a plan of European

recovery, open to all such nations which cooperate in such plan ... no assistance to the participating countries herein contemplated shall seriously impair the economic stability of the United States. It is further declared to be the policy of the United States that continuity of assistance provided by the United States should, at all times, be 
dependent upon continuity of cooperation among countries participating in the program" (Economic Cooperation Act of 1948 s.102 (US), p. 137.) (Emphasis added)

Roles were formulated and defined at global level for the OECC and engagement in the manner of partnerships and trade under the ideas of mutual economic prosperity (Weissman, 2013, p. 111).

\subsubsection{OECD}

By 1961 a lot had changed in terms of economics, development, and politics particularly the state of Europe since the OECC was created. Woodward (2009) writes that:

\footnotetext{
"changing economic circumstances violated the donor-recipient model upon which the OEEC was premised. Originally, the United States supplied aid and tolerated trade discrimination against their products because the political remuneration from European rebuilding and integration exceeded the economic cost. By the late 1950s, Western Europe's recuperation and the tribulations afflicting the American economy precipitated a recalculation of this position." (p.17)
}

In other words, Europe had recovered from the ruin of the Second World War and the OECC appeared to have served its fundamental purpose of managing an aid programme towards recovery and reconstruction. The OECC had achieved its objective, and as Woodward interprets the global economic and political landscape, the organisation needed to reconfigure accordingly (2009). The needs of the organisation morphed from recovery and reconstruction to restructure for an updated purpose.

How and why change occurs in the international system together with the influence it has is an important overarching feature even to today. For example, one feature is the international system went from a 'colonizer/colonized' to a 'developed/underdeveloped 'dichotomy (Rist, 1997, p. 73). The latter feature prescribes principles of self-determination and sovereignty for the newly decolonized states. As Rist (1997) argues, the change in the international system altered the concept of development from an "intransitive phenomenon" to a "transitive meaning" (p.73). This was, at the time, a new way to look at the international system with foreign aid a means to an end for development. For different reasons this is not what happened in Oceania. Australia and New Zealand were colonisers or administrators in this region even up to the 1960s. For example, Australia colonized Papua New Guinea (Denoon, 2012) and New Zealand colonized, on behalf of Britain, Western Samoa, Cook Islands and Niue (McGibbon, 2014). Compared to the rest of the world, independence came late 
to the region: first for Sāmoa 1962 then for Papua New Guinea not until 1975 (Denoon, 2012). Tonga was a British Protectorate until 1970 (Campbell, 2001). This demonstrates for states in the Pacific region we have a unique historical experience relative to development and influence by the international system takes time.

Features in the nature of the international system imply that it influences the behaviour exerted by states. For example, neorealism in the discipline of International Relations explains the "behaviour of states in light of the structure of the international system" (Schornig, 2014, p. 37). On the other hand, neoliberalists such as Keohane (2011) make the claim "the ability of states to communicate and cooperate depends on human-constructed institutions, which vary historically and across issues" (p. 158). They are a lens that provide a conceptual framework to analyse primarily the behaviour of European states proximate to the OECC. Different ways of understanding how global institutions and agreements on development cooperation norms are formed. Keeping in mind the previous paragraph on Oceania, they have experienced the international system differently.

Going beyond the surface description, it is not only asking why did European states agree to the terms and conditions of the OECC and subsequently the OECD but also what are the norms and institutions 'humans' have constructed? For example, the OECC entered a convention or treaty (Grant, Barker, Parry, 2009, p.126). Next is how then is that treaty adopted, which is when it is ratified or approved by the legal authority of the sovereign state. For Tonga this would mean, for example, the legislative assembly. The ratification may exist in the form of a document which is referred to as an instrument and in turn is then handed over to a 'depositary' (Grant, Barker, Parry, 2009, p.150). Recognizing, studying, and understanding this 'international' component is important. We appreciate better how interaction and relationships matter at different levels of engagement and shared ideas that bind countries. This process was gradual and grew throughout the years to be a process of consensus.

Change, driven by recovery and reconstruction, to the global economic and political context shaped OEEC's morph into the OECD. Leimgruber and Schmelzer argue the United States was the key architect (2017, p.34). They interpret the events and reality of the period as international development aid holding a 'key function in balancing US deficits through increased foreign aid of surplus countries such as Japan or West Germany' (Leimgruber and Schmelzer, 2017, p. 37). Other key economies such as Japan and Germany held a role to play in the changing times and in providing aid programs due to recovery from ruins of the Second World War. This 'semi-conjured' need by the United States coupled with the need for a multilateral organisation familiar enough for the members to trust, and serve a 
multifaceted purpose, is arguably what turned the Organisation for European Economic Cooperation into the Organisation for Economic Co-operation and Development. Thus in 1960 the OECD came into existence under the Convention on the Organisation for Economic Co-operation and Development and subsequently into force in September of 1961 (Organisation for Economic Co-operation and Development, 1960).

The global body that assisted the aid effectiveness principles being created is the OECD Development Assistance Committee (DAC). The OECD DAC throughout the years has played a pivotal role in establishing norms and concepts pertaining to development cooperation. As Verschaeve and Orbie (2015) summarise:

"Along with other achievements, the DAC established the concepts of official development assistance (ODA), which has provided policy coherence for development or (un)tied aid. The Paris Declaration on Aid Effectiveness (2005) also finds its origins in the DAC" (p. 572)

DAC is also "a global quasi-legislative body, defining, monitoring and reporting ODA from both its members and non-members since the 1960s" (Verschaeve and Orbie, 2018, p.45). The DAC is essentially a platform for dialogue, coordination, international consensus with regards to development cooperation and is composed of the world's main donors (Verschaeve and Orbie, 2018, p.44). The global theories of modernisation, neoliberalism, and neostructualism as development paradigms are steered into operation at this level by DAC. The DAC currently has 31 members including Australia and New Zealand. Looking at the history of the establishment of the OECD and the precursor, helps us understand what the OECD is as an organisation. We better appreciate why it holds de facto legitimacy at the global level as the authority that wields the bar for foreign aid and development cooperation.

Collectively the members are provided an opportunity at the international level to define the concepts and adhere to mutually agreed processes and policies. As noted earlier, foreign aid took the inheritance of being multilateral in the guise of grants, loans, and conditional aid to Europe but eventually grew a significant, and often dominant, bilateral feature (Barbezat, 1997, p.34).

So far, the focus on aid institutions has been at the global level but with reference to Oceania at different points in time. The reason for that approach is to show how the OECD DAC originated 
together with the nature of consensus building toward development cooperation. Implicitly for the purposes of this research contextualise where that links up with Oceania.

Australia's membership to the OECD echoed similar interest to the original members, how its national interest is served proximate to economic and political interest within its region. The latter point is important as prior to that Japan was the only member outside the North Atlantic. A consistent view at that time was because the makeup of the OECD DAC constituted of donors then by logic, "excluded those that were most affected by what it discussed" (Leimgruber and Schmelzer, 2017, p. 37), and it held perceptions of being a 'rich man's club' (Kellow and Carroll, 2011, p.98). If wealth, norms, and rules is concentrated and dictated from the North Atlantic, then access played a key role in swaying Australia to not only join the OECD, and subsequently the DAC, but outweighed initial concerns it had regarding whose interest is being served (Kellow and Carroll, 2011, pp.95-99).

The same cannot be expressly said for New Zealand but their national interest and economic development implicitly held a role, upon invitation from the OECD (Organisation for Economic Cooperation and Development, 1973). The closer priority for Oceania, was not so much recovery and reconstruction or the realpolitik of the Cold War, but the sensitive issue of decolonisation. Both countries, Australia and New Zealand, have the unique moniker of being former colonies that held colonies, Australia administrating Papua New Guinea and Nauru whilst New Zealand in free association with the Cook Islands, Niue, Tokelau, and Sāmoa. For countries in Oceania such as Tonga it was striving for due recognition to respect our right to sovereignty and co-existence at an equal plane within international relations.

\subsection{Aid Effectiveness}

Modernisation theory emphasized the state and how it should manage economic development as the focus. Neoliberalism pertaining to foreign aid, advocated strongly for states to implement deregulatory policies and apply Structural Adjustment Programs. The approach by neoliberalism is so greater freedom is allowed for the market to lead development. Neostructualism, as we have seen, grew out of the inconsistencies of results from Structural Adjustment Programs and how neoliberalism did not explain the growing tide of inequality and poverty. From a historical perspective the quality of foreign aid has always been contested in how effective it is relative to intended development outcomes. For example, literature has looked at foreign aid and economic growth (Rajan and Subramaniam, 2008) with no definitive answer, fiscal composition and aid effectiveness which varies according to the fiscal policy being implemented (Mosley, 2015), and donor coordination and aid 
effectiveness that argues concentration to fewer partner countries and program-based approaches reduce costs (Bigsten and Tengstam, 2015). In similar light foreign aid to Oceania has been studied, the tune is no different, with some pointing to high investment but little impact (Feeny, lamsiraroj, and McGillivray, 2014), indecisive model of partnership (Moloney, 2019), or the impact foreign aid has on sovereignty (Murray and Overton, 2011a). Under the range of factors listed it is not too much of a stretch to assume this issue is still highly contested.

\subsubsection{Country Programmable Aid}

Foreign aid is also given for different reasons for example economic development (Lewis, 1955), regionalism (Dornan and Newton Cain, 2014), poverty reduction (Collier and Dollar, 2002), or for political and strategic goals (Alesina and Dollar, 2000). With the European Recovery Program acting as the prototype for the modern iteration of foreign aid (Dornan and Pryke, 2017), its design still has familiar components, features, and composition currently existing. The design is what is referred to as programming foreign aid. The European Recovery Program was both a grant and loan (Burk, 2001) that varied within and between the European countries. Austria received USD\$677.8 million in grants whilst the United Kingdom had an arrangement of USD\$2.8 billion in grants and USD\$384.8 million in loans, a feature reoccurring amongst the countries (Magid, 2012, pp. 4-5). The composition of the European Recovery Program did not mean funding was directly deposited to the Europeans but rather used to pay for goods exported to Europe (Magid, 2012, p. 4). These components, features, and composition are all still very familiar approaches to programming aid today. This approach is adapted under the current paradigm by Australia and New Zealand through Country Programmable Aid.

Country Programmable Aid is the product of gradual stages in how foreign aid was understood and refined over time. Modernisation theory under Rostow (1960) understood development to be about transition into the modern industrial society, with the application of foreign focused on a model that addresses the lack of industrialisation and economic growth (Bull and Bøås, 2012, pp. 319- 320). At the international level foreign aid begins to be more 'globalised' in the truest sense with the Sector Wide Approaches, Poverty Reduction Strategy Papers, UN Global Conferences, and the Structural Adjustment Programs (Dabelstein and Michael, 2012, p. 22) under neoliberalism. Foreign aid is still donor-driven in the realm of both theories. The gradual application throughout the years and mixed results added to the growing perspective on quality of aid and impact on development (Dabelstein and Michael, 2012). Thus, foreign aid became not only about delivery but also a greater emphasis on quality and the impact. Neostructualism as a paradigm interprets development as resource allocation and state intervention with a strong focus on poverty alleviation (Bielschowsky, 2008, p. 172) together 
with global agendas. Here, foreign aid had reached at a global level an understanding of questioning the effectiveness and the impact through the High Level Meetings.

The Paris Aid Effectiveness Principles are a paradigm shift (Dabelstein and Michael, 2012) and important toward a more meaningful development. This paradigm shift is on the idea of partnership being a two-way exchange instead of only one party dictating (Dabelstein and Michael, 2012). As we have seen with the origin and evolution of the OECD, agreements between countries establish norms and breaths legitimacy in the actions conducted by its members through consensus, which is important to them. This is what the Paris Aid Effectiveness Principles ultimately represent and symbolize: the normalization of a partnership pertaining to foreign aid. From a historical background, this was not always the case but a gradual global process via the delivery, purpose, agreement, and global meetings. Partnership within that iteration and eventually the Paris aid effectiveness principles were crucial to address the wealth of details associated with foreign aid, such as donor coordination (Owa, 2011; Nunnenkamp, Ohler, and Thiele, 2013), evaluating foreign aid (Armytage, 2011), and proliferation of donors and projects (Deutscher and Fyson, 2008).

The global meetings eventuated in the 'Monterrey Consensus' in 2002 - which focused on six areas but relevant to this discussion was "addressing systemic and implementation issues such as enhancing the coherence and consistency of international aid" (Dabelstein and Michael, 2012, p. 24). Having committed to the MDGs and, following Monterrey, to substantially increase their aid budgets, donors were concerned that this new aid spending should be 'effective': it should go to the right places and achieve the results it intended. There was a clear need to identify what worked well in aid. This led to the first High Level Forum on Aid Effectiveness in 2003 in Rome which focused on harmonisation where donors "make plans for applying good practice principles at the country level" (Dabelstein and Michael, 2012, p. 25).

Following the foundations laid at the Rome meeting, much work was conducted by the OECD DAC in defining and refining some wider principles that could guide aid effectiveness. The resultant five aid effectiveness principles were:

- Ownership: Developing countries set their own strategies for poverty reduction, improve their institutions and tackle corruption.

- Alignment: Donor countries align behind these objectives and use local systems. 
- Harmonisation: Donor countries coordinate, simplify procedures and share information to avoid duplication.

- Results: Developing countries and donors shift focus to development results and results get measured.

- Mutual accountability: Donors and partners are accountable for development results. (Organisation for Economic Co-operation and Development, 2005).

The five principles are significant because they are an agreement at the global level not just by those who previously exclusively determined how foreign aid is delivered, but also by those who receive aid. It should not be underestimated how meaningful this paradigm shift is in giving a voice and empowerment to States, Oceania and Tonga in mind here.

According to Buiter: "Country Ownership is a property or programmes, processes, plans, or strategies involving both a 'domestic' party (generally a nation state) and a foreign party" (2007, p.647). He then moved to question the integrity of the principle of 'ownership' in reality. Buiter (2007), highlighted some evident realities on the different dimensions the principle of 'ownership' embodies as "it can mean one or more of the following:

- 'The country has designed and drafted the programme'; or its weaker siblings, ranging from 'The country has had a significant involvement in the drafting and design of the programme' to 'The authorities of the country were informed of the programme after it had been drawn up by other parties, typically the World Bank and the IMF'.

- 'The country agrees with the objectives of the programme.'

- 'The country believes that the implementation of the programme as envisaged will achieve the programme's objectives.'

- 'The country implements the programme'; or its weaker siblings, ranging from 'The country plays a significant role in the implementation of the programme' to 'The authorities of the country are kept informed of how and when the programme has been implemented'." (Buiter, 2007, p. 648)

The language used here not only opens a window into how the principle of ownership is actually practiced but insight on how its application, in this case for Tonga, is not a singularity or straightforward. Aspects of ownership assume that countries in Oceania such as Fiji, Sāmoa, and Tonga struggle in owning their development or let alone international aid assistance. Feeny and McGillivray refer to the capacity to absorb greater volume of aid (2008, pp. 166-167), Dearden covers issues to aid programming (2008, p. 213), and Dornan (2017) examines the applicability of the ownership 
principle (pp. 48-49). Country programmes by donors such as Australia and New Zealand are rigorous due to context and often an arduous process, at certain stages with recipients being unapologetic in calling out the perceived hypocrisy of donors. Perhaps more convincing up until the end of 2017, and indicative of the aid landscape my research encounters, is Harman and Williams' (2014) take on how international development is undergoing a fundamental transition. They indicate that you have new actors are entering the scene, China for example, and the role of the state being reinterpreted. The implications of this to countries such as Tonga include having a centralized or decentralized approach to development $(2014$, p.926). This no doubt will further add to the attempt on defining and more importantly understanding the application the ownership principle.

Literature has informed our journey here in international development and how vast of an area it is to cover. The three different theories of development have made an impact on how and why foreign aid is implemented. The chronological approach has highlighted how the global context development first originated and the elements that underpinned how it was initially understood. New challenges arose as the years have gone by that question the original foundations concerning development and foreign aid. In many ways these shifts have come from the 'centre', from ideological and theoretical changes within donor countries and institutions. Donors, thus, have largely determined what aid is, what it should achieve and how it should be delivered. Furthermore, they have changed their minds on these points, sometimes significantly, over time. Recipient states have had little say, at least until the Paris Declaration made the point that they should have a leading role in manging their own development. In addition, the international institutional framework for aid has also evolved over time. The OECD has been at the centre, though the IMF and the World Bank have also played their part at times. However, in recent years, it has been the DAC of the OECD that has been critical in articulating and guiding the global aid agenda and, in particular, in setting in place the neostructural architecture of the aid effectiveness agenda set in the Paris declaration of 2005.

For their part, Oceania and Tonga, the ways development and foreign aid was conceptualized from decolonisation to today was gradual and sometimes unique to the region. Much of this process of understanding is still on going. It is reflected in the policies and strategic plans of the countries. The five year plans that Tonga began in 1965 and continued until 1995 reflected both global trends and local priorities. Even up to the change of the national development policy into the strategic development plans, Tonga through its Minister of Finance, was still formulating strategies to address development cooperation at a national level. Thus we can see how international understandings of aid and the institutions and agreements used to guide and promote aid have changed markedly over 
time. Tonga has been an observer of these global shifts and has had to react and adapt. This research will trace how it has attempted to chart its own development course but interacted in complex ways with aid donors. With the above theories and structures in mind, it is important to ask whether and how donors support or direct Tonga's development through aid. 


\section{Chapter Three: Methodology}

\subsection{Introduction}

In this chapter I will explain why I chose this specific research topic, what I will focus on, and what guided my focus. Next, I will outline how I designed my research, how the design was managed, and the challenges to the design. This looks at the conceptual framework, interview design and purpose, and techniques and approaches that acknowledges documentation as a research method. The key feature of this chapter is how I went about conducting my research and what tools, in the form of interviews and documentation, I used to do so. This chapter is laid out in a narrative with a minor visual representation in the form of a conceptual diagram.

\subsection{Research topic}

Prior to undertaking my research, I had what I presumed was a firm idea on what topic I wanted to conduct on an independent academic journey within the discipline of Development Studies. I use the word 'independent' here as being neither donor- nor recipient-driven, the contested dichotomy through which the foreign aid aspect of development is perceived. I wanted to utilize all the knowledge I had ascertained in being a development practitioner having worked for three different donors. At the same time, however, I was in the rare position of being a Tongan but Western educated with the opportunity to bridge some intellectual gaps between the two worlds. There were several loaded concepts within the discipline that I wanted to embrace or add a layer of understanding to, such as national development priorities and unpacking Tonga's development under the Tonga Strategic Development Frameworks of 2011-2014 and 2015-2025 (Tonga Ministry of Finance and National Planning, 2011 and 2015b).

Refining the focus further I wanted to concentrate on what factors influenced Official Development Assistance (ODA) or 'foreign aid' by looking at what determines bilateral programmes, and allocations shown in reports for example by the Australia Department of Foreign Affairs and Trade (Australia Department of Foreign Affairs and Trade, 2013a) and the New Zealand Ministry of Foreign Affairs and Trade (New Zealand Ministry of Foreign Affairs and Trade, 2017a). However, when designing the method and what such research holistically would entail, it become clear that the magnitude in terms of numerical data involved and capturing the complex innuendos within aid relationships were overwhelming. It would be difficult to know for sure what factors determined a specific monetary allocation to foreign aid on specific projects at specific points in time. 
I was guided by Booth, Colomb, and Williams (2008), who present a fundamental principle, if you will, that research is about finding a 'question whose answer solves a problem that you can convince readers to care about' $(2008$, p. 35$)$. In this instance the problem is appropriate development and the question is why has international aid struggled to achieve this? It then became an issue of managing such broad concepts to a much narrower scope and focus hence my choice of research topic. The research here is offering only an interpretation of the topic and sub-topics being presented drawn from the data in a manner which I argue is a reinterpretation from a different perspective. As O'Leary (2010) recommends, it then is an exercise of turning my topic of interest into a researchable question (pp.41-42). Instead of looking at 'What factors determine international aid?' or 'Why has development not worked?' I focus on 'To what extent are national development priorities shaped or supported by international aid?'. For now, this gives me clarity on what my research topic is being the national development priorities of Tonga and I ask six sub-questions guided by the Paris Aid Effectiveness Principles (Organisation for Economic Co-operation and Development, 2005).

\subsection{Research focus}

My research focuses is on the dynamic interaction the three different actors - Australia, New Zealand, and Tonga - had between 2013 to 2017 and the context they operated in under the Paris Aid Effectiveness Principles. In this chronology Tonga operates under the four-year Tonga Strategic Development Framework, committing to "follow through with the achievement of all Millennium Development Goal targets" between 2011 to 2014 (Tonga Ministry of Finance and National Planning, 2011) and subsequently the Tonga Strategic Development Framework II 2015-2025 (Tonga Ministry of Finance and National Planning, 2015b). At the global level the TSDF I and II positions and links Tonga's development aspirations institutionally with the rest of the world through the United Nations Millennium Development Goals or MDGs (United Nations, 2000) and then the Sustainable Development Goals or SDGs (United Nations, 2015). How and why Tonga positions and links itself with the MDGs and SDGs respectively offer important insight into the foreign aid context. Connecting to that is where the three parties are situated geo-politically, economically, and historically within the region that is Oceania.

Bearing in mind the Paris Aid Effectiveness and guided by my research topic, I formulated six subquestions that are designed and centred around the five principles. They are outlined as follows:

- How does Tonga develop and articulate its development priorities? The aid effectiveness principle this question explores is Ownership which is defined as "partner countries exercise effective leadership over their development policies, 
and strategies and co-ordinate development actions" (Organisation for Economic Cooperation and Development, 2005, p.3).

- What is the external aid environment and to what extent does it align or not with Tonga's development priorities?

Here I will focus on the principle of Alignment looking at how "donors base their overall support on partner countries' national development strategies, institutions and procedures" (Organisation for Economic Co-operation and Development, 2005, p.3).

- How do donor priorities and systems help shape the way Tonga articulates its own priorities?

Ownership will be further analysed under this question.

- What analytical tools do donors and Tongan agencies use in the aid relationship? This question is intended to demonstrate how the principle of Mutual Accountability (Organisation for Economic Co-operation and Development, 2005, p. 8) exists between the parties, further exploring accountability and transparency amongst them.

- How do these systems and relationships deal with the dynamics of aid (changes in policies and personnel on each side)?

Harmonisation is the principle under the microscope with this question as it seeks to understand and with "donor countries coordinate, simplify procedures and share information to avoid duplication" (Organisation for Economic Co-operation and Development, 2005, pp. 6-7).

- How do the relationships within aid systems in Tonga accommodate differences in the definition, prioritising, and evaluation of development?

This question seeks to understand how "managing resources and improving decisionmaking" achieves Results (Organisation for Economic Co-operation and Development, 2005, p.7).

\subsection{Conceptual framework}

There are interesting Oceanic conceptual frameworks for research that exist, such as the Kakala Research Framework (Thaman, 1993, p. 256). Thaman incorporates Tongan culture and offers an alternative indigenous lens. The Kakala Research Framework uses the process associated with the Tongan concept of Kakala which is toli that is to gather knowledge, tui what method is used, and luva metaphorically meaning to share the knowledge (Thaman, 1993, p. 256). There is also the Teu Le Va 
approach by Anae (2016) who uses this Sāmoan indigenous concept, but also exists similarly in other Oceania cultures, to emphasize relationships and context between people and space. Ka'ili (2008) provides the Tongan conceptual framework of Tauhi Vā which looks at sociospatial relations quite similar to the way Anae (2016) did with the Sāmoan conceptual framework. These models are useful, and they offer valuable insights into explaining some of the findings to a western audience. For my research, though, I acknowledge the existence of the neo-structural lens alongside the Oceania models mentioned here. This neostructural lens for aid, as we have seen, involves a more concrete conceptualisation of the relationships between donor and recipient states, seeing a mixed statemarket development model focused on poverty alleviation.

As I emphasized earlier, my research focus evolved after the first iteration as an opportunity to offer a reinterpretation and draw upon close observation. This recognition arose to utilize some key advantages I have and how these can enrich my research. Firstly, the opportunity to bridge certain gaps between donor understanding and recipient perception arises from the unique position I am in as a Tongan who has worked closely with, and for, donors. I have work experience with three of the 'Five Eyes', namely Australia, Canada, and New Zealand. The 'Five Eyes' refers to the strategic intelligence agreement between Australia, Canada, New Zealand, United Kingdom, and the United States of America (O'Neil, 2017). My work experience includes designing, managing, reviewing activities in the private sector, tourism, energy, small grants funding, agriculture, fisheries etc. At programme level, this includes managing and coordinating the Canada Fund for Local Initiatives, evaluation of the New Zealand Partnerships for International Development Programme, contributing to the Tonga Programme Evaluation, and lastly as a research analyst for Australia in Tonga. In this regard I, as a researcher, am better equipped to appreciate the very processes, structures, and systems analysed in my research. This is something very few Tongans are able to do. Yet, on the other hand, as a Tongan practitioner working for donor agencies in these ways, I can draw on a close appreciation and understanding of the complexities of local culture, society and politics that few donor officials have.

Subsequently my challenge is understanding the principles at different levels - globally, regionally, and nationally. To carry out this exercise I am assisted here by Mawdsley, Savage, and Kim (2014) who, in their analysis of the Paris High Level Forum in 2005, Accra HLF 2008, and the Busan HLF in 2011, echo the observation made by Harman and Williams (2014) that international development is in significant transition. The emergence of private sector, the promotion of economic growth as the key premise of development, the role of non-state actors, and the growing landscape of other influential donors that offset the current power structures is leading to a significant reconstruction of aid relationships and it even challenges the very idea of 'aid' (Mawdsley, Savage, and Kim, 2014, pp. 27- 
35). Harman and Williams contend four areas international development is changing: the role or capacity of the state and which economic model to adhere to; a shift in focus from human development to large infrastructure provision; the emergence of non-traditional actors (such as China); and lastly the change in nature of the relationship between actors (2014, pp. 925-941).

Bearing in mind these forms of change in the international aid environment, particularly in the past decade, nonetheless it is important to note that the 'neostructural' framework for aid, established in the first decade of the new millennium, still pervades aid practices and relationships through to the present. The Paris Aid Effectiveness principles of 2005 remain very relevant to the way we understand how aid operates today, though their key concepts have evolved and been adopted and adapted since. Tilley and Tavakoli provide several conclusions that show a common thread, namely that aid is a reciprocal exercise which both the donor and recipient find trouble practicing $(2012$, p.29). The supplier, that is the donor, needs the expertise of the recipient just as much as its own to help ensure success of the aid provided. This means how successfully foreign aid is implemented depends much on how the recipient's perspective, capacity, and buy-in is applied throughout the overarching programme and subsequently the activity cycle. This theme - that donors and recipients are interconnected and co-dependent - is a key one for this research and the way it is conceived. Figure One below conceptualises this line of thought. The idea here, looking at this conceptual framework under the lens of neostructualism, is the principles at play - ownership, alignment, harmonisation, results, and mutual accountability - act in a constant state of motion. Movement by one party leads to movement in others. The OECD aid effectiveness principles are represented by the arrows that help turn the gears and similarly the gears also act in their own ways as a driving force and determine the direction the arrows turn. 
Figure One: Conceptual Framework

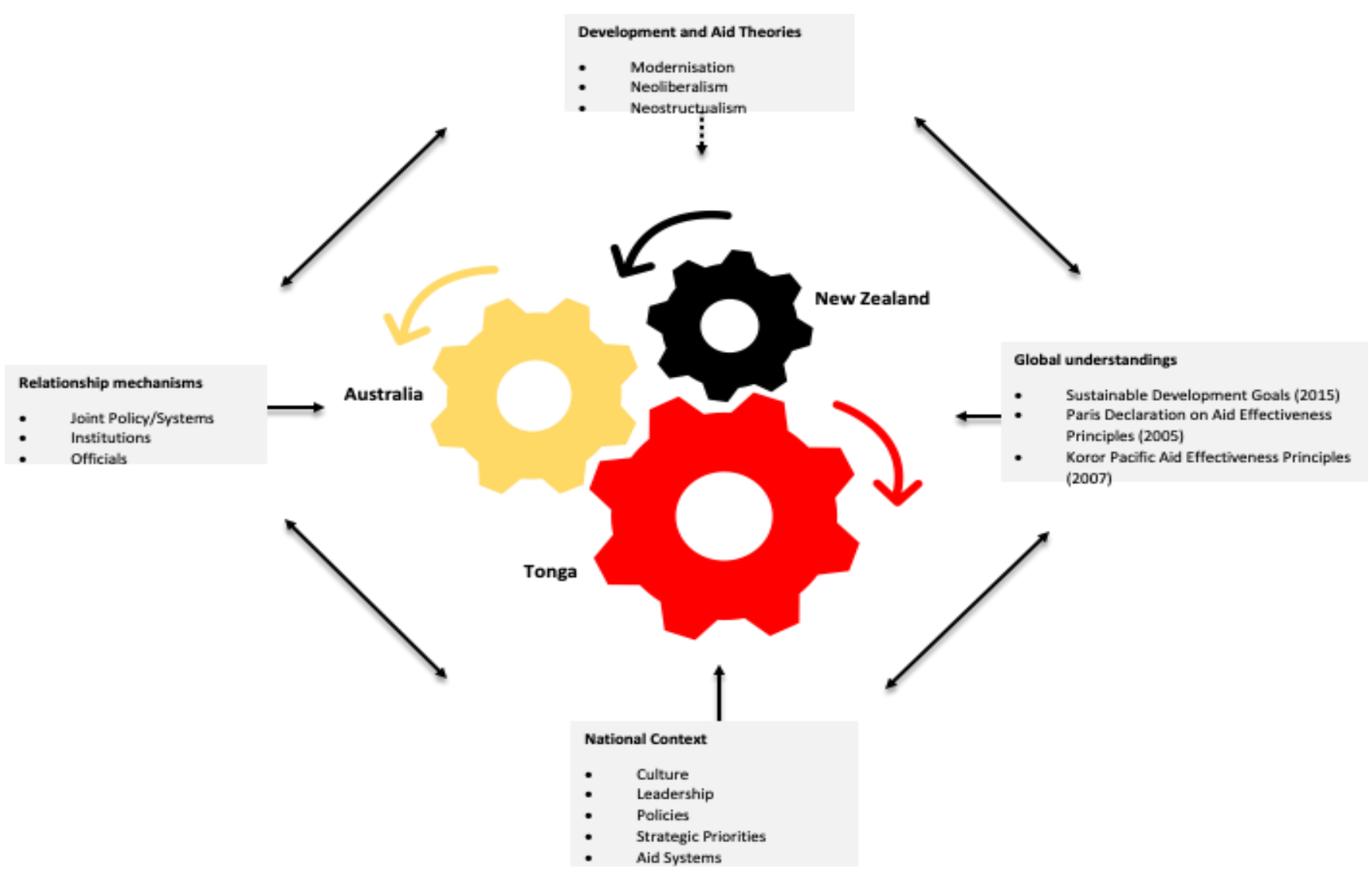

The gears are the countries and metaphorically just as in physics whereby the smaller gear rotates faster than the larger gear, this symbolism is meant to reflect the dynamic relationship between the donor and recipient. The attempt here is not to represent the relationship as a dichotomy but a constant flow of exchanges. Such exchanges occur at different frequencies and pace between the two donors and Tonga and at unequal pacing at times. This is meant to reflect two things: the supply and demand aspect of aid; and how, as an assumption, Tonga barely has the time and capacity to articulate its national development priorities.

There is a link here between development theory, relationship mechanisms, national context, and global understandings. The literature review touched on the aspects of development theory and global understandings on countries such as Fiji, Sāmoa, and Tonga and the region (Buiter, 2007; Feeny and McGillivray, 2008; Dearden, 2008). However, more appreciation should be shown to better reflect the national context, diverse nature of Oceania, and complex relationship mechanisms. As Overton et al. (2019) emphasize that for Oceania "the relationship between any given donor and recipient is highly contingent and dynamic" (p. 30). The development lens used often categorize the region into 'cultural roots' or by colonial history but this approach reveals less what the true nature of the region is in being 
heterogeneous (Overton et al., 2019, p. 30). Equally important are the relationship mechanisms all three parties engage in strategically and the roles they play in reinforcing the evolution and collectiveness of foreign aid, for example, the High Level Forums, such as the Paris Declaration, that Australia and New Zealand apply with Tonga and the local Development Partners Forum that Tonga applies with regard to Australia and New Zealand. The conceptual framework applied here acknowledges the linkages between these aspects to better appreciate the experience Tonga encounters with the Country Programmable Aid of Australia and New Zealand. We need to recognize also that Tonga has its own unique history to the region and it articulates its development priorities through the Tonga Strategic Development Framework I and II. All in turn are both implicitly and explicitly influenced by global understandings which is where the Paris aid effectiveness principles, with other notable agreements, are linked.

The conceptual framework is drawn up in response to Hau'ofa (2008) challenge: “... if we fail to construct our own realities other people will do it for us" (p.60). I would like to reinforce the arguments of academics such as Hau'ofa (2008), Thaman (2008), and Wesley-Smith (1995) on peoples from Oceania to own the research they study. For example, in addition to Hau'ofa's stance aforementioned I reinforce my viewpoint that takes on board sentiments expressed by Thaman:

"... of being able to apply a Polynesian concept to a global context, without having to compare, or defer, to a Western worldview, but instead accept the concepts as globally and intellectually instructive" (2008, p.468).

In addition, within his 'Rethinking Pacific Island Studies' paper Wesley-Smith writes: "The decolonization of the region remains incomplete, but it has already changed the nature of the Pacific Islands scholarship ... More important, the former objects of inquiry have acquired the political and educational abilities to speak up and answer back" (1995, p.124). However, such a task is not without challenges. In practice I anticipate that I would encounter the same dilemma and realization as Nabobo-Baba, that it is one thing to follow rigorously University ethics and guidelines of research, but it is local protocols and ethics knowledge that dictate research processes on the ground (2008, p.141). Therefore, I have taken the liberty in owning my understanding and presented the neostructualismderived framework detailed above. It is not so much simply emphasizing the neostructualism lens at the expense of neglecting other conceptual lenses but more of this is how I as a researcher own my understanding of the study I am conducting. I am seeking to take a largely global intellectual construct - neostructuralism - but interrogate it from, and adapt it to, an Oceanic and Tongan context.

Thus, in the conceptual framework Tonga's size represents its unique development potential but under the lens of the indigenous Oceania scholars mentioned earlier and the neo-structural lens. That 
is, under the indigenous epistemologies and ontologies of a Tongan, the size of the gear in the conceptual framework is not referring to the physical land and small-scale economy but the 'inheritance of each Tongan'. To a Tongan the understanding of foreign aid and development will emphasize or have a different meaning from the predominant western view centred on apparently universal concepts of measurement and analytical tools. The epistemology of a Tongan, in terms of development, is that growth is what you give someone instead of what you gain. This outlook has broader implications on approach towards development at the national level which is reflected in the themes prominent in the national development documents, the TSDF I and II. This conceptual framework aims to reflect this but in a way that knowledge is added to the neostructualism lens used here. We have a western understanding of development, which has been the dominant aspect, but when we recognize the national context and why that is so, we add a better appreciation and knowledge to the development paradigm.

\subsection{Methodology}

This research embraces the qualitative tradition and is composed of two fundamental approaches, interviews and document analysis. Guided by this I examine the different aspects of the key concepts of development and foreign aid highlighted in the conceptual framework by aid donors to Tonga's national development priorities, and a comparative observation of the Country Programmable Aid of the two bilateral donors. The research topic sets the focus and scope whilst the six sub-questions inform the intent of the research. Before setting out the methods used, however, I briefly consider the broader epistemological basis for this research.

\subsubsection{Epistemology}

The intent of this section is to outline the "epistemology, theoretical worldview, and the blueprint of the project" (Flamez, Lenz, Balkin, and Smith, 2017, p.94). This can be problematic because not many researchers have a signpost that signals a particular Tongan epistemology or the Tongan theoretical worldview and how you should go about conducting your research. I view a predominant variable throughout the research is the action of interpretation but from different demarcations, both domestic and international. The closest conceptual model I perceive in terms of epistemology, which offers a bridge between the Tongan and non-Tongan, is, to an extent, social constructionism. Social constructionism is defined as "theories of knowledge that emphasize that the world is constructed by human beings as they interact and engage in interpretation" (O'Leary, 2010, p.7). As Burr tells us "social constructionism argues that the ways in which we commonly understand the world, the categories and concepts we use, are historically and culturally specific" $(2015, \mathrm{p} .4)$. This final aspect bit, the historic and cultural, is critical to how I interpret the key concepts and themes we will encounter. It acknowledges that perceptions and experiences of aid in Tonga are subjectively 
developed with regard to underlying cultural values and worldviews. This parallels the way Gegeo (1998) has analysed 'indigenous epistemologies' of development in Solomon Islands.

Pushing this perspective forward is challenging to navigate, because I need to examine how my interpretations of my culture are credible for this research under my very argument. Whether there should be a centralized approach to interpreting and conveying the Tongan culture is beyond the scope of this research. Instead, the argument here is that there are questions regarding the practice of Tongan culture being interpreted by any Tongan who simply, on the merit of publishing an academic paper, becomes a presumed authority. A rich history of the interpretations of our Tongan culture written by Hau'ofa (2008), Lātūkefu (1980), Taufa (1993), Thaman (1995), and particularly Māhina (2007) exist. In this research I offer my own interpretations of our Tongan culture. I am not seeking to assign who or not is Tongan or that my interpretation of our Tongan culture carries more weight than the aforementioned scholars. On the contrary, I applaud them for our culture is a collective and take note. However, abiding by our own Tongan culture, I acknowledge the difficulty of my own position, seeking to interpret and explain it when I am of lower rank.

Arguably, as many Tongan academics have done, to attempt to interpret Tongan culture when writing a thesis involves founga fakamuli or working in a western medium. Hence a fundamental question I raise and grapple with, is: what authority do others or I have to interpret and explain the/our Tongan culture? It is a question I am not satisfied is given enough due respect. It should also be acknowledged that there does exist a Committee on Tonga Traditions under the Tonga Preservation of Objects of Archaeological Interest Act (2016). There are some overlaps with my argument, but the main point drawing from that Act, is that respect should be shown to our culture and at the very least some discernible caution exercised first and foremost as an acknowledgement when interpreting and detailing it in a medium that is dominated by a foreign outlook.

Social constructionism as an epistemology seeks to understand how attitudes, behaviours and experiences are developed and employs largely qualitative methodologies. In this research, I employ qualitative approaches to both interview material and document analysis. For example, a document that reflects a key concept in development such as the Tonga Strategic Development Framework is important to understand and interpret from a Tongan perspective. Similarly, the interviews conducted in this research enable us the opportunity to generate knowledge through an understanding of how the informants have interpreted the world of development and foreign aid. My knowledge and experience in the field of foreign aid and Tongan culture is a link to understanding the interpretation conveyed. 
The epistemology of social constructionism is also a framework to appreciate the existing understandings of how Tongans views the world of development. Whilst in the broad spectrum of decolonisation, advocacy for exercising caution might intuitively align with the growing recognition towards the emergence in Oceania argued by Fry and Tarte (2015) on matters of diplomacy or Thaman (1995) on matters relating to education. This framework of understanding the world and how knowledge is generated is important. It is a well-known model to follow whereby an aid programme process or stage needs input from a 'local perspective'. Finding the people with integrity, legitimacy, and knowledge is complicated which is why you often end up with reports, as Buiter highlighted concerning the principle of ownership, using the language 'country has designed' or 'authorities were informed' (2007, p. 648). The interviews are a direct source into the local perspective and assist in not only understanding the 'model' and key concepts in this research but also how they have evolved or been used.

\subsubsection{Interviews}

I used both semi-structured interviews and unstructured interviews in this research. For semistructured interviews, I found Maxwell (2013), Harrell and Bradley (2009) and Wengraf (2001) useful in designing, sequencing, and conceptualizing. Informants from different levels at the Australia Department of Foreign Affairs and Trade, New Zealand Ministry of Foreign Affairs and Trade, Government of Tonga, Tonga State Own Enterprises, Non-Governmental Organisations in Tonga, multi-lateral organisations in Tonga, and former development practitioners were interviewed. I drew from my network of informants who have years of working experience on specific country programmes, sectors, international institutions, and multilateral organisations not only for Australia but also New Zealand and Tonga. The group of informants also included informants who have worked on the different project cycles being analysed which covered the concept, design, implementation, review, and evaluation stages. A total of 21 informants were interviewed across the three countries, eleven different organisations, and seven different sectors.

The following criteria were utilized to select key informants:

(1) Timeframe this research focuses 2013-2017;

(2) Official role for organisation that is whether it is the donor or recipient;

(3) Different levels being Senior, Intermediary, or Officer Level.

(4) As much as possible equal numerical representation for Tonga, Australia, and New Zealand 
In this sense, the recruitment of interviewees was purposive, in that I sought out officials who I knew had important insights and experiences to offer, and who spanned a range of institutions and experiences. I acknowledge that their recruitment was influenced by my own personal networks and pre-existing relationships and knowledge. However, given the small relative size of the pool of potential participants who have worked in and on aid in Tonga over the time period, and my own professional involvement, such personal contacts were inevitable.

Informants were selected according to situation in the broader context of my research and therefore how their information might be analysed. For example, I considered issues such as experience, nationality, and familiarity with development policies in Tonga and analytical tools used (or not) throughout. The categorization of my interviews and informants involves three broad groups: (1) Diplomats and, using the normative term, 'seconded staff'; (2) Counterparts to (1) in Tonga who are most likely Government officials but depending on the project and stage it is at it can include other stakeholders; and (3) and staff from Non-Government Organisations in Tonga. Overall, I recruited ten informants from category 1 , eight from the second group, and three from the third. Interviews were conducted in both Tonga and New Zealand over the period of May 2018 in New Zealand and June to end of July 2018 in Tonga.

Key informants were assured confidentiality taking into consideration respect for the working environment they operate under, the nature of their role and responsibilities, and gratitude for the time given. It is my view these aspects are not be taken lightly. Upon reflection, each interviewee was different in time given and availability. The confidentiality of the informants was maintained throughout the research beginning from research proposal to interviewing to data analysis. This is adhered to for ethical reasons, which is integral to the Victoria University of Wellington human ethics approval process and is explained further in the ethics section below.

The following techniques were employed in my semi-structured interviews. Optimizing questions (Aurini, Heath, and Howells 2016, p.100) with the rationale here follows Wengraf's model of Central Research Question- Theory Question- Interview question or CRQ-TQ-IQ (2001, p.63). Being aware of the different informants coming from diverse backgrounds I interviewed it was important to use everyday language in designing the interview questions. There was possible overlap between the research question and interview question in language and conceptual framework, however when taken into consideration the specific category of the informant, the level of exposure to the theoretical jargon via experience in the area or not, and probing questions for clarification during the interview 
infers better management of the quality of the data collected. The types of semi-structured interview questions were derived from the sub-questions of the main research question.

The role of unstructured or open enquiry interviews in this research is auxiliary rather than an added approach to that of semi-structured interviews. What I mean by this is that I used the types of questions from my semi-structured interviews but considered when circumstances, time, and observation as an added research technique dictate. For example, during the course of my interview, one informant provided data that at first glance was not immediately relevant. After careful reflection the data turned out to provide useful background context for a specific project, this otherwise would not have been ascertained if my interview question adhered a strict schedule of questions. It is also worth noting that this approach has limitations in the form of accessibility to an informant, credible data, and reluctance to share information pose hindrances that are beyond the design of semistructured interviews.

My experience as a former practitioner facilitated interviews in two ways. One was this aspect made engagement more efficient given many of the interviewees knew me. Requesting for them to participate still went through due diligence, process, and protocols. Following this format fulfilled a level of objectivity, enabled me to document the engagement, and arguably for me as a researcher keeping intact the integrity of the data. The other factor was managing the volume of interviews spread across the breadth of levels and across different types of organisations. This knowledge made the interview process consider the scope and limitations. That is, balancing the objective of this research with what is realistic and not overly ambitious in design. Herein the research question and six sub questions were useful as guidance pertaining to the data collection.

\subsubsection{Talanoa}

In the interviews, I was mindful of the talanoa method. The research method of talanoa is attributed to have been introduced gradually into academia by Halapua (Tecun, Hafoka, 'Inoke, 'Ulu'ave, and 'Ulu'ave-Hafoka, 2018, p. 157) although this should not to be confused with it already existing within Oceania societies. Tecun et al. (2018) offer different interpretations of talanoa and insight on the debate if it is a research method in of itself or "merely replacing open-ended informal interviews, which glosses over its emotional and cultural complexity" (pp. 157 - 158). For example, Halapua defines talanoa as "a process of storytelling without concealment" $(2013$, p. 1) whereas Vaioleti (2006) defines talanoa as "a phenomenological research approach which is ecological, oral and interactive" (p. 34). For Oceania researchers talanoa as a research methodology offers the freedom as an art form for research (Māhina, 2007) or enactment of cultural competence (Fa'avae, Jones, and Manu'atu, 
2016). Hence, talanoa encompasses a culturally appropriate way to gather and understand knowledge.

Altogether the insight provided by several authors (Fa'avae et al., 2016; Halapua, 2006; Māhina, 2007; and Tecun et al., 2018) appreciates talanoa no doubt as a welcomed concept overall into academia but for people of Oceania respectfully. I, as a researcher of Tongan heritage, welcome talanoa into this space and acknowledge it. However, for my research I have not employed talanoa explicitly but used instead the more conventional semi-structured interview method discussed above. My employment of this method rather than talanoa is not implying any critique or shortcoming. Rather I am practicing what I perceive is advocated by both Hau'ofa, whereby I am using the tools available for research to construct my own reality $(2008$, p. 60$)$, and Thaman that I am interpreting as a Polynesian but accept "concepts are globally and intellectually instructive" (2008, p. 468). Throughout this research the lens of being a Tongan and contextualizing the concepts we encounter is done so with what Hau'ofa (2008) and Thaman (2008) champion. This is an opportunity to offer as far as possible a Tongan perspective but acknowledge and bridge that with the western concepts involved here. This has been employed already with concepts of Fakatapu, Fakafe'iloaki, and Siutakahe'ahoafā, for example. Talanoa being recognized academically, whether as a research method or a methodology, is acknowledged most in this research for the pathway it has given researchers of Oceania heritage such as myself. It should also be noted that many of my interviews were with non-Tongans and a talanoa approach would not have been appropriate for these interviewees.

\subsubsection{Ethics}

I followed the Victoria University Human Ethics guidelines in conducting my interviews. This requires consent and approval from the interviewee and from the organisation for me to carry out my interviews. In an information sheet provided to informants, I outlined how the interview would be conducted and how the information they provided would be used according to their consent under confidentiality. It is worth noting here that part of this process included gaining a research permit from the Tonga Prime Minister's Office. The human ethics approval letter is attached as Annex A.

Interviews carried out were relatively accessible after demonstrating the due diligence necessary at Victoria University of Wellington for Human Ethics approval, adhering prior requirement by the organisation or individual, and when applicable by following all the cultural or professional protocols. Participants were engaging in the interview process which is attributed to assurances from my part as the researcher. The assurances came in the form of briefing document explaining my research but more importantly how their participation is confidential. In addition to this the information obtained 
would be reaffirmed when unsure or withdrawn if the participant requested to do so. Location, time, and date for the interview was dependent first on preference by those being interviewed.

Confidentiality in planning, conducting, and using the interviews as data is important. As Kaiser (2012) points out, "researchers should be aware of the risks that confidentiality breaches pose for individuals and communities" (p.10). This cautionary warning by Kaiser (2012) aligns with the clauses stipulated by the Victoria University of Wellington Human Ethics Guidelines (2018). This is the approach employed throughout the methodology component of this research.

In addition to this some specific clauses of the Victoria University Human Ethics Guidelines pertaining to sensitive information and consent were given attention. They are the following:

- Clause 3.1. (c) Special care of potentially vulnerable participants

- Clause 11 Recruiting Participants

- Clause 12 Consent

(Victoria University of Wellington, 2018, pp. 2-10)

These clauses are highlighted because of the nature of the data being collected together with the personnel involved in the interviews. The data collected is sensitive because of the content and working relationships, especially at senior level, involved. Ethical issues may arise due to the management of information. This research has conducted interviews in a manner where the need is recognized to provide confidentiality of participants with assurances information is managed carefully. This included consultation after being interviewed on analysis of their interview and any follow up interpretation. This helps minimise chances of doing harm in possible likelihoods of interviewees conveying things that are critical of their management or development partners.

\subsection{Documents}

The purpose of using documents in this research is based on the written representation of aid relationships, understandings and protocols in key documents. In mind here is determining what a document is and which documents are collected as data. Useful criteria employed was what Scott formulated, namely authenticity, credibility, representativeness and meaning (Scott, 1990 as cited by Mogalakwe, 2006). Mogalakwe expands on this in that "authenticity refers to whether the evidence is genuine and from impeccable sources; credibility refers to whether the evidence is typical of its kind, representativeness refers to whether the documents consulted are representative of the totality of the relevant documents; and meaning refers to whether the evidence is clear and comprehensible" (Mogalakwe, 2006, pp. 224-225). In this research it is important to understand what the key role of the document is relative to aid practice. 
As a researcher two points also must be raised regarding validity and for this I agree with Maxwell in that it is impossible to list all the 'validity threats to the conclusion of a qualitative study' (2013, pp.124-125). The first concerns researcher bias which generally regards how data, or a method, is used to accommodate the views or perspective of the researcher. The important thing to keep in mind as a researcher is to understand one's biases and how to manage this. Part of this has already been touched upon in my interviews and conceptual framework parts mentioned earlier, in that I recognize and acknowledge being a Tongan and applying a Tongan lens is not a weakness but enriches my study. It does this by maximizing key strengths I have: Western educated but raised culturally and living in Tonga, experience working for both donors (Australia, New Zealand, and Canada) and the recipient (Tongan Government), and an understanding of both the Western and Tongan ontology and epistemologies. Secondly, and linked, is 'reactivity' (Maxwell, 2013: 124) whereby 'the goal is to prevent differences between researchers from being an unwanted cause of variability in the outcome' (Maxwell, 2013, p.125). Again, the same principles are applied whereby the important thing is to keep in mind how to manage my position within the study.

Many times, we will encounter aid practice, for example, the result of a High Level Consultation or Forum and the outcome is communicated through a document. This document comes in the form of the Joint Commitment for Development or the Grant Funding Arrangement between New Zealand and Tonga. Aid practice, such as high level consultation to determine and agree on the national development priorities the donor can support via foreign aid, together with the process of which the document is created (the outcome of the consultations), is something this research considers and examines. The choice of is guided first and foremost by the research questions but documents that pertain to donor policy, guidelines, activity stages, performance reports, evaluations, and analytical tools comprise a large portion of the relevant material. However, the document analysis also applies to relevant documents of the Government of Tonga which includes the Tonga Strategic Development Framework I and II, the sector plans available, both the budget statement and estimate documents which give an insight into monetary and financial commitments, and any historical document relevant to the research.

In my view, doing so enriches my data collection and assists in determining the extent that aid shapes or supports national development priorities. From this approach are analytical strengths applicable to boost the integrity of my research such as triangulation and applying both a comparative and longitudinal qualitative analysis to the data being collected.

Using the four criteria by Scott (1990) is not the sole technique used to interpret documents and analyse the data it presents. The interviews, encompassed with the techniques employed, offer an 
additional format to follow. O'Leary (2010) makes a valuable point in this regard concerning document analysis. Just as it is important to address your subjectivity as the researcher it is equally applicable of the documents treated. In other words, being transparent about biases and "how you read and draw from the documents will be coloured by your own researcher reality" (O'Leary, 2010, pp. 223224). Important and relevant questions, honed by the research topic, are asked of the document and the supposed truths its bears as evidence. As a research technique you are essentially 'interviewing' the document as if it was an informant and asking the key questions such as who the author is, how was the truth or evidence it presents gathered, how was the data interpreted, and under my own research topic, focus, method, and conceptual framework do I agree or disagree with how the 'truth' being presented.

Additionally, it is important to note that, whilst most of this research adopts a qualitative approach to analysing interviews and documents, there is also interesting and relevant quantitative data to be gathered from documentary sources. These involves aspects such as budget figures, aid allocations, and government expenditure. This is a secondary research methodology but provides important contextual material, showing, for example, the relative size and temporal shifts in volumes of country programmable aid to Tonga and its relative importance in its economy.

Lastly, by way of summary, the table below provides a visual model of the methodology employed. The table provides a skeleton sketch with details of the methodology that have been touched on. The table follows a left to right logical flow in the columns with the intention being in this research, to apply the logical flow the opposite direction. The table lays out the research questions and the subquestions, useful in underlying scope and relevance. To answer these questions, I have employed qualitative methods using interviews and documentation gathering data. These are the design options for the purposes of this research and to answer my research question in a meaningful coherent manner. The data, both interviews and documentation, is subsequently analysed according to the aid effectiveness principles and disseminated.

This chapter has covered the methodology of this research but also the research topic, research focus, conceptual framework, method, and an overview of the purpose of documents. The research topic is important because it sets the destination this research journey aims to reach. The research focus section refines the topic further and gives a sense of direction on the scope of this journey. The conceptual framework is developed from an understanding of the neostructualism lens of development, and subsequently foreign aid, and owning this academic space I offer my own interpretation. The conceptual framework acts as a compass and guide. The tools used are interviews 
in the form of semi-structured interviews, and document analysis. Each employed with different techniques and considerations so as to generate knowledge reflective of the epistemology this research understands. It is also to gather data from several informants spread across different spectrums of aid practice and development. 


\subsection{Table Two: Methods summary}

Research question

\begin{tabular}{|c|c|}
\hline \multirow{5}{*}{$\begin{array}{l}\text { To what extent are National } \\
\text { development priorities } \\
\text { shaped and supported by } \\
\text { aid? }\end{array}$} & $\begin{array}{l}\text { How does Tonga develop } \\
\text { and articulate its } \\
\text { development priorities? }\end{array}$ \\
\hline & $\begin{array}{l}\text { What is the external aid } \\
\text { environment and to what } \\
\text { extent does it align or not } \\
\text { with Tonga's development } \\
\text { priorities? } \\
\text { How do donor priorities and } \\
\text { systems help shape the way } \\
\text { Tonga articulates its own } \\
\text { priorities? }\end{array}$ \\
\hline & $\begin{array}{l}\text { What analytical tools do } \\
\text { donors and Tongan agencies } \\
\text { use in the aid relationship? }\end{array}$ \\
\hline & $\begin{array}{l}\text { How do these systems and } \\
\text { relationships deal with the } \\
\text { dynamics of aid changes in } \\
\text { policies and personnel on } \\
\text { each side? }\end{array}$ \\
\hline & $\begin{array}{l}\text { How do the relationships } \\
\text { within aid systems in Tonga } \\
\text { accommodate differences in } \\
\text { the definition, prioritising } \\
\text { and evaluation of } \\
\text { development? }\end{array}$ \\
\hline
\end{tabular}

Design option

\section{Qualitative}

Semi-structured

descriptive interviews

whereby both the

question and informant

are categorized.

Semi-structured

descriptive interviews

whereby both the

question and informant

are categorized.

Semi-structured

interviews whereby

both the question and

informant are

categorized.

Semi-structured

interviews whereby

both the question and

informant are

categorized.

\section{Semi-structured}

descriptive interviews

whereby both the

question and informant

are categorized.

Semi-structured

descriptive interviews

whereby both the

question and informant

are categorized.

\section{Quantitative}

nt

OECD Principle

Focus

Document analysis.

Australia, New

Zealand, and Tong

\section{Document analysis.}

Australia, New

Zealand, and Tong

Document analysis.

Australia, New

Zealand, and Tonga

Document analysis.

Australia, New

Zealand, and Tong

Mutual Accountability

Australia, New

Zealand, and Tonga

Harmonisation

Document analysis.

Australia, New

Zealand, and Tonga

Document analysis
Ownership

Alignment

Ownership

Results

c.

.

\section{Analysis/Dissemination}

(1) Coded datum according to OECD Paris Principles.

(2) Selective longitudinal qualitative

analysis.

(3) Comparative analysis

(1) Coded datum according to OECD Paris Principles.

(2) Selective longitudinal qualitative

analysis.

(3) Comparative analysis

(1) Coded datum according to OECD Paris Principles.

(2) Selective longitudinal qualitative

analysis.

(3) Comparative analysis

(1) Coded datum according to OECD Paris

Principles.

(2) Selective longitudinal qualitative

analysis.

(3) Comparative analysis Comparative

analysis

(1) Coded datum according to OECD Paris Principles.

(2) Selective longitudinal qualitative

analysis.

(3) Comparative analysis Comparative analysis

(1) Coded datum according to OECD Paris Principles.

(2) Selective longitudinal qualitative

analysis.

(3) Comparative analysis Comparative

analysis 


\section{Chapter Four: Development Context in Tonga}

\subsection{Introduction}

Understanding the development context in the Kingdom of Tonga requires an analysis of the different but interconnected threads of development. Between 2013 to 2017 the Kingdom of Tonga had some unique features about its national development which will be analysed in this chapter. Firstly, the political context of Tonga is examined, including its history, leadership and political system. Secondly, we look at the development priorities with some focus on the economic development of Tonga at the macro level and the planning and development framework. Lastly it is important to provide an overview of aid and the development partners that Tonga engages with.

\subsection{Background: The Kingdom of Tonga}

Tonga is a kingdom, a state and a nation. From a prescriptive sense, the word 'nation' is defined by the Oxford dictionary as:

"a large body of people united by common descent, history, culture, or language, inhabiting a particular state or territory" (2008, p. 952).

If the supposed origin of the word nation derives from Latin 'natio' meaning 'be born' (Oxford Dictionary, 2008, p.952), then the concept of the Tongan nation has been very important, particularly up into the $21^{\text {st }}$ century. For our focus and scope, we begin by establishing the relative criteria of this notion, of nation, and whether contemporary features of the Kingdom of Tonga prescribe to this definition. From the beginning, and importantly from the political realm, if we adopt this concept of nation, then the nation-state of Tonga involves a question of legitimacy and we can draw on the ideas of Jean-Jacques Rousseau in his 'The Social Contract' (as cited by Benner, 2012). As Benner describes,

"both Locke and Machiavelli connected the geopolitical and cultural ideals of territorial integrity and citizen identity to a new moral and political ideal, which, in Rousseau's writings, emerges as a doctrine of national self-constitution and selfdetermination" [emphasis added] (2012, p.700).

And therefore, Rousseau concluded 
"only the whole population of a territory - considered without distinctions of birth or wealth - may determine whether and how to constitute itself as a people or nation" (as cited by Benner, 2012, p. 700).

The criteria of the concept of nation hence is not exclusive to only a criterion of governance but also a criterion of belonging, distinction, and uniqueness. This does not discount the dimension of governance being evident in the concept of nation, but rather the essence, at least from my perspective as a Tongan, is about who do I belong to, why are we different, and what makes us unique.

Under the above interpretation, the concept of nation inherits a slightly different nuance but retains its core features that make it recognizable. Here the historical and political context of the Kingdom of Tonga is important in distinguishing between the more orthodox meaning and this nuanced interpretation. It needs to be said that Tonga has a history which spans 3000 years and a detailed investigation of this history is beyond the scope of this research. For the purposes of the thesis though, selected events and periods in our history will come under analysis, particularly within the last 300 years. Much has been written and researched by historians and scholars, such as Lātūkefu (1979) and Campbell (1992), on the history and political development of Tonga but their treatment follows the orthodox definition of nation uses it interchangeably with the concept of statehood. Both Lātūkefu (1975) and Campbell (2001) acknowledge the existing power structures and political makeup the Kingdom of Tonga had prior European contact meets the criteria of an already existing nation. However, they place particular emphasis on the rise of Ko 'ene 'Afio Taufa'ahau Tupou I who consolidated his power using to his advantage the traditional Tongan power structures and norms of legitimacy at the time. He also introduced European concepts of statehood. These included parliamentary rule, division of power through the three branches (Judiciary, Legislature, and Executive), codified laws with significance for Tongan society, rights afforded to tu'a including land, dis-establishment of the Tamaha and other ranks with titles, and the restructuring of the aristocracy by the alienation of some Hou' eiki and the elevation of others.

In other words, if outsiders apply Rousseau's concept of nation to Tonga, more likely they would conclude the makeup of these group of people and the legitimacy of the power structure they follow would rest on criteria of governance, power structures, and sovereignty. This is historically accurate, for once a upon a time Tongans and Europeans did not know each other and then they met. With this meeting an outside interpretation of the Tongan nation state appears to have been more dominant (Fa'avae, 2019; Kēpa and Manu'atu, 2008). It should be noted though that my usage of their treatment 
of the concept of nation should not be taken as critique of Lātūkefu (1975) and Campbell (2001) but only as an example of how the orthodox definition has gone largely unchallenged. What is offered here as an alternative interpretation of the concept and that those mentioned dimensions do exist, but they shadow more prominent dimensions which are more characteristic to Tongans. I argue that it is not 'will' that binds the 'social contract', it is tauhi vā meaning 'maintaining the respect' under the Tongan mindset. Arguably, unlike the European context, the Tongan nation is even to this day is still heavily focused on blood connections in history.

The concept of nation is fundamentally important to fully comprehend the current political status of the Kingdom of Tonga. The history of the Tongan nation is viewed pre-dominantly from a perspective of when European forms of power structures were adopted and what existed as part of the global decolonization process that occurred after the Second World War. For example, Rutherford, Ve'ehala, and Fanua, detail the complex aristocracy of Tonga (1977). There were absolute and ranking rulers, the Tu'i Tonga, Tu'i Ha'atakalaua, and the Tu'i Kanokupolu with their own subordinate chiefs. It is very difficult to translate what these power structures were in an academic sense, because they were more than just monarchs when viewed under a European framework. Equally, oral history implies that each dynasty expressed some form of temporal or influence in the domain of authority. This followed the criteria of physical territory, lineage, power relationships, physical prowess, and divine right but not from the 'Christian' deity.

These dynasties commanded loyalty, though the legitimacy extended well beyond the physical realm from a Tongan mindset. The foundation of legitimacy derives from divine right for the Tu'i Tonga, rebellion for the Tu'i Ha'atakalaua, and functionality for the Tu'i Kanokupolu (Rutherford, 1977, pp. 27-40). Other historians share this interpretation such as Wood who was a Principal at Tupou College (1943) and Lātūkefu with his historical take on King George Tupou I (1975). What all these historical interpretations highlight is a common thread that Tonga as a 'nation' existed well before European contact, albeit under a slightly different power configuration. One last point of key difference between the orthodox definition and the interpretation offered here is how under the European pretext divine right preceded nation. For Tonga, nation co-existed with divine right and has so before European contact and even after.

The Kingdom of Tonga today should really be defined as the Kingdom of the Tu'i Kanokupolu being the official traditional title held by the current monarchy. As history has focused on repeatedly for Tonga, the catalyst for the transition into modernisation is the Tu'i Kanokupolu Taufa'ahau Tupou I. 
For outsiders this title and distinction may not mean much but for Tongans even to this day it represents a lot of our blood ties and bonds to each other. This is whether we are tu'a or hou'eiki and whether we know it or not. Interestingly the title King of Tonga or Tu'i Tonga no longer exists. In Tonga, that dynasty and subsequently title is invested in the current ruler. However, the direct descendant through the paternal line is one of the Lord titles Kalaniuvalu, a by-product of Taufa'ahau Tupou I's reconfiguration upon consolidating his power in the $19^{\text {th }}$ century. Needless to say, understanding contemporary Tonga means understanding our 3000-year history and to do so with care and respect.

An extensive literature exists, but summarising key historical highlights are Taufa'ahau Tupou I's consolidation of power. It is a mischaracterization to say Tonga was united by King George Tupou I. He only consolidated his power over the other dynasties and eventually destabilised them. He did this through the introduction of an European form of power structure by the adoption of the Constitution in 1875 (founding a Constitutional Monarchy) and the Treaty with Germany in 1876 (Wood, 1943) which was Tonga's first international Treaty but more importantly it symbolically represented recognition from the colonial powers at the time of Tonga's sovereignty. These events in the $19^{\text {th }}$ century were owned and driven internally and reconfigured Tonga into how it exists today. This distinguishes the history of Tonga from our perspective to reflect blood ties rather than class divisions. Furthermore, there was consent and direction 'from the top' instead of resulting from popular uprising, a prominent feature in Tonga's social-political development, although the 2006 riots do represent an erosion of the $19^{\text {th }}$ power structure and the transition into a more democratic society with challenges to power 'from below'. Thus, this historical context means Tonga has a different emphasis on development. The emphasis still strongly rests on underlying norms that are binding and culturally constructed, such as the Tongan concept of tauhi vā.

Following 3000 years of history, our own concepts such as tauhi vā, are still strong and play a pivotal role in development. Undermining tauhi va - reciprocal relationships - ultimately undermines the stability for the Tongan society. Thus, when we perceive the development of Tonga through other than the western and orthodox definition of nation, we can better appreciate where the overarching theme of Tonga's development comes from. For example, the key document - the Tonga Strategic Development Framework - contains a declaration of nationalistic sentiments:

... "the framework is embedded within our National Motto and understanding of our culture" (Tonga Ministry of Finance and National Planning, 2015b, p.11) 
This is derived from a place of ownership, pride in a culture which spans thousands of years and arguably should be encouraged and nurtured. For Tongans, being a Tongan means who do I belong to amongst the collective, why are we different, and what makes us unique. This is an aspect of legitimacy that is borne out of structures that both Tongans and outsiders have still yet to grasp and sadly at times, appreciate.

Academic literature exists on the historical accounts, effectiveness, circumstances of development planning, and constructive critique against the predominately applied external lens over the local Tongan viewpoint. For example, Campbell discussed the role of aid in Tonga around the 1950s under the reign of Queen Salote and some of the early actors on the scene (2001, p.188). More recently, Mountfort (2013) has studied aid and development principles that are supposed to guide donor funding in Tonga. Scholars with Tongan heritage such as Thaman (2003) have written extensively on viewpoints regarding decolonizing Pacific studies and a different approach to the Pacific curriculum (2009) when it comes to education. Others such as 'Utoikamanu (1980) analyse the structural characteristics by focusing on Tonga's development planning under the overall experience of other Third World countries (1980). Arguably the most well-known and celebrated 'Oceanian' is Hau'ofa (1993) who strongly influenced reshaping ideological perspectives of the Pacific. Their work is acknowledged and given credit here.

Similarly, there are volumes of secondary sources that reflect aid initiatives of different donor funding to Tonga, documents that outline the donor's strategic plan, or highlight the technical assistance. Such documents are easily obtained online for example the Public Financial Management Performance Report for Tonga (Cadogan-Cowper, Faletau, Gouy, Lemani, 2010) or the New Zealand Aid Programme Strategic Plan 2015-2019 (New Zealand Ministry of Foreign Affairs and Trade, 2015a).

I argue the existing literature does not adequately address the extent to which Tonga's national development priorities are shaped or supported by aid. Although some of the above research appears to question certain norms and assumptions, the factors that influence how donor funding decisions to Tonga shape and support national development priorities have scarcely been addressed. The research literature is fragmented and disconnected. In addition to this, as with the more general historical perspectives noted above, the literature that exists on aid in Tonga does not adequately consider both the Tongan and foreign perspectives. My aim is to research foreign aid in the context of Tonga's national development priorities. The objective is to make sense of the factors that shape or influence donor funding decisions to Tonga and how Tonga's national development priorities are formed. 
This will also mean drawing as much as possible from local perspectives. For example, when analysing the secondary sources mentioned, the Public Financial Performance Report and the New Zealand Aid Programme Strategic Plan 2015-2019, they are at best a product of a donor policy or reflect the donor's policy. As the historical take on Tonga highlights and considering the caution by Thaman (2003), understandings of the concepts involved here, and their constructs are from a predominately European framework of understanding. What is focused on under the conceptual frameworks of modernisation, neoliberalism, and neostructualism do not necessarily overlap with what Tongans focus on in development, tauhi vā for example.

Certain questions therefore naturally arise such as how does Tonga develop and articulate its development priorities? This should occur at Ministerial and officials' level; at international, regional, and national forums; through processes and organisational structures, and so forth. What is the external aid environment (donors) and to what extent does it align or not with these priorities? This is reflective of the OECD DAC aid effectiveness principle of alignment. How do donor priorities and systems help shape the way Tonga articulates its own priorities? Similarly, to the points mentioned already, but questions of the level of 'buy-in' from donor and Tongan counterparts, objectives of the donor, resources and capacity on the ground, the OECD aid effectiveness principle of harmonisation.

Is it the interaction of multiple agencies and officials that play an intricate part in the equation or is it dominated by one constant factor? Are analytical tools used, by both sides, to identify the likelihood of an outcome and how or whether this informs policies pertaining to the funding? Are donor funding policies shaped by Tonga's development priorities? The other objective is to look at the demand for international aid, same questions but from the vantage point of the recipient. These two combined will better enable me to determine to what extent are national development priorities shaped and supported by aid.

\subsection{Leadership in Tonga}

Contextualising politics in Tonga and understanding the Government of Tonga between 2013 and 2017, one must go back to 2010. Kefu (2005) provides a detailed insight helpful to understanding the make-up of the modern form of government for the Kingdom of Tonga up to 2010. These include the powers of the monarchy conferred under the Constitution, the role of the Executive, and the land laws just to name a few (Kefu, 2005). The objective here is to highlight the key governance structures in place but importantly to understand how they eventuated, or changed, together with their intended purposes. Intended purposes are important because the design might have been for certain stated reasons but often the practitioners and later custodians differed from these. In this regard, what we observe is an adaptation of what Tongans, domestically and abroad, perceive as the most suitable 
form of governance. This process was not an immediate outcome but gradual and contested with tense political friction at times. Despite narratives of continuity and tradition, Tonga's history has experienced political restructuring, with one key consistent variable over thousands of years being ownership.

In relation to this theme is also the question of leadership, inherently pointing towards the hou'eiki (the aristocracy). Ideally, in a western conceptual framework the aristocracy form a class but to Tongans they are not necessarily so. As Bott explains:

"there is no word to translate 'eiki adequately because 'eiki is confusingly similar to but different from the English word "Chief". In English the word has a strong connotation of ruling or leading, whereas in Tongan it has an even stronger connotation of rank, that is, of being an aristocrat by blood, of having by inheritance a large quantity of sacred stuff in one's person through being descended from a king and preferably also from the sister of a king." $(1981$, p. 10)

So, whilst hou'eiki do have elements of functionality, that is to rule, their legitimacy to do so is not materialistic in origin but by values. In addition to this Lātūkefu highlights that:

"Three important values governed these relationships: faka'apa'apa (respect); fatongia (obligation) and mateaki (loyalty)." (1980, p. 65)

Hence, arguably an updated description here is that leadership for Tonga is more about relationships and influence than about status. At least this used to be the case. These values were taught to Tongans over time but now they appear to be eroding. Relationships and influences arguably now lean more towards benefiting each other's circle of affiliations rather than the best interests of the collective good. Tonga does have a national leadership code, with 14 principles that comprise a uniquely Tongan set of leadership values. Interestingly, this code was a semi-product of an Australian Aid Programme. The term 'semi-product' is appropriate because it is hard to fathom why such an important initiative needed to be funded by an external foreign actor, instead of resulting from an impetus by Tongans. 
According to a respected leader interviewed for this research as an informant (Participant F, June 2018), these 14 principles of the Tonga National leadership code (or Makatu'unga Fakataki Fakafonua 'o Tonga) are:

- Mo'ui Faka-e-'Otua (Piety)

- 'Ofa (Love)

- Faitotonu (Honesty)

- Faka'apa'apa (Respect)

- Mamahi'i Me'a (Commitment/Loyalty)

- Tauhi Vā (Reciprocal Relationship)

- Vahevahe Taau (Equity)

- Fa'a Kataki (Patience)

- Tali Ui (Accountability)

- 'Ata ki Tu'a (Transparency)

- Falala'anga (Integrity)

- Mo'ui Visione (Vision)

- Fakatōkilalo (Humility)

- Mo'ui Lelei Faka-e-sino (Health)

The national leadership code evolved through a consultative process involving communities, government, and members of parliament. A signing ceremony endorsed the leadership code and they now appear on page 42 of the Tonga Strategic Development Framework (Tonga Ministry of Finance and National Planning, 2015b).

The form of government for the Kingdom of Tonga is a Constitutional Monarchy under King Tupou VI. This is entrenched in the Act of the Constitution made up of three parts: the Declaration of Rights; the Form of Government; and the Land (Tonga Act of the Constitution, 2016). The Government is then made up of three bodies: the Executive consisting of the Pule'anga or Government; the Fale Alea or Legislative Assembly which is a unicameral body made up of 28 seats divided between People's Representatives and Lords; and the Fakamaau'anga or Judiciary (Kefu, 2005, p. 28). Two key points 
are important here for consideration. Up until 2010 the make-up of the Legislative Assembly consisted of 33 seats divided between 15 Cabinet Ministers, nine Lords elected from 33 aristocratic hereditary title members, and nine People's Representatives.

From this, historically the People's Representatives did not have the majority in the Fale Alea nor Government, as the King appointed Cabinet Ministers. Different agendas were championed by different sides but with the imbalance in seats within parliament it was hard to harmonize loyalties. The perception was that Cabinet and Nobles loyalties rested with the Monarchy whilst the People's Representative supposedly rested with the will of the people. An often bought up factor was that, with a minority in the number of seats in the Legislative Body and the Executive being appointed by the Monarch, the People's Representatives held very little power. Both could equally argue they represent the interests of the population via different levels and forms of representation and therefore they could claim that they are acting in the interest of the nation as a whole.

The Constitutional Amendments recommended in 2009 and enacted in 2010 enabled greater representation to the People's Representatives. The Executive was elected in the Fale Alea then subsequently assented by the King, in contrast to the previous process whereby the Monarchy directly appointed the Cabinet and Prime Minister. The elections in 2010 meant that for the first time in Tonga's modern history the Monarchy did not appoint the government - essentially giving this power to the electorate (Powles, 2013). Thus, in 2010 under the updated political system, Tu'ivakanō became the $14^{\text {th }}$ Prime Minister of the Kingdom of Tonga until 30 December 2014. In 2014, after the general election, and by winning the majority of backers in the Fale Alea, 'Akilisi Pohiva became the $15^{\text {th }}$ Prime Minister. These are the two Prime Ministers whose tenure is covered between 2013 to 2017. Both administrations were fraught with challenges which will be covered in greater detail in later chapters relative to national development priorities and the scope of the research.

The second key point for consideration in terms of governance and political development is still, even after all the claims of political progress, how divisive and irresponsible it often appears. Tongans can demonstrate glimpses of political maturity for example, ownership in the form of the Constitutional reforms driven by Tongans covered earlier. This feat which should not be taken for granted due to the manner and the nature of how this was instigated and carried out, in a peaceful and consultative process. Although the 2006 riots occurred, what is meant here is how the consultation process and subsequent agreement on which amendment to the Constitution was implemented without violence. It could be suggested that this should be acknowledged domestically more often and used to 
strengthen the nation-building message. However, it could be suggested that for every seemingly positive political step forward there is always some divisive connotation. Politics in Tonga remains characterized by competing ideological battles. This context provides valuable insight to consider under this research, particularly pertaining to policies on national development priorities.

The competing ideological battles within Tonga are a reflection of the Kingdom still adjusting to political changes. Indeed, whilst the Constitutional Amendments in 2010 ushered in a more democratic governance, such as the expansion of the People's Representation in the Legislative Assembly, the democratic changes have yet to result in the desired economic outcomes perhaps a lot of Tongans were anticipating to eventuate. Tied in with the overall development of the Kingdom between 2013 to 2017, Tonga is at a moment whereby important traditions are either reinforced, redefined, or established. The Makatu'unga Fakataki Fakafonua 'o Tonga (National Leadership Code) is important in this regard. As a leadership code it provides a platform these traditions can build on to strengthen many of the principles within the leaders of the country, be it Hou'eiki or Tu'a. It is an opportunity to reinforce the cultural norms and values Tongans are proud of or redefine leadership accordingly. Perhaps two principles that stand out from the political landscape between 2013 to 2017 is Falala'anga (integrity) and Faitotonu (honesty).

Given this political structure and the change in Prime Minister in 2014, there have been significant shifts in leadership. One important aspect of this is the composition of Cabinet. The following tables provide an insight into the changing Cabinet make-up of 2013 to 2017, conveying the time span of this research.

Table Three: Cabinet Ministers 2013

\begin{tabular}{|l|l|}
\hline Minister & Portfolio \\
\hline Lord Tu'ivakanō & $\begin{array}{l}\text { Prime Minister, Minister for Foreign Affairs and Trade, } \\
\text { Minister for Defence, } \\
\text { Minister for Information and Communication }\end{array}$ \\
\hline Samiu Vaipulu & Deputy Prime Minister and Minister for Infrastructure \\
\hline Lord Ma'afu & Minister for Lands, Natural Resources, Environment, and Climate Change \\
\hline Lord Vaea & Minister for Internal Affairs \\
\hline Lisiate 'Akolo & Minister for Finance and National Planning \\
\hline Fe'aomoeata Vakata & Minister for Revenue Services \\
\hline
\end{tabular}




\begin{tabular}{|l|l|}
\hline Viliami Latu & Minister for Commerce and Tourism \\
\hline Lisiate ‘Aloveita ‘Akolo & Minister for Police, Prisons and Fire Services \\
\hline Lord Tu'iafitu & Minister for Health \\
\hline William Clive Edwards & Minister for Justice and Minister for Public Enterprises \\
\hline Dr 'Ana Maui Taufe'ulungaki & Minister for Education and Training \\
\hline Sangster Saulala & Minister for Agriculture, Food, Forests and Fisheries \\
\hline Sifa Tu'utafaiva & Minister for Police, Fire Services and Prisons \\
\hline
\end{tabular}

Politically we are given a snapshot of Government after the 2010 amendment to the Constitution. The composition of Cabinet is made up of Independents, those that campaigned with no affiliation to the main democratic 'party', and Hou'eiki led by Lord Tu'ivakanō. The word Party is used loosely here because there are no formal political parties in Tonga but a group of people band together under a memorandum of understanding. Two Ministers, Dr 'Ana Maui Taufe'ulungaki and William Clive Edwards, were not elected but appointed under Clause 51.2 (a) of the Constitution of Tonga which states "the Prime Minister may nominate as Cabinet Ministers not more than 4 persons who are not elected representatives" (2016, p. 20). From 2010 to 2013 Tonga experienced a high turnover of Cabinet Ministers. The reasons for this are debatable but strongly indicated here is the People's Representative, whilst divided between 'Democrats' and 'Independents', knew they held the majority within Parliament. That is, seventeen seats versus nine for the Nobles. As such, each main faction of Independents, Democrats, and Hou'eiki vied for allies and subsequently power.

Table Four: Cabinet Ministers 2014

\begin{tabular}{|l|l|}
\hline Minister & Portfolio \\
\hline 'Akilisi Pōhiva & $\begin{array}{l}\text { Prime Minister, Minister for Foreign Affairs and Trade, } \\
\text { Minister for Education and Training }\end{array}$ \\
\hline Siaosi Sovaleni & Deputy Prime Minister and Minister for Environment and Communication \\
\hline Lord Ma'afu & Minister for Lands and Natural Resources \\
\hline Fe'ao Vakata & Minister for Internal Affairs, Women, Culture, Youth and Sports \\
\hline 'Etuate Lavulavu & Minister for Infrastructure and Works \\
\hline Dr Pohiva Tu'ionetoa & Minister for Police, Tourism, Labour and Commerce \\
\hline Dr Saia Piukala & Minister for Health \\
\hline Dr 'Aisake Eke & Minister for Finance and National Planning \\
\hline Poasi Tei & Minister for Public Enterprises \\
\hline
\end{tabular}




\begin{tabular}{|l|l|}
\hline Vuna Fa'otusia & Minister for Justice \\
\hline Semisi Fakahau & Minister for Agriculture, Food, Forests and Fisheries \\
\hline Tevita Lavemaau & Minister for Revenue and Customs \\
\hline
\end{tabular}

The year 2014 would act as a moment the Constitutional amendments were truly tested according to the aspirations they were designed. The pro-democratic leader 'Akilisi Pohiva was, after a close vote for Premiership (15 - 11 with the other candidate and former Deputy Prime Minister Samiu Vaipulu), elected as the fifteenth Prime Minister of Tonga (Matangi Tonga, 2014). Doing so immediately propelled forward expectations of economic growth, more transparent and accountable leadership, and an effective Government. Expectations that were a cumulation of several decades where advocates touted a more democratic system would translate into more progress. All except one (Lord Ma'afu) of the Ministers (in Table Four) were People's Representatives. Thus this was a Cabinet that for the first time in the history of Tonga was elected by the people and composed primarily of commoners. It is reasonable to argue this was an opportunity to further the momentum towards the People's Representative holding power.

Looking more closely, the 2014 Cabinet primarily reflects a sense of novelty under the premise of the Constitutional amendment. At an individual level, a wealth of experience is found with many having worked at senior level within Tonga - Tu'ionetoa former Auditor General, and Fa'otusia, Lavemaau, and Eke all former Chief Executive Officers. Regional experience came with Sovaleni and internationally Fakahau having worked at the Commonwealth Secretariat. The Prime Minister was a veteran politician together with Lord Ma'afu. Collectively on paper this combination would appear sound and strong to govern Tonga.

Table Five: Cabinet Ministers 2015

\begin{tabular}{|l|l|}
\hline Minister & Portfolio \\
\hline 'Akilisi Pōhiva & $\begin{array}{l}\text { Prime Minister, Minister for Foreign Affairs and Trade, } \\
\text { Minister for Education and Training }\end{array}$ \\
\hline Siaosi Sovaleni & $\begin{array}{l}\text { Deputy Prime Minister and Minister for Meteorology, Energy, Information, } \\
\text { Disaster Management, Climate Change and Communications }\end{array}$ \\
\hline Lord Ma'afu & Minister for Lands and Natural Resources \\
\hline Fe'ao Vakata & Minister for Internal Affairs, Women, Culture, Youth and Sports \\
\hline 'Etuate Lavulavu & Minister for Infrastructure and Works \\
\hline
\end{tabular}




\begin{tabular}{|l|l|}
\hline Dr Pohiva Tu'ionetoa & Minister for Police, Tourism, Labour and Commerce \\
\hline Dr Saia Piukala & Minister for Health \\
\hline Dr 'Aisake Eke & Minister for Finance and National Planning \\
\hline Poasi Tei & Minister for Public Enterprises \\
\hline Vuna Fa'otusia & Minister for Justice \\
\hline Semisi Fakahau & Minister for Agriculture, Food, Forests and Fisheries \\
\hline Tevita Lavemaau & Minister for Revenue and Customs \\
\hline
\end{tabular}

After a year in power small progress was made, but the high expectations remained present. This was coupled with the challenges Government encountered but appeared unprepared or divisive in addressing - the costs and preparations for the 2019 South Pacific Games, public backlash over Government aiming to ratify the Convention on the Elimination of all Forms of Discrimination Against Women or CEDAW (Radio New Zealand, 2015), and perhaps the most distracting was Minister Lavulavu being accused of bribery during the election. Minister Lavulavu was subsequently found by the Supreme Court to have committed bribery and declared his seat to be void (Matangi Tonga, 2016b). In a twist of fate, his wife subsequently won the by-election and in another turn of events as of May 2020 they are both awaiting trial for fraud (Matangi Tonga, 2020).

Table Six: Cabinet Ministers 2016

\begin{tabular}{|l|l|}
\hline Minister & Portfolio \\
\hline 'Akilisi Pōhiva & $\begin{array}{l}\text { Prime Minister, Minister for Foreign Affairs and Trade, } \\
\text { Minister for Education and Training }\end{array}$ \\
\hline Siaosi Sovaleni & $\begin{array}{l}\text { Deputy Prime Minister and Minister for Meteorology, Energy, Information, } \\
\text { Disaster Management, Climate Change and Communications }\end{array}$ \\
\hline Lord Ma'afu & Minister for Lands and Natural Resources \\
\hline Penisimani Fifita & Minister for Internal Affairs \\
\hline Simisi Sika & Minister for Infrastructure and Tourism \\
\hline Dr Saia Piukala & Minister for Health \\
\hline Tevita Lavemaau & Minister for Finance and National Planning \\
\hline Poasi Tei & Minister for Public Enterprises \\
\hline Vuna Fa'otusia & Minister for Justice \\
\hline Semisi Fakahau & Minister for Agriculture, Food, Forests and Fisheries \\
\hline Dr Pohiva Tu'ionetoa & Minister for Revenue and Customs and Minister of Labour and Commerce \\
\hline
\end{tabular}


Just as Minister Lavulavu proved to be a political distraction in 2015 so to then became Minister Vakata who subsequently was forced to resign due to allegations of assault on a civil servant (Radio New Zealand, 2016). In turn the continued flux of Ministers is a constant theme with broader implications on governance. Keen observers of the performance up to this time were starting to question the capacity of the Ministers. As one Informant relayed:

"The issue in my view is a politician coming in without any knowledge or experience in running a Ministry and he demands to have his way. We have a CEO ... we see a lot of Ministers who never go through the Civil Servant and wants the CEO to do what he says." (Participant K, June 2018)

Table Seven: Cabinet Ministers 2017

\begin{tabular}{|l|l|}
\hline Minister & Portfolio \\
\hline 'Akilisi Pōhiva & Prime Minister, Minister for Foreign Affairs and Trade, \\
\hline Siaosi Sovaleni & $\begin{array}{l}\text { Deputy Prime Minister and Minister for Meteorology, Energy, Information, } \\
\text { Disaster Management, Climate Change and Communications }\end{array}$ \\
\hline Lord Ma'afu & Minister for Lands and Natural Resources \\
\hline Penisimani Fifita & Minister for Internal Affairs \\
\hline Simisi Sika & Minister for Infrastructure and Tourism \\
\hline Dr Saia Piukala & Minister for Health \\
\hline Tevita Lavemaau & Minister for Finance and National Planning \\
\hline Poasi Tei & Minister for Public Enterprises \\
\hline Vuna Fa'otusia & Minister for Justice \\
\hline Semisi Fakahau & Minister for Agriculture, Food, Forests and Fisheries \\
\hline Dr Pohiva Tu'ionetoa & Minister for Revenue and Customs and Minister of Labour and Commerce \\
\hline
\end{tabular}

Perhaps the most significant event in 2017 was when the King used his prerogative and dissolved Parliament (Radio New Zealand, 2017). This set a precedent in the history of the Kingdom as this power had not previously been exercised. A new election was held later in the year and Pohiva together with his supporters won another majority of seats in the Legislative Assembly. 
This analysis has demonstrated that over the period of this research, the context for aid negotiations and relationships between donors and the Government of Tonga was marked by a state of considerable flux in political leadership. The articulation and promotion of Tonga's 'ownership' of its development priorities was therefore made problematic.

\subsubsection{Governance}

Governance is understood in different ways. For Tonga, Mailangi (2017) perceives that good governance is composed of elements such as accountability, transparency, and efficiency. The context for which these elements exist, in this case the Tongan hierarchical society, is important to note as well. Emphasising the element of accountability but within the systems of Government, "commoners are now holding those higher up in the pyramid accountable depending on their roles and functions" (Mailangi, 2017, p.4). Hassall writes that Governance "comprises the traditions, institutions, mechanisms and processes that determine how power is exercised" (2010, p. 51). Added to this concept is governance includes the role of citizens and non-governmental organisations and how they participate in governance (Hassall, 2010, p. 51). Huffer sums up governance in Oceania as being viewed from an outsider's perspective (2005, pp. 118-140). Considering the composition of Cabinet covered from 2013 to 2017 it can be fair to reflect that both Governments, of Pohiva and Tu'ivakano, needed to find common ground on an understanding of what governance.

The above tables alone do not tell us much other than the individuals who held different Ministerial portfolios during their tenure. A lot of reshuffles of both individuals and portfolios sanitizes the complicated political dynamism. To fully appreciate Tongan politics takes time and measure depending on the principles you apply. For example, under the principle of good governance Taumoepeau tells us that establishing the office of the Ombudsman took decades to finally be operational and was "subject of much debate in the Legislative Assembly" (2019, p. 34). What also appears to be indicated is that just as there is an external view on what governance is per se, as Huffer (2005) argues, there is not a uniform consensus what it means amongst Tongans. Vaea echoes similar observation with notable cases concerning "issues arising about leadership and the extent of the Cabinet's ability to work effectively" $(2019$, p.43)

According to Vaea (2019):

"between 2014 to 2018 several ministers were dismissed from office and the Prime Minister relinquished one of his portfolios. These and other developments have 
conveyed a strong message to the community that the government has not been functioning well” (p. 43)

The range of issues at the time included the lack adequate preparation for hosting the South Pacific Games and the subsequent withdrawal to host (Matangi Tonga, 2017) ${ }^{1}$, impeachment-related proceedings by the Legislative Assembly, mismanagement of a core element of education, a conviction for financial irregularities, and action in relation to senior administrators (Vaea, 2019, p. 43). Looking at the years, this reflects a negative view of the performance of the much-hyped more democratically elected Parliament. In this light, the tenure of 'Akilisi Pohiva as Prime Minister is now synonymous with being the first in Tonga's history whereby the King dissolved the Legislative Assembly. These issues arguably reflect the lack of Falala'anga (integrity) and Faitotonu (honesty) principles mentioned earlier under the National Leadership Code.

Examined under a different perspective, governance takes time and needs leadership, leadership that respects the interpretations of others but manages to find affirmation on a common overlapping thread with a collective buy-in. Perhaps, this is what the true issue is that pertained to Pohiva's time in power. It was not so much the political and management issues he encountered but that he needed time for the elements pertaining to governance to grow.

It was not only the Pohiva administration that had issues. The Tu'ivakanō Cabinet was equally plagued. Some notables during the time of the Tu'ivakanō Premiership were the strain on bilateral relations with New Zealand over Tonga using the MA60 aircraft loaned by China, accusations of mismanagement of Tongan passports, and, as one informant put it "Tu'ivakanō had the opportunity to set the values and principles moving forward especially the Prime Minister's working relationship with His Majesty" (Participant C, June 2018).

Whilst Tu'ivakanō's working relationship arguably was not as strained as Pohiva's working relationship with the Monarchy, one thing is inferred, namely the difficulty for both to exert effective leadership. It is what they, Pohiva and Tu'ivakano, in their role as Prime Ministers symbolized more broadly. Each represented both a rank and a system within the political make-up of Tonga. Pohiva leaned more towards a pro-democracy system whilst Tu'ivakano represented maintaining the hybrid Constitutional Monarchy infused with both western and Tongan culture. Subsequently the way they led the country as Prime Ministers and how the responded to issues plays into how governance is understood, not

\footnotetext{
${ }^{1}$ In 2012 Tonga won the bid to host the South Pacific Games in 2019 by a vote of $16-11$ over Tahiti.
} 
only within the context of Tonga's hierarchical society but the competing political ideologies they symbolized. If the 14 principles of Makatu'unga Fakataki Fakafonua 'o Tonga act as the criteria of effective leadership in Tonga or at the very least represent the expectations of the nation, then both these leaders and their administrations seem to have fallen short.

\subsubsection{Working Relationships}

Working relationships between Tonga and development partners play a key role in aid delivery and the ways Tonga articulates its national development priorities. This relationship, because of its strategic importance, is established early amongst the actors and maintained but not without some challenges. An independent evaluation carried out by Adam Smith International on New Zealand's aid programme to Tonga highlighted:

"Effective aid delivery is also constrained by the state of flux that is characteristic of this period of Tonga's national development. Leadership changes at ministerial and chief executive levels affect strategic direction and result in constant policy shifts, which cause problems with alignment." (New Zealand Ministry of Foreign Affairs and Trade, 2016d, p. 42)

The state of flux referred to by Adam Smith International is demonstrated when observing the political landscape of Tonga. The political landscape strongly points to a mismatch between the intended purposes of Tonga's architectural design to the Constitution, and therefore how it embraces democracy, and the capacity of the elected representatives. Whilst candidates are elected, the inference from documents and interviews strongly indicates this does not automatically translate into adequate levels of competence. Ideally elected representatives are chosen based on merit, experience in a relevant field, and virtues or code of conduct such as the 14 National Leadership Codes. The composition of the Cabinet for both tenures, of Tu'ivakanō and Pohiva, do not necessarily reflect this ideal reality, with every year highlighting Cabinet dogged with, in some respect, unnecessary distractions. In Latu and Silivenusi v LavuLavu (2015) the Supreme Court found Minister Lavulavu committed bribery in the 2014 elections and subsequently his election was declared void. There has been incompetence: PM Pohiva falling to a hoax interview paying third party intermediaries USD150,00 for an article in Forbes magazine which was never published (Matangi Tonga, 2015). Unethical conduct has been observed: PM Pohiva hired his son as a personal assistant and a former Minister of Internal Affairs was accused of throwing a wine glass at a civil servant. 
Relationship mechanisms and how they are connected to the institutions assist us understand governance in Tonga. What could be suggested from the consistency in issues irrespective of the hou'eiki (Tu'ivakano) or tu'a (Pohiva) administrations is that they appear to have different ways of understanding their role first as Prime Minister and second how to govern. The governance style therefore has broader implications that suggest the intended way the political system was designed needs further consideration. This concern was raised in the interim report by the Tonga Constitutional and Electoral Commission:

"The removal from Privy Council of any executive governmental function would leave the Cabinet as the highest level of government and the method of selection of the Prime Minister and his Cabinet will mean, as has also been stated previously, that the Government will be accountable to the Assembly and the people. Accountability is a vital safeguard against malpractice and incompetence and a government guilty of any such conduct in future can be called to account by the electorate through the ballot box." (Tonga Constitutional and Electoral Commission, paragraph 47, 2009)

Unfortunately, the accountability feature in this case, dependent on the electorate being literate on such matters, has been found wanting. This mechanism designed as a safeguard against malpractice and incompetence will take time to adjust and function according to the desired intentions.

However, it may not be just the governance style and political landscape that are culprits for the state of flux. The operational means and system of the Ministry plays a role as well. One informant gives the example where the "Minister and Chief Executive Officer are not on the same page which is a concern" (Participant K, June 2020). This implies a strained working relationship at the key decisionmaking level and incentivises the Chief Executive Officer to move on from the role. The means of the Ministry are important as well. As one informant pointed out correctly: "the Ministry has been really overwhelmed with an unexpected election, caretaker government, cyclone, cyclone recovery, and budget support plan" (Participant I, June 2020). Thus, changes at leadership level within a Ministry occur because of reasons dependent on different situations. In turn making aid delivery delayed but dynamic and adaptable. It is adaptable since the development context in Tonga offers challenges to pre-conceived notions - that the state of flux is the norm and it would be prudent to consider accordingly. 
More aligned with the research focus at hand though is not so much what is going on, which is important and observed domestically and externally, but what do development partners do with the 'what is going on?' By observing 'what is going on?' or the manner to which development actors behave, this gives valuable insight and acts as an analytical tool. The existing working relationships matter because each actor, Australia and New Zealand, wish to know who it is they are working with in Tonga and subsequently this has implications. To do so requires information gathering about the individual, their placement in the intricate influential and working networks, and capacity to ensure the objectives intended by their foreign aid is achieved.

At the highest level of engagement between sovereign countries, working relationships at the officials' level play a vital role. This is difficult to maintain if the nature of the relationship is always in a state of flux, exemplified by the Tonga Cabinet reshuffle in the tables above. However, this phenomenon applies both ways between the parties, Australia and New Zealand, and in this case, Tonga. It also applies at different levels of personnel. Changes do happen for different reasons as already touched on and, for example in the years covered in this research, Australia has changed Prime Ministers five times - Rudd, Gillard, Abbott, Turnbull, and Rudd again - whilst Tonga has had only two.

Leadership for Tonga between 2013 to 2017, under the threads of leadership discussed, impact Tonga's ability to articulate its national development priorities. The indication made by interviewees is that development partners are ready to support Tonga achieve its development priorities. The principle of sovereignty is practiced here in this regard. Although to some the Tongan Government may appear incompetent and inadequate to an extent, exemplified by the points raised earlier, they are nonetheless exercising their right to govern under the system of government and rule of law chosen by Tongans. Sovereignty is a principle that informs us it is not Australia or New Zealand's responsibility to decide for Tonga how it should govern. At the operational level Ministers, for all three countries, may not have a full grasp of certain technical details concerning an activity or project. Key institutional structures, working relationships, and processes are in place to mitigate this flaw. At a very senior level one such structure is the High Level Consultations (HLCs) or Meetings between either Australia and Tonga or New Zealand and Tonga. The idea behind this forum is to use it as an opportunity, for both development partner and Tonga, to articulate Tonga's national development priorities and donor's development programmes.

To summarize, change and a constant state of flux for all parties impacts aid delivery. However, the working relationships and institutional structures in place help mitigate likely risks. This challenges the 
ability of Tonga to articulate their development priorities and for donors to determine the effectiveness of their aid programmes. As a by-product of this environment the implementation of foreign aid under the Paris Air Effectiveness Principles is unique depending on the level of engagement and development outcome intended. Tonga, Australia, and New Zealand have more or less gone through changes in Government which has had an impact on how foreign aid shapes Tonga's national development priorities.

\subsection{Tonga's Strategic Development Framework}

This section looks at the national development priorities of the Kingdom of Tonga from 2013 to 2017 with the aim of providing a general overview. I will highlight what the Kingdom of Tonga has chosen as its national development priorities and detail some fundamental aspects. This is justified by the purpose of giving us a context regarding development, relative to the intended definition of the aid effectiveness principles. As a result, the positioning of the narrative looks at the Kingdom of Tonga's national development priorities relative to foreign aid and development. Creating competing realities and difficult to ascertain which is being dominate. The implication therefore is that at the very least the elements of each aid effectiveness principle is evident.

\subsubsection{Overview}

National development priorities are almost entirely juxtaposed with economics as a model of development. One of the challenges to ascertaining the status quo of the economy of Tonga though is reliable, independent information, and data. In turn this becomes an issue of transparency between the development partner and the recipient in how foreign aid should be operationalized (Easterly and Pfutze, 2008).

Considering the principle of ownership, the question then becomes what Tonga thinks of their economy and where is this articulated. The Ministry of Finance is an immediate contender and covering the years in this research, analysis of the released, and made available to the public, budget statements offer a window. In general, the foreword provided in the budget statements between 2013 to 2017 have four main themes - the Tonga Strategic Development Framework I and II, constant reconfiguration of priorities, and cultural value driven economy. The Tonga Strategic Development Framework is supposed to be the overarching national framework for development. Rolled out in 2011 the first Tonga Strategic Development Framework had nine 'outcome objectives': 
1. Strong inclusive communities, by engaging districts/villages/communities in meeting their prioritised service needs and ensuring equitable distribution of development benefits.

2. Dynamic public and private sector partnership as the engine of growth, by promoting better collaboration between government and business, appropriate incentives and streamlining of rules and regulations.

3. Appropriate, well planned and maintained infrastructure that improves the everyday lives of the people and lowers the cost of business, by the adequate funding and implementation of the National Infrastructure Investment Plan (NIIP).

4. Sound education standards, by emphasising quality universal basic education.

5. Appropriately skilled workforce to meet the available opportunities in Tonga and overseas, by delivering improved Technical and Vocational Education and Training.

6. Improved health of the people, by promoting healthy lifestyle choices with particular focus on addressing non-communicable diseases, and providing quality, effective and sustainable health services.

7. Cultural awareness, environmental sustainability, disaster risk management and climate change adaptation, integrated into all planning and implementation of programmes, by establishing and adhering to appropriate procedures and consultation mechanisms.

8. Better governance, by adopting the qualities of good governance, accountability, transparency, anti-corruption and rule of law.

9. Safe, secure and stable society, by maintaining law and order.

(Tonga Ministry of Finance and National Planning, 2011, p.14)

In 2015 the second Tonga Strategic Development Framework commenced, and the wording slightly changed from 'outcome objectives' to 'national outcomes'. The emphasis was explained as:

"The Outcome Objectives and Enabling Themes of TSDF I have been merged into a more tightly articulated set of National Outcomes which are supported by clear Organisational Outcomes" (Tonga Ministry of Finance and National Planning, 2015b)

Throughout the Tonga Strategic Development Framework II document there is a consistent reference to the term 'tightly articulated'. This infers that the authors are aiming for efficiency either in approach, ensuring different perspectives are represented, or leaving scope for future 
administrations. Thus, from nine outcome objectives in the Tonga Strategic Development Framework I, the Tonga Strategic Development Framework II has seven national outcomes. They are:

1. a more inclusive, sustainable and dynamic knowledge-based economy

2. a more inclusive, sustainable and balanced urban and rural development across island groups

3. a more inclusive, sustainable and empowering human development with gender equality

4. a more inclusive, sustainable and responsive good-governance with law and order

5. a more inclusive, sustainable and successful provision and maintenance of infrastructure and technology

6. a more inclusive, sustainable and effective land administration, environment management, and resilience to climate and risk

7. a more inclusive, sustainable and consistent advancement of our external interests, security and sovereignty

(Tonga Ministry of Finance and National Planning, 2015b, p.18)

Whether they achieved this efficiency by 'tightly articulating' the objectives is debatable. The other overarching message being interpreted when reading the document, is that it is convoluted. What is interesting with the Tonga Strategic Development Frameworks is the narrative positions development, and by extension the economy, from a standpoint of potential and being values-driven. This counters the way Pacific development is commonly through a lens of deficiency and vulnerability. Hau'ofa has identified how Oceania is often described:

"According to this view, the small island states and territories of the Pacific, all of Polynesia and Micronesia, are much too small, too poorly endowed with resources, and too isolated from the centres of economic growth" (Hau'ofa, 1993, p.150)

This view argues that countries such as Tonga are typically described as being small with little resources but it is notable that the Tonga Strategic Development Framework themes and focus do not exhibit this perspective. Indeed, this positionality and characterisation is acknowledged in the Tonga Strategic Development Framework II. However, the document itself does provide a word of caution how to treat it, as presumably, it could easily fall under the misunderstanding of being a national plan. As it states: 
... "The Role of TSDF II: ... It is not a national plan with detailed priorities. It is a tenyear framework within which government, and other organisations in the Kingdom, can plan in a more consistent and integrated manner. Detail of the implementation of the framework will be identified in the planning and budgeting documents of sectors, districts and MDAs. There is also scope for each political administration to choose certain key areas for focus and to document them in a Priority Agenda within the framework." (Tonga Ministry of Finance and National Planning, 2015b, p. 48 emphasis in original)

\subsubsection{Nature of Official Development Assistance to Tonga}

In this section I provide a broad overview of key aspects about how Official Development Assistance is provided and reported in Tonga. The approach used here is to give an overall yearly budget provided by the Government of Tonga from 2013 to 2017 and highlight the interaction and adaptability that occurred. The nature of ODA to Tonga is contractual, challenging at times to report, and can be interpreted in different ways. The objective of this section is to give an insight into the nature of ODA to Tonga. It does not focus on macroeconomics where we would compare ODA to Gross Domestic Product for example, but more on the aid relationship and how that relationship is influenced, shaped, or supported. This research observes that 'relationship mechanisms' in the form of joint policy and systems, institutions, and officials all have a bearing on how we understand foreign aid.

Fiscally, in 2016 Tonga's Parliament approved the 2016/2017 'Plan the work and work the plan' budget of TOP545 million, roughly NZD343 million, that combines both Government of Tonga recurrent TOP285 million and development funds 'donor cash and in-kind' at TOP260 million (Tonga Ministry of Finance and National Planning, 2016). As one can calculate from these figures, Tonga has an unhealthy monetary appetite by heavily relying on donor funding. This unhealthy monetary appetite is reflected in the years covered within this research, 2013 to 2017, shown in Figure Two below. The Government of Tonga fiscal year runs from July to June meaning for the figure below the year '2013' reflects July 2013 to June 2014 and so forth.

However, further analysis does counter this assumption. Considering the bilateral programme of Australia and New Zealand within these years, the Joint Commitment for Development, and High Level Meetings between the three countries, it then paints a more balanced picture. These are not just meetings but important institutions that all parties are involved in and offer a forum for discussion and dialogue on setting what and how foreign aid can support the national development priorities of 
Tonga. A mutual exchange occurs whereby the parties try as much to coordinate funding not only between the donor and Tonga but also with the relevant Ministries. For example:

"Our coordination point within Government is with the aid management division within the Ministry of Finance but also the Ministry of Foreign Affairs and we interact with them as our coordination point but I think we can expect to do a bit more widely" (Participant I, June 2018)

The joint nature of the policy and aid system at a high level is an important relationship mechanism that strengthens and supports the development strategies together with the main aid institutions in Tonga. Such as the Australia and Tonga Partnership, Joint Commitment for Development by Tonga and New Zealand, and the Tonga Strategic Development Framework. Arguably, Tonga is maximizing the support and willingness of both development partners, Australia and New Zealand, to provide foreign aid.

Figure Two: Government of Tonga Budget 2013 to 2017 (Tongan Pa'anga)

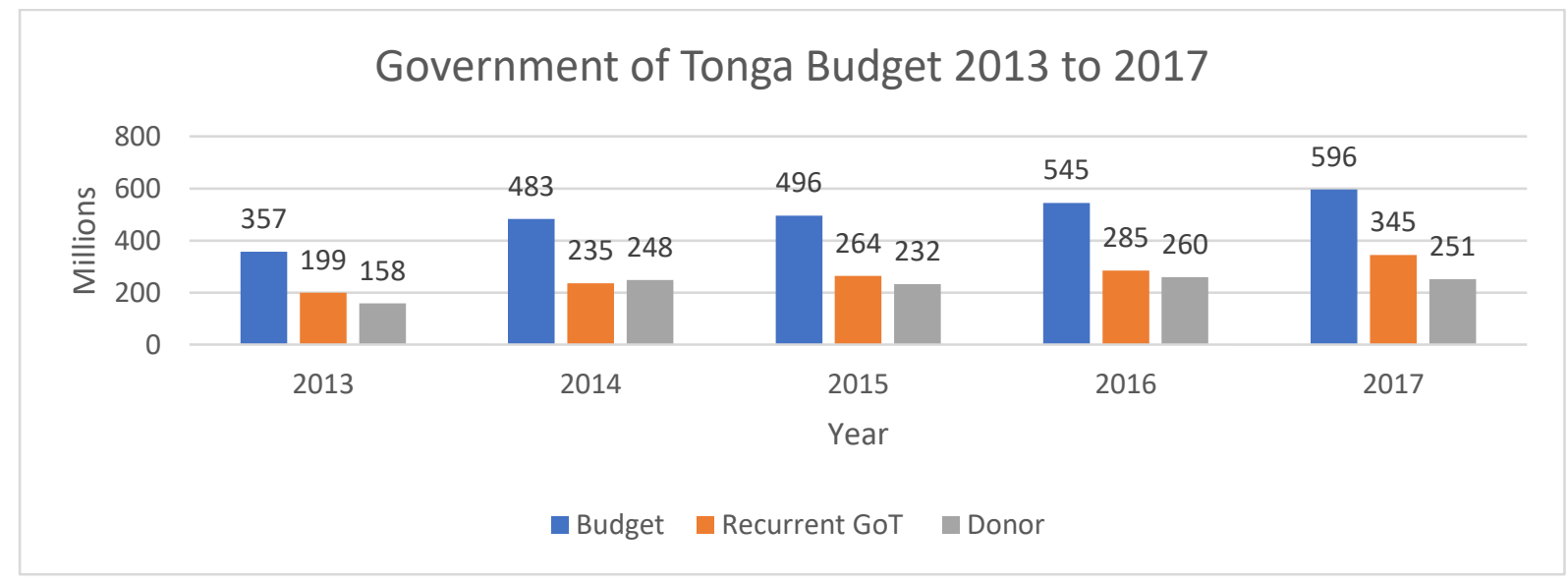

(Source: Tonga Ministry of Finance and National Planning Budget Statements and Estimates 2013 to 2018)

In Figure Two the Total Budget Expenditure column is composed of both Recurrent and Donor funding. The Recurrent column is mainly revenue the Government collects through taxes and other sources, such as dividends, but it also includes Budget Support from donors. Budget Support since 2009 is Tonga implementing 'reform areas' such as fiscal strategy, revenue, debt management, and public service management reform to name a few (Asian Development Bank, 2017). This is a multilateral mechanism named the Joint Policy for Reform Matrix and the donors are composed of the Asian 
Development Bank, Australia, New Zealand, and the World Bank (Asian Development Bank, 2017). The Donor column in Figure Two is composed of two components, cash and in-kind. Perhaps the most obvious trend from Figure Two is the increase in total budget every year from 2013 to 2017. It is not made clear in the Budget Statements what this means from an operational standpoint, that is whether the Government has become more efficient in expenditure or raising revenue, or if it is due to the economy growing for example. This trend over continual is replicated by the Recurrent column but not the Donor column which fluctuated between TOP 158 and 260 million.

The Government of Tonga is clearly the key institution whereby foreign aid is shaped or influenced to support the national development priorities. However, this institution has different dimensions. It is generally a consistent theme from interviewed participants that the Ministry of Finance and National Planning Aid Management Division leads ODA management in Tonga. As Participant D explains "the aid division they look after $X^{2}$ funding, so within the aid division they have $X$ and $Y$ funding" (June 2018). This is where funding is deposited into a general development account. The Aid Management Division in general are to plan, monitor, report, and recommend on foreign aid to the Ministry of Finance who are then tasked with submitting the Government of Tonga Budget to Parliament (Participant B, June 2018). Internally, there are three ways the Ministry calculates the development budget. Having its own information, gather information from other Ministries, and information provided by development partners (Participant B, June 2018). This view highlights that the different line ministries are another dimension and the development partners are an important party as well.

As well as the Aid Management Division within the Ministry of Finance, at a higher level is the Aid Development Committee (ADC), which is a subcommittee of Cabinet, chaired by the Deputy Prime Minister and members include selected Ministers together with three Chief Executive Officers (Participant B, June 2018). The responsibilities of the ADC are to review development partners' programs and projects. This process includes the threshold if a proposal is up to the value of one million TOP, if it is more than that then is submitted to Cabinet for their consideration prior to their submission to development partners. These dimensions inform an understanding of Tonga on what it perceives as development priorities and at times Tonga may articulate competing development priorities, a result of the complexity of government structures and priorities. Two significant development priorities - health and education -are reflected in the volume allocated in the overall Government of Tonga Budget depicted in Figure Three.

\footnotetext{
${ }^{2} \mathrm{X}$ and $\mathrm{Y}$ refer to development partners.
} 
Figure Three: Ministry of Health and Ministry of Education Expenditure Budget 2013 to 2017 (TOP)

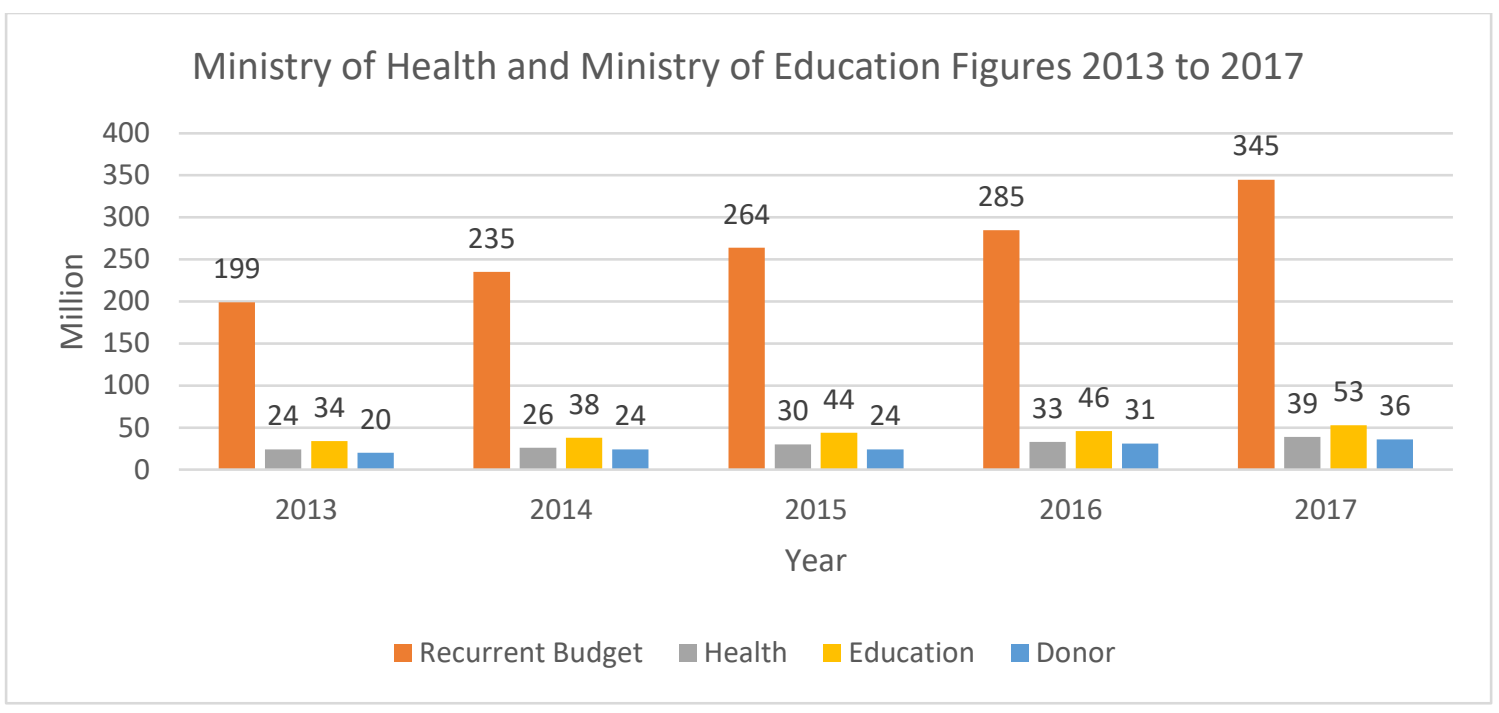

(Source: Tonga Ministry of Finance and National Planning Budget Statements and Estimates 2013 to 2018)

We can identify two themes when we move away from the aggregate data in Figure Two. Firstly, there has been consistent priority in allocation through 2013 to 2017 toward the Ministry of Health and the Ministry of Education. For example, in Figure Three, in 2013 the two Ministries accounted for $29 \%$ of the recurrent Government of Tonga budget, 27\% in 2014, 28\% in 2015, 27\% in 2016, and 26\% in 2017. That is for each year the estimated budget for each of the Ministry of Education and the Ministry of Health are added together than calculated to the total recurrent budget. For example, 2014 the estimated recurrent Government of Tonga budget for Ministry of Education and Ministry of Health was roughly TOP38 million and TOP26 million respectively. Added together they equate to around TOP64 million which is mostly $27 \%$ of the total recurrent Government of Tonga budget of TOP235 million (Tonga Ministry of Finance and National Planning, 2014, pp. 7-8). In a similar way, we can calculate the donor contribution (cash plus in-kind) to these two ministries, expressed as the percentage of total donor funds to Tonga that goes to these two ministries: $13 \%$ in $2013,9.7 \%$ in 2014 , $10.3 \%$ in $2015,11.9 \%$ in 2016 , and $14.3 \%$ in 2017 . The same calculation methods were employed, in 2014 the Donor Cash and In-Kind columns for both the Ministry of Education and Ministry of Health were added - MoH being TOP5 million (Cash) plus TOP4 million (In-Kind) and MoE being TOP8 million (Cash) plus TOP7 million (In-Kind). Then that total of TOP24 million is calculated to what percentage of TOP248 million which is the total for 2014 of Donor Cash and Donor In-kind ${ }^{3}$, equating to around 9.7\% (Tonga Ministry of Finance and National Planning, 2014, pp. 7-8). ${ }^{4}$ What this informs us, is that

\footnotetext{
${ }^{3}$ Refer to the figure in Donor Column in Figure Two

${ }^{4}$ Note the numbers used in these descriptions have been rounded to the nearest whole number.
} 
Tonga, as much as it can, supports these two key pillars of development, health and education, but donors support them seemingly proportionately less.

Secondly, it needs to be highlighted that it may appear that donors invest heavily in Tonga, reflected by the donor budget almost equivalent when compared to the government's recurrent budget. $\mathrm{A}$ more thorough unpacking of the figures reveals a more complicated situation. We need to keep in mind that the donor figures, both cash and in-kind, are only estimates. They represent actual committed and transferred credit and they reflect more accurately contractual arrangements subject to conditions. For example, the contractual arrangement is subject to conditions, that is, the full monetary amount is not transferred from the donor to Tonga in one lump sum but attached to certain milestones being met. Thus, the amount of the figure in the Tonga Government Budget Estimates is subject to the conditions being met. The amount the Government of Tonga receive in actuals is contingent on not only the delivery but also reporting on the milestone expected by the donor.

In consequence, this full amount that appears in the Tonga Government Budget Estimates may be reflected in the budget under the 'donor' column but, for contractual and different reasons, the actual amount given with its conditions is a non-disclosure. The nature of this non-disclosure is not clarified nor is it questioned in the Government of Tonga Budget Estimate documents. For Tonga, it is often a tedious exercise trying to determine the correct figure (Participant $B$, June 2018) comments above. This is a continuing evolution of the dynamic relationship between donors and recipients to reflect the exact ODA contribution amount.

As this Tonga Country Programme Evaluation highlighted concerning accounting systems:

"In the lead-up to each budget, MoFNP attempts to collect information on anticipated in-kind and in-cash donor assistance by sending two forms to donors. One asks for estimates of the magnitude of cash grants that will be disbursed through the Treasury system; the second seeks information on in-kind assistance (that is, any assistance that does not involve the transfer of funds through MoFNP). It was observed that most donors do not respond to this request and many do not provide estimates in time to be incorporated into the budget." (New Zealand Ministry of Foreign Affairs and Trade, 2016d, p. 21) 
This aspect of 'donor in-kind' estimates not only follow the same 'optical illusion' as the 'donor cash' estimates but is more accurately characterized as a selective amalgamation of estimations rather than the accurate actual funds donated or expended. For example, equipment or salaries for technical assistance, estimated valuation of construction, and estimation on the costs pertaining to a feasibility study. This consequently inflates the monetary figures reflected in the 'donor' column of the budget. It may look like at first glance that Tonga has an unhealthy monetary appetite but arguably Tonga encounters competing accountability issues from donors either reluctant or unable to provide accurate figures themselves.

Figure Four is an example of the activity cycle for New Zealand funded projects. In summary it has six stages all of which involve monetary figures. What the diagram below highlights is that one activity may be at one of the six stages. The monetary figure discussed earlier (Figure Two and Figure Three) that is reflected by the Government of Tonga does not specifically state what stage the 'support' derives from and whether it has been committed or not.

Figure Four: New Zealand Aid Programme Activity Cycle

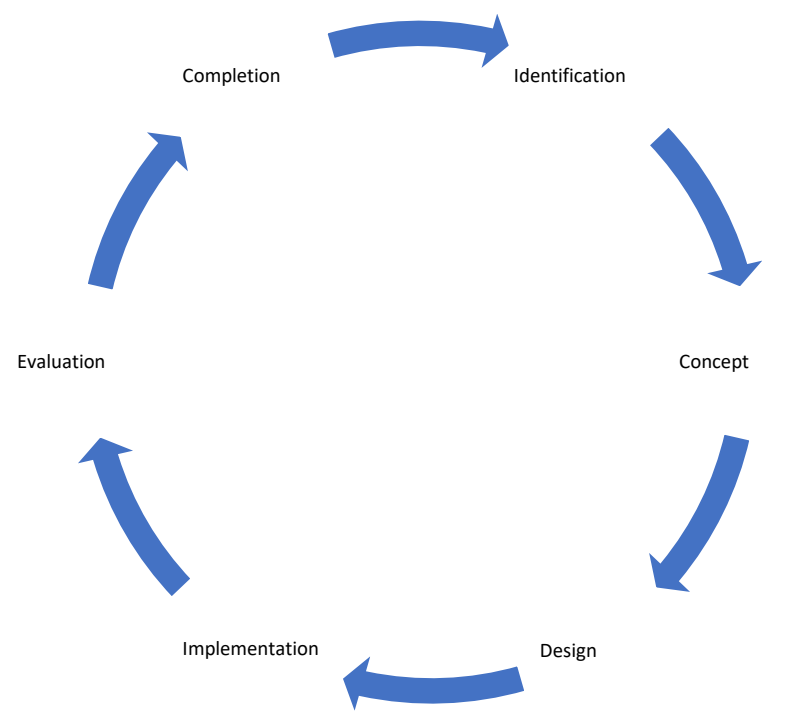

During the implementation phase of the project quality controls and mitigating risk processes are established, one being recipients submitting interchangeably quarterly to bi-annual progress reports and financial acquittals. For example, under the New Zealand system this requisite acts as a measurement against effectiveness, relevance, efficiency, and sustainability (New Zealand Ministry of Foreign Affairs and Trade, 2016a). The concepts of effectiveness, relevance, efficiency and sustainability are themselves pre-structured whereby recipients are asked sub-questions, at times irrelevant to an activity but perhaps important, pertaining to the concepts. This process under the 
Paris Principles of Aid Effectiveness should be appreciated and act as a reinforcement. Rightly so, the process is an opportunity for participants at the personnel and officials level to take a step back and reflect on what is working and what is not working. Both from an operational level but equally from a principle value driven perspective. Interpreting the interviews with informants, this sadly is seen more of a chore, and it can be without adequate harmonisation, to just being another unnecessary bureaucratic step. Hence, from a certain point of view it may be that the figure reported, for example financial year 2014/2015 has foreign aid figure at TOP248 million, does not mean Tonga spent that figure. The Ministry of Finance of Tonga points out that only 'TOP138.71 million was expended' (New Zealand Ministry of Foreign Affairs and Trade, 2016d, p. 21).

This section observed the yearly budget of the Government of Tonga from 2013 to 2017 to highlight the nature of official development assistance to Tonga. The ability of Tonga to report on donor contribution to their budget reflects a process and need for better communication. In turn, this identifies the relevance of aid effectiveness principles such as harmonisation and mutual accountability. A working relationship exists between Tonga and the two development partners, Australia and New Zealand, strengthen by key institutions. These structures in place assist dialogue and enable Tonga to own to an extent the space to articulate its development priorities, albeit at times competing needs. Overall, the nature of official development assistance to Tonga is influenced, supported, and shaped differently by important aid delivery mechanisms.

\subsection{The Development Landscape}

This section gives a brief overview of the development partners to which Tonga worked with between 2013 to 2017 . Whilst the list aims to be comprehensive, it more accurately reflects the challenges to which Tonga and its development partners encounter when it comes to the Paris Principles of Mutual Accountability, Harmonisation, and Alignment. The list is sourced from Government of Tonga Budget Estimates for 2013, 2014, 2015, 2016, and 2017 (Tonga Ministry of Finance and National Planning, 2019). The purpose here is to give an indicative insight into the context of the national development priorities financing and associated challenges especially donor coordination. In addition to this is how despite being an international agreement over a decade ago, the Paris Principles of Aid Effectiveness still hold valuable relevance. The relevance arguably is the principles are adhered but that the exchange in aid effectiveness is an open channel. 


\subsubsection{Tonga's Development Partners}

Tonga hosts only two residential embassies and two residential High Commissions, a point that is not always appreciated. Japan and China are the two Embassies, and Australia and New Zealand are the High Commissions. Table Eight below lists development partners between 2013 to 2017 according to the Government of Tonga Budget Estimates. However, some caveats need to be outlined. Firstly, Table Eight below is meant to only provide an indication of the number of development partners. It is not arranged according to the monetary amount the development partner provided, this information appears in the Government of Tonga Budget Estimates, separately. By way of volume of development partners in Table Eight, it is also an indication of how the Paris Principles of Aid Effectiveness are hard to implement. As one can imagine, each development partner adheres to a different policy in reporting and therefore hinders harmonisation (Sjöstedt and Sundström, 2017), for example. Table Eight is not a measurement of the performance of the aid effectiveness principles but rather an indication.

The list below has also referenced the official and extant names of organisations, some names are left in place due to ambiguity, and divided the rows according to different levels. Referencing the official names here means some are listed in the Government of Tonga Budget Statements but either no longer exist, even at the time of the document (for example the South Pacific Applied Geoscience Commission) or are listed incorrectly (such as the United Nations Fund for Population Activities as the UN Family Planning and Forum Fisheries Agency as Forum Fisheries Agencies). Perhaps the most obvious in the list below is that the Government of Tonga Budget Estimate document does not distinguish between North Korea or South Korea but simply lists 'Korea' (hence it is given as such in Table Eight as it appears in the document). Equally, the People's Republic of China is listed as China and is not a reference to the Republic of China (i.e. Taiwan). In addition, along these lines, are listed modalities instead of the development partner. For example, the United Nations Convention on the Law of the Sea is listed even though it is an international agreement not an actual development agency or partner. 
Table Eight: Development Partners to Tonga between 2013 to 2017

\begin{tabular}{|c|c|c|c|c|c|}
\hline & 2013 & 2014 & 2015 & 2016 & 2017 \\
\hline Country & $\begin{array}{l}\text { 1. Australia } \\
\text { 2. New Zealand } \\
\text { 3. Japan } \\
\text { 4. China } \\
\text { 5. United Kingdom } \\
\text { 6. India } \\
\text { 7. Germany } \\
\text { 8. United Arab } \\
\text { 9. Papua New Guinea. }\end{array}$ & $\begin{array}{ll}\text { 1. } & \text { Australia } \\
\text { 2. New Zealand } \\
\text { 3. Japan } \\
\text { 4. China } \\
\text { 5. United Kingdom } \\
\text { 6. Korea } \\
\text { 7. Nauru } \\
\text { 8. United Arab } \\
\text { 9. } \\
\text { 9. Turkey } \\
\text { 10. Papua New Guinea. }\end{array}$ & $\begin{array}{l}\text { 1. Australia } \\
\text { 2. Japan } \\
\text { 3. New Zealand } \\
\text { 4. United States of } \\
\text { America } \\
\text { 5. China } \\
\text { 6. United Kingdom } \\
\text { 7. India } \\
\text { 8. Korea } \\
\text { 9. Nauru } \\
\text { 10. United Arab } \\
\text { 11. Turkey } \\
\text { 12. Papua New Guinea }\end{array}$ & $\begin{array}{ll}\text { 1. } & \text { Australia } \\
\text { 2. Japan } \\
\text { 3. New Zealand } \\
\text { 4. China } \\
\text { 5. India } \\
\text { 6. Korea } \\
\text { 7. Papua New Guinea } \\
\text { 8. } & \text { Germany }\end{array}$ & $\begin{array}{ll}\text { 1. } & \text { Australia } \\
\text { 2. } & \text { France } \\
\text { 3. Japan } \\
\text { 4. New Zealand } \\
\text { 5. China } \\
\text { 6. India } \\
\text { 7. Korea } \\
\text { 8. Nauru } \\
\text { 9. Turkey } \\
\text { 10. } \\
\text { Germany }\end{array}$ \\
\hline Multilateral & 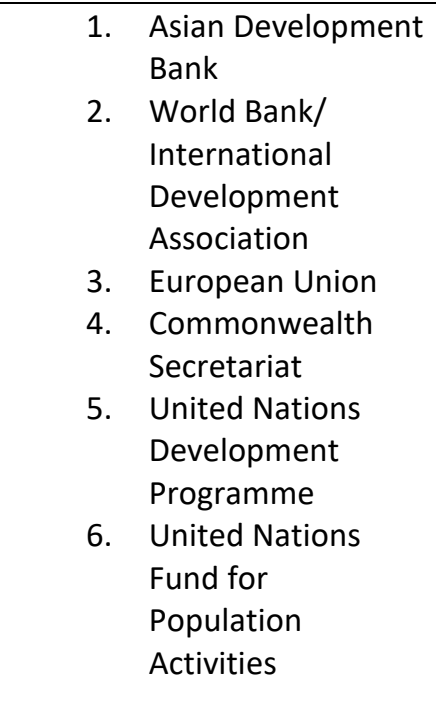 & $\begin{array}{ll}\text { 1. Inter- } \\
\text { Parliamentary } \\
\text { Union } \\
\text { 2. Asian } \\
\text { Development Bank } \\
\text { 3. World Bank/ } \\
\text { International } \\
\text { Development } \\
\text { Association } \\
\text { 4. European Union } \\
\text { 5. Commonwealth } \\
\text { Secretariat } \\
\text { 6. United Nations } \\
\text { Development } \\
\text { Programme } \\
\text { 7. United Nations } \\
\text { Fund for }\end{array}$ & $\begin{array}{ll}\text { 1. } & \text { Inter- } \\
& \text { Parliamentary } \\
\text { Union } \\
\text { 2. Asian } \\
\text { Development Bank } \\
\text { 3. } \text { World Bank/ } \\
\text { International } \\
\text { Development } \\
\text { Association } \\
\text { 4. European Union } \\
\text { 5. Commonwealth } \\
\text { Secretariat } \\
\text { 6. European Union } \\
\text { 7. United Nations } \\
\text { Development } \\
\text { Programme }\end{array}$ & $\begin{array}{ll}\text { 1. } & \text { Asian } \\
\text { Development Bank } \\
\text { 2. World Bank/ } \\
\text { International } \\
\text { Development } \\
\text { Association } \\
\text { 3. European Union } \\
\text { 4. United Nations } \\
\text { Education, } \\
\text { Scientific and } \\
\text { Cultural } \\
\text { Organisation } \\
\text { 5. United Nations } \\
\text { Development } \\
\text { Programme } \\
\text { 6. United Nations } \\
\text { Fund for }\end{array}$ & $\begin{array}{ll}\text { 1. } & \text { Asian } \\
\text { Development Bank } \\
\text { 2. World Bank/ } \\
\text { International } \\
\text { Development } \\
\text { Agency } \\
\text { 3. European Union } \\
\text { 4. United Nations } \\
\text { Educational, } \\
\text { Scientific and } \\
\text { Cultural } \\
\text { Organisation } \\
\text { United Nations } \\
\text { Development } \\
\text { Programme } \\
\text { United Nations } \\
\text { Fund for }\end{array}$ \\
\hline
\end{tabular}

${ }^{5}$ Not specified whether this is North or South Korea (although it is probably South Korea). 


\begin{tabular}{|c|c|c|c|c|c|c|c|c|}
\hline & $\begin{array}{l}\text { 7. United Nations } \\
\text { International } \\
\text { Children's } \\
\text { Emergency Fund } \\
\text { 8. World Health } \\
\text { Organisation } \\
\text { 9. Food and } \\
\text { Agriculture } \\
\text { Organisation } \\
\text { 10. International Union } \\
\text { for Conservation of } \\
\text { Nature } \\
\text { 11. United Nations } \\
\text { Environment } \\
\text { Programme }\end{array}$ & 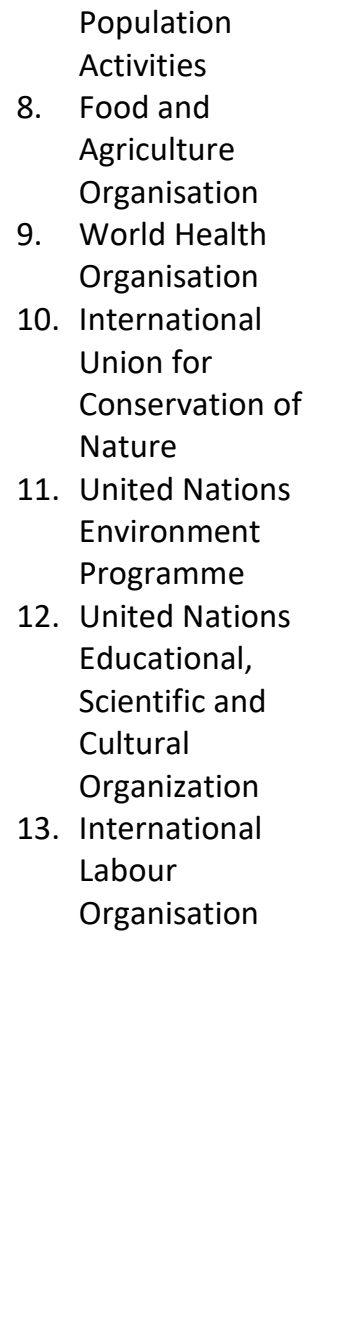 & $\begin{array}{l}8 . \\
9 . \\
10 \\
11 \\
12 \\
13 . \\
14 \\
15 \\
14\end{array}$ & $\begin{array}{l}\text { United Nations } \\
\text { Fund for } \\
\text { Population } \\
\text { Activities } \\
\text { United Nations } \\
\text { International } \\
\text { Children's } \\
\text { Emergency Fund } \\
\text { International } \\
\text { Labour } \\
\text { Organisation } \\
\text { World Health } \\
\text { Organisation } \\
\text { United Nations } \\
\text { Environment } \\
\text { Programme } \\
\text { International } \\
\text { Union for } \\
\text { Conservation of } \\
\text { Nature } \\
\text { United Nations } \\
\text { Educational, } \\
\text { Scientific and } \\
\text { Cultural } \\
\text { Organisation } \\
\text { Food and } \\
\text { Agriculture } \\
\text { Organisation } \\
\text { International } \\
\text { Labour } \\
\text { Organisation }\end{array}$ & $\begin{array}{l}7 . \\
8 . \\
9 . \\
10 \\
11 \\
12\end{array}$ & $\begin{array}{l}\text { Population } \\
\text { Activities } \\
\text { United Nations } \\
\text { International } \\
\text { Children's } \\
\text { Emergency Fund } \\
\text { International } \\
\text { Labour } \\
\text { Organisation } \\
\text { World Health } \\
\text { Organisation } \\
\text { United Nations } \\
\text { Environment } \\
\text { Programme } \\
\text { International } \\
\text { Union for } \\
\text { Conservation of } \\
\text { Nature } \\
\text { United Nations } \\
\text { Entity for Gender } \\
\text { Equality and the } \\
\text { Empowerment of } \\
\text { Women } \\
\text { Food and } \\
\text { Agriculture } \\
\text { Organisation } \\
\text { World Health } \\
\text { Organisation }\end{array}$ & $\begin{array}{l}7 . \\
7 . \\
8 . \\
9 . \\
10 . \\
11 . \\
14 . \\
12 . \\
13 . \\
15 . \\
\\
9 .\end{array}$ & $\begin{array}{l}\text { Population } \\
\text { Activities } \\
\text { United Nations } \\
\text { International } \\
\text { Children's } \\
\text { Emergency Fund } \\
\text { World Health } \\
\text { Organisation } \\
\text { United Nations } \\
\text { Environment } \\
\text { Programme } \\
\text { International } \\
\text { Union for } \\
\text { Conservation of } \\
\text { Nature } \\
\text { United Nations } \\
\text { Entity for Gender } \\
\text { Equality and the } \\
\text { Empowerment of } \\
\text { Women } \\
\text { United Nations } \\
\text { Convention on the } \\
\text { Law of the Sea } \\
\text { International Fund } \\
\text { for Agricultural } \\
\text { Development } \\
\text { Commonwealth } \\
\text { Organisation }\end{array}$ \\
\hline Regional & 7. Pacific Community 6 & 1. Pacific Community & 1. & $\begin{array}{l}\text { Pacific Islands } \\
\text { Forum Secretariat }\end{array}$ & 1. & $\begin{array}{l}\text { Pacific Islands } \\
\text { Forum Secretariat }\end{array}$ & 1. & $\begin{array}{l}\text { Pacific Islands } \\
\text { Forum Secretariat }\end{array}$ \\
\hline
\end{tabular}

${ }^{6}$ Previously known as Secretariat of the South Pacific Community or SPC but officially renamed the Pacific Community. 


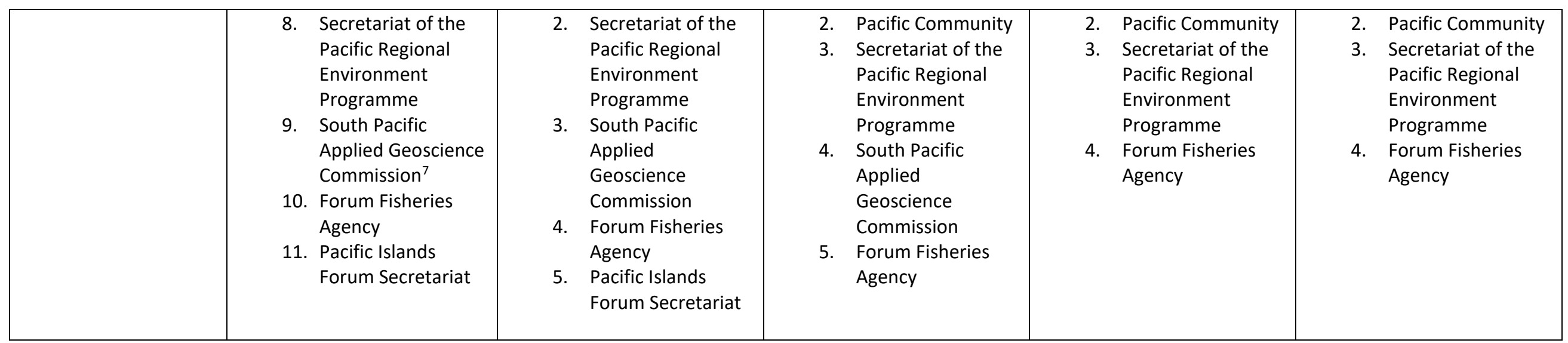

${ }^{7}$ Previously known as SOPAC but disestablished in 2010 and integrated into the Pacific Community and SPREP 
An alternative measurement of ODA to Tonga to those analysed above is provided from the OECD. These data were obtained not from the Tongan budget accounting system but from data provided to the Development Assistance Committee (DAC) of the OECD and found in their data sets. This measures actual disbursements by donors that matches the DAC's definition of ODA. However, it does not distinguish between cash and in-kind donations and, as we can see from the difficult issues within Tonga's financial management systems, it rather simplifies what is a complex flow and management of funds. We can gain an impression of the number and relative importance of aid donors in Tonga, and changes over time, from this data set (Figure Five). Because of the different definitions, time periods and currency calculations used, it is almost impossible to match these OECD data with those used by Tonga's government. Whilst these OECD data give a useful overview of aid flows, their standardised nature means they are not as good an indication of the realities of handling aid funding within a government system as those provided in Figures One and Two above. We should also note that they only count official flows of ODA and do not include development assistance from some countries such as the People's republic of China.

Figure Five: ODA to Tonga $2000-2018$ by donor (\$US mill constant $\$ 2018$ )

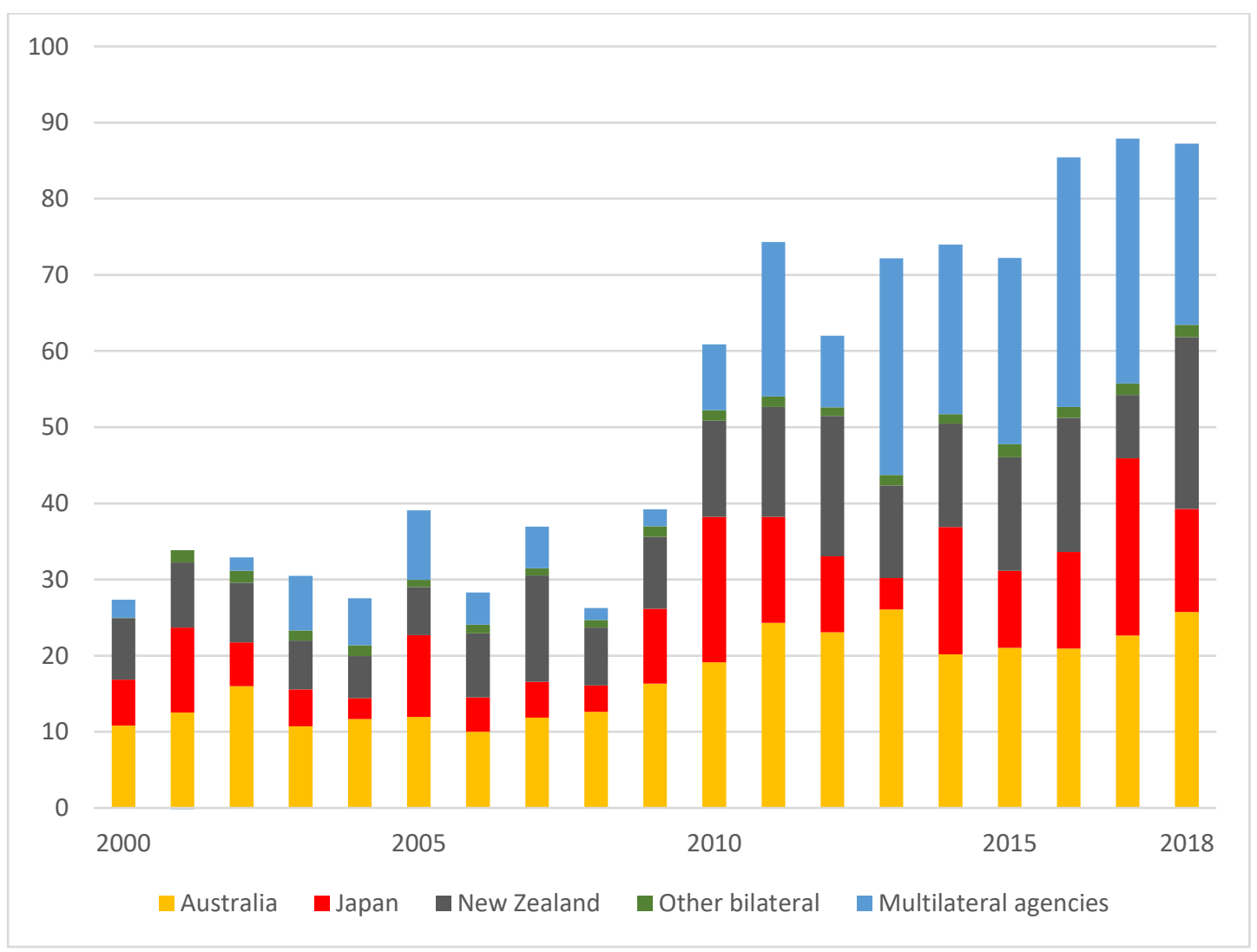

Source: Organisation for Economic Co-operation and Development: Stat (https://stats.oecd.org/\#) accessed 5 September 2020 
This overview illustrates a number of important points regarding aid to Tonga. Firstly, there was a significant increase in volumes of ODA to Tonga from the first decade of the 2000s to the second (at least until the latest data in 2018). The period 2013-17 of concern for this research is therefore a time of relatively high volumes. Secondly, it is apparent that three main bilateral donors dominate aid to Tonga: Australia, Japan and New Zealand. Multilateral agencies, principally the Asian Development Bank and World Bank, were also important providing both concessional loans and some grants. Despite the long list of donors in Table Eight, we can also note that a large number of small donors contribute relatively small amounts: our focus on Australia and New Zealand is justified in that together they contribute consistently over half of Tonga's ODA. Finally, we can see from Figure Five that aid volumes vary over time, sometimes markedly from year to year, as is seen with Japan over the 2010-18. The large number of donors and these fluctuations pose particular problems for recipient governments such as Tonga. As a result, their smooth working relationships with their main bilateral donors is of critical importance.

What stands out also from both Table Eight and Figure Five is the high volume of development partners and with it the indication of an intricate system Tonga must navigate. The volume has become something of a paradox in a certain way. Whilst the assistance is welcomed, the management and operational aspect is trying to keep up with the high influx of foreign aid. Each donor has their own systems and processes.

This is repeatedly conveyed by participants who are aware of the situation and are reacting accordingly. One approach conveyed by a participant:

"is being strategic on which in-country visits to attend, who to involve or represent as a stakeholder at the meeting, and dependent on availability." (Participant G, June 2018).

However, for Tonga even applying strategically and trying to efficiently manage the demand and objectives is difficult. The demand is challenged by both the volume and nature of foreign aid supply. This holds true not for just the number of donors but also the financial component as well.

Table Eight is also not just a list of development partners by donor but a reflection of many thematic areas and different modalities. If we examine closer Table Eight it offers a window into how donors operate. From the bilateral with a focus on Government-to-Government working relationship to the 
multilaterals who convey a sense of being a reservoir of technical expertise. This is important to understanding not only foreign aid but how it shapes or supports Tonga's national development priorities. In addition to this, not all of the development needs articulated by the Government of Tonga are funded by bilateral development partners. Some priorities are met by multilateral or thematic modalities. For example, Participant J explains:

"This strengthens my belief that it is possible to carry this out and I asked FAO (Food and Agriculture Organization of the United Nations) and the guy did come here but I can't remember who it was exactly. I'm waiting on some funds because we don't have further funding from New Zealand MFAT, so we asked for their process." (June 2018)

This aspect ties in with the earlier discussion on defining foreign aid. Here we are presented with data that highlights how multifaceted foreign aid is and in this what the development landscape is in Tonga.

\subsubsection{Donor Agendas}

Noting from Table Eight we can see that Tonga has some development partners who have a global reach and importantly provide a platform at this level. This is vital for countries such as Tonga because it enables an avenue for addressing issues which need a globally collective approach. The most wellknown example is climate change. Some of these multilateral or inter-governmental institutions from Table Eight can be further grouped into thematic areas or niche depending on the sector, area, or modality they specialise. For example, the Asian Development Bank and the World Bank prominently appear in the Government of Tonga Budget Statements specialising in budget support together with Australia and New Zealand. Of equal significance to keep in mind here is the global framework countries have made a commitment to adhere and aspire towards. This is the United Nations Sustainable Development Goals or SDGs to which Tonga, Australia, and New Zealand are signatories to.

The Sustainable Development Goals as a development framework enables both donors and recipients to streamline an understanding where motivations at the global level for foreign aid programmes originate. The Sustainable Development Goals have 17 goals:

1. Goal 1: No Poverty - Economic Growth must be inclusive to provide sustainable jobs and promote equality. 
2. Goal 2: Zero Hunger - The food and agriculture sector offers key solutions for development, and is central for hunger and poverty eradication.

3. Goal 3: Good Health and Well-Being - Ensuring healthy lives and promoting the well-being for all at all ages is essential to sustainable development.

4. Goal 4: Quality Education - Obtaining a quality education is the foundation to improving people's lives and sustainable development.

5. Goal 5: Gender Equality - Gender equality is not only a fundamental human right, but a necessary foundation for a peaceful, prosperous and sustainable world.

6. Goal 6: Clean Water and Sanitation - Clean, accessible water for all is an essential part of the world we want to live in.

7. Goal 7: Affordable and Clean Energy - Energy is central to nearly every major challenge and opportunity.

8. Goal 8: Decent Work and Economic Growth - Sustainable economic growth will require societies to create the conditions that allow people to have quality jobs.

9. Goal 9: Industry, Innovation and Infrastructure - Investments in infrastructure are crucial to achieving sustainable development.

10. Goal 10: Reduced Inequalities - To reduce inequalities, policies should be universal in principle, paying attention to the needs of disadvantaged and marginalized populations.

11. Goal 11: Sustainable Cities and Communities - There needs to be a future in which cities provide opportunities for all, with access to basic services, energy, housing, transportation and more.

12. Goal 12: Responsible Production and Consumption - Responsible Production and Consumption.

13. Goal 13: Climate Action - Climate change is a global challenge that affects everyone, everywhere.

14. Goal 14: Life Below Water - Careful management of this essential global resource is a key feature of a sustainable future.

15. Goal 15: Life on Land Sustainably manage forests, combat desertification, halt and reverse land degradation, halt biodiversity loss.

16. Goal 16: Peace, Justice and Strong Institutions - Access to justice for all, and building effective, accountable institutions at all levels.

17. Goal 17: Partnerships for the Goals - Revitalize the global partnership for sustainable development

(United Nations, 2015) 
Prior to the Sustainable Development Goals were the Millennium Development Goals which Tonga subscribed to and adopted as part of its development agenda. It provided a third and final report on the MDGs in September 2015 (Tonga Ministry of Finance and National Planning, 2015a). Some of the notable points from the final report are the complexities relating to achieving the Millennium Development Goals. The report notes that with some of the MDG targets how indicators for measurement of the targets do not necessarily reflect the reality on the ground. For example, the MDG Goal 1 of Eradicate extreme poverty and hunger has a monetary indicator and measurement. The report rightly contextualizes Tonga's situation stating:

"It was clear that there is no 'absolute poverty in Tonga' but 'hardship', defined."

(Tonga Ministry of Finance and National Planning, 2015a, p. 30)

The report listed six new and arising challenges, being reducing poverty and hardship through policy, a more inclusive education, women's employment and decision making, healthy mothers and children, HIV/AIDS and non-communicable diseases, and the environment (Tonga Ministry of Finance and National Planning, 2015a, pp. 162 -164). There are also seven 'unfinished business' areas being poverty eradication, universal primary education, gender equality and women empowerment, child mortality and maternal health, HIV/AIDs and NCDs, environmental sustainability, and global partnership for development. At the global level therefore, the external aid environment relative to Tonga to an extent has some alignment with its national development priorities.

For Tonga, there are many UN agencies, the Asian Development Bank, the World Bank, European Union agencies and so forth funding different activities on the ground. For example, in the multilateral row in Table Eight each year Tonga received support from ten different multilateral organisations. They assist the national development priorities but there does not appear to be a strong coordination. Although ownership is articulated in national documents, such as the Tonga Strategic Development Framework II and other frameworks like the Agriculture Sector Plan and the Tonga Energy Road Map or TERM, many of the Tongan government institutions either struggle or need improvement in leading development activities with so many potential partners with different mechanisms for following, adhering to, and implementing these broad policies and objectives. Be it a Government agency, Ministry, or a non-governmental organisation, for example, agencies often have to juggle multiple activities even for the same development partner. 
Agendas at the global Level are hard to implement at regional and let alone national level. For Tonga, the Strategic Development Frameworks I and II offer a bridge where policies between levels overlap or are shared. Global agendas need to be tailored for the national level because of both the development landscape - pertaining to the focus areas of donors and different modalities - and development context - understanding the economic and political situation on the ground together with the actors involved. In rarer circumstances we find success in ownership and implementation, such as the Asian Development Bank funded Outer Island Renewable Energy Project (Asian Development Bank, 2013a). Success in this case is deemed by criteria like the capacity of the implementing partner, Tonga Power Limited, to meet project deadlines and targets, and an effective governance structure. Success is therefore the performance of the mechanisms and the personnel. This success of implementation aligns with many of the SDGs and at the same time reflects how the aid effectiveness principles are relevant.

\subsubsection{From Paris to Nuku'alofa}

One important instance of translating global agendas into the national development priorities of countries such as Tonga is the way aid is managed. In this case worth highlighting is the progression of High-Level Forums (HLF) pertaining to aid effectiveness (Murray and Overton, 2011a, pp. 272 284). These have focused on the management and quality of foreign aid and the promotion of best practices and principles to achieve more effective aid delivery. For the purposes of this research it is important to give an overview of how much this paradigm of foreign aid, especially concerning aid effectiveness, has evolved. We can also see how Tonga gradually came to be involved in these discussions and adopt the frameworks and principles.

Tonga has participated in several international meetings and agreements which have generally influenced the aid environment. These have included the Millennium Development Goals and Sustainable Development Goals as global frameworks, the HLF meetings, and the Koror Pacific Aid Effectiveness Principles (derived from the Paris Aid Effectiveness principles). These international and regional meetings and agreements have influenced the development of the Tonga Strategic Development Framework at the national level.

The HLF meetings on aid effectiveness have been of particular importance. There have been four High Level Forums on Aid Effectiveness since the first in Rome 2003 and the last in Busan 2011 which established the Global Partnership for Effective Development Cooperation or GPEDC. The HLF Busan Partnership Agreement 2011 also founded the principles for development co-operation being 
ownership of development priorities by developing countries, focus on results, inclusive development partnerships, transparency and accountability to each other (Organisation for Economic Co-operation and Development, 2011). This is a notable shift in emphasis and recognition towards the development landscape.

Provided is a timeline of these high-level meetings on aid effectiveness:

\begin{tabular}{|c|c|c|c|}
\hline Year & Location & Consensus and Occasion & Key Details \\
\hline 2003 & Rome & $\begin{array}{l}\text { Rome Declaration, First High-Level } \\
\text { Forum }\end{array}$ & $\begin{array}{l}3 \text { Priority Actions - } \\
\text { - } \quad \begin{array}{l}\text { Development assistance } \\
\text { based on priorities of }\end{array} \\
\text { recipient countries } \\
\text { - } \quad \begin{array}{l}\text { Donor efforts concentrate } \\
\text { on cooperation and being } \\
\text { more flexible }\end{array} \\
\text { - Encourage good practices }\end{array}$ \\
\hline 2005 & Paris & $\begin{array}{l}\text { Paris Declaration on Aid Effectiveness, } \\
\text { Second High-Level Forum }\end{array}$ & $\begin{array}{ll}5 & \text { Principles of Aid Effectiveness - } \\
\text { - } & \text { Ownership } \\
\text { - } & \text { Alignment } \\
\text { - } & \text { Harmonisation } \\
\text { - } & \text { Results } \\
\text { - } & \text { Mutual Accountability }\end{array}$ \\
\hline 2008 & Accra & $\begin{array}{l}\text { Accra Action Agenda, Third High-Level } \\
\text { Forum }\end{array}$ & $\begin{array}{l}\text { Stocktake and Action Plan for } \\
\text { strengthening the Paris } \\
\text { Declaration }\end{array}$ \\
\hline 2011 & Busan & $\begin{array}{l}\text { Busan Partnership Agreement, Fourth } \\
\text { High Level Forum }\end{array}$ & $\begin{array}{l}\text { Creation of the Principles for } \\
\text { Development Co-operation and } \\
\text { the Global Partnership for } \\
\text { Effective Development Co- } \\
\text { operation or GPEDC }\end{array}$ \\
\hline 2014 & Mexico & $\begin{array}{l}\text { Mexico Communique, First High-Level } \\
\text { Meeting of the GPEDC }\end{array}$ & $\begin{array}{l}\text { Effective Development Co- } \\
\text { operation post-2015 (MDG } \\
\text { completed) }\end{array}$ \\
\hline 2016 & Nairobi & $\begin{array}{l}\text { Nairobi Outcome Document, Second } \\
\text { High-Level Meeting of the GPEDC }\end{array}$ & $\begin{array}{l}\text { Pathway for development } \\
\text { partners to achieving the SDGs. }\end{array}$ \\
\hline
\end{tabular}

Each HLF had a unique distinguishing feature about them as explained by Mawdsley, Savage, and Kim (2014) and they can be seen as responses to a paradigm shift in international aid (p. 28). This paradigm shift involves changes in the roles and responsibilities between donor and recipient, and the overall concern to improve aid effectiveness (Mawdsley, Savage, and Kim, 2014, pp. 27 - 28). Whilst each distinguishing feature may seem to have changed focus with every forum meeting, overall it does imply a collective will for improvement and cooperation. We can also see a shift in the language being used. The Paris Declaration in 2005 uses 'aid effectiveness' whereas the Busan Partnership centres on 
'development effectiveness' instead (Blampied, 2016). Importantly, the Busan Partnership reflected the ever-changing global development landscape and attempted to promote more 'inclusive' development co-operation. This was because other actors, such as the private sector, were involved in delivery and implementation of aid but also new donors, particularly China, were directly providing large amounts of development assistance, largely outside of the OECD and aid effectiveness framework. Hence at Busan in 2011, the 'development co-operation principles' were promoted outlining how actors should behave, and the expectations in a partnership. Interestingly though, this does not necessarily mean a significant paradigm shift, as the Paris Declaration was intended to be. Rather, the Busan agreement was more of an attempt to broaden partnership amongst the providers rather than those who received assistance (Organisation for Economic Co-operation and Development, 2012) whilst still largely adhering to the Paris Declaration principles.

For Tonga at the global stage it has agreed commitment to both the Paris Declaration and the Global Partnerships for Effective Development Co-operation (GPEDC). At this high level, it was a seemingly straightforward matter for Tonga to agree to principles which would have recognised its ownership and leadership of its development and asked donors to align and harmonise with this. However, what this meant at a national level in terms of practice is hard to ascertain. One of the biggest challenges to Tonga at times is translating the relevance of global commitments to the national level. This is evident no doubt in other countries, as well, including Australia and New Zealand. However, for Tonga given its own unique challenges relating to the society, political development, and economic circumstances, its implementation capacity is stretched thin. The indication implied by interviewee participants is that leadership at the Cabinet and senior officials' level, public and private sector, encounter significant capacity restraints.

This raises questions of ownership, harmonisation, and mutual accountability. Tonga is compounded by the volume of foreign aid to challenge ownership in two of the three criteria that partner countries make commitments. One is to translate the national development strategy into prioritised resultsoriented operational programmes and the second is to lead co-ordination (Organisation for Economic Co-operation and Development, 2005, p. 3). Harmonisation is challenging in this light because just as there is shortage in personnel, there does not seem to be much of an incentive for a centralized or streamlined approach. There are varying reasons why this is the case, ranging from the lack of experience in donor processes to the donor's own interests being given precedence. Mutual accountability therefore is relevant in this sense. Whilst the Paris Declaration has further fostered a 
more open and transparent dynamic between the two sides, donor and recipient, more improvement is needed.

At the most fundamental level, the Paris Declaration, together with other HLFs and the GPEDC, question the effectiveness of foreign aid and development. Aid and development are separate things, although at times the documentation and language used make them interchangeable. The HLF process put particular emphasis on 'aid' and its delivery but largely by-passed consideration of how effective or not more long-term 'development' was.

Tonga has joined and participated in the continuing GPEDC (Global Partnerships for Effective Development Co-operation, n.d.). Participation in such forums is important for Tonga as it offers a platform for Tonga to engage at such a level in how aid is delivered and remain part of the global discussion on aid. In return, a collective approach is applied to issues that Tonga alone cannot address or at the very least give their voice to how aid is understood, delivered, or can be improved.

\subsubsection{Regional Development Partners}

As well this global engagement, Tonga has been a part of more regional-level discussions and agreements on aid. The Pacific Islands Forum in particular has been important. Its annual meeting of leaders and the work of officials in between the meetings has resulted in a high degree of communication and cooperation. There have been agreements, such as the Pacific Plan of 2005 and its review in 2013 (The Pacific Islands Forum Secretariat, 2007b, 2013), which have called for greater regional co-operation in development. The leaders' meetings have also allowed for communication with leading donors, as Australia and New Zealand are present. However, such meetings, as in 2009 with the Cairns Compact, are also open to donors leading the agenda and sometimes imposing their views over those of regional leaders (see Eafeare in Overton et al 2019, pp.198-200).

One of the most important products of the Pacific Islands Forum with regard to aid was the Koror Declaration - the Pacific Aid Effectiveness Principles - adopted at the leaders' meeting on the $13^{\text {th }}$ July 2007 in Koror, Palau (The Pacific Islands Forum Secretariat, 2007a). This agreement represented engagement by Pacific Island governments with the Paris Declaration principles and the adoption of a modified set of aid effectiveness principles for the region. Little was fundamentally changed from the Paris principles but it was important to see a strong Pacific endorsement for the key concepts of local ownership and donor alignment and harmonisation. Tonga was a part of this process and we can infer that its leaders and officials came away from the Koror meeting having been well versed in the need 
to focus on aid effectiveness and take more of a lead. Furthermore, the Koror agreement has also led to continuing activities by the Forum with regard to aid effectiveness, such as its peer review process.

The support provided by the Pacific Islands Forum and similar regional institutions operate in a niche way. That is, they heavily specialise providing technical assistance to the member countries including Tonga. Like the Asian Development Bank and the World Bank, the regional institutions receive funding from donor countries such as Australia and New Zealand. The technical assistance the regional institutions provide fill a gap needed often during implementation and aim to maximize the effectiveness of the funding. An aspect of this maximisation is that the technical assistance is often in the form of fellow member country citizens who have a real familiarity with the development context of the region together with in-depth experience. This is a competitive advantage, so to speak, the technical advantage component has in comparison to other service providers.

However, capacity restraints referred earlier are not necessarily a result of ineptitude. Capacity restraints for Tonga are often a combination of the lack of coordination, little to ineffective communication channels, and the sheer volume of work. This is supported by the budget figures above, Tonga has to manage all that foreign aid according to the conditionalities, processes, requirements of the donor. This is a challenge for Tonga and almost contradicts the very reason for development assistance, at the expense of relying on foreign aid. Technical assistance has evolved to be more of an additional human resource donors perceive at times without proper acknowledgment of existing local expertise due to volume rather than the actual lack of technical capacity on the ground.

Like the multi-lateral institutions, the regional development partners specialise in thematic areas such as climate change and fisheries. These topics require a collective effort above Tonga's national level, fish and climate do not recognize Exclusive Economic Zones or Sovereign borders. Collectively the member states of the regional institutions develop frameworks and mechanisms to implement and monitor accordingly. For example, at the global level the United Nations have adopted the Small Island Developing States Accelerated Modalities of Action Pathway or, as it is more colloquially known, the SAMOA Pathway (United Nations Department of Economic and Social Affairs, 2014). What this means at the regional level is priority areas such as climate change uses regional frameworks such as the Pacific Islands Framework for Action on Climate Change and the Integrated Strategy for Climate and Disaster Resilient Development in the Pacific. 
Overall, Tonga has ample opportunity to relay, communicate, and articulate its national development priorities to these regional institutions and more importantly, participate in shaping foreign aid towards its national development priorities and domestic context. Indeed, Tonga does take command. Yet, as the development landscape has highlighted, the Paris Declaration principles are hard to implement and adhere to. At first glance, the implementation of the principles seems to be arbitrary and overly generalised. I would argue they are not, and they are followed but with certain limitations. The key lens to use in understanding their application and manifestation, relies on the drivers and intended outcomes of the provider.

The international, regional, and activity frameworks are not just policy guidelines, they also act as a reference point for commonality and assurances between, amongst, international parties. Participation at global and regional forums offers Tonga an avenue to ensure it plays a role shaping the decisions that hold implications for itself. Tonga's development landscape influences how its development priorities are supported yet the development landscape is diverse and interwoven. There are ample opportunities whereby foreign aid holds potential for Tonga to eventuate the national development priorities. As we have touched on, this is a circumstance of leadership, the national development priorities themselves - that is how they are articulated, justified, and approached, and collective norms and rules factors.

Under the main headings in this Chapter - the Kingdom of Tonga, Leadership, the Tonga Strategic Development Framework, and the Development Landscape each has examined and detailed the development context for Tonga. Understanding the origins and how the concepts of nation, aid, and development have been perceived offers a starting point. Leadership is coded in the Constitution and with the Makatu'unga Fakataki Fakafonua 'o Tonga but remains elusive. The nature of it being exercised for effectiveness relies on maintaining good working relationships. This aspect of leadership is important to keep in mind as the style of leadership offers a better understanding of how and why Tonga articulates its national development priorities the way it does. For Tonga, the Tonga Strategic Development Framework I and II acts as the overarching development framework of the Kingdom. They are a window into what the Kingdom perceives as the national development priorities and why they are so. Assigned along this important framework is the Government of Tonga Budgets which are shown in Figure Two and as a discussion, Figure Three. The framework and budgets are intrinsic of each other. The ebb and flow of foreign aid, the activity cycles, and how figures are represented demonstrate this intrinsic relationship. 
A greater analysis of this relationship highlights the nature of official development assistance to Tonga. Under this analysis, the key institutions are identified and detailed in how they shape or influence how aid is managed, implemented, and reported in Tonga. The nature of official development assistance to Tonga has competing elements about it, dependent on what it focuses on, and who delivers or implements it. Equally linked is understanding the volume and the nature of donors that work with Tonga as development partners. This is not only an indication of volume, a deeper appreciation shows us different types of donor systems and thematic areas. Table Eight alludes to this indication and illustrates the two points. In turn the impact of both the volume and diversity of systems tie closely to much broader questions concerning aid effectiveness - the role of the donor, the responsibility of the recipient, and the nature of development cooperation. Each donor that Tonga collaborates with has different aspects about it - bilateral, multilateral, or regional - coupled with different agenda levels. As the last section of this Chapter suggests, there is a greater awareness of this under the aid effectiveness theme but more importantly is understanding how Tonga chooses to engage. We now need to turn to examining how the two main donors operate with regard to aid in Tonga. 


\section{Chapter Five: Australia in Tonga}

\subsection{Introduction}

In this section we will focus on Australia as the largest donor to Tonga and cover the Country Programmable Aid (CPA) component of the Australia Aid Programme to Tonga between 2013 to 2017. We examine the Country Programmable Aid structure and where possible some of the fundamental factors that shape it. Using the Paris Declaration on Aid Effectiveness we attempt to see the nature of the relationship between Australia's Country Programmable Aid and Tonga's national development priorities. The objective of this is to observe and analyse, under the Paris Declaration principles on aid effectiveness, how Country Programmable Aid, shapes or supports Tonga's national development priorities. As noted in the previous chapter, the overarching document Tonga pushes forward to donors as the national development framework is the Tonga Strategic Development Framework. This includes both Phase One from 2011 to 2014 and Phase Two from 2015 to 2025. This document is quoted by many donors, including Australia, in a diversity of activity designs and high-level policy bilateral papers.

Along the way we are presented some challenges. One example is the challenge of ascertaining information concerning the Australia Aid Programme available in the public domain. It was implied by some participants that were interviewed that the nature of the aid programme contains sensitive information and almost determines the dynamics involved in the working relationship (Participant $D$, June 2018). This research has managed the challenge of ascertaining information in three ways. Firstly, it uses information from the Government of Tonga in official documents available to the public. Secondly, there are interviews with key personnel. Lastly, information is available online from official websites such as the Australia Department of Foreign Affairs and Trade and Tonga Ministry of Finance. All three are then triangulated to illustrate a more complete picture of Australia's Country Programmable Aid to Tonga between 2013 to 2017. The Country Programmable Aid is the focus but the nature of it is reflected more as the chapter progresses.

The approach this research employs is to highlight through a thematic lens Tonga's national development priorities over this period and whether Australia's Country Programmable Aid follows the Paris Declaration on Aid Effectiveness principles. The different investments in areas and the objectives outlined by Australia in their performance reports between 2013 to 2017 are organised here as five themes: economic development, public sector governance, education, health, and infrastructure. It is important to note at this stage that for the period that is covered here Australia's foreign aid investments are reported on within an annual frame. This is one way an external aid 
environment shapes Tonga's development priority, as the external development partner has required outcomes within an ambitious and annual timeframe.

\subsection{Australia's Country Programmable Aid}

Before we analyse the CPA, it is important to provide the context of where it originates from within Australia's broader Official Development Assistance. In 2013 the Australia Aid Program experienced changes in the motives and methods of its foreign aid delivery. Prior to 2013 the program was administered through an agency, AusAID, which was semi-autonomous from the Australia Department of Foreign Affairs and Trade. Wood, Burkot, and Howes (2017, p. 238) summarize the key changes as covering three main aspects firstly, the former agency known as AusAid was integrated into the Department of Foreign Affairs and Trade (DFAT); secondly there was an overall aid budget cut; and thirdly, there was a stronger focus on economic diplomacy. Wood et al. (2017) analysed the changes as a result of the change in government for Australia, with the election of the Liberal-National coalition Tony Abbot-led government in September 2013. Abbot, in turn, was replaced as leader by Malcolm Turnbull in September 2015 though the coalition remained in power. However, Davis (2011) expands on the different narratives that change can occur to Australia's development assistance ( $p$. 389) and aspects of 'why' foreign aid is delivered. The narratives involved:

"an ongoing questioning within the aid 'policy community', such as it is, of the purpose of foreign aid and the nature of its relationship to foreign policy; bureaucratic contestation over access to foreign aid resources; the desire of Australian foreign aid decision-makers to ensure their control, increasingly via managerialist methods, of aid delivery; and an avoidance by decision-makers of viewing the South as a politically relevant entity." (Davis, 2011, p. 389)

These are themes familiar to what was seen in the Australia Aid Programme between 2013 to 2017 in Tonga. What shapes the aid programme is dependent on competing and parallel factors as Davis (2011) indicates and Wood et al. (2017) attribute to change of government. Each change of administration resulted in a refocus on what the aid programme should concentrate on or emphasize for the region and how it is delivered. This is the context from where the CPA is at in 2013 onwards and encompasses operational, geo-political, and political connotations.

The different themes that shape Australia's Aid Programme is reflected in the policy documents and how they are interconnected. This assists our understanding of the nature of Australia's foreign aid. For example, the key 2014 document Australia aid: Promoting prosperity, reducing poverty, enhancing 
stability (Australia Department of Foreign Affairs and Trade, 2014a) outlines the programme's overarching objectives and priorities. It emphasised reform of the aid program (at the time) by articulating that Australia would strengthen its focus on in the Indo-Pacific region, focus on promoting economic growth, change how aid is delivered to use private sector partnership models, give increased attention to empowering women and girls, and structurally to integrate the management of the aid program into the Department of Foreign Affairs and Trade (Australia Department of Foreign Affairs and Trade, 2014a, p. 5).

These policy documents and policy shifts proved to be crucial for Tonga. They led to important changes in the way donors shaped their aid programmes. As one participant noted:

"for the Pacific that means primarily working in three core areas. One is economic cooperation which means expanding the existing labour mobility programs, looking at what trade agreements we can strike for example PacerPLUS, and it is also putting more on our people to people links focusing more on our scholarships program and our alumni, volunteers, public diplomacy and security" (Participant I, June 2018)

The development policy acknowledges the change in development landscape with other actors holding an increasing influence in development and, at the time, a global focus on transitioning from the Millennium Development Goals (Australia Department of Foreign Affairs and Trade, 2014a, p. 29). This is the background to how the Australian Aid program through this period both informs and shapes the CPA to Tonga.

To gain some indication of the place of Tonga in Australia's aid 'portfolio', we can examine its ODA expenditure from 2000 to 2018 (Figure Six). Tonga does not figure prominently in terms of volume in Australia's ODA landscape. For the years since 2000, only in 2018 did it amount to over $1.0 \%$ of Australia's total ODA disbursements and for the period 2013-17, it varied between a low of $0.66 \%$ and a high of only $0.94 \%$. However, the Pacific Island region did figure significantly, particularly with Papua New Guinea being Australia's largest single bilateral recipient. So, although Tonga was not a large partner, it could be suggested that Australia's aid programme at least did recognise Oceania as a priority, even if it was dominated by attention given to Melanesia (Fry 1997). The other point to note from these data is the decline in real ODA expenditure after a peak in 2012. So, for the period of this study, we can see a steady decline in total Australian aid overall, though for Tonga, the volumes stayed relatively stable between a high of \$US26.1 mill in 2013 and a low of \$US 20.2 in 2014. Thus, whilst 
the business of Australia-Tonga aid relationships was being conducted in 2013-17, it was against a backdrop of cuts in the aid programme and, as we have seen, institutional restructuring and changes in overall aid priorities.

Figure Six: Australia ODA Disbursements by Region 2000-2018 (\$US mill constant \$2018)

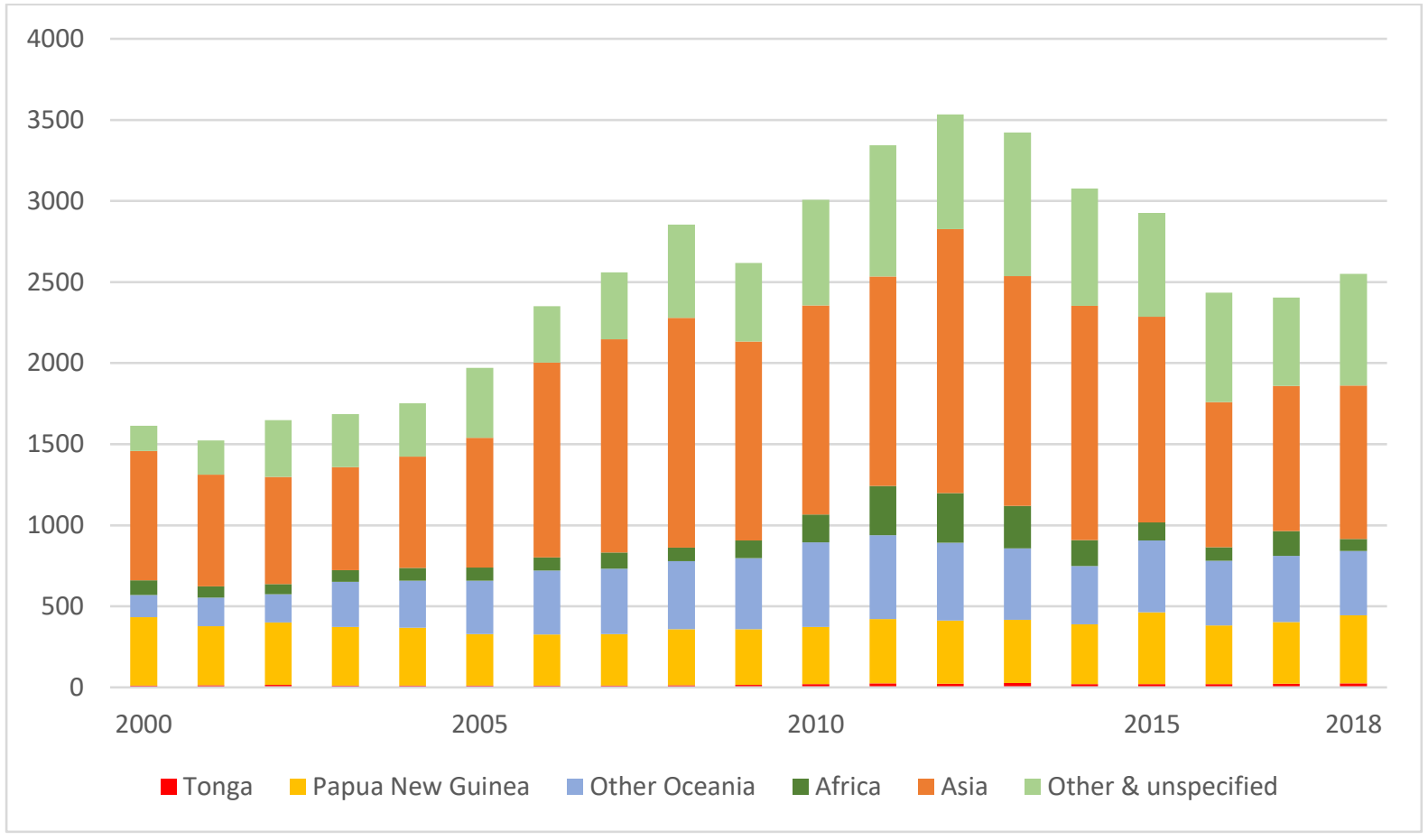

Source: Organisation for Economic Co-operation and Development: Stat (https://stats.oecd.org/\#) accessed 5 September 2020

Linked into this central document at the bilateral level is the Aid Investment Plans to Tonga from 2013 to 2017 (Australia Department of Foreign Affairs and Trade, 2015a). These were tailored a bit more towards the bilateral relationship between Australia and Tonga, considering how Tonga articulates its national development priorities. Australia continued to adapt to the development needs of Tonga with:

\footnotetext{
"an aid investment plan which broadly sets out the bilateral aid program priorities and under each, the aid investment plan has three pillars with cross cutting issues, so each pillar has a set of investments..." (Participant I, June 2018).
}

Like other donors who are members of the Organisation for Economic Co-operation and Development, Australia uses Country Programmable Aid. This form of aid was defined in Chapter One but, to re- 
iterate, "reflects the amount of aid that is subjected to multi-year planning at country/regional level" and is defined through exclusions to the ODA bilateral of a country such as humanitarian assistance and core funding for non-governmental organisations (Organisation for Economic Co-operation and Development, 2007a). One interesting feature, drawn from documentation and interviewing informants about Australia's Country Programmable Aid, is the nature of how it is reported. That is, it is reported against an objective, measured towards a policy outcome, and presented on an annual basis. For example, from 2013 to 2017 Australia reports its Aid Program Performance Report as progress towards its bilateral aid program 'objectives', objectives that with each of the years covered in this research have a distinctive high-level bilateral understanding. This ranges from open-ended language such as "the Australian aid program remains relevant to Tonga's development priorities, and mutual development objectives" (Australia Department of Foreign Affairs and Trade, 2014c, para. 2) to affirmed high-level arrangements such as the Australia-Tonga Aid Partnership Arrangement 20162019 and the Partnership for Development 2009-2015, respectively. This approach in reporting implies that the aid effectiveness, under the given the development mechanisms and institutions, is best characterized and defined by time. Two concurrent time frames under this lens are at play: the quick, timely, and rigid policy planned pace by the donor versus the endearing, spatial, and almost ad hoc approach by the recipient. In other words, producing results within a year is should be contingent on the project. This research analyses the CPA taking a thematic approach to capture a better understanding of how the broader aid program shapes the CPA and subsequently each year, 2013 to 2017 , is covered thematically.

The scope here does not entail deciding whether Australia's Country Programmable Aid has failed or whether it has met its aspired intentions. We should also keep in mind here that the scope of this research is only looking at Country Programmable Aid. This is but one of many modalities just one donor carries out. Australia, like New Zealand, China, Japan, have other aid programmes running simultaneously to the bilateral priorities. For example, in 2017 Australia provided humanitarian response to Tonga due to the destruction caused by Cyclone Gita (Australia Department of Foreign Affairs and Trade, 2018a, p. 6). Other modalities are tailored to other important aid programmes which address global issues like climate change. As Table Eight in the previous chapter indicates, there is a myriad of players on the ground. Development prioritization, especially at the national level for Tonga, then becomes challenging. Yet the environment is also challenging for donors, particularly, as also seen in the previous chapter when there is a continually changing political environment (both in Australia and Tonga) and some lack of clarity regarding the institutional structure in Tonga. 
The thematic areas analysed here outline the linkage between the Country Programmable Aid and Tonga's national development priorities. There are overlaps in strategies and outcome objectives. Two other approaches were considered in this research as the best way to present the analysis of the data. One has been touched on earlier which is reflecting the year by year report structured according to Australia's aid program performance reports. This is challenging mainly due to repetitiveness and that as a method together with the research questions it was hard to find consistency in how their CPA was presented. The other approach would be according to the monetary expenditure of the CPA and the individual projects, but this is problematic. The monetary figures given in reports are according to the duration of the project, budget approved, or not at all. Interviewees were hesitant to give certain monetary amounts attached to projects or programmes, no doubt partly because of the complexity of the accounting and reporting systems involved where discrete amounts year-by-year and activityby-activity are very difficult to ascertain. With these considerations in mind and given the focus and scope of this research, it was determined that a thematic presentation and analysis of Australia's CPA would be more appropriate.

Five main themes under the Country Programmable Aid are covered. These are: economic development, public sector governance, education, health, and infrastructure. Each thematic area of the CPA is examined throughout the years of this research. Note that this approach treats the thematic areas as the CPA as reported by Australia. For example, the thematic area of Economic and Public Sector Governance are two different areas but presented under one section with all the relevant projects. Within the years and thematic area are objectives set out by Australia. Similarly, education and health are combined. This research observes how the objective also shape or support the national development priorities of Tonga and highlighting, when relevant, the Paris Declaration on Aid Effectiveness Principles. One other parameter to disclose is that Australia has chosen to include 'other bilateral aid', in the Australia Aid Program Performance Reports, which is either humanitarian or gender driven.

\subsection{Economic and Public Sector Governance}

The aid context around economic and public sector governance that Australia was operating is shaped by internal and external elements in aid delivery. Externally, at regional level this involves a focus is on transnational issues such as climate change together with issues such as understandings of newer models of development co-operation. Internally in Tonga, it involves key aid institutions such as the line ministries with their resources and focus, the nature of official development assistance in terms of volume and modality, the constant change of senior positions at officials' level and the political environment of Tonga. The development context though for Tonga that Australia perceived under these thematic areas is the impact of its geographical remoteness to its economy, increasing reliance 
on remittances for household consumption and foreign aid for budget support, the impact of the Global Financial Crisis from 2008, political change that occurred in 2010, and being frequently prone to natural disasters (Australia Department of Foreign Affairs and Trade, 2018a, pp. 6-7).

Australia has between 2013 to 2017 made different investments toward Economic and Public Governance. As an objective it is labelled 'more efficient and effective public sector' and then it transitioned into 'governance, economic and private sector development reforms" in 2015. With the first version - 'more efficient and effective public sector' - the impetus stems from Australia wanting to strengthen Tonga's capacity within the public sector. This is inferred in the 2013-2014 Australia Aid Program Report where it stated:

“Australia's overarching aims for this sector are to support the Government of Tonga to ensure that policies and programs are fiscally sustainable, strategically targeted on core development priorities and implemented in the most cost-effective manner." (Australia Department of Foreign Affairs and Trade, 2014c, p. 6)

The transition in 2015 was to focus more on 'medium term program of economic reform' (Australia Department of Foreign Affairs and Trade, 2016b, p. 3). The objective is constituted by three overlapping benchmarks being: (1) Strengthening Public Financial Management; (2) Reducing debt; and (3) Enhancing the Business-Enabling Environment (Australia Department of Foreign Affairs and Trade, 2014c, pp. 6-8). Inclusive in this is “Women's Practice Parliament, which promoted the participation of Tongan women as potential future political leaders" (Australia Department of Foreign Affairs and Trade, 2014c, p. 8). The aim for Australia is to address public sector reform such as strengthening revenue collection, managing government expenditure, reducing debt, and promoting economic growth. Also, it supports economic growth through boosting Tonga's trade capabilities. This is done by targeting infrastructure investments in renewable energy and the Pacific Agreement on Closer Economic Relations or PACER Plus upon signing (Participant I, June 2018).

Australia has different approaches towards the two thematic areas and where they focus in their CPA bilateral investments to support Tonga. Broken down into specific projects the economic area is implemented under the Outer Islands Renewable Energy Project, Tonga Energy Road Map, Tonga Transport Consolidation Project, Private sector development pilot project -Vava'u, and the Private sector development pilot project - 'Eua (Australia Department of Foreign Affairs and Trade, 2016b). The Joint Policy for Reform Matrix (JPRM), provided by the Asian Development Bank of which Australia is a donor, under their 'Strengthening Public Finance Management Program' (Asian Development Bank, 2013b) is the Public Sector Governance flagship project for Australia. Whilst the Ministry of Finance is the main agency involved in implementation of the JPRM, they have more of a coordination 
role (Participant S, June 2018). Implementation areas for the reform program and intended aim are closely aligned including public financial management, strengthening health procurement, audit capacity, to name a few (Australia Department of Foreign Affairs and Trade, 2018a, p. 4).

In terms of strengthening private sector and sustainable economic growth, Australia invested through the Asian Development Bank in the Private Sector Development Initiative. Specifically, this involved the private sector development pilot project -Vava'u and private sector development pilot project 'Eua (Australia Department of Foreign Affairs and Trade, 2016b). The two had the following outputs: (1) Diagnostic studies, dialogue, and communication; (2) Rapid response, technical advice, and capacity development; and (3) Regional initiatives and monitoring (Asian Development Bank, 2018, p. 18). As the nature of these sort of investments exhibit, five recommendations were made in the areas of clarity concerning priorities, re-design of the monitoring and evaluation system of the Asian Development Bank (ADB), review the management structure, and re-look at the focus with the suggestion being women's economic empowerment (Asian Development Bank, 2018, pp. 61-63). More relevant to this research is that this is a CPA project but it is channelled through a multilateral agency (the ADB). The evaluation of the PSDI gives us an insight regarding the challenges in delivery, implementation, and monitoring and evaluation under such a model.

Arguably, the national development priorities of Tonga are supported in different ways under these two thematic areas. Australia supports Tonga by linking foreign aid to mutually agreed reform benchmarks in governance, economics, and private sector (Australia Department of Foreign Affairs and Trade, 2018b). The closest alignment of all these projects under the Tonga Strategic Development Framework are to Tonga's primary outcome objectives of a "Dynamic public and private sector partnership as the engine of growth" and "Better Governance" (Tonga Ministry of Finance, 2011, pp. 5-7). Australia supports the delivery and coordination mechanism as Tonga would prefer. As a participant highlighted:

"of course, the policy side of things the Ministry of Finance being responsible for national planning for the country, putting together the Tonga National Strategic Plan" (Participant D, June 2018).

The linkage between the projects and national development priority captures alignment as articulated by Clause 16 (Organisation for Economic Development and Cooperation, 2005, p.3). In this clause donors try to adhere to country strategies, policy dialogues, and development co-operation of the partner's national development priorities (Organisation for Economic Co-operation and Development, 2005, p. 3). Hence, the different forms of support for Tonga's development priorities are reflected in subject area, aid effectiveness principles, and delivery mechanisms by Australia. 
Australia elaborated on alignment with the national development priorities of Tonga, aiming:

"to work with Tonga to develop a more efficient public sector, by supporting partner government reforms to promote fiscal sustainability and improve public expenditure management." (Australia Department of Foreign Affairs and Trade - Tonga Aid Program Performance Report, 2015c, p. 3)

The report emphasizes, as almost a perceived strength, the many policy reforms to develop a 'more efficient public sector' and for the release of funding under the JPRM. This included support in the form of technical assistance regarding procurement regulation, fiscal policy, tax compliance, and revenue collection. One participant echoed these initiatives:

"as a Ministry we are responsible and follow certain processes which include managing resources provided by development partners" (Participant G, June 2018)

The exact wording may not be used but the joint enterprise is strongly inferred via page 9 of the Grant Agreement between the Kingdom of Tonga and the Asian Development Bank (Asian Development Bank, 2013b, p. 9). The grant stipulates the 'policy actions' to trigger the grant release. The joint enterprise with Australia, Asian Development Bank, and other development partners is expanded in greater detailed in the 'Development Co-ordination' document going as far as stating development partner, project name, duration, and amount (Asian Development Bank, 2013c, p.1). Indicated implicitly under that arrangement model of the joint enterprise is how the donors drive donor coordination.

From Tonga's perspective, in terms of their national development priorities, the Joint Policy for Reform Matrix is relevant to the aid effectiveness principles of ownership and harmonisation. The relevant line Ministries - Ministry of Meteorology, Energy, Information, Disaster Management, Climate Change and Communications, Ministry of Revenue, Ministry of Public Enterprise, Ministry of Commerce, Tourism, and Labour for example - lead on many of the intended reform programs (Asian Development Bank, 2017, pp. 1-4). Tonga has the freedom to choose how the funds are allocated and for what purpose upon deposit. Different from other aid modalities whereby the funds are deposited but are already pre-allocated with conditionalities, any changes need a thorough and go through a rigid process. Under the JPRM:

"the donor recipient relationship is about strengthening and supporting systems in place by the Government of Tonga" (Participant D, June 2018). 
This sequencing is interesting because it indicates how following harmonisation and alignment principles are used to shape, via 'policy actions' that trigger grant release, Tonga on development priorities.

As an analytical tool for both Australia and Tonga, evaluations give insight into how foreign aid is delivered and what the implementation challenges are (Rebien, 1997 and Cracknell, 1988). The Tonga Economic and Public Sector Governance Program Phase III (EPSG III) purposely drew from what it perceived as outcomes in Phase I and Phase II (Australia Department of Foreign Affairs and Trade, 2018c, p. 7). It focused on two components: budget support and technical assistance. While some strides towards results were made, the Evaluation of Phase III does make a point which applies here. The evaluators conceded that:

"The evaluation faced the general limitation that establishing causality can be difficult in budget support programs. Even where data on impacts is available, it is difficult to precisely know which changes were attributable to budget support funding" (Australia Department of Foreign Affairs and Trade, 2018c, p. 6, emphasis added)

This analytical tool informs us that working relationships between officials and key institutions be it the implementing agency or the documented arrangement of parties are important elements to keep in mind. That is, foreign aid with its aim toward shaping, influencing, or shaping development priorities is inclusive of the interaction that exists when it is actioned. Foreign aid rests on different ideals such as accountability or what is the money spent on, participation including collaboration with the recipient designing the project, and effectiveness that asks what the result was (Winters, 2010). For both Australia and Tonga, it is an ongoing collaboration to find the right balance of addressing a development priority and programming foreign aid even with analytical tools such as an evaluation.

The Economic and Public Sector Governance Program Phase III reflected the utility development priorities in ownership value for Tonga. The Tonga Aid Program Performance Report 2016 (Australia Department of Foreign Affairs and Trade, 2017) highlights the policy objectives met by Tonga but specific to sector and implementing agency. In doing so, Tonga triggered the funding being released under the Joint Policy for Reform Matrix. The results being given approval included fiscal targets, implementation of import duties and excise taxes to discourage alcohol and tobacco consumption, and the introduction of major reforms to public service management (Australia Department of Foreign Affairs and Trade, 2017, p. 3). They are an indication into how Tonga's national development priorities are influenced not only in a sector (health), but the institutional tools used to do so (policy). In this interpretation, the nature of implementing foreign aid - conditionality and sector specific 
development need - shapes what Tonga perceives as a national development priority. That is Tonga is incentivised in what is a development priority by an external influence.

What appears to be the main highlight in this section when examining the two thematic areas is the ability of Australia and Tonga to translate foreign aid into meaningful cohesive action. Under the lens of the Paris Principles of Aid Effectiveness, it is apparent that support exists for the national development priorities of Tonga. The principles of alignment, harmonisation, and ownership are manifested in unique functional ways and followed with a purpose. Australia does not adhere to perhaps the conventional definition of what bilateral aid under the CPA is understood. It has used different models in aid delivery such as a multilateral and different aid mechanisms through a joint enterprise. The different investments and the Tonga Strategic Development Framework have had to adapt to the different arrangements and what the implications are in doing so. Despite the challenges being multifaceted and at times beyond their control, both countries have managed the circumstances with a willingness to improve.

\subsection{Education and Health}

In this section we examine Australia's focus on education and health. In 2013 the Education and Health category of Australian CPA consisted of targeted components exemplified in the nature of the activities, one created collaboratively with Tonga and New Zealand as a tripartite. Education activities were the Tonga Technical and Vocational Education and Training (TVET) Support Program, the Interim Skills and Development Facility, Tonga Skills, the Tonga Education Support Program Phase Two, which was a tripartite between Australia, New Zealand and Tonga, and lastly the Australia Awards or colloquially known as 'Scholarships'. Australia supported Health under Tonga Health Sector Support Program Phase I and subsequently Phase II (Australia Department of Foreign Affairs and Trade, 2015d). Table Nine below gives a visual comparison against the national development priorities of Tonga, and the Paris Principles on aid effectiveness, together with how it is composed of the activities in the two thematic areas. Australia's Seasonal Worker Programme is covered in this section later, but its inclusion is reflective of a project that aims to meet the objective of the thematic areas "Skills development in support of economic opportunities for Tongan workers" (Australia Department of Foreign Affairs and Trade, 2016b, p. 5). 
Table Nine: Education and Health Focus

\begin{tabular}{|l|l|l|}
\hline $\begin{array}{l}\text { Country Programmable Aid - Objective } \\
\text { Two }\end{array}$ & $\begin{array}{l}\text { Tonga National } \\
\text { Development Priority }\end{array}$ & Paris Principle \\
\hline $\begin{array}{l}\text { Education and Training (TVET) Support } \\
\text { Program }\end{array}$ & Education & Alignment \\
\hline $\begin{array}{l}\text { Tonga Education Support Program } \\
\text { Phase Two }\end{array}$ & Education & Alignment \\
\hline Australia Awards & Education & Alignment \\
\hline $\begin{array}{l}\text { Interim Skills and Development Facility } \\
\text { (ended 2016) }\end{array}$ & Education & Alignment \\
Tonga Skills (design 2016 and \\
implemented to 2021)
\end{tabular}

In 2014 there was a strong indication from the performance report (Australia Department of Foreign Affairs and Trade, 2015c) that strategic adaptation to the situation on the ground was needed with regard to the education sector. Most evident is in the investment in the Tonga Vocational Education and Training Program. The development context needed to be better understood, particularly the aid institution and mechanism. It was a case of both inadequate design and therefore manifesting certain issues during implementation plus the design not fully appreciating the operational circumstances changed. As participant $\mathrm{H}$ conveys:

"It was identified even during the consultations that much was not visible in the class room level despite millions in support from previous years, we had to identify what the loopholes were and one of the things identified was the capacity constraint within the Ministry and the lack of capacity to effectively monitor the support to the Ministry as well to the schools" (Participant $H$, June 2018)

The Tonga Technical and Vocational Education and Training (TVET) Support Program aimed to: 
"make Tongans more competitive in domestic, regional and international labour markets through improved demand based TVET and internationally recognised qualifications" (Australia Department of Foreign Affairs and Trade, 2012, p. 7)

The Tonga Technical and Vocational Education and Training Support Program was assessed then rated according to the aid effectiveness principles of relevance, effectiveness, efficiency, monitoring and evaluation, sustainability, gender equality, and lastly analysis and learning (Australia Department of Foreign Affairs and Trade, 2012). Observation suggests that it was a case of both where the design of the project was appropriate, but the situation on the ground faced constant changes. In May 2014 Australia programmed the Interim Skills and Development Facility in place of TVET.

The Interim Skills and Development Facility was implemented in May 2014 to October 2016 (Australia Department of Foreign Affairs and Trade, 2016c, p. 6). The driver for the Interim Skills and Development Facility was to address immediate skills demand (Australia Department of Foreign Affairs and Trade, 2013b, p.1). As an activity with a short period for implementation it was shaped in how governance structure and personnel were allocated. At the same time, it was a realistic approach because it would be nigh impossible to expect it to have met all outcomes within a year or so. The transition of the TVET into the Interim Skills and Development Facility suggests the intention for the latter to be a placeholder mechanism. This was a goodwill gesture on behalf of the donor but was based on some lessons learned and an element of hesitation to re-join the main activity in the education sector. A donor participant commented:

"As a development partner we had some serious conversations with Tonga regarding the education sector and Australia had that serious conversation with Tonga as well. However, at the time of the High-Level Consultations, Australia remained in the education sector despite some initial hesitations" (Participant H, June 2018)

In the 2013 performance report, the Technical and Vocational Education and Training Program Phase I was reviewed. The review, following Organisation for Economic Co-operation and Development aid effectiveness evaluation criteria, found it "unsatisfactory" (Australia Department of Foreign Affairs and Trade, 2012, p. 6). By way of programming, the 'Interim Skills and Development Facility' appears to have been designed simultaneously with the Tonga Education Support Program Phase II. It did deliver some results with " 54 places for women in new horticulture courses and a further 25 places for women and men in agriculture courses" (Australia Department of Foreign Affairs and Trade, 2015c, p. 5). 
A couple of important programming themes are implied between the TVET and the Interim Skills and Development Facility. One theme relates to programming an activity but based on the lessons learned from a similar activity. This is highlighted in the design document of the Interim Skills and Development Facility:

"a commitment for on-going support to the TVET sector in Tonga it was proposed that an Interim Skill Development Facility be established (under a direct contracting model) to address immediate skill demand identified in the labour market study (March 2013)" (Australia Department of Foreign Affairs and Trade, 2013b, p.1)

Consultation with the Government of Tonga and the relevant Ministry is another theme when an Activity is considered. As an informant attests to in an interview:

"The consultation was very useful in a sense it already provided information what the funding wanted to achieve as well as the priority within the period" (Participant $U$, June 2018)

Context is equally important for an activity such as the TVET and Interim Skills and Development Facility. For the Interim Skills and Development Facility context in this regard refers to 'policy context' which is expanded in the design document (Australia Department of Foreign Affairs and Trade, 2013b). The successor to the TVET and ISDF is the Tonga Skills program which began in 2016 and ends in 2021 (Australia Department of Foreign Affairs and Trade, 2016d).

The Tonga Education Support Program - Phase 2 or TESP 2 - was a tripartite arrangement between Australia, New Zealand, and Tonga. Phase Two is described as improving student learning outcomes and teacher quality, access to education, and performance assessment framework, development of a Unified Grant System, and an Inclusive Education (IE) scoping report (Australia Department of Foreign Affairs and Trade, 2014c, p. 9). At the time, all three governments in the tripartite arrangement, observed implementation constraints with the Phase One program. It was found that:

"a complex mix of causal factors that have led to unsatisfactory performance against almost all of the AusAID OECD/DAC evaluation criteria" (Australia Department of Foreign Affairs and Trade, 2012, p. 6)

These constraints do appear to have echoed aspects of the lack of appreciation to Tonga's development landscape. However, during the design process the lessons learned were taken into consideration: 
"Result Framework took a while to design and two different experts were hired. Consultation was with the Ministry of Education and assisting as much as possible, promoting ownership" (Participant U, June 2018)

The education sector presents many competing dimensions and reflects also Tonga's development landscape.

When TESP II 2015 was reviewed, the development landscape as an important differentiating factor is acknowledged (Australia Department of Foreign Affairs and Trade, 2015e, p. 1). The review outlines important aspects relating to development landscape when considering aid programming. Below are three key points from the review of TESP II in summary:

- Context in which TESP II was designed was very different from TESP I.

○ Development Partners changed and institutional, regulatory, and political reform occurred from the Tonga side (p.1)

- Design ambition

- Realistic parameters on Human resources, availability of skills, and timeframe

- Adaptation to situational change

- A reoccurring theme throughout but TESP II need to be more flexible to changes during implementation and the nature of the changes

(Australia Department of Foreign Affairs and Trade, 2015e, pp. 1-2)

The points the review raises echo circumstances found in many other activities within the Country Programmable Aid of Australia. Context in this case of the sector, the design and what to include, and what happens when the situation changes.

The Australia Awards are aimed at developing Tonga's leadership and management capacity across development priority areas (Australia Department of Foreign Affairs and Trade, 2019). The 'Awards' come in the form of scholarships to the regional institution, the University of The South Pacific, or universities in Australia. What is a distinctive feature of the Australia Awards, relative to its sister activities, is how development contribution is measured almost solely according to completion rates. Arguably more should be done to link the program with the development needs of Tonga after students complete their studies. Assessing and categorizing the awards as 'an achieved outcome' upon completion of a qualification - whatever it might be - is a premature and inadequate assessment of their meaningful impact on Tonga's development. Despite this weak explicit link to Tonga's development priorities, scholarship schemes, such as the Australia Awards, are popular for donors for several reasons. Most of the funds spent are spent within the donor's economy (on fees, 
accommodation etc), awards schemes are straightforward to administer and the 'achieved on qualification completion' approach can yield timely and concrete evidence of supposed activity success.

The experience of one participant reflects the doubts about scholarships contributing to Tonga's development. On returning after completing a scholarship, the participant reflected:

"Sad to say I have been side-lined and told to come and do research but there is nothing being done officially for research. I personally think I am not given that officially because I have not been given my job description, but my official title oversees policy and planning, that is when I came back to the Ministry in 2006. They thought if you had a PhD you are overqualified to go back into the classroom, so I was brought to the policy and planning division. This was my first introduction to the projects and learning on the job. The current director told me to come and take care of the research division" (Participant U, June 2018)

As voiced by several informants in interviews, there are three scenarios a scholarship recipient returns to in Tonga. One is unemployment and another is employment with the Government of Tonga due to being processed via the closed application channel. Lastly, there is the outcome of migration after completing the two-year bond which is the duration a recipient is expected to stay in Tonga. The closed application channel refers to applicants who were selected on the basis they will return, having been secured prior employment for the Government of Tonga, to the Ministry. This is to ensure the Ministry utilises the 'skills and experience' ascertained from the degree program. One participant remarked somewhat cryptically:

"The Scholarship Program is highly administrative but interesting because of the process" (Participant H, June 2018)

The last contractual mechanism, the two-year bond, is a supposed development safeguard to ensure graduates return to Tonga. This mechanism presumes, but with no real practical work plan evident, that returnees will immediately contribute to the development of Tonga. It assumes that a tertiary education equates to automatic progress and development of the nation. The pressing issue though is that there is not a meaningful and strategic program in place to ensure that meaningful contribution to Tonga's development eventuates. More realistically, this assumption is misleading and creates a seemingly false expectation on the shoulders of those who have completed their studies, the wider community, and stakeholders. In addition to this, no real meaningful monitoring program is conducted after returning other than the occasional alumni events. As an activity, then, the Australia Awards 
suggests that programming can recognise and prioritise short term quantity as a measurement over longer term development impact.

Arguably since 2012 Tonga has participated in Australia's Seasonal Worker Programme (Australia Department of Foreign Affairs and Trade, 2015c, p. 5). This is an interesting topic for analysis. The immediate question that springs to mind is determining the impetus for it which appears to be from lobbying, internally and externally, to the Australian government (Millbank, 2008). Indeed, the financial benefits and the numbers of Tongan seasonal workers participating is worth noting. The pressing dilemma here, in terms of the investment per se, is whether the Government of Tonga maximizes the opportunity relative to the intended economic benefits being proudly proclaimed, on both sides (Fogerty, 2020). At a project leve,I the SWP has an ever-growing mixed development impact on households especially from a moral perspective (Gibson and McKenzie, 2011: Gibson and McKenzie, 2014: Ball, Beacroft, and Lindley, 2011). It is possible we can find certain tangible linkages between this component and certain national development priorities of Tonga. Relative to this research, it informs us of the impact, however well intended, a project has towards the means to attaining a level of economic security.

The Tonga Health Sector Support Program Phase I and subsequently Phase II main components are management of Non-Communicable Diseases (NCDs) in primary care - primary and secondary prevention, health promotion related to NCDs, health systems strengthening, support for mental health and disability services (Australia Department of Foreign Affairs and Trade, 2015d, p. 28). Health falls under one of the three pillars that support the national outcomes intended under the Tonga Strategic Development Framework 2015-2025. As such, health as a priority in Tonga's perspective is a multifaceted issue and addressed in organisational outcomes 2.5 to 2.7 under the Social Institutional Pillar -

“Organisational Outcome 2.5: Improved, country-wide, health care systems which better address the medical conditions becoming more prevalent in Tonga so hastening recovery and limiting pain and suffering.

Organisational Outcome 2.6: A stronger and more integrated approach by all parts of society, to address communicable and non-communicable disease, significantly cutting the rate of these diseases and the burden they place upon communities and the economy. Organisational Outcome 2.7: Better care and support for vulnerable people that ensures the elderly, the young, disabled and others with particular needs 
continue to be supported and protected despite shrinking extended families and other changing social institutions..."

(Tonga Ministry of Finance and National Planning, 2015b, p. 19)

The main health issue being addressed here is Non-communicable Diseases. As a development problem the Tonga Health Sector Support Program Phase II design document highlights the project addressing issues in multiple areas. Results included training to the outer islands in health services, the anti-smoking campaign, development of a work health and safety policy for the Ministry of Health, and a pilot program to digitize the Ministry of Health's reproductive health section (Australia Department of Foreign Affairs and Trade, 2017, p. 5). Three areas the investment in the sector aims to strengthen overall is driving an evidence-based application to policy by the Ministry of Health, ability to report progress and analyse it, and gender and social inclusion. From an aid programming perspective, the areas may seem to be too much too soon given the capacity and resources on the ground. Perhaps by way of approach via utilizing stakeholder engagement and taking a lesson learned standpoint, recommendation under the design was to ensure recognition is given to gender, disability, or geographical location (Australia Department of Foreign Affairs and Trade, 2015d, p. 14). Country ownership and systems was also considered to -

"ensure that decisions about resource allocation and the practicalities of implementation will be made by local organisations. This is vital for developing a sustained response to the NCD crisis." (Australia Department of Foreign Affairs and Trade, 2015d, p. 14)

This last point was touched on further by way of answering how the activity should be implemented and governed. Both Australia and the Government of Tonga, based on lessons from the Tonga Health Sector Support Program Phase I, agreed on financing agreement based on high-quality annual plans as the way forward. The Government of Australia signed an agreement with the Ministry of Finance and Ministry of Health as representing the Government of Tonga and a separate Direct Funding Agreement (DFA - what the funding 'contracts' are called) with Tonga Health (Australia Department of Foreign Affairs and Trade, 2015d, p. 31). Health is Australia's largest bilateral funding arrangement with Tonga with AUD16 million over five years (Participant D, June 2018).

The thematic areas of education and health offer perspectives on the development context, the nature of the interaction between the Country Programmable Aid of Australia and Tonga's national development priorities. The two areas each present different needs and situations that Australia has had to work around designing how it delivers its foreign aid and what to include in it. Education and 
health are important development priorities for Tonga and as this section has observed, the investments by Australia do shape and support them. The scale, size, and scope of the investments appear at times hard to manage even with the expertise on the ground. Between 2013 to 2017 nine projects were implemented between education and health with a significant monetary cost. The wider implication for Tonga's development concerning this research is that Australia is willing to support the development priorities. However, it is important to put this support into perspective. That is, domestically in Tonga the support given by Australia is large compared to other development partners. When compared to the region, and the Australia CPA is viewed from the national interests of Australia, their support is proportionate. The returns to Australia from both the scholarship scheme and the seasonal work programme, for example, point to the way Australia's aid for education and health can bring benefits for both donor and recipient. Yet, despite the challenges experienced by the investments in the sector, the development assistance by Australia plays a crucial role in the 'people to people' links which are impactful and meaningful (Participant I, June 2018).

\subsection{Infrastructure}

Australia has invested to increase the proportion of Tonga's population with reliable and affordable links to markets and services (Australia Department of Foreign Affairs and Trade, 2015c, p. 5). These activities included four main investments - the Nuku'alofa Urban Development Program, the Outer Islands Renewable Energy Project, the Tonga Energy Roadmap Institutional and Regulatory Framework Strengthening Project, and the Transport Sector Consolidation Project. According to the Tonga Power Limited website, the Outer Island Renewable Energy Project (OIREP) came into effective in June 2014 and set to conclude at the end of June 2020 (Tonga Power Limited, n.d.). Support to the Infrastructure sector by Australia are implemented in different modalities but reported as Country Programmable Aid.

Like other investments in economic and public sector governance, Australia has selected a model that does not fit the conventional definitional of bilateral arrangements. This is the same with the activities in infrastructure because of the nature of the partnership arrangement. That is:

“Australia's assistance to Tonga's infrastructure sector is implemented through cofinancing agreements with multilateral development banks, due to their comparative advantage in this area." (Australia Department of Foreign Affairs and Trade, 2014c, p. 10)

Figure Seven is a visual articulation of this model, Australia has elected to report investing in infrastructure with activities as bilateral and co-finance with other development partners (Australia Department of Foreign Affairs and Trade, 2014c, p. 10). 
Figure Seven: Multilateral and Bilateral Aid Channels

Multilateral

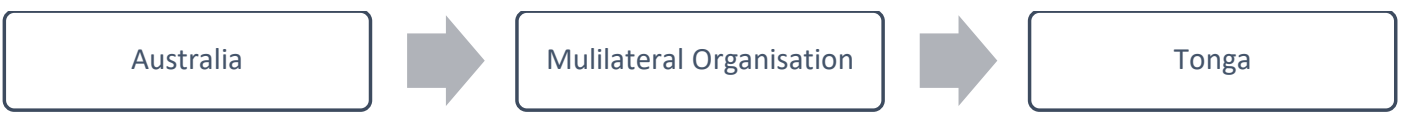

Bilateral

Australia

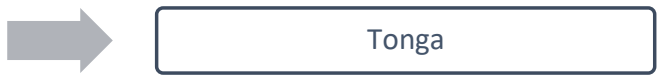

The details as why this model is adopted, or if this type of partnership arrangement was a request by Tonga, are not explicit but inferred by participants. As the following informant articulates:

"Some of the programs that are not managed by the bilateral program are also country specific interventions. So, some of the programs are regional and multilateral to which Tonga is one of the countries involved" (Participant E, June 2018)

Furthermore:

"It is different for different projects, but we have the OIREP projects which got multiple donors. It's got Asian Development Bank, it's got DFAT, GEF, EU, but the head management is through ADB, so they collect the funds and they manage the delivery of the project. They become the point of contact for us and follow all of their procurement rules, so we follow all the guidelines." (Participant L, June 2018)

Using multilaterals and regional modalities have their strengths and weaknesses relative to bilateral programming. This context is important to understanding the nature of the partnership arrangements. Transnational issues to which Tonga encounters is an example where regional would be used. Other reasons are hinted above as being operational and functional where the line ministries may not have the resources or expertise and a third party (i.e. ADB) are used for project management.

However, we should also note that this type of funding arrangement with bilateral donors and multilateral agencies working together, co-funding large programmes, is consistent with the Harmonisation principle of the Paris Declaration. The 'lead donor' mechanism, whereby one donor (in this case the ADB) co-ordinates the others and heads the interaction with the host government, makes for a more efficient aid delivery model and the Government of Tonga does not have to negotiate with several different donors, and use their different systems, for one activity. 
Another infrastructure activity was the Transport Sector Consolidation Project and it focused on four goals, namely it:

"strengthens policy, planning and institutional arrangements for the transport sector, improves safety and security for air and sea transport, and builds domestic private sector capacity to undertake road maintenance activities" (Australia Department of Foreign Affairs and Trade, 2014c, p. 11)

As an activity the four goals encountered three primary challenges: issues in implementation; disbursement of tranches; and reporting (Australia Department of Foreign Affairs and Trade, 2014c). Each of the three primary challenges have unique and overlapping dimensions about them. For example, the implementation stage in this case is coordinating with the relevant agencies, whether they are stakeholders or a contractual party, into how to action the goals or outputs. During this stage monitoring then evaluating the project is led by the co-financiers, Australia and the World Bank. They rely on the partners to report back on implementation with the understanding that the reports, after meeting certain criteria in content, triggers the tranche payment. This is referenced by an informant who acknowledges a role for donors in this regard:

"there are some things we could do to help and supporting the upgrade of information management system in the Ministry. That is a small thing to make a little bit of difference. Working in a coordinating way also helps" (Participant O, June 2018)

This example demonstrates how coordination between Australia and Tonga can work together to implementing an activity toward supporting the national development priorities.

The project existed in a context of constant restructuring of the relevant ministry. When the Transport Sector Consolidation Project was first effective back in 2008, it was housed under the Ministry of Transport (World Bank, 2019, p. 7). During the time of its implementation it went through three different 'houses' - Ministry of Transport, Ministry of Infrastructure, and Ministry of Infrastructure and Tourism. This also meant it went through the same number of different ministers. This required restarting at every change to the new ministry structure - the working relationships, commitment to priorities, management of expectations, and a general brief to keep the minister up to date. From the perspective of this research, one key theme here is that Tonga is always trying to accommodate how it sees fit the national development priorities. This is whether that re-orientation or re-interpretation they perceive fits with current and existing bilateral partnership arrangements. From a different perspective the changes and the project itself still fell under the overall national development priority. 
The nearest fitting priority was: "National Outcome E. a more inclusive, sustainable and successful provision and maintenance of infrastructure and technology" (Tonga Ministry of Finance and National Planning, 2015b, p. 18)

Similarly, the disbursement of tranches and reporting have distinctive but interconnected dimensions. Tranche payments depend on the conditions being met by the recipient, in this case Tonga. The implementation dimensions - timeline, budget, coordination, aid modality - act as an example of the multifaceted matters that need to align. There does exist an appetite for risk and recognition that issues are bound to arise. The important process to follow explained further:

"We have an Annual Financial Acquittal and a Quarterly Acquittal. The latter must be signed by the Minister, but the Annual Financial Acquittal is what we rely on for the tranche payments. This document articulates if the tranche is needed for expenses" (Participant G, June 2018)

Together with the example of coordination mentioned in the last paragraph, this example touches on tranche payments triggered by reporting being met. From a collective standpoint, the harmonisation principle is supposed to streamline and create efficiency.

Country Programmable Aid by Australia in the infrastructure sector also demonstrates the aid effectiveness principle of alignment. As an investment the Nuku'alofa Urban Development Project seeks to:

"improve the policy environment for urban planning and the availability of water supply and solid waste management services in Nuku'alofa." (Australia Department of Foreign Affairs and Trade, 2014c, p. 11)

Australia reports on the outcomes it has achieved and how the project makes a good linkage with the national level plan: the Tonga National Infrastructure Investment Plan II. The Asian Development Bank led this project and seems to have achieved some positive outcomes. These outcomes included improvement in solid waste collection services, purchase of equipment such as septage tanker and two waste collection trucks, water meters, and some policy strengthening initiatives (Australia Department of Foreign Affairs and Trade, 2014c, p. 11).

The Nuku'alofa Urban Development Project had many familiar structures and systems put in place under the agreement between the parties. With differentiation between the executing and implementing agency - Ministry of Finance and the National Spatial Planning Authority Office respectively - the creation of a Project Steering Committee aimed to provide "strategic direction, 
guidance, and oversight of the project", and an executive role in the form of a project manager - in this case the Chief Operating Officer of NSPAO - to carry out project management duties (Asian Development Bank, 2015, pp. 11-12). The project also added two, perhaps extra strengthening measures: structures in the form of a procurement tender committee and implementation assistance consultants (Asian Development Bank, 2015, pp. 11-12). These systems and structures whilst designed to ensure that project outcomes are guaranteed, they also have an impact on Tonga's ability to articulate what it perceives as being a priority.

The Nuku'alofa Urban Development Project investment had six planned outputs which were:

- Output 1: Strengthened policy environment for delivery of urban services.

- Output 2: Effective, efficient, and sustainable water supply services in Nuku'alofa.

- Output 3: Sustainable solid waste services in Nuku'alofa.

- Output 4: Other municipal services within Nuku'alofa.

- Output 5: Raised community awareness of municipal services

- Output 6-Effective project management.

(Australia Department of Foreign Affairs and Trade, 2016e, pp. 20-24)

By 2015 the six outputs were in general making satisfactory progress and meeting the expectations from the parties involved (Australia Department of Foreign Affairs and Trade, 2016e, pp. 20-24). From the standpoint of Tonga's national development priorities, this investment strengthened national outcome B "a more inclusive, sustainable and balanced urban and rural development across island groups" and E "a more inclusive, sustainable and successful provision and maintenance of infrastructure and technology" (Tonga Ministry of Finance and National Planning, 2015b, p. 18). The basis of the activity aimed to improve policy in urban planning, availability of water, and increase access to waste management services which arguably it has achieved some positive and tangible success.

Progress under the activity indicates aspects for greater examination. Development outcomes need effective coordination and engagement from Tonga in the governance mechanisms at senior officials' level to eventuate. Aid programming here manifests in this investment through assurance via the application of multiple and strategic outputs. Whilst the 2013 and 2014 iteration results came in the form of equipment and figuring out the suitable system to be in place, the 2015 situation built on that. The necessary parties and stakeholders were engaged with the standard bureaucratic processes and 
adherence. Time is an important factor to consider. One crucial element under the definition of sustainable development provided by the Tonga Strategic Development Framework is "development that meets the needs of the present" (Tonga Ministry of Finance and National Planning, 2015b, p. 15).

The World Bank-led Tonga Energy Roadmap Institutional and Regulatory Framework Strengthening Project is an Activity aimed to provide:

"a 'least cost approach' implementation plan to reduce Tonga's vulnerability to oil price shocks and achieve an increase in quality access to modern energy services in a financially and environmentally sustainable manner." (Australia Department of Foreign Affairs and Trade, 2014c, p. 12)

The Tonga Energy Road Map Institutional and Regulatory Framework Strengthening Project also made some progress in 2014. Most evident being the determination and strengthening the regulatory environment most suitable for Tonga. This includes the area of renewable energy, energy efficiency, and energy access. The project also met some significant delays. A review published in 2015 echoed progress to be made:

- Capacity gaps in institutionalising TERM-IU into the newly created DoE while guarding against establishing unsustainably large government departments.

- Capacity to ensure progress on TERM-IU Director's responsibilities.

- Weak project, fiduciary and risk management capacity to deliver Phase 0 Activities.

- Adjusting energy targets to be achievable.

- Risks with recipient-executed Trust Fund instrument for capacity-constrained agency.

- Importance of robust policy frameworks which will allow Tonga to clearly establish and articulate their solution to economic, environmental and social problems.

- Stronger awareness campaigns and continuing to promote strong stakeholder coordination.

- Harmonising energy and climate change policy.

- Ensuring sustainability of funded assets.

- Addressing energy issues in the transportation sector.

- Explicit recognition of private sector participation if RE targets are to be met by 2020. 
- Ensuring government's role is focused on policy issues, rather than implementation.

- Presenting a more detailed achievement target on RE, EE and Access to electricity annually, until the year 2020 based on current and forecast project pipeline, by the new Department of Energy.

- Integration of TERM, along with this TERM Review Report into the new DoE Corporate Plan.

(Source: Pacific Centre for Renewable Energy and Energy Efficiency, 2015, p. 3)

Indirectly the activity made good progress in the energy sector despite being heavily focused on policy. For example:

"Tonga has achieved a lot, we have connected between the villages and we have connected $25 \%$ people that were not beforehand and we have got a cyclone resilient grid, if we had not done that we still might have been working without electricity after cyclone Gita, it has saved us so much" (Participant M, June 2018)

From a more national level and strategic point of view this activity is an example of the principle of ownership, arguably this project reflects Tonga's commitment to driving the agenda on energy as a national development priority. Between the parties a level of commitment must be demonstrated by the recipient towards a priority they perceive is of national importance. In this case energy and the Tonga Energy Road Map acts as an assurance to the donor pertaining to their funding.

The priorities within the energy sector remained and to an extent were still championed as before, however Lord Tu'ivakanō at times did question the logic (Radio New Zealand, 2014a) of the investment. The intention of the project was to promote sustainable energy production but most public concern in the sector concerned perceived high electricity tariffs. This is shared by views on how it can be to manage expectations specific to the infrastructure being built and the correlation to electricity prices:

"It is challenging for us to explain in terms of renewable and how much that is in reducing tariff. I think over the years for us because I think we have communicated a lot more we have had a lot more exposure in how we benefit in terms of the projects because they see how hard we work and they are also seeing other benefits through the projects and I think it is a good balance right now" (Participant N, June 2018)

Much funding, including Tonga's own resources, were being poured into renewable energy but it was perceived that this had little or no impact on lowering electricity tariffs. This ties in with the issue of 
expectations. Expectations are managed effectively when stakeholders are open and realistic on the outcomes of the activity together with a clear demonstration on the work carried out.

The Outer Islands Renewable Energy Project or OIREP is an activity that aligns with the Tonga Energy Road Map Institutional and Regulatory Framework Strengthening Project. Together both activities link well with the national development priority for Tonga in the energy sector. The Outer Islands Renewable Energy Project "supported on and off-grid solar installations for nine outer islands, to increase energy access and energy efficiency" (Australia Department of Foreign Affairs and Trade, 2015c, p. 7). Again, we can see from the Grant Agreement and the Project Agreement between the Asian Development Bank and the Government of Tonga the similar contractual format. Differentiation between the contracting agency - Tonga Ministry of Finance, the support agency - TERM Agency, and the implementing agency - Tonga Power Limited (Asian Development Bank, 2013a, p.1). The main drive behind this contractual make-up is at the most part an appreciation for the development context on the ground around functionality and operation. Tonga Power Limited in this instance has the capacity for implementation but from a policy directive and national development standpoint, the Tongan Government is the contractual partner. This points in part towards a deeper understanding of the issues the principles of harmonisation and mutual accountability raise. Specifically, clause 32 to 35 of the Paris Declaration harmonisation states that parties should attempt to strike a balance between: 'donors implement common arrangements and simplify procedures' and 'complementarity: more effective division of labour' (Organisation for Economic Co-operation and Development - The Paris Declaration on Aid Effectiveness and the Accra Agenda for Action, 2005, p. 6).

\subsection{Conclusion}

Each of the five themes examined in the Country Programmable Aid of Australia show varying aspects of the relationship with the national development priorities of Tonga. Whilst the activities are targeted and specific in nature, the implementation challenges and outcomes achieved offer a helpful understanding towards actioning the aid effectiveness principles in this context - between Australia and Tonga. We observe that there exist different dimensions of the aid effectiveness principles, such as what the alignment of priorities looks like between an activity and a development outcome. Change on the ground and time are also factors to consider, with the Economic and Public Sector Governance themes highlighting this point. This chapter has shown a factor to acknowledge alongside the Country Programmable Aid of Australia, national development priorities of Tonga, and aid effectiveness principles is development landscape.

Specific to the make up and nature of the Country Programmable Aid is the functional and operational elements inferred by the different sections. Australia has applied a mixture of both bilateral 
arrangements and multilateral arrangements. This research finds the latter the most intriguing from a functional viewpoint. The JPRM and the OIREP are examples. Australia demonstrates it is willing to contract an implementing agency, in most examples ADB and WB, to contract, monitor and evaluate, project manage, and provide the grant with Tonga. To do so is decided on a case by case approach by Australia with criteria being state of the sector, timeframe, risk appetite, and lessons learned. There does not seem to be a clear indication in the documents (or expressed by participants) reported by Australia, Asian Development Bank, World Bank, and Government of Tonga whether Tonga opted for this modality. Overall between 2013 to 2017 the CPA of Australia attempts to cover key sectors to align with the national development priorities articulated by Tonga.

The Paris Declaration on Aid Effectiveness principles are a paradigm shift, particularly on entertaining the idea of a partnership towards the delivery of aid (Dabelstein, Niels, and Patton, 2013). Taking into consideration what is implied in the programming of activities listed in Table Nine is that ownership requires a consolidated approach. Its absence causes to a degree different misalignment at the operational level between outputs and their intended outcomes. Ownership is reflected in consultations and the input of content by Tonga which is exemplified by this interviewee:

"Consultation was carried out with the Government of Tonga and a face to face presentation. The idea behind it was for promoting ownership and Government to lead in the bulk of it" (Participant A, June 2018)

In line are consultations concerning assessments, monitoring and evaluation, reviews, and evaluations just to name a few touched upon. The extent to which Tonga drives and owns this space is hard to ascertain exactly but aspects of ownership are reflected to an extent. The variables for harmonisation are challenging to attain - the absence of a Coordinator at the Tonga Ministry of Education pertaining to TESP Phase II or the bureaucratic process the donor official needs to follow, for example. Lack of results and vague mutual accountability, by way of it being actioned may fracture the partnership intended under the aid effectiveness principles.

Arguably, and perhaps the most significant principle, ownership holds a vital role. Leadership in Tonga is being examined and tested. Civil Servants are burdened with coming up with important strategic policies and owning them. This is in a working environment without a clear direction at the highest level. The situation implies an environment where policies are conjured but misalign with the resources available. At times, and troublingly becoming more often, they are given directions contradictory to the legal regulations in place. The leadership that seems to be floated is inadequate, a shadow of its intentions, and found wanting in many strategic and pivotal areas of statesmanship. An effect of this sort of environment only breeds and reinforces the status quo. Accordingly, if the 
status quo represents embracing incompetence and nurtures fear towards due diligence then sadly this translates into more development agitation. This interpretation is on both parties - Australia and Tonga. 


\section{Chapter Six: New Zealand Country Programmable Aid to Tonga}

\subsection{Introduction}

The purpose of this chapter is to examine the relationship between the Country Programmable Aid of New Zealand and the national development priorities of Tonga under the Paris Declaration on Aid Effectiveness. Between 2013 to 2017 the New Zealand aid programme continued with the organisational arrangements and regional and thematic foci that were put in place after 2008 (Spratt and Wood, 2018, p. 25). This chapter firstly examines this context for the New Zealand aid programme then looks in turn at the key thematic areas of New Zealand aid activities in Tonga in 2013-17, namely energy, law and justice, education, tourism, agriculture and fisheries and economic governance. Throughout we will see some similarities, overlaps and cooperation with the Australian programme but also some important differences.

\subsection{The context of New Zealand aid}

Over the period 2013-17, the New Zealand aid programme was characterised by a period of continuity with a single administration in power (the Key National-led government, which had been elected in 2008 and returned to power in elections in 2011 and 2014) and a single minister, Murray McCully who directed the aid programme through his role as Minister of Foreign Affairs. Only in late 2017 did things change with the election of the Ardern-led Labour-NZ First coalition, with Foreign Affairs Minister Winston Peters. However, this change did not affect policies on the ground in Tonga until later.

The Key government introduced some major and rapid changes to the New Zealand aid programme following its election in 2008 but these were well-embedded by 2013. Prior to the changes the New Zealand Aid Programme operated through a semi-autonomous agency, known as NZAID. The context behind the changes derive from the Minister of Foreign Affairs and Trade, Murray McCully taking "an active interest in the New Zealand government's aid programme" (Spratt and Wood, 2018, p. 25). McCully oversaw several critical changes particularly during 2009 (Banks et al 2012), in line with what some have termed a 'retroliberal' paradigm for aid (Murray and Overton 2016: Mawdsley et al 2018). NZAID was dis-established and re-integrated back into MFAT, the poverty alleviation focus of the previous near decade - closely aligned with the MDGs - was replaced with a new priority for 'sustainable economic growth', relationships with NGOs were changed so they came into line with the new approach, there was a stronger focus on the Pacific Islands region, and a more explicit statement of aid supporting New Zealand's wider economic and strategic interests (see Banks et al 2012; 
McGregor et al 2013; Spratt and Wood, 2018). However, despite the effects of the Global Financial Crisis of 2007-08, aid volumes were not reduced by the new government.

Figure Eight shows New Zealand's ODA disbursements, as reported to the OECD and allowing for inflation, from 2000-2018 (this can be directly compared with Figure Six for Australia). After 2008, real aid volumes increased, except for a drop in 2013 and small falls in 2015 and 2016. Also, unlike Australia, the Pacific region dominated the New Zealand portfolio, not so much (as with Australia) Papua New Guinea as the largest country in the region but more a wider range including New Zealand's constitutional and historical ties with countries such as Cook islands, Tokelau, Niue and Sāmoa. Similarly, Tonga figured more prominently for New Zealand, accounting for between 3 and 5 percent (growing from \$US 12.2 mill in 2013 to \$US17.7 mill in 2016) of its total ODA budget, before falling in 2017 to 2.3 percent and \$US 8.3 mill. We can conclude that the context for New Zealand aid to Tonga over the period (at least up to 2016), then, was one of stability and rising budget allocations. The Pacific, and the smaller countries of the Eastern Pacific, were firmly on New Zealand's aid and strategic agenda.

Figure Eight: New Zealand ODA Disbursements by Region 2000-2018 (\$US mill constant \$2018)

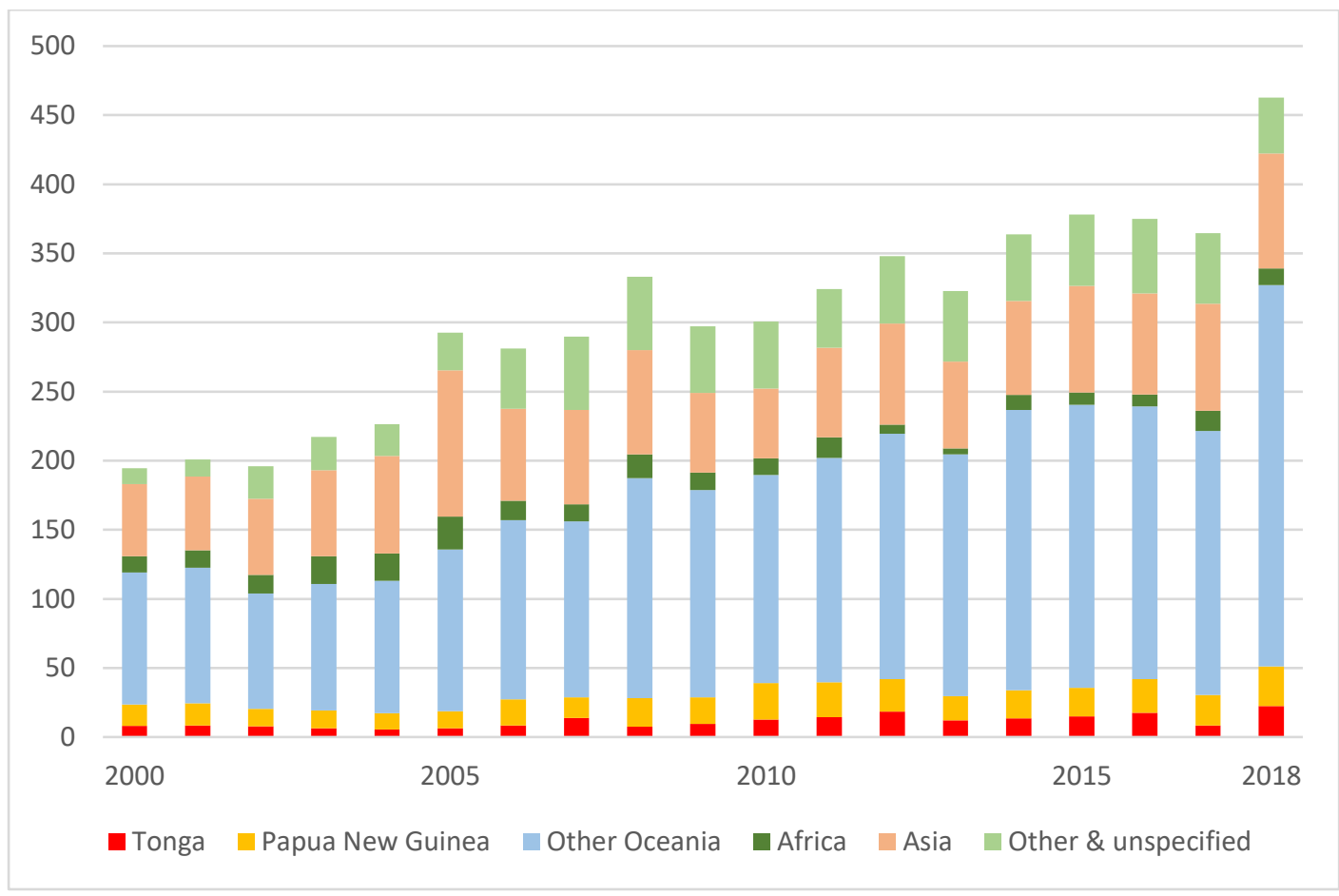

Source: Source: Organisation for Economic Co-operation and Development: Stat (https://stats.oecd.org/\#) accessed 5 September 2020 
The Country Programmable Aid we are to focus on in this research exists within this political background. As well as these aid allocations, the New Zealand programme had developed some key policy documents to guide its aid priorities and relationships. There were two strategic plans for the aid programme during the period, one covering the years 2012-15 (New Zealand Ministry of Foreign Affairs and Trade, 2012) and 2015-19 (New Zealand Ministry of Foreign Affairs and Trade, 2015a). The two plans were substantially similar and laid out the government's priorities with regard to economic development (covering agriculture, fisheries, tourism and energy in particular). These plans were augmented by a further layer of policy documents including International Development Policy Statement Supporting Sustainable Development (New Zealand Ministry of Foreign Affairs and Trade, 2011a) and the aid 'Investment Priorities 2015-19' (New Zealand Ministry of Foreign Affairs and Trade, 2015b).

In the strategic plans, the policy statement and investment priorities documents, New Zealand took a thematic focus which positioned investment in economic development, promoting human development, improving resilience and responding to disasters, and building safe and secure communities. The Strategic Plan 2015-19 and Investment Priorities 2015-19 refined these further with a principle of 'Pacific focus, global reach'. The 'investment priorities' spelled out a list of 12 favoured activities:

- Renewable Energy

- Agriculture

- Information and Communications Technology

- Fisheries

- Tourism

- Trade and Labour Mobility

- Economic Governance

- Law and Justice

- Health

- Education

- Resilience

- Humanitarian response

(New Zealand Ministry of Foreign Affairs and Trade, 2015b, p.11 -15)

Of these, the first two - renewable energy and agriculture were given 'flagship' status, indicating a higher level of priority. It is also worthy of note that two examples from Tonga were used, alongside 
others, to illustrate these priorities. The 'Tonga Village Network Upgrade Project' was included as one of three examples under the flagship 'energy' heading ("upgrading power distribution to 50 villages across Tongatapu to reduce network losses and make the network safer through a \$28 million, fiveyear project") and the 'Tonga Police Development Programme' appeared under the 'law and justice' heading ("a \$12.8 million, five-year programme in partnership with the Australian Government to strengthen professional skills of Tongan police officers and improve leadership, policies, processes and systems") (New Zealand Ministry of Foreign Affairs and Trade, 2015b, p.9). So, we can see that aid activities in Tonga figured quite prominently in, and matched the priorities of, the New Zealand aid programme in the period.

The importance of Oceania - and Tonga - for New Zealand was recognised by participants from the New Zealand side. One interviewee noted, with Tonga in mind, that "there are constant changes at the bilateral level and is a sophisticated country in the Pacific" (Participant Q, June 2018) and another commented that "the Pacific is our community and New Zealand" (Participant P, June 2018).

The higher level documents and statements were supported by more operational agreements and processes. New Zealand entered into an agreement with Tonga in the 2011 Joint Commitment for Development (JCfD) (New Zealand Ministry of Foreign Affairs and Trade, 2011b). The Joint Commitment for Development 2011 was the overarching arrangement the two countries agreed upon and it outlined which development priorities took precedence for the aid programme. The Joint Commitment for Development also signalled priorities are articulated through relationship mechanisms and aid institutions. Personalities also played a factor in how the high-level consultation and arrangements eventuated because they informed and held a lot of internal influence, especially on articulating national development priorities (Fuchs and Richert, 2018; Alesina and Dollar, 2000). This is important not only from a relationship mechanism lens but also with regard to the importance of engagement:

"Getting the policy settings right and getting alongside Cabinet Ministers at a person to person level to encourage what New Zealand perceive as rational policy choices" (Participant S, June 2018)

In terms of thematic priorities, New Zealand's aid assistance to Tonga has been relatively consistent over the long run but broad in sectoral scope since the 1960s and well into the 2000s (Needs, 1988; Campbell, 1992; Campbell, 2001). Agriculture and forestry, private sector development, tourism, law 
and justice, education and scholarships, transport and disaster relief consistently feature in the aid programme (New Zealand Ministry of Foreign Affairs and Trade, 2015a, p.11 -15). Energy was added in 2011, with the construction of the Maama Mai solar power farm. In 2016 the new Joint Commitment for Development added 'improved economic governance and public support sector performance' (New Zealand Ministry of Foreign Affairs and Trade, 2016c, p. 1). In this chapter we will look at these sectors the New Zealand Country Programmable Aid prioritized relative to Tonga's Strategic Development Framework Phase I and Phase II.

The analysis will approach the New Zealand Country Programmable Aid and will reflect on thematic priorities. That is, the analysis is on the thematic priority mostly but will unpack the investment because, as we have seen earlier some project timelines mismatch with the timeframe of this research. The New Zealand Country Programmable Aid from 2013 to 2017 provides a wealth of detail in engagement, project cycle, delivery, and outcomes. The thematic approach in examining the Country Programmable Aid offers a different angle and insight. For example, Tonga under the years covered in this research has two different but consecutive national development documents: nine Outcome Objectives in the 2011 to 2014 Tonga Strategic Development Framework and seven national outcomes conveyed in the Strategic Development Framework 2015 to 2025.

In 2016 the New Zealand Ministry of Foreign Affairs hired Adam Smith International to carry out the Evaluation of its aid programme to Tonga, particularly the bilateral component. The evaluation program gives insight into the monetary figures New Zealand provided Tonga between 2011 to 2016 below:

Table Ten: New Zealand aid programme funding to Tonga between 2011 to 2016

\begin{tabular}{|c|c|c|c|c|c|c|c|c|c|c|}
\hline \multicolumn{11}{|l|}{ FAP - 2011/12 to $2015 / 16$} \\
\hline & \multicolumn{2}{|c|}{$2011 / 12$} & \multicolumn{2}{|c|}{$2012 / 13$} & \multicolumn{2}{|c|}{$2013 / 14$} & \multicolumn{2}{|c|}{$2014 / 15$} & \multicolumn{2}{|c|}{$2015 / 16$} \\
\hline Bilateral & Funding & Activities & Funding & Activities & Funding & Activities & Funding & Activities & Funding & Activities \\
\hline Investing in Economic Development & $14,628,195$ & 6 & $3,536,897$ & 5 & $8,765,432$ & 9 & $7,054,684$ & 7 & $8,983,000$ & 9 \\
\hline Promoting Human Development & $4,938,579$ & 3 & $3,479,471$ & 3 & $4,353,000$ & 4 & $5,479,792$ & 4 & $2,400,000$ & 4 \\
\hline Building Safe and Secure Communities & $1,703,839$ & 2 & $2,362,310$ & 2 & $2,512,704$ & 3 & $3,114,123$ & 2 & $3,200,000$ & 2 \\
\hline Multi Sector Activities / Other & 696,517 & 3 & 387,758 & 3 & 0 & 0 & 0 & 0 & 0 & 0 \\
\hline Total bilateral & $21,967,130$ & 14 & $9,766,436$ & 13 & $15,631,136$ & 16 & $15,648,599$ & 13 & $14,583,000$ & 15 \\
\hline & & & & & & & & & & \\
\hline \multicolumn{11}{|l|}{ Non-bilateral } \\
\hline Tonga Transformational Programme & 0 & 0 & 0 & 0 & 0 & 0 & 0 & 0 & 850,000 & 2 \\
\hline Humanitarian & 99,750 & 1 & 146,553 & 1 & 211,491 & 1 & 120,000 & 1 & 150,000 & 1 \\
\hline Pacific Economic Development & $1,332,303$ & 15 & $2,553,527$ & 19 & $3,504,673$ & 16 & $2,813,631$ & 10 & $1,724,142$ & 20 \\
\hline Human Development & $2,138,167$ & 15 & 898,273 & 11 & $1,243,562$ & 14 & $1,033,412$ & 5 & 596,960 & 3 \\
\hline Pacific Regional Agencies & & & $1,233,639$ & 8 & $1,365,262$ & 7 & $1,295,388$ & 7 & & \\
\hline Partnerships & $2,042,794$ & 15 & $2,674,179$ & 22 & $3,358,360$ & 26 & $5,224,265$ & 17 & $2,305,445$ & 15 \\
\hline Scholarships & $2,908,481$ & 3 & $3,166,191$ & 4 & $3,949,845$ & 3 & $3,787,017$ & 3 & $3,200,000$ & 1 \\
\hline Energy, Infrastructure and Environment & & & & & & & & & 632,372 & 3 \\
\hline Pacific Transformational & & & & & & & & & 84,734 & 1 \\
\hline Pacific High Commission/Embassy Fund & & & & & & & & & 74,667 & 1 \\
\hline Total non-bilateral & $8,521,494$ & 49 & $10,672,362$ & 65 & $13,633,192$ & 67 & $14,273,714$ & 43 & $9,618,320$ & 47 \\
\hline TOTAL (ALL PROGRAMMES) & $30,488,624$ & 63 & $20,438,798$ & 78 & $29,264,328$ & 83 & $29,922,313$ & 56 & $24,201,320$ & 62 \\
\hline
\end{tabular}

(Source: New Zealand Ministry of Foreign Affairs and Trade, 2016d, p. 24) 
Table Ten is reflective of the 'International Development Policy Statement' 2011 focus by New Zealand because we can read some of the thematic areas. Another notable feature is that between 2013 and 2017 New Zealand has seen an up and down pattern with the volume of its activities in Tonga. For example, from 2013 to 2014 the number of activities was 83 whilst in 2015 to 2016 it was 62 (New Zealand Ministry of Foreign Affairs and Trade, $2016 \mathrm{~d}, \mathrm{p}$. 33). The number of activities is provided but discerning whether they are bilateral also with other modalities given. The volume of activities also does not reflect the monetary figure on expenditure, outcomes, or performances per activity or as the sum of the bilateral component. Non-bilateral activities, which have ramped up the numbers and spread of activities, tend to involve significantly smaller spending on average than the bilateral activities.

In a way leading up to the latter years, 2015 to 2017, this is one impetus that has forced New Zealand to readapt how it delivers its aid programme. The volume of activities across the years is an indicator of aid proliferation. The adaptation by New Zealand has been driven by several factors but one, which many donors encounter, is due to the increased transaction costs (Acharya, Fuzzo de Lima, and Moore, 2004, pp. 7-8). By association and linked to that from Tonga's side is their capacity to absorb the consequent issues tied with aid proliferation. Tongan officials are assigned according to the donor, not the sector, and so have to manage multiple activities within a sector:

"the main donor that I take care of is New Zealand, but I am back up to Australia and the Japanese aid program as well. So, when officers are away on leave than I have to try and pick up on their work as well" (Participant G, June 2018)

As well as sector one official from the Tonga end can be the focal point for an activity but also multiple donors. This means that the personnel could be responsible for all New Zealand, Australia, and Japan aid irrespective of thematic priority or modality. To an extent this scenario applies to New Zealand as well, for at post (i.e. located in Nuku'alofa) is where most of the operational work for each activity is conducted. The skills, local knowledge, and experience provided by Tongans working there are invaluable. The nature of aid programming in this instance not only has investment priorities but also impetus priorities that underline ownership, alignment, and harmonisation. New Zealand has made strides in 2016 to:

"pursue a progressive shift from small, administratively expensive aid projects to larger, higher impact, more comprehensive initiatives." (New Zealand Ministry of Foreign Affairs and Trade, 2016a, p.2) 
Aid effectiveness is implied to have a real impact towards development when it is given time and proper human resources. This quote also indicates that aid effectiveness may be seen in terms of efficiencies gained through scale of operation and thus encourage a move to larger programme-based modalities.

By and large, New Zealand's Country Programmable Aid is also perceived as to complement broader foreign policy and trade objectives by encouraging trade and investment flows between the two countries. This is in line with what is regarded by some as a neoliberal approach to development: "real hope for enhanced development, it is argued, is to become ever more tightly enmeshed in global trade and merging global production networks" (McKay, 2016, p. 39). This is of course not distinct to New Zealand as a development partner. Arguably the aid policy in spirit adheres to this neoliberal economic basis whilst in modality it best fits the neostructural lens where the state plays a central role in dispersing aid, supporting the market and meeting some social goals (Murray and Overton, 2011b). I argue that between 2013 to 2017 New Zealand in Tonga did not follow zealously one development theory but manifests neoliberalism elements together with the neostructualism touched on in the literature review. We better understand New Zealand under both lenses, they encourage the implementation of promising sound economic management together with the promotion of a transparent governance and leadership helping to enhance Tonga's national development aspirations.

The thematic priorities of New Zealand of relevance to Tonga are energy, education, law and justice, tourism, agriculture and fisheries, and economic governance. All of them appear as priorities in the Government to Government arrangement, and the Joint Commitment for Development 2011 and 2016. The priorities were updated and reconfigured between the years, but the fundamental content remained, nonetheless. Each of these is now examined in detail in the following sections.

\subsection{Energy}

From 2013 to 2017 New Zealand had three main areas of investment priorities within the energy sector: energy efficiency via grid upgrade; renewable energy in solar, wind, and biomass; and private sector generation (New Zealand Ministry of Foreign Affairs and Trade, 2016d, pp. 44-48). The grid upgrade by 2013 was a continuation into Stage 2 and was New Zealand's largest investment not only in the sector but within Country Programmable Aid: the Tonga Village Network Upgrade was worth upwards of NZD \$22 million between 2013 to 2018 (New Zealand Ministry of Foreign Affairs and Trade, 2016d, p. 46). Stage One of the Tonga Village Upgrade Network started in 2011 and was completed in August 2013. Stage Two and Three ran from 2013 to 2018. This activity is routinely touted proudly, in some respects justifiably, by New Zealand as the flagship investment to Tonga. The Tonga Village Network Upgrade has connected over 50 villages, more than 7,000 households, and generated an 
estimated savings of up to NZD \$220,000 per year (New Zealand Ministry of Foreign Affairs and Trade, 2016d, p. 46). Energy is perceived as a strength of New Zealand's aid programme in terms of delivery, technical advice, bilateral relationship, and delivering tangible outcomes (Participant T, June 2018).

In the pipeline is the Nuku'alofa Network Upgrade Project which would be the next stage after the Tonga Village Network Upgrade is completed. To guide them deciding on the Nuku'alofa Network Upgrade Project, New Zealand, via the multi-partner mechanism the Pacific Region Infrastructure Facility, carried out a due diligence report in 2016. This due diligence report assessed technical analysis, procurement assessment, safeguards assessment, and an economic and financial analysis (Pacific Region Infrastructure Facility, 2016). Inclusive in the process was the utility and the regulator, Tonga Power Limited and the Ministry of Energy. ${ }^{8}$ These energy efficiency projects demonstrate New Zealand's commitments under the 2011 priority of energy and the 2016 priority of strengthening economic development set out in the Joint Commitment for Developments. Tonga appreciates energy efficiency projects such as the NNUP but is also looking at other areas such as storage (Participant E, June 2018).

New Zealand invested in the Maama Mai Solar Energy Farm project which cost NZD \$9.24 million (New Zealand Ministry of Foreign Affairs and Trade, 2016d, p. 45). Wind and biomass electricity generation are not specific to New Zealand in terms of lead interest but their possibilities were approached along with other development partners. For example, albeit outside the timeframe of this research, as of 2019 through a Japanese grant, Tonga commissioned its first wind farm (Radio New Zealand, 2019). New Zealand did show interest in the activity after commissioning an initial feasibility study (Infratec, n.d.). The feasibility study arguably acted also as an analytical tool providing vital information for New Zealand to make, as much as it can, an objective decision. Under-appreciated at times is how the process of the feasibility study and similar types of contracting is considered commitment but blurs definitions. Implied here is the argument that foreign aid leads to returns to the pockets of donor personnel or companies (Ratuva, 2019, p.59: Anderson, 2011).

Private sector revenue generation comes in the form of a power purchasing agreement (PPA) and private sector investments. New Zealand perceives an opportunity in this regard and has shared this in the open. For example, at the Pacific Energy Conference 2016:

"Up to $11 \mathrm{MW}$ of renewable generation could be provided by independent power producers. Regulatory reform and a donor-supported risk reduction facility are

\footnotetext{
${ }^{8}$ Ministry of Meteorology, Energy, Information, Disaster Management, Environment, Climate Change and Communications (MEIDECC)
} 
planned to enable investment." (New Zealand Ministry of Foreign Affairs and Trade, 2016b, p. 9)

A power purchasing agreement can be defined as "a financing mechanism that state and local government entities can use to acquire clean, renewable energy" (Cory, Canavan, and Koenig, 2009, p.1). The model here is the outsourcing of the generation of power then for that entity, the 'independent power producer', to sell the energy to the utility. New Zealand see opportunities to assist Tonga Power Limited to attract private sector investment in energy infrastructure in Tonga. In the immediate term, New Zealand is maximizing on existing mechanisms through the Pacific Region Infrastructure Facility (PRIF). Whilst Maama Mai was the only activity that was funded in the end, New Zealand in general is collaborative by nature towards Tonga's requests and more importantly its national development priorities.

These areas of support within the energy sector indicate New Zealand has a strong case of alignment at national and working level. Strongly hinted at why this is so, voiced by interviewees, is because the two activities, the Tonga Village Network Upgrade and Maama Mai Solar Farm project, delivered outcomes on time and were managed by an excellent implementing partner, Tonga Power Limited. The following views are expressed in support:

"I think it is positive because the Tonga Village Network Upgrade has had visible outcomes, so I think it is relatively easy for the argument that results are delivered" (Participant N, June 2018)

Over time, from inception to the different stages, the activities have performed satisfactorily or better despite the complex macro-economic and political circumstances on the ground. On its part New Zealand demonstrates a strategic and cautious approach to its commitments in the sector. If we consider the two reports, the due diligence on the Nuku'alofa Network Upgrade project and the wind feasibility, as analytical tools, then as a donor New Zealand wanted to assure itself objectively concerning the investments. At the same time it used these 'potential' commitments to leverage its own self-interests, maximize on information concerning the sector, and effectively demonstrate to Tonga their part under the joint commitment.

From Tonga's end, there were assurances in the same strategic sense but with some limitations and there was no clear explanation as to why. Lack of ownership does not appear to be the issue or as a hinderance given Tonga expand on the priorities in important national documents such as the Tonga Strategic Development Framework I and II together with sector specific frameworks related to energy. Inclusiveness and accessibility as well were adhered to. Tonga was consulted, widely and repeatedly 
during the process, together with being provided the same material as New Zealand. It is reasonable to interpret that the culprit lies in difference of priorities in outcome. For Tonga there is a strong indication that the preferred approach is securing funding, whilst for New Zealand they are, on the surface, about what development outcome is assured. Tonga Power Limited as a result has shown leadership and more than ample capacity. The working relationship in turn will continue to evolve and mature as a partnership with Ministry of Energy/Tonga Energy Road Map (TERM) and Tonga Power Ltd (TPL). This overall aligns well with the national development priority being a solid strategic direction through the TERM goal for $50 \%$ renewables by 2020 , however unrealistic that goal may appear.

A distinctive feature of the energy sector in Tonga is that, unlike the other sectors we encounter, internal fragmentation appears mitigated. The mitigating factor appears to be the joint capacity of the utility and technical knowledge at the Ministry. This factor, the recipient having enough initial administrative capacity, whilst it cushions the negative it also reinforces the positive effects of fragmentation (Gehring, Michaelowa, et.al, 2017). Well established working relationships exist which in a way strengthens and facilitates coordination. A clear line of communication exists, at different levels and in governance bodies, and core roles and responsibilities are not necessarily defined to the letter but are essentially understood. Fragmentation has positive effects with interviewees expressing opportunities to be networking not only for funding but expertise as well, diversity of modalities, and development partners. This section informs us that Tonga and New Zealand enjoy a close relationship in the energy sector driven by the development outcome. This close relationship enjoys the capacity found not only in operationalising in implementing the activity, but the policies applied by the Ministry of Energy. This gives meaning and a strategic purpose.

\subsection{Law and Justice}

The development context that New Zealand supports the judiciary, and equally the Tonga Police Force, derives from strengthening the 2010 constitutional reform (New Zealand Ministry of Foreign Affairs and Trade, 2016d, pp. 55-60). Under the Tonga Strategic Development Framework 2011 to 2014 and 2015 to 2025, the assistance aligns with "Better governance", "Safe, secure and stable society", and "Responsive good governance and strengthened rule of law" respectively (Tonga Ministry of Finance and National Planning, 2011; Tonga Ministry of Finance and National Planning, 2015b). Between 2013 to 2017 New Zealand supported Tonga's national development priorities in law and justice primarily under the Tonga Police Development Programme Phase II and contributes to the salaries of Supreme Court Judges (Participant R, June 2018). 
New Zealand contributes to the salaries of Supreme Court Judges in Tonga (New Zealand Ministry of Foreign Affairs and Trade, 2016d, p. 57). There is a misleading assumption that the Justices of the Supreme Court have never been Tongans but, as Ellem points out, there have been a few, namely 'Ahome'e, Taniela Lasike, Maealiuaki, and Siosiua Kaho (1989, p. 21). Tonga having an independent judiciary, covering all the island groups, is crucial to a well-functioning court system (Maloney, 2007; Vuki, 1995; Kefu, 2005). The impetus for strengthening the Supreme Court also ties in heavily with the characterisation that Tonga is a young democracy. The implication is that it would be prudent for New Zealand to remain engaged in policing and the judiciary to reinforce Tonga's more democratic form of government. At present this holds merit given there would be considerable development risks to the effectiveness of the judiciary if Tonga does not have a well-thought out plan to fill the gap. That is, should New Zealand abruptly withdraw the support, Tonga would not have the institutional and monetary capacity to function effectively. The assumption when weighed under the backdrop of the 2006 riots holds weight but also should build on the political situation since.

The stability of Tonga and the fact of being a young democracy is contingent on interconnected factors including foreign aid. The immediate assumption by outsiders is that because Tonga's monarchy exists and still has executive power it is therefore a less effective form of government compared to a republic. Ratuva (2018) details the plagued leadership of the first elected commoner in Tonga's history becoming a Prime Minister. Others, such as Bogle (2019), attempt at contextualizing the democratic transition and the factors that make or break the two power structures co-existing. Metuamate makes a core argument that Tonga is governed by kinship not Kingship which acknowledges the existing strong historical ties and links (2018). Similarly, Campbell (2019) studies 'the avoidance of conflict' in Tonga from the 1875 Constitution to 2006, and then to the present, as a result of two attributes: the close alignment between culture with the political structure and the role of key people (p.143). Tonga's judiciary does hold an important role within these arguments. In Tonga's case thus far the current monarchy, King Tupou VI, has been more measured and has adhered to norms of transparency, following due process, and the rule of law. On the other hand, as Ratuva lists, Pohiva's government had a Cabinet Minister assault a woman, a Cabinet Minister found guilty of bribery, it has seen Tonga withdrawn from hosting the South Pacific Games, it has allowed construction of a supposed golf course at an environmentally hazardous location, and Pohiva directly hired his son against a breach of existing regulations, to name a few (2018, pp. $205-209)$.

Equally, even in Tonga's history the aristocracy have not risen at times to the leadership as intended by Tonga's most famous 'Hau', temporal ruler, Taufa'ahau Tupou I. Tupou I created the 1875 Constitution (Kefu, 2005). The compelling argument in my view here is that a republic can be just as inept at governing as a constitutional monarchy. To imply tolerating the actions of representatives 
which impact disproportionately on the populous because they are elected is misguided. Tonga's stability is not contingent on foreign aid but rather on Tongans embracing the interconnected factors. Tied to this perhaps more importantly is Tongans with the qualification and experience being maintained in Tonga. The monarchy and other institutions, including the judiciary, for the time being are maintaining civil order. There is hope Tonga is heading in the right direction with the newly selected Tongan as a Justice of the Supreme Court (Matangi Tonga, 2018) and have taken responsibility by funding the Chief Justice's salary. Whilst New Zealand supports Tonga in this important development priority, the latter still has to accept the likelihood this is a finite and unsustainable model of aid programming, namely the salaries of Supreme Court Judges. Should the arrangement end, Tonga will initially have trouble securing the appropriate candidates, whether a Tongan or an expatriate. Tonga is given time, under the Tonga Police Support Program and funding of the judicial salaries, to prepare for the next step. From an aid effectiveness perspective many of the principles apply. Harmonisation is straightforward given funding is deposited to the Tongans with performance-based conditionalities tied to the arrangement. Ownership is placed within the institutional elements in law and justice pertaining to the arrangement and guided by the national development priorities. That is there is a strong alignment of the activity from New Zealand but shaped by Tonga's need and acknowledgement.

The Tonga Police Development Programme Phase II was a five year (2013 to 2018), trilateral programme between New Zealand, Australia, and Tonga. New Zealand committed NZD 14.4 million spread across outputs, advisor roles to build leadership capacity, and salary support for the Police Commissioner and Deputy of Public Prosecutions (New Zealand Ministry of Foreign Affairs and Trade, 2016d, p.59). As noted, the dilemma proposed to Tonga is maintaining capable Tongans in key roles within the sector. Recognition was given in supporting the then Solicitor General who was perceived, given the right individual, as having a key role (New Zealand Ministry of Foreign Affairs and Trade, 2016d, p. 59). Even up to 2017 New Zealand continued to be supportive of the Deputy of Public Prosecutions, a key complimentary role to the Police Programme which ensures that good police work results in competent prosecutions. For the Tonga Police Development Programme Phase II itself there have been significant improvements in the quality of police investigations and prosecutions, a developing Attorney General's office and highly qualified Supreme Court Judges and Chief Justice.

\subsection{Education}

New Zealand, together with Australia, entered a trilateral arrangement with the Government of Tonga, the Tonga Education Support Programme II budgeted at NZD 20.15 million (New Zealand Ministry of Foreign Affairs and Trade, 2016d, p. 49). For New Zealand their impetus and therefore priorities fell under their commitment to strengthen education and workforce skills (New Zealand 
Ministry of Foreign Affairs and Trade, 2016c). Education is important for Tonga under the Tonga Strategic Development Framework II national outcome that empowers human development and gender equality. This activity is the primary support within the sector from New Zealand and runs from 2013 to 2016. From a development context support for education is highly fragmented (New Zealand Ministry of Foreign Affairs and Trade, 2016d, p. 49).

The 2016 Programme Evaluation of New Zealand's Aid Programme to Tonga, mentions for New Zealand alone around seven different activities supporting Education (New Zealand Ministry of Foreign Affairs and Trade, 2016d, p. 49). These in turn are delivered via different modalities separate from the Country Programmable Aid modality. From Tonga's perspective the high volume of different activities relative to one donor builds up pressure on the Ministry of Education to deliver with relatively limited human resources. This was not for a lack of enthusiasm by the Ministry of Education but perhaps a product of the context:

"The challenge in terms of capacity is we would need more human resources on the ground but at the same time meet our commitments in the classroom" (Participant U, June 2018)

This issue is raised in a 2015 review of the activity (Australia Department of Foreign Affairs and Trade, 2015e, p. 20). Unfortunately, to exacerbate the situation the Ministry of Education and Training also went through a period of capacity and organisational loss. An interviewee expressed that the most obvious issues were three different acting CEOs, internal dissent between officials and a largely disengaged Minister, a frustrated non-government school system and negative publicity (Participant $\mathrm{H}$, June 2018). Under these circumstances of development, it is easy assume that the quick fix is incorporating some form of technical assistance. This approach is problematic though under the Paris Declaration on Aid Effectiveness because it can undermine the ownership and alignment principles.

Despite the issues by the Tongans, ownership is still important. As inferred strongly by other activities, stability is more assured to a sector and outcomes achieved to a degree only by building from local leadership. Tonga did not properly appoint a Chief Executive Officer for the Ministry until 2016 (Matangi Tonga, 2016a). The appointment sits towards the later end of the Tonga Education Support Program II. From this position Tonga could assure more certainty in communicating its development needs for donor funding, particularly to what the Ministry perceived as output priorities.

The other issue, and arguably cross cutting throughout the Country Programme, that is hinted in interviews, is a parallel understanding by Tongans on what constitutes the parameters of using foreign aid. Participant R affirms that "a lot of conversations occur leading to the High-Level Consultations 
starting with planning. Bilateral thought is there but we need to phase out questions" (June 2018). Decisions seem to be more political in nature and based on reputation (Participant $P$, June 2018). The indication points to an understanding along the lines that foreign aid can easily be reallocated for other outputs. This is a meaning which is elusive to define. For example, aid is defined as financial or other assistance whilst an activity is defined as a "discrete grouping of actions taken, or work performed, through which inputs are mobilised to produce outputs and outcomes" (New Zealand Ministry of Foreign Affairs and Trade, 2017b, p. 17). It is hard to marry at first glance why the 'financial assistance' cannot be taken from one to another separate output. Despite being involved in numerous processes at different stages and for different activities officials seemingly do not apprehend the 'how' and 'why' donors give foreign aid. The pattern here and linked to the personnel especially at Tonga's Ministerial level, is each newcomer will want either reconfiguration or changes, rarely keeping the status quo of the activity. For example, one informant conveyed what a change at the 'leadership' position can entail:

"In the past leadership they would call all the Heads of Division and they would come in and chip in and we would feel connected even though we are doing our own work in our own divisions. We would have an input and of course there are things we would know more than others, but I can help. With the current leadership, unless there is a decision or meeting, we need to attend that is demanded by the donors then we would turn up and ask what is happening because we were in the dark. So, it is basically what is happening with the current leadership and it is causing a lot of confusion" (Participant U, June 2018)

There is almost a disregard and lack of appreciation for donor process and why having a process is important. Access, at least for the New Zealand Aid Programme, does not appear to be an issue because certain documents are online as 'tools and guides for aid activities' (New Zealand Ministry of Foreign Affairs and Trade, n.d.). Yet the fundamentals of a process and associated polices do not appear to be fully appreciated. There is a question whether officials appreciate the distinct processes and policies at the different juncture of an activity. Some basic knowledge is required for example of how foreign aid is contracted, in New Zealand's case, in a Grant Funding Arrangement and the Activity Design Document which outlines purpose and implementation arrangements.

On New Zealand's part the supply of aid programming seven activities outweighed the demand in the sector and although aligned with the development priority, it was not harmonized in modality and operation. There is no clear detail that sufficiently explains why this was the case. Analysing the documents of the modalities available (New Zealand Ministry of Foreign Affairs and Trade, 2016b; 
Sapere Research Group, 2018; New Zealand Ministry of Foreign Affairs and Trade, 2015c) indicate a lack of internal coordination driven by different reasons and competing but parallel divisional priorities. What this translated to in terms of practice was the result that the Ministry of Education was overwhelmed with donor demand pertaining to, ironically, the support being provided. The competing priorities stemming from the situation, for teachers to implement the outputs or carry out their core teaching functions, restricted the intended effectiveness. This example exemplifies well how an activity design can be ambitious and rigid, so that during implementation the situation on the ground may have changed significantly and confused what areas within the sector to support, focus on, or deliver. Furthermore, during the design a question arises as to whether an activity needs to consider other similar activities and which takes precedence over the other.

Yet overflow of activity acts as but one indicator of aid effectiveness because the development need within the sector exists regardless. The situation above implies the need exists but delay in delivery and constant internal change to the implementation agency were underestimated as a risk and compounded by issues within the Ministry. Examples include classrooms needing of repairment, room for teacher's capacity building, and construction of infrastructure facilities to name a few. Two factors would have arguably likely led to better aid effectiveness. Most obvious is if the Ministry had sorted out the missing leadership it required. Secondly, better coordination was needed not only by Tonga but by New Zealand itself. One interviewee expressed the situation where the Government of Tonga Ministries operated in silos:

"I think the workers just don't make the connection, the major problem with the Ministries is that they work in silos and they don't coordinate, and there is always that power pool and the funding comes to me. The public service needs to learn that they need to work together in a coordinated way to share the expertise to proceed forward together" (Participant A, June 2018)

This is just as true for New Zealand. Often at times post would be caught off-guard when a New Zealand contracted partner conducted an in-country monitoring and evaluation visit. Relatively little was shared prior or across divisions on the activity and important information. Just like the Tongan counterparts, more than often one staff member at post would be juggling multiple activities at once, sometimes six or more.

The volume of supply is not an automatically inherent negative impact on aid effectiveness. The issues pertaining to the flow of aid are layered and broad, accurately identifying and timely addressing potential misalignment or excess of activities can lead to the aspired outcomes. In a way pointing out one instance whereby although the donor supports the national development priorities of Tonga, it 
comes with some limitations on aid effectiveness. Ownership plays an essential role here with the Ministry of Education and Training needing to show specific and strategic commitment in management. The intention is to demonstrate stability and the leadership to apply appropriate resourcing. Mutual accountability requires the element of trust, amongst others, and as a donor New Zealand need to feel comfortable with their investment producing the outcomes in education. Otherwise, Tonga is more likely to receive piecemeal approaches concerning aid programming.

\subsection{Tourism}

The aid programming New Zealand provides to Tonga relating to its national development priorities in the tourism sector offer valuable insight. Between 2013 to 2017 the primary investment activity in this sector was the Tonga New Zealand Tourism Partnership which commenced in 2012 and was still being implemented in 2017. The initial commitment by New Zealand for the Tonga New Zealand Tourism Partnership was around NZD 10 million. The activity focused on two main areas: destination development and destination marketing. Tonga made regulatory and structural commitments, for example passing the Tonga Tourism Act (2013) which established the Tonga Tourism Authority and restructuring the Ministry of Commerce and Industries into the Ministry of Commerce, Tourism, and Labour. Key here was the idea that through the 'Authority' the tourism sector would have wider representation through its Boards of Directors.

The idea behind the Act built on prior public and private sector consultation within the sector to determine the collective way forward. The 'Board' would be composed of two ex-officio members, from Government, and seven appointed by Cabinet with the intention to select capable industry personnel (Tonga Tourism Act, 2013). In addition to this the Ministry of Commerce, Tourism, and Labour at the time, 2013, commissioned a Tonga Tourism Road Map. The Tonga Tourism Road Map would act as the overarching framework that guided coordinated efforts within the tourism sector. For Tonga the tourism sector has real untapped potential to grow and sustain the economy (Orams, 2013; Taumoepeau, 2016) and therefore is a development priority under the national outcome of a dynamic and knowledge-based economy (Tonga Ministry of Finance and National Planning, 2015b, p. 61). Some unique features about Tonga gives it a niche appeal that differentiates the same sector compared to its neighbours. Perhaps the most appealing attraction is the opportunity to swim with whales. All these steps aimed at confidence and assurance that the correct pieces were in place that warrant a more likelihood of development outcomes eventuating.

However, whilst the tourism sector planning with New Zealand aid support was proceeding, an incident arose which threatened to derail the Tonga-New Zealand relationship. In mid-2013 China gifted an aircraft to Tonga in support of building the tourism sector and meeting a growing demand 
for air services. There was a gap in domestic flights and services to the outer islands (Matangi Tonga, 2013a). The specific aircraft provided by China was the MA60. New Zealand held strong reservations concerning the safety of the aircraft and it not being certified from a recognized international aviation body (Matangi Tonga, 2013b). Tonga by and large did not apprehend New Zealand's point of view. In their mind the aircraft was safe to fly and had been certified, albeit only by the Tongan Ministry of Infrastructure. Tonga stood strongly on the grounds it was acting within its "sovereign right to use the aircraft as it saw fit" (New Zealand Ministry of Foreign Affairs and Trade, 2016d, p. 64). Ultimately this created almost an impasse between the two countries concerning not only the aircraft but the rippling effect into other bilateral arrangements.

The Tonga New Zealand Tourism Partnership was subsequently 'frozen' and New Zealand put out a travel safety warning for Tonga. It revisited the issue a year later, and downsized the investment to focus only on certain pre-determined mutually-agreed areas in destination development. New Zealand to some degree used vague language to communicate to Tonga specifics pertaining to the investment. For example, it utilized words such as 'frozen' and New Zealand Minister McCully said:

"I think we need to get past any sense of differences over particular items of equipment or transport modes and focus on good processes that are regarded as internationally robust" (Radio New Zealand, 2014b)

These comments were made on the assumption that New Zealand would accept the MA60 aircraft going through a certification process led by the World Bank. Implied with this approach is that by going through the certification process via a multilateral intermediary New Zealand would be seen as impartial.

New Zealand were, and mimicking the argument made by Tonga earlier, within their sovereign right to exercise caution with regards to foreign aid funding. From a strategic standpoint, Minister McCully conveyed subtly where New Zealand stood about their foreign policy but also foreign aid, the two being interwoven. And whilst this view was not immediately clear to Tonga, it was nonetheless diplomatic. Effectively it said in that one sentence that New Zealand would continue to support Tonga, subject to a 'focus on good processes', but was moving on. Having these communications and signals can be an effective tool that is sometimes not picked up by recipients, such as Tonga. What it does in practice is it leaves leeway for the donor to strategize the next ste, and indirectly achieve their objective without agitating the already strained relationship.

Perhaps the most challenging principle to adhere under the Paris Declaration on Aid Effectiveness here is ownership and mutual accountability. It is reasonable to attest that Tonga received due 
ownership under the aid effectiveness definition. Tonga met all the elements under the ownership principle - to develop and consult on national development priorities, translate priorities into resultoriented programmes, and lead in aid co-ordination (Organisation for Economic Co-operation and Development, 2005, p. 3). At the same time, given the material changes in development context on the ground New Zealand held a responsibility to act diligently. The Tongan Government perceived that once the grant was agreed and signed between the two countries, the donor was obliged to comply irrespective of the change in development context. Whilst it could be seen from Tonga's perspective New Zealand was acting in bad faith, Tonga perhaps also not properly read the relevant Grant Funding Arrangement clauses.

\subsection{Agriculture and Fisheries}

As with most of the national development priorities we have come across, the agriculture and fisheries sector are similar in development context. The Government of Tonga position the Tonga Agriculture Sector Plan 2016 to 2020 to serve as a framework for the sector coordinating priorities. The Plan details this accordingly:

“(i) articulate specific programmes and activities which are required to achieve sector priorities; (ii) clarify the roles and responsibilities of the different sector stakeholders; (iii) estimate investment needs; and (iv) provide a framework for measuring progress over the short- and medium-terms." (Pacific Community Pacific Agricultural Policy Programme. n.d., p.9)

Subsequently, The Tonga Agriculture Sector Plan 2016 to 2020 claims four Strategic Objectives -

- Strategic Objective 1: To develop a climate-resilient environment;

- Strategic Objective 2: To improve the enabling environment;

- Strategic Objective 3: To develop diverse, climate-resilient farming systems for the Kingdom's islands; and

- Strategic Objective 4: To increase and sustain rural incomes across the Kingdom

(Pacific Community Pacific Agricultural Policy Programme, n.d., p.10)

The four strategic objectives are supposed to feed into the national and organisation outcomes of the Tonga Strategic Development Framework II, specifically 'A. a more inclusive, sustainable and dynamic knowledge-based economy'; 'C. a more inclusive, sustainable and empowering human development with gender equality'; 'E. an more inclusive, sustainable and successful provision and maintenance of infrastructure and technology'; and 'G. a more inclusive, sustainable and consistent advancement of our external interests, security and sovereignty' (Government of Tonga et al., n.d., p.15) 
New Zealand focused its support to Tonga through system strengthening and approaches in three ways. Firstly, it offered support via technical assistance from the New Zealand Ministry of Primary Industries which included capacity building and supervision over management tools for example Hazard Analysis and Critical Control Points (New Zealand Ministry of Foreign Affairs and Trade, 2016d, pp. 67 -68). Secondly, it co-funded through a regional modality the Pacific Horticulture and Agriculture Market Access program or PHAMA that assisted exporters to improve compliance on primary or valueadded products (Pacific Horticultural and Agricultural Market Access Program, n.d.). Lastly, it supported the umbrella organisation in the sector, the Growers Federation or GroFed to support increased production and quality of crops for export.

New Zealand faced certain unique country aid programming challenges due to the development context specific to the agriculture sector. Arguably the biggest issue for Tonga was how disorganised the sector was without any real leadership. As one senior official conveyed, the agriculture sector is a bit 'all over the place' and the Government sent out mixed signals that disrupted initiatives. This official went on to say:

"My view is that the Government should have stepped in or looked at it because when there is uncertainty then growers within the industry feel the uncertainty" (Participant J, June 2018).

Despite this, the intention did exist for the Government to steer in the right direction. The Tonga Agriculture Sector Plan funded by World Bank, the International Fund for Agricultural Development, and United Nations Development Programme was a good start (Pacific Community Pacific Agricultural Policy Programme. n.d.). However, that in itself took considerable time and effort and the development context and issues that impede the sector were multifaceted.

Determining where to start and embark on and agreeing what it was exactly the Government of Tonga wished to achieve was rather opaque. Whilst the Tongan Government aimed to provide a clear collective way forward for the agriculture sector, stakeholders, particularly farmers, became disillusioned with the process. Other stakeholders, with a wealth of experience in the sector and having worked in development, found the consultation process more a 'rubber stamp'. Consider the following view:

"Yes, they did consult us a while back when it was still on-going but at that time I was at the Chamber, but it is annoying because they just came for it to be rubber stamped" (Participant J, June 2018) 
Ownership is elusive. The nature of the development context in the agriculture sector in Tonga highlight certain factions. The most notable faction is the Government of Tonga represented by the Ministry of Agriculture. The Ministry has different divisions, regulatory services, and formulates national policies pertaining to food security and export. Another faction is the private sector, in this case a small number of commercial enterprises. Regarding exporting, Tonga interviewees indicated three main exporters who had the experience and capacity to fulfil the strenuous, hazard analysis and critical control points (HACCP) compliance required. The other faction, which make up the bulk of the agriculture sector, is made up of subsistence farmers some of whom are occasional exporters. The biggest issue impeding the agriculture sector is the reality of trading in a global economy. In competition with large-scale producers in more favoured locations, Tonga continues to struggle to grow its agricultural economy given its geographical isolation and fragmentation together with high vulnerability to external market shocks (Fairbairn, 1998).

The fisheries sector in Tonga has a similar development context and encounters almost identical issues as agriculture. Tonga's waters are in the southern tuna fishery which allows catches of different types of tuna such as albacore, yellowfin, and bigeye. A combination of foreign flagged and domestic flagged vessels operates in the fishery which has an estimated first point of sale value of US\$17 million (Pacific Community, 2016, p.13). There is clear potential for development but also many constraints. Identified in the Tonga Fisheries Sector Plan the state of fisheries in Tonga:

"has fluctuated considerably due to boom and bust cycles driven by resource depletion, changes in the distribution of tuna, market access and prices, and environmental factors." (Pacific Community, 2016, p.13)

Tonga has taken different steps to grow the industry with tax exemption, establishment of a Fisheries Growth Committee to bridge high level dialogue between industry and government, and a soft loan facility initially operated by the Ministry but then transferred to the Tonga Development Bank (Pacific Community, 2016, p.12). Weighed together with other development priorities, it is reasonable to conclude that investment by New Zealand in the fisheries sector is needed but not an immediate priority. There is some support by New Zealand in the form of technical assistance to the Ministry of Fisheries via the bilateral programme but this is relatively small compared to other activities.

\subsection{Economic Governance}

New Zealand supports the Joint Policy for Reform Matrix or JPFRM led by the World Bank and includes other donors. As a sub-priority, economic governance is agreed with Tonga under strengthening economic development in the Joint Commitment for Development 2016-2018 (New Zealand Ministry of Foreign Affairs and Trade, 2016c). During the years covered in this research, 2013 to 2017, New 
Zealand took a cautious approach towards joining the reform-linked programme. From a Country Programmable Aid context, and drawing from the issues we have covered related to the different stages of an activity, we can better appreciate this. Some development priorities in New Zealand's view take precedence over others. For example, the significant investment in the energy sector was effective and produced financial and tangible outcomes. In renewable energy:

"We are achieving pretty maximum 15\%, some days we could get more but annually $15 \%$ is what we can achieve in renewable" (Participant N, June 2018)

New Zealand eventually joined and programmed the priority after the 2016 high level consultation that led into the Joint Commitment for Development 2016 (New Zealand Ministry of Foreign Affairs and Trade, 2016c).

It should however be noted that the language used by New Zealand differs between the 2011 Joint Commitment for Development and the 2016 version of the same, at least in modality, priority. In 2011 the terminology adopted was 'targeted sector budget support' (New Zealand Ministry of Foreign Affairs and Trade, 2011b) whilst in 2016 it is improved economic governance and public sector performance' (New Zealand Ministry of Foreign Affairs and Trade, 2016c). The two reflect the different forms of the modality - general budget support, sector budget support, and conditional budget support (Jelovac and Vandeninden, 2008). New Zealand does not adhere strictly to the contours of definition allocated to those different forms but employs elements that best fit the purpose. For example, in 2011 the targeted sector budget support was intended for an agreed sector but with conditions. The Tonga Education Support Program Phase One fitted this prescription and indeed was perceived this way (New Zealand Ministry of Foreign Affairs and Trade, 2016d, p. 49).

Tonga views the Joint Policy for Reform Matrix as an enabler towards effective development. With ongoing support from Australia and the Asian Development Bank, Tonga has made some good progress in implementing Public Financial Management (PFM) reforms that have returned the budget to surplus, reduced debt (to some degree), and increased revenue performance. Both the importance of budget support and the public financial management reforms are referenced repeatedly in the Government of Tonga Budget Statements 2013 to 2017 (Tonga Ministry of Finance and National Planning, 2013, 2014, 2015, 2016, 2017). The multilateral approach and Tonga producing some meaningful outcomes towards debt management and fiscal policy acted as assurance to New Zealand. As noted earlier, New Zealand committed to providing direct budget support to Tonga in 2016 under the priority of economic governance. This move was similarly strategic on New Zealand's part as well by offering an opportunity and platform to engage in the established policy dialogue and associated reform process. There are also issues with Tonga's ability to deliver the reforms. 
Under the Paris Declaration on aid effectiveness, the reforms identified in Tonga's joint policy reform matrix align well with New Zealand's economic development, including economic governance, policy objectives in aid programming. For example, the joint policy for reform matrix has three main reform areas: (1) supporting fiscal resilience, (2) supporting an inclusive, modern and accountable state, (3) supporting a more dynamic and inclusive economy (Asian Development Bank, 2017, pp. 1-7). Strengthening economic governance in the Pacific is an investment priority under New Zealand's new strategic plan for 2015-2019 (New Zealand Ministry of Foreign Affairs and Trade, 2015a, p. 13). Commitment is shown working with Tonga under the budget support modality to improve the way public money is collected, managed and spent. The aim of financial and policy reform also fits well the Paris Declaration principle of alignment, where donors build trust in the ability of recipient agencies to manage resources and move to providing more substantial and long-term programme activities and budget support. It is therefore important for government agencies to conform to international standards of transparent financial management, for example, if government ministries are to receive more direct funding and substantially larger allocations from donors.

Alignment, ownership, harmonisation, and mutual accountability are consistently raised pertaining to the management of foreign aid on the Tonga side. Tonga's senior officials express the need for clarity and information sharing, transparency, awareness, and are all important at the very beginning and inception stage of a project. Being the leader, because of responsibility, the Ministry of Finance sees the need for stronger coordination and pushing for the confirmation of information from development partners. There is an Aid Development Committee for Cabinet which is only a sub-committee Chaired by the Deputy Prime Minister, Minister of Finance as Deputy Chair, with member being other Ministers and one or two other Chief Executive Officers including the Chief Executive Officer of Finance. Alluded to in interviews with the Ministry is how important it is for those involved to identify what does the activity means for people, the scope of the program, who is going to benefit, and key stakeholders to ensure a successful outcome.

There is an implied understanding from informants that because of the limited human resources ratio to volume of development partners, the way to manage aid effectively is by nurturing strong relationships. This has not been fully achieved yet and there is room for improvement in the relationship and by extension the partnership so that, as one official put it, all the elements of the Paris agreement are there. However, one possible detriment to this approach is the quality of information being provided and how information can be pre-packaged to push forward an agenda. It was also expressed that development partners do need to take responsibilities in areas of providing more timely information. This is most needed on the Tongan side because the appropriation of approval by parliament is just on an annual basis, despite the budget forecasting for the triennium. In 
addition to this it is implied in interviews that there is a disparity in skills, experience, and knowledge pertaining to the management of foreign aid. Earlier it was touched on how Tonga at times struggles to understand the fundamentals of why foreign aid is provided and how. This is accurate but what is also accurate is that there exists a disparity between and within levels of management on both aisles. What is meant here is that the skills, experience, and knowledge do exist but sporadically and appear to be trumped by seniority in personnel and subsequently that individuals mandate.

This section reflects how New Zealand provided bilateral funding, but the aid mechanism - Joint Policy for Reform Matrix - is multilateral in nature. New Zealand supports Tonga through economic governance but uses the JPFRM to strengthen the ability to influence Tonga. This has wider implications on Tonga and the ownership principle.

\subsection{Conclusion}

This chapter has observed the Country Programmable Aid of New Zealand to Tonga between 2013 to 2017 under their strategic plans and the Joint Commitment for Development. New Zealand has a broad but targeted investment towards supporting and shaping the national development priorities of Tonga. This support that New Zealand demonstrates has different aspects about it dependent on the sector and the delivery. In the energy sector Tonga has strengthened its partnership with New Zealand successfully, as measured by the capacity of the implementing agency, Tonga Power Limited, to project manage large and multiple activities. The approach taken with law and justice is through the Tonga Police program and assisting with the Supreme Court to manage the volume of cases. Education is characterised by the ability of the Ministry to provide leadership and articulate their focus where development partners such as New Zealand can maximise their investment. New Zealand applies a systematic approach towards economic development through the two primary industries and budget support in the form of the improved economic governance and public sector performance'. New Zealand overall abides by the Paris principles but there are examples of where its own priorities and interests intercede. This is often due to where there are problems aligning with the sometimes under-staffed or uncertainty from the Tonga side. As a high-level framework between the two countries, the Joint Commitment for Development, New Zealand aspires to meet the arrangement. 


\section{Chapter Seven: Aid Effectiveness in Tonga}

\subsection{Introduction}

This chapter turns from the country-by-country analysis of the previous three chapters to address the issue of aid effectiveness as the three parties attempt to work together to deliver aid programmes for the development of Tonga. We have seen how Tonga, within its changing political environment, has developed a strategic approach to articulating its development priorities and how the two large donors have brought their own objectives and systems. These interact in complex ways across different sectors. Yet all three parties are signatories to the Paris Declaration on aid effectiveness and they have attempted, in various ways to subscribe to these principles. This chapter uses those five principles - ownership, alignment, ownership, mutual accountability, harmonisation, and managing for results - as a framework for analysis. In each, both the relevant documentary evidence and the experiences of practitioners will be drawn upon to ascertain whether and how the aid effectiveness principles have been followed and what the consequences have been for Tonga's ability to shape and support its national development priorities.

This analysis is important to provide a more Oceania and Tonga centred perspective on aid effectiveness. There are some existing reviews and evaluations that have been conducted by the OECD. These reviews and evaluations were conducted on the performance of the Paris Declaration principles and recommended practices and did include some consultation with countries within the region. For example, the progress review of implementing the Paris Declaration acknowledges the participation of Fiji, Sāmoa, and Tonga focal points (Organisation for Economic Co-operation and Development, 2012, pp. 6-7). Since 2005 when the Paris Declaration entered force, there have been two review reports and two evaluation reports notwithstanding the sector specific, thematic area, and survey monitoring reports (Organisation for Economic Co-operation and Development, n.d.). However, these analyses to date have focused largely on compliance issues and not looked deeply or critically at Tonga's particular development priorities and political and social context. Thus we need a better understanding of the realities of Tonga's development and how the parties interact in detail in their aid relationships.

\subsection{Ownership}

The main research question of this thesis ('To what extent are the national development priorities of Tonga shaped or supported by international aid?') turns centrally on the question of ownership: how Tonga 'owns' and leads its own development.

In the Paris Declaration the ownership principle is defined as follows: 
“Partner countries exercise effective leadership over their development policies, and strategies and co-ordinate development actions." (Organisation for Economic Development and Co-operation, 2005, p. 3)

The above definition has two dimensions and four elements, or 'commitments', that help construct the definition. Recipient countries are to play a critical role and make three commitments which are:

(1) develop and implement a national development strategy:

(2) formulate a result orientated budget of these national development strategies: and

(3) lead the co-ordination (Organisation for Economic Development and Co-operation, 2005, p. 3).

Donors add the fourth commitment to respect country leadership and strengthen capacity to exercise it (Organisation for Economic Development and Co-operation, 2005, p. 3).

At a high level, Tonga's leadership is clear. Tonga practices ownership by possessing an innate and unique understanding of its future. The foreword in the TSDF II gives us an insight into this understanding by Tongans whereby "while embracing that change is necessary and reforms are needed, we wish to recognize and reconfirm our special Tongan identity bequeathed us by Tupou I: God and Tonga are my inheritance" (Tonga Ministry of Finance, 2015b, p. 9). Regardless of the constant change that happens, the institutions, the norms followed, and the working relationships in place all work collectively to mitigate disruption and remain focused on this key foundation of Tongan identity. It appears that there is enough institutional knowledge as a foundation for Tonga to build on and articulate what it perceives as its development priorities. This does not rely on a specific individual or even Government, as we saw with both the Tu'ivakanō and Pohiva administrations, as the Kingdom was still able to engage with development partners.

However, below this high level affirmation of identity, the exercise of ownership becomes more problematic. There exist different and competing notions of ownership that do not necessarily conform to the intended definition implied in the Paris Declaration. The first sentence of the Paris Declaration uses the language:

"We, Ministers of developed and developing countries responsible for promoting development and Heads of multilateral and bilateral development institutions" (Organisation for Economic Development and Co-operation, 2005, p. 1)

The political context for of all three actors in this research reveals a constant state of flux as the norm at the level of ministers and officials. This is more evident with Tonga and Australia. In chapter four, 
we saw the continual change of political leadership over the 2013-17 period, and Australia also experienced a lot of change at the Prime Minister level. With this unpredictable situation of political leadership, and the distraction of political challenges and changes, the articulation and effective guiding of Tonga's development priorities was made very difficult in practice. Even if the broad outlines of strategic direction stayed in place, Tonga lacked strong and consistent leadership in development that could be conveyed to donors and drive aid-supported activities assertively.

The exercise of ownership by the government of the day is also complicated further by the strong calls in the Paris Declaration for wide citizen consultation and participation. In the development field, Chambers (1994) has influenced the operational approach through championing participation. As Wrighton and Overton (2012) write:

"The gradual but systematic embracing of a participatory paradigm led to a significant change in the development model and to the institutionalisation of participation and consultation in development practice" (pp. 245-246)

This ideal, enshrined in the Paris Declaration and continually pushed by donors, means that governments need to demonstrate that they engage in public consultation even beyond the normal electoral process. Donors "were reluctant to merely pass on funding without robust systems for ensuring that funds were spent appropriately" (Overton et al., 2019, p. 8). For Tonga, this has been problematic when wider political debates and transformations were occurring during the period under study. The challenge for development partners - Australia, New Zealand, and Tonga - than is to balance between three competing drivers relating to ownership: ensuring participation (requiring continual public consultation), compliance with the modus operandi of the donor, and allowing countries, through the governments in power, to formulate their own development strategies.

Even more elusive within the language of the Paris Declaration are the words 'partner' and 'donors' used throughout. Although it seems at one level to support 'recipient ownership', there is some confusion when this is coupled with notions of 'partnership'. What was encountered in this research is that ownership is not the domain of one but of several different, and at times competing, entities in Tonga. The nature of the development context in Tonga is fragmented which means ownership falls on the stakeholder with the nous, drive, existing working relationships, capacity, and personnel to operate effectively. This is demonstrated with the Country Programmable Aid of both Australia and New Zealand contracting a broad range of development partners, not just the central government. It may be that the intended target when reading the Paris Declaration, in this example, is the Tonga Ministry of Finance conveniently representing all matters aid and development. In practice, implementation and due to the broad nature of the volume of foreign aid, coordination and therefore 
'who is supposed to own?' and 'what is to be owned?' falls on more than one entity (Hasselskog and Schierenbeck, 2017). Ownership is multidimensional given it has a shared functional and operational aspect to it and not exclusively a 'principle'.

An unintended by-product of shared ownership is duplication. Duplication is adequately explained by one interviewee as:

"I think Tonga duplicates its efforts. There would be one project under one Ministry and next thing you know another Ministry would be coming up with another project and it could be run by a different donor when in fact you could be looking at placing them all together, such as alignment just so you align what is happening, I think it may be just a governance or situational issue" (Participant D, June 2018)

Despite these difficult questions, it seems as if Tonga has put in place a reasonably clear institutional framework for managing aid relationships with donors. As expressed in the many interviews with different informants, Tonga plans and strategizes its national development priorities on both objective, external requirements, and domestic needs. The Tonga Strategic Development Framework I and II are central examples. However, the practicalities of following this strategic framework and harnessing additional resources through aid, requires a strong institutional structure within which to work and an agreed set of processes for implementation. Participant B, as seen in chapter four, outlines how the budget process works in this regard:

"We have the aid division, so they would be the responsible division to put together the development budget. There are three ways of them having to try and come up with the development budget. Firstly, the information we already have. Secondly, the information that the implementing Ministries have and thirdly the information from the development partners themselves. With those three ways with the collaboration we should be able to have the numbers for the budget as close as possible." (Participant B, June 2018)

This demonstrates the importance of the Tongan Government, in this case the aid division, taking the lead to gather relevant financial information and prepare an overall budget. Tonga in this way is adhering to two of the three commitments - to implement a national development strategy and develop a results-oriented budget. However, this process is not so simple in practice. Tonga recognises the processes of Australia and New Zealand's CPA via the working relationships, aid mechanisms, and institutions. Thus, it is not just collecting information on the development budget but strategically gathering knowledge on why, how, and where Australia and New Zealand apply their foreign aid. This 
knowledge assists Tonga which they subsequently use under the ownership principle. It goes beyond budgetary data and just taking exclusive control of the process to instead involve a more subtle and complex process of trying to understand the other partners and how they operate and what they are trying to achieve. So, Tonga does not formulate its national development priorities independent of donors. The actors here do not wait on the other to finalize their end and then build on the result of it. For example, Australia and New Zealand do not wait on Tonga to finalize the Tonga Strategic Development Framework and vice versa Tonga does not wait on the two donors. The state of play here is a situation each one finds where their national interests can best be achieved. Interplay is constant.

This is also a dynamic process that has to be fitted into medium-term funding cycles and the changing priorities of all parties. Participant $\mathrm{G}$ elaborates on these external requirements and domestic needs:

"I think everything and at the time prior to the Activity being formulated that we are taking on board because Tonga's priorities will be different every three to four years because of the Government cycle. ... Personally and talking on the New Zealand aid programme it works well for me because they work in a three year period so when we had the negotiations at the beginning of the three year triennium we already had a fair idea for what government wants for that four years so we are able to articulate to MFAT." (Participant G, June 2018)

Under the Country Programmable Aid of Australia and New Zealand, the national development priorities of Tonga were articulated through conventional bilateral channels and institutions, specifically, the Government-to-Government dialogue, meetings, and high level mutually agreed commitments. These detailed discussions resulted in important guiding documents. For example, the understandings are manifested in such documents as the Joint Commitment for Development between New Zealand and Tonga (New Zealand Ministry of Foreign Affairs and Trade, 2016c) and the Australia - Tonga Aid Partnership (Australia Department of Foreign Affairs and Trade, 2016a) between Australia and Tonga.

The Tongan Government, represented by a Minister or senior official, uses the conventional bilateral engagement as a communication tool to articulate the national development priorities. This process is one key feature of Tonga's ownership. This pertains to the question of how Tonga develops and articulates its national development priorities or, as Participant G conveys above, it shows they have a 'fair idea' what government wants and can express that to donors. A further aspect of ownership is how many of the thematic areas of the CPAs of Australia and New Zealand are dependent on how Tonga conveys through the working relationships how it sees challenges to implementation. 
Australian and New Zealand support to education, New Zealand support to (renewable) energy, and Australian support to health activities are defined in large part by information provided by Tonga. In this example Tonga follows both dimensions of the principles, namely effective leadership and coordination of development actions. The key feature here for Tonga's ownership is producing national level documents and participating with donors to help them implement their foreign aid.

Concerning the elements of the definition of ownership, Tonga is strongest developing and estimating a budget for the national development priorities but weaker in others. Tonga has the capacity to deliver a national development strategy but arguably is less able to produce this as a development output. The distinction between strategy and output is important because it is an indicator of underlying challenges for Tonga if they wish to determine the most effective use of foreign aid and achieve their development aspirations. For their part, donors appear to allow ownership, that is where Tonga takes the lead in the process as articulated in the four commitments, but in practice they remain heavily involved throughout the process, usually with little pushback from Tonga. Keeping in mind the Country Programmable Aid is a product of the two donors, the subsequent high-level agreement, represented in their own respective formats, shapes which development priorities of Tonga are given precedence over others. In other words, whilst the process of engagement at high-level official and Ministerial level has cordial relations and the expression of reciprocity, each donor subtly selects the priorities according to its interests, perceived strengths in skills and expertise, and management capacity. By choosing some activities to support, and not others, they conform in principle to following Tonga's lead but their selection in reality shapes the development priorities in certain directions that align with what the donors want to do. Through these different funding decisions, donors influence as much as they can the preferred courses of action.

Nonetheless, although Tonga does not have direct control in the total allocated amount of Country Programmable Aid, and it has to accept that donors have their own priorities and favoured sectors, they can influence the distribution of CPA to a considerable degree. Influence comes in the form of which national development priority takes precedence because, as we have seen, the action of budgeting an activity to a pinpoint absolute figure is challenging. Many factors influence the budget of an activity with guaranteed changes bound to occur during implementation. Tonga does have a means to influence the final figure at activity and national level dependent on which national development priority takes precedence. For example, the disappointing performance of the activities aimed to support and strengthen the education sector led Australia and New Zealand to express legitimate concerns. Tonga strongly opposed a withdrawal of funding of the activity and advocated for continued partnership but with amendments to fine tune the focus. Taking aspects of a 'lessons 
learned' approach, the two donors then agreed to proceed with funding incorporating Tonga's position.

Foreign aid strongly also conditions the form of the national development priority that Tonga articulates. Foreign aid under the Country Programmable Aid provided by Australia and New Zealand does support national development priorities. For example, New Zealand champions the energy sector, mutually agreed with Tonga through their high-level mechanism - the Joint Commitment for Development, and compliments Tonga's aspirations manifested in the Tonga National Strategic Development Framework I and II. Australia, like New Zealand, strategically channels the broad range of tools at its disposal to better achieve its national interests which includes the most effective way to use its foreign aid. The fiduciary condition Tonga finds itself in means that what the support from Australia and New Zealand looks like - for example designing the activity - leans more favourably to the perception of the donors. A result of this is the version of the priority articulated by Tonga may look completely different, and in some circumstances foreign, to the definition comprehended and pushed by the two donors.

The ownership principle is heavily reliant on the extent donors perceive a purpose for it within their investment. Tonga leans towards accommodating donor foreign aid priorities and systems. Informant interviews imply the perception on the Tonga end is that here are external processes and systems to adhere to which by doing so will aim to result in their development objectives being met.

However, whilst donors do shape the priorities that are funded, there are instances where this promotion of the issues and concerns that donors have - and which they are prepared to fund - do seem to cross a line and run counter to the exercise of Tonga's ownership.

When questioned about the principle of ownership Participant F replied:

"It is not clear to the donor or understood" (June 2018)

Furthermore:

"I am practicing the principle of ownership; they are the ones who come and tell us of it and sustainability is ownership. I argued with a lady at DFAT, I was very angry, she is a consultant working on gender. She came and enquired to me about work like how many women and men, and she said we don't look good. I said, and she came with $X$, you know don't come and say we don't look good, coming from you is unacceptable. Firstly, what have you done for women? You have come and pushed for women's' rights since when? You are not doing anything. You come to change the policy of gender to this and you disappear. There was a coalition and we supported 
the coalition for women for parliament. Do you know A? She has campaigned and has won, what support have you shown A? Nothing and she is struggling to do work as a district officer. She works with an environment where the majority are men and who don't understand the issues she raises. She is frustrated and you guys are doing nothing at all. You come here and tell us to push gender, where are your 30 million that you said you will come and give. I am happy to have a dialogue, what I don't like is for them to come and make a judgement that this is wrong and that is bad, it should be clear to them the situation we are in and we do have a lot of shortcomings but there is a way to have an engagement" (Participant F, June 2018)

Therefore, we can conclude that the Paris Declaration principle of ownership in this research has to an extent been followed by donors and practiced by Tonga. Overall, Tonga does manifest the ownership principle under its commitments to (1) develop and implement a national development strategy: (2) formulate a result orientated budget of these national development strategies and (3) lead the co-ordination. Donors also seem to 'commit to respect country leadership and strengthen capacity to exercise it' (Organisation for Economic Development and Co-operation, 2005, p. 3).

However, Tonga encounters challenges to how it enacts the components. For Tonga, enacting the ownership principle is dependent on certain operational caveats. It depends on how Tonga develops and articulates its development priorities together with how donor priorities and systems help shape these in practice. It was also raised many times in this research that the constant change at officials' level, and to an extent of governments, posed challenges to the leadership and delivery of the aid program. Tonga employs some effective steps to articulate the country's national development priorities. This comes in the form of forums, meetings, and established communication lines which Tonga and its development partners mutually abide. On the other hand, there are examples of how donors are able to exercise influence on the shaping of priorities - by deciding which activities they will support and which they will not. There are also instances on where they push particular their own agendas, sometimes meeting with resistance. Thus, as a principle, ownership is dependent on the parties relate to one another and how they continually negotiate and advocate their own positions. Tonga's ownership of its development priorities is not absolute nor always transparent. Despite this Tonga still manifests an ability to manage, engage, and articulate its national development priorities and is not contingent on the changing political environment. The Kingdom of Tonga embraces thus change but wishes to reconfirm the special Tongan identity bequeathed by Taufa'ahau Tupou I: God and Tonga are my inheritance (Tonga Ministry of Finance and National Planning, 2015b, p. 9). Tonga continues to own its national development priorities by striving to define what that change is heading into the future. 


\subsection{Alignment}

The Country Programmable Aid of Australia and New Zealand has made strides to apply the Paris Declaration on the aid effectiveness principle of alignment. The alignment principle is a necessary companion to the ownership principle because it takes the overarching aim to build local leadership of development and considers the importance of this at the operational level, using local systems and expertise, and building these if they are lacking. Understanding alignment requires a closer understanding of the definition afforded by the Paris Declaration so as to start from a common reference point, comparing the commitments articulated in the bilateral documents so as to understand the nuances involved in the exercise of the alignment principle.

Under the Paris Declaration alignment is defined as:

“Donors base their overall support on partner countries' national development strategies, institutions and procedures." (Organisation for Economic Development and Co-operation, 2005, p. 3)

Expanding further in the Declaration we encounter further stipulation of what may appropriately be referred to as elements of alignment. They are:

(1) Donors align with partners' strategies

(2) Donors use strengthened country systems

(3) Partner countries strengthen development capacity with support from donors

(4) Strengthen public financial management capacity

(5) Strengthen national procurement systems

(6) Untie aid: getting better value for money

(Organisation for Economic Development and Co-operation, 2005, pp. 3-5)

Thus, alignment is crucial in terms of this research because of the way it seeks to strengthen Tonga's own systems to shape and support its national development priorities.

Firstly though, it is necessary to re-iterate the importance of Tonga's own strategic plans. The Tonga Strategic Development Framework I and II is the main national level document that outlines what Tonga perceives as its priorities. These provide the basis, in theory, for what is to be aligned with. Following this, the recognition of the principle of alignment by Australia and New Zealand is demonstrated by the high-level mutual commitments in the Australia-Tonga Aid Partnership Arrangement (Australia Department of Foreign Affairs and Trade, 2016a) and the Joint Commitment 
for Development between New Zealand and Tonga (New Zealand Ministry of Foreign Affairs and Trade, 2016c). These agreements aim to guide the ways the parties will work together, and the demarcation of commitments allocated to the donor and the partner assist in understanding the nature of the principle of alignment. They prescribe to the two sides certain commitments with the intent to facilitate and achieve the principle. In the Australia-Tonga Partnership 2016 to 2019 and the Partnership for Development 2009 document, the donor in this case arguably abides by the commitment of aligning with the partner's development strategies as outlined in TSDF I and II. Australia acknowledges this as a 'mutually reinforced commitment' (Australia Department of Foreign Affairs and Trade, 2016a, p. 3). One donor interviewee outlined how this happens in practice:

"We get together as a group of donors and sit with Government and agree on a set of key reforms and then monitor implementing those performances" (Participant $D$, June 2018)

This seemingly strong adherence to alignment, however, may become rather less clear in practice. Australian aid can involve manoeuvring around what constitutes a priority at the activity level to accommodate its own assessments. For example, Australia may align its focus of economic and public sector governance to Tonga's "Dynamic public and private sector partnership as the engine of growth" and "Better governance" (Tonga Ministry of Finance and National Planning, 2011, pp. 5-7) but it selected to do so via different aid modalities that employed strategies which did not appreciate Tonga's capacity and to an extent ownership. At times, Australia took a cautious approach whether to follow Tonga's aid systems and agencies.

New Zealand's Joint Commitments for Development with Tonga, both in 2011 and 2016, is similar to the Australian template but have some key differences. One is the concise nature of the text which reflects more the amount of pre-planning and prior meetings. The lead up to the Joint Commitment for Development involved a series of meetings with the relevant and contractual partners. This in turn implies a more strategic and hands-on approach compared to Australia. New Zealand's approach seems to have been to anticipate or get an indication of any point of contest from the partner, Tonga. However, this may not have been matched by clear indications from the Tongan side. As an interviewee highlighted:

"New Zealand are actively involved and having to manage and monitor and really be interested what the outputs and results are but from the Government's perspective it was not similar. The commitment for the program, the rate is different, it is not the same 
and it is not consistent across the board" (Participant $\mathrm{H}$, July 2018)

This approach by New Zealand is based on the view that the meetings prior to formal agreements act as an opportunity to voice concerns and consult on progress. Prior meetings are not the only method the high-level arrangement is formulated. Diagnostic reviews by New Zealand and Tonga are carried out and feed into the prior meetings parallel to act as an additional method of alignment. The diagnostic reviews are an important source of information to determine the state of affairs by both donor and partner (Organisation for Economic Development and Co-operation, 2008, p. 4). Reviews take the form of activity level progress reports, reviews of an activity, feasibility studies, and evaluations just to name a few. The make-up of the donor organisational structure of a 'Country division' and the personnel involved positions New Zealand with a wealth of information at its disposal. In turn this is strategically selected, concurrently with the pre-high-level meetings, to ensure the Joint Commitment for Development with Tonga has a higher probability to achieve New Zealand's objectives.

One feature of alignment that is not adequately considered by both donors is arguably the oversupply of foreign aid relative to the ability of Tonga's systems (and even perhaps donor systems) to handle it. There is a constant back and forth on the need for foreign aid expressed by both Australia, New Zealand, and Tonga. However, the influx of foreign aid acts as an operational and bureaucratic pressure on all parties. This stands in contrast to the earlier observation that Tonga has a well thoughtout high level plan outlines desired development outcomes. In practice, Tonga is constrained by a shallow pool of expertise, constant change at operational and the political levels, and at times administrative limitations. This is exemplified in the following observation from a Tongan official:

"There were a lot of things we were not prepared for in terms of capacity, that is where I came, and I learned on the job we had other issues. The capacity was, what are we going to do with all this money? After every year the progress was slowed done by many factors that were involved such as procuring certain things, mobilizing, but remember we were doing our own things. Then our workload went up then the donors realized" (Participant A, June 2018)

Australia and New Zealand on their part may contribute to this problem with the volume of activities they support with Tonga having little input and sometimes being caught off-guard. Both the ownership and alignment principle are important here with a high ration of aid supply to demand and capacity. 
The issue of capacity here also refers to all the parties involved, not just Tonga. Donor staff, especially in-country, have to deal with many different activities to administer, consult on, report regularly on and co-ordinate. This is compounded by the need to comply with donor systems of auditing and reporting in addition to working with Tonga's own systems. Foreign aid and all its systems and requirements place burdens that may be overwhelming on countries such as Tonga (and Tuvalu - see Wrighton and Overton, 2012) as well as strain the donors' own structures and staff. Thus, the highlevel commitment to alignment is not always matched the operational level, with all three parties challenged to deliver adequately with a large number of activities.

Both donors build alignment within the national development priorities Tonga expresses in the Tonga Strategic Development Framework I and II. However, Tonga can find the alignment principle overwhelming due to the volume, conditionality, and requirements by donors. Overton et al. (2019) refer to this phenomenon as the 'inverse sovereignty effect'. The inverse sovereignty effect is:

"the idea that, despite the adopted principles of the Paris Declaration, and indeed, rhetoric regarding ownership of the development policies and programmes by the recipient country, the actual practice of development assistance has resulted in diminished room for the countries and territories in the Pacific to determine their own policies. A new set of conditions has been imposed on Pacific governments, which significantly undermines recipients' ability to exert self-determination, thus reducing their sovereignty" (Overton et al., 2019, p. 185)

Oceania experiences a reality of over-stretched local systems and officials struggling to keep up with donor requirements.

In addition to these capacity issues, alignment is affected by the selective nature of donor funding in practice. The nature of the external foreign aid environment leans more towards shaping which national development priority of Tonga takes precedence over others. Alignment is therefore a relative term and not simply about the primacy of Tonga's sovereignty. Decisions regarding which activities donors will fund is different from deciding 'the' development priority of Tonga. For example, Australia's Country Programmable Aid for Tonga is pre-dominantly shaped by priorities in:

- Governance, economic and private sector development reforms

- Effective, efficient and equitable health system

- Skills development in support of economic opportunities for Tongan workers

(Australia Department of Foreign Affairs and Trade, 2016b, p.2) 
Alignment then is adjusted towards the strategic priority parties perceive their strengths lie, strength in capacity, human and material resources, for example. Both Australia and New Zealand Country Programmable Aid covered a broad and diverse range of activities. Their own broader priorities led to the decisions as to where they concentrated the most resources, both financially in foreign aid but also in human resources. Australia consistently between 2013 to 2017 in their Country Programmable Aid to Tonga allocated more funding towards good governance and public sector reforms. On the other hand, New Zealand championed the energy sector, both renewable energy and energy efficiency. So, whereas the alignment principle might direct donors to support Tonga's development priorities as a comprehensive and integrated set of strategies, instead they have seen these priorities as a sort of menu, from which they have selected some activities that match their own objectives and resources. Donors have applied the alignment principle unevenly with a precedence to highlight their own CPA - and broader national aid strategies - rather than the main core of Tonga's national development priorities.

In summary, the Paris Declaration emphasizes in the alignment principle the goal to use partner country systems and build their capacity (Organisation for Economic Development and Co-operation, 2005, pp. 3 - 5) and Tonga, Australia and New Zealand have agreed to follow this. However, the above analysis has shown how the large volume of aid, in the form of multiple activities, has compromised alignment in practice. Whilst working relationships do exist between Australia, New Zealand, and Tonga, and there is high-level adherence to alignment, the partners have struggled with issues of capacity and the selective nature of donor funding. The high volume of aid reflects the changing landscape of international aid with an increase in the types of donors, with more bilateral partners, more private sector partnerships, and the growing issues, such as climate change, that cross borders and require a multilateral approach. This leads us to the issue of donor Harmonisation - another Paris Declaration principle - to be examined in the following section.

\subsection{Harmonisation}

The harmonisation principle provides a third key element of aid effectiveness alongside alignment and ownership. At the core of the harmonisation principle of aid effectiveness is finding common ground by the donor and partner country when actioning foreign aid. Furthermore, the principle focuses on donors and the way they should work together in ways which make it more likely that recipients can exercise effective leadership. Harmonisation is defined as:

"Donor's actions are more harmonised, transparent and collectively effective." (Organisation for Economic Development and Co-operation, 2008, p.6) 
Accompanying this is five elements with four only relevant here (the fifth involves fragile states, which does not apply to Tonga as it is not internationally categorized as such):

i. Donors implement common arrangements and simplify procedures

ii. Complementary: more effective division of labour

iii. Incentives for collaborative behaviour

iv. Promoting a harmonised approach to environmental assessments

(Organisation for Economic Development and Co-operation, 2008, p.6)

One of the main problems observed with regard to the Harmonisation principle in Oceania, is the large number of aid agencies involved relative to both the small (by global standards) total volumes of aid and the limited capacity of local agencies. In chapters three and four the long lists of donor agencies working in Tonga was presented and it was apparent that some agencies were associated with only very small projects and financial commitments. However, each donor agency has to be dealt with by Tonga and they usually bring their own principles, objectives and systems of working. As Wrighton and Overton (2012) highlighted when focused on the experiences in Tuvalu pertaining to reporting:

"Given the alphabet soup of agencies working in Tuvalu it is not surprising that many officials commented on the onerous nature of reporting. One respondent summed it up as follows: 'obligations on reporting are very time-consuming - we are faced with different types of reporting, different timeframes, projects, programme and international instruments reporting, and as well as that the templates of some donors not similar with our terms and structure" (p. 250)

This is a shared administrative experience which Tonga encounters as well. This can be seen not only in the proliferation of donor agencies (seen in table eight) but also in the many activities that make up the Country Programmable Aid of both Australia and New Zealand in Tonga.

New Zealand Country Programmable Aid between 2013 to 2017, for example, had a high volume of activities. The range fluctuated from 83 activities between 2013 to 2014 and 62 between 2015 to 2016 (New Zealand Ministry of Foreign Affairs and Trade, 2016d, p. 33). For New Zealand, the harmonisation principle is applied depending on the strategy to deliver aid, the make-up of the contractual partner and implementing partner, and modality. For example, several activities during this time - the Tonga New Zealand Tourism Partnership, the Tonga Village Network Upgrade Stage 2, and the Tonga Police Development Programme Phase II - adhered to a 'more effective division of labour' (Organisation for Economic Development and Co-operation, 2008, p.6). That is the Ministry of Finance was the 
contractual partner whereby funding was deposited to the Government Development Account. Subsequently, the funding would then be allocated according to the agreement with the relevant implementing partner - Ministry of Commerce, Labour, and Tourism, Tonga Power Limited, and the Tonga Police Force.

From the perspective of Tonga issues arise which question the donor's commitment to the harmonisation principle when multiple activities by the same donor are implemented in the same sector by the same agency. This is an aspect of the development landscape in Tonga in that it is not only the CPA modality but others as well such as thematic and regional. For Australia and New Zealand this is reflected in the support afforded to health and education:

"The Ministries of both Health and Education in Tonga acknowledge that the Partnerships Fund activities fill a need in the health and education sectors. However, senior officials we spoke with in Tonga would like more oversight of Partnerships Fund activities with government agencies at the concept design stage to avoid replication, and to help with planning and management of staffing." (Sapere Research Group, 2018, p. 86)

Harmonisation appears here to entail the need for a mechanism to take ownership in this space. Such a mechanism would have a general birds eye view on the development landscape in Tonga and a general idea of where gaps are that CPAs could strengthen.

A further challenge for Tonga, pertaining to the Country Programmable Aid of Australia and New Zealand between 2013 to 2017, is understanding the donor systems and compliance. Between 2013 to 2017 Australia implemented a broad range of Activities structured around thematic areas, alignment, ownership, and modality. This is exemplified in the Tonga Technical and Vocational Education and Training Support Program, the Transport Sector Consolidation Project, Tonga Health Systems Support Program, and the Tonga Economic and Public Sector Governance Program Phase III just to name a few. Each individual Activity has a specific design to it but adheres to an Australia Department of Foreign Affairs and Trade process, policy, and template. Collating the Country Programmable Aid of Australia between 2013 to 2017, Tonga is involved in the design at different entry points, with this practice inconsistently applied. Various interviews with Government of Tonga officials and non-governmental organisations do not raise whether they are provided training or informed of the process and policies in designing an Activity until later. As conveyed here:

"the New Zealand portfolio when I first started, New Zealand's program was pretty broad. It became very hard to monitor these projects. We had the first High Level 
Talks in March 2016 and that is when the review told us (about the volume of Activities) but it was pretty obvious on the ground the lack of manpower not only here on our side to monitor how many projects" (Participant G, June 2018)

Further to this, is that at the bilateral level it still does strongly indicate for programming foreign aid the systems of the donor, albeit shared amongst them, is preferably utilized. Participant $\mathrm{G}$ appears to suggest, from Tonga's perspective the two donors do not harmonise but are following systems which compete and duplicate work.

One implementing agency in Tonga adheres to three different procurement systems - Asian Development Bank, Government of Tonga, and the New Zealand Aid Programme (Participant N, June 2018). That is an example of the challenges to alignment in the context of Tonga and its development partners finding an agreed system.

One feature of harmonisation which is not expanded on in the Paris Declaration on aid effectiveness is the ability to carry out with reasonable confidence the necessary 'division of labour' (Organisation for Economic Development and Co-operation, 2005, p.6). The language used by the Paris Declaration aims to reduce transactional costs due to fragmentation. However, when collating the Country Programmable Aid and considering the donor system exerting more dominance there are some misconceptions that arise relating to 'division of labour'. What is questioned here is that harmonisation is selective when it comes to recognizing ability or capacity. The whole process constructing the Country Programmable Aid and up to the activity level adheres to the donor system. The donor constructs the Country Programmable Aid, consulting the partner, and depending on the feedback from the partner, the final iteration is more likely a unilateral donor decision. Australia and New Zealand, at least, seem to be aware of the differences from each other's system:

"The actual system in DFAT is a lot more complicated than MFAT from an administrative side and from a document side. There is a lot more involved from Post and is a lot more than MFAT. So we have to do a lot of the contracting and approval, the variation, we do have a central management team which we send things through for checking but essentially it all rests here at Post so it is quite different from the MFAT situation, the desk does a lot more" Participant D, June 2018)

The argument here is that on both sides the ability, expertise, knowledge, and technical skills are imbalanced in recognition, appreciation, and acknowledgement. The prevailing assumption on the conception of foreign aid is that the provider knows more not only than the receiver but can also better deal with other donor systems. There are grounds to this belief driven in part by the lack of due 
process and adequate representation pushed forward by Tonga to coordinate development partners. However, the relationship is not entirely unilateral and has meaningful symbiosis in some areas.

Another aspect of this issue of capacity is the observation of how much of the work in delivering foreign aid is outsourced to multiple foreign/expatriate consultants and foreign organisations. Yet these agencies are, in turn, dependent on local knowledge (through locally-engaged staff and consultation) and there is inadequate recognition given to local expertise, and duplication of existing work as local staff often have to give the same information over and again to different agencies. Donors, then, could do much better to collaborate on their respective activities and share information and resources. There is an imbalance that exists with how local capacity and used is perceived and the extent the harmonisation principle is actioned. The prime example here is what has happened in the education sector where competing and concurrent perceptions of capacity manifest. One perception of how capacity in Tonga is perceived is exemplified by the ambition of the activity design. As the Tonga Education Sector Support Program Phase 2 states:

"The ambition of the program is much greater than the capacity available to implement it." (Australia Department of Foreign Affairs and Trade - Tonga Education Sector Project II Independent Progress Review, p. ii)

Another perception pertains to how capacity is forced to accommodate the design of the activity rather than the design recognizes and incentivizes what capacity exists on the ground. As the Tonga Education Support Project II Independent Progress Review further expresses:

"Capacity to plan for such an ambitious program is still weak. In particular, the absence of a functional Education Management Information System has had a critical effect on the ability to manage efficiently as well as provide adequate reporting." (Australia Department of Foreign Affairs and Trade - Tonga Education Sector Project II Independent Progress Review, p. ii)

The different perceptions of capacity make the elements that constitute the definition of the harmonisation principle challenging to action. The consequences of this, which does not appear to be adequately acknowledged by the donor, is over supply of foreign aid or proliferation. In the two examples regarding capacity above, not much is acknowledged on the administrative burden, specifically the 'incentives for collaborative behaviour'. One scenario here is demonstrated in New Zealand's assistance to Tonga in the education sector: 
"At the sectoral level, particularly in education, where there are seven separate New Zealand-funded activities running in parallel, there was also concern about the coherence and complementarity of these activities and the burden they placed on education staff managing these projects." (New Zealand Ministry of Foreign Affairs and Trade, 2016d, p. 35)

Clearly, local systems and expertise is being stretched and used inefficiently as a result of donors not harmonizing effectively, either between themselves or even across their own multiple activities. Here ownership plays a crucial role to how effective foreign aid can be if the right factors exist on the ground and there is enough confidence to justify a cost-effective approach. What is not detailed in the examples is whether the educational staff were reimbursed for their time, expertise, and given an opportunity for prior consultation. Inferred though is that the activities were implemented on a voluntary basis from the Tonga end, something which donors, including Australia and New Zealand, need to rectify. Tonga Ministry of Education staff members are paid, relative to their Australia and New Zealand counterparts, very much less and this almost positions the activity and relationship in such a way that it demands their involvement on a voluntary basis. The attitude as it appears here is that because donors provide foreign aid, therefore the recipients should provide something in return. The question not often raised here in the first instance is whether the locals asked for the assistance? Another facet of this pressure on local officials is the requirements for donors to 'consult' locally something which often falls on a very small number of key staff in small departments. There are also frequent requests for local staff to attend meetings and conferences overseas, taking them away from their busy offices and pressing jobs. Tonga is not unique when it comes to this challenge of enacting the principle of Harmonisation in Oceania. Indeed, the example by Wrighton and Overton (2012) refers to the situation encountered by Tuvalu. Donors are aware of the demands to meet reporting requirements not just from one donor but multiple, conditionalities expected in the bilateral arrangements, and trying to attend meetings with officials being absent having a due effect on implementation and management. One interviewee acknowledges this as a donor for example:

"Actually, other things we could do better is donors be strategic about what meetings we are asking Tongan officials to go to internationally because there is a lot of travel time involved" (Participant I, June 2018)

Therefore, returning the example of New Zealand's multiple activities in the education sector, applying seven separate activities running parallel therefore should not be interpreted as a lack of capacity, if by design then implementation is almost impossible to achieve an effective and meaningful result. The key feature of the examples which question if Australia and New Zealand followed the 
harmonisation principle is the arrangement itself. The Tonga Education Sector Project II was a tripartite meaning Australia and New Zealand had the opportunity to harmonise their procedures and processes but as the examples have discussed, they did not. The reason to this is that the tripartite existed more as a high-level agreement, not a governing mechanism or operational manual. Doing so would have avoiding the competitive and duplicating nature of the Tonga Education Sector Project II.

To achieve better Harmonisation, donors, such as Australia and New Zealand, have to adjust to the working environment in Tonga. Harmonisation only works effectively if there is a balance between the donor and recipient. Harmonisation not only involves what policies, systems, or processes to follow but the capacity, knowledge, and expertise between donors and recipients. The exchange needs to be more meaningful because at present, the donors are dominating both how foreign aid is applied and what version of the national development priority looks like in implementation. On the other side of this argument Tonga needs to present a more collective front. There is a successful model here for harmonisation in the form of Country Programmable Aid for both Australia and New Zealand. This is the policy and activities in the energy sector evidenced by the Tonga Energy Roadmap, Tonga Village Network Upgrade, and the Outer Islands Renewable Energy Project.

As well as donors making efforts to better achieve Harmonisation by reducing duplication and proliferation and by better using and understanding local expertise and resources, there is scope for Tonga to address the issue of Harmonisation by adopting a more assertive approach to requiring better donor co-ordination. In this, it could learn from the example of Sāmoa, where its aid coordination unit, under the former leadership of Peseta Noumea Simi (see Ulu in Overton et al 2019, pp.256-7), has been successful in instituting a wide range of policies and practices 'encouraging' donors to avoid duplication and abide by Sāmoan systems and timetables.

Tonga has attempted to address donor coordination but with little traction and mixed results. Donor coordination according to the Tongans exists but appears to be rather compartmentalized. Platforms such as the annual Donor Partners Forum called by the Tonga Ministry of Finance each year and the re-instigated High-Level Bilateral Meetings are expressed by Tongan officials as efforts to increase donor coordination. The development partner forum has also been held in response to a natural disaster and better coordinate the response with development partners (Participant B, June 2018). At the same time, the Government of Tonga has brought back the bilateral high-level consultations and held one with Australia in 2017 and the other year in 2016 was with New Zealand (Participant B, June 2018). However, on the opposite side, arguably these platforms are used by donors as an opportunity to showcase their monetary contributions and highlight the 'strengths' of their aid programmes rather 
than represent a serious attempt to work more closely together. In addition to this there exists a subcommittee of Cabinet specifically created for the said purpose of donor coordination, the Aid Development Coordination Committee. The make-up of the Aid Development Coordination Committee as explained by an interviewee is:

"Chaired by the Deputy Prime Minister and the Deputy Chair is Minister of Finance and selected Ministers and other CEOs." (Participant B, June 2018)

The role of the Aid Development Coordination Committee is explained thus:

"they would be responsible for reviewing development partners programs and projects and proposal" (Participant B, June 2018)

Relatively little is known of this Cabinet Committee and it appears that there is hardly any wider buyin, on the purpose and effectiveness of this mechanism. The Aid Development Coordination Committee even being set up does not guarantee meaningful success. Members would need to be competent and well versed not only on domestic issues of development but donor priorities and systems. Compounded by existing volume, duplication, proliferation, and fragmentation just to name a few concerns, Tonga continues to be more prone to reactionary measures.

To a degree it would be reasonable to argue that Tonga needs to show more responsibility concerning the management of its national development priorities. Strategically for Tonga this is in the areas of planning, communication, and coordination of these national development priorities at different levels. At the moment two systems, that is the programming and activity policy and processes adhered, are competing as we have seen in the example of the activities implemented in the education sector. No clear guidance is given which system should take precedence but perhaps more appropriately should be decided on a case by case merit-based ownership. However, overall, it seems as if the principle of Harmonisation is not well embedded in Tonga. Donors have subscribed to the principle but their practices have continued on largely separate paths, with continuing large numbers of activities across multiple sectors and actors, with different systems and priorities and with seemingly little commitment to provide incentives for collaborative approaches or simplified and streamlined ways of operating.

\subsection{Managing for Results}

The last two principles of the Paris Declaration are rather different from the first three. Ownership, alignment and Harmonisation, as seen above, are critical in establishing relationships between donors and recipients that strive to establish and support recipient leadership of national development. The next two principles only expand on these in specific ways, with regard to monitoring and accountability 
for results. This section focuses on 'managing for results' which takes the analysis into more operational areas.

The Paris Declaration defines the principle of 'managing for results' in terms of two commitments for partner countries. They are:

- Strengthen the linkages between national development strategies and annual and multiannual budget processes.

- Endeavour to establish results-oriented reporting and assessment frameworks that monitor progress against key dimensions of the national and sector development strategies; and that these frameworks should track a manageable number of indicators for which data are cost-effectively available. (Organisation for Economic Development and Co-operation, 2005, p.7)

The first point applies to the Tonga Strategic Development Framework I and II, which outlines the country's development strategies, together with the annual Government of Tonga Budget which has multi-year projections alongside annual allocations. It should be noted that these documents are driven by other purposes than the Paris Declaration. The Tonga Strategic Development Frameworks I and II are, for example and according to interviewees, policy documents. By extension it is not only a manifestation of the ownership principle but also the responsibility of the Tonga Ministry of Finance which plans the country's national development priorities. Similarly, the annual budget serves a much wider purpose to outline the financial management of the government's finances. The impetus of this 'managing for results' principle's first point is for successful action on the ability to strengthen linkages between planning and budgeting. Tonga has met this commitment albeit with mixed impact and relies heavily on limited and revolving expertise. The 'managing for results' principle, therefore works with existing Tongan systems to ensure Tonga achieves the development priorities it aspires to.

The second point, however, requires the use of largely new reporting systems at a level of regularity and detail not usually previously used. Here, commitment to establish results-oriented reporting and assessment framework is driven by donors. They arise largely because donors want to be able to demonstrate to their own constituents that their aid budgets are being spent well and achieving what they say they want to, such as the poverty alleviation goals of the MDGs. However, in practice, 'resultsoriented reporting' and assessment and monitoring frameworks have proved very difficult to implement. Existing activity design and data collection systems in Tonga appear to be inadequate. Tonga does have forms for activity design readily available on the Ministry of Finance website (Tonga Ministry of Finance, n.d.) but the forms appear to be outdated and seem to only involve the concept 
stage. In addition to this, donors, with limited degree of participation by Tonga, control what encompasses as the design of templates. Tonga does express in the different bilateral platforms and forums available the keen interest and aspiration to be more involved in the design of activities. Tonga is heavily focused on engagement and utilizing as much as it can the limited human resources available. This focus is expressed by a Tongan official:

"The two main outputs of our division is one better platform for aid management, effectiveness, and harmonisation. And second is a better project cycle system to formulate, appraise, and approve to report on projects. This would be done through activities ... more specifically support and coordinate external aid resources that are coming into Tonga" (Participant G, June 2018)

Tonga is limited by both circumstance and limited strategic directive to lean toward a more support and coordination role but only where they can concerning the influx of foreign aid. Therefore, Australia and New Zealand carry the necessity to measure the impact and effectiveness of their aid programmes.

Reporting and monitoring require human resources. This is a question of the size of relevant government agencies to undertake these tasks and also of the capability - requiring training Tongans and building their capacity, to do so. One of the constraints here is the shallow depth of expertise in Tonga and how the same personnel are involved in multiple, and often conflicting, roles. For example, one interviewee held multiple positions in government, the board of the Central Bank, a government sector committee, and an executive role in a non-governmental organisation whilst securing successful consultancy contracts from Ministries.

Under the managing for results principle Australia and New Zealand are, in general, asked to commit to the frameworks Tonga has created. However, Tonga has only partially met that commitment due to limited capacity. This in turn has impacted how Australia and New Zealand address their commitment to the principle. The principle asks Australia and New Zealand to link country programmes and resources to the partner equivalent systems, to collaborate and rely as far as possible on the partner frameworks, and to harmonise monitoring reporting requirement. These commitments individually and collectively are reliant on the appetite Australia and New Zealand have toward perceived and real risk, when results are poor.

However, despite these practical difficulties regarding reporting and monitoring, there are signs that all parties are committed to the general principle of managing for results. The high-level consultations, the joint commitments for development, the annual Donors' Forum organised by Tonga, all act as 
ways such results-management objectives can be addressed. This affords both sides a voice and demonstrates close collaboration which includes reflection on past achievements and room for improvement on future priorities. Results are produced and discussed, such as the activities New Zealand has implemented on the energy network upgrade and the assistance in the justice sector, or, for Australia, on the seasonal workers programme and economic governance. Reflections of these activities play a crucial role in understanding what works and what has not worked and they offer opportunity to suggest reasons why results are hard to achieve. What is challenging with reporting the results concerns the manner in which activities are first designed, then implemented, and then managed. It is not unfair to assume that ultimately there is no 'perfect' activity which has a flawless design and produces the desired results. However, there is a strong indication that all sides are indirectly driven to focus on immediate and short term recognition of their efforts, and there is a stronger imperative to achieve foreign policy outcomes, together with an inability to adequately manage the volume of activities within unrealistic timeframes. This seems to be a long way from the ideal expressed in the managing for results principle.

The 'managing for results' principle also reflects an underappreciated reality, the inequality that exists between Australia, New Zealand, and Tonga. This is not referring to the obvious inequality of economies of scale but the existing inequality from where they begin with whether it is the Country Programmable Aid of Australia and New Zealand or the Tonga Strategic Development Framework I and II. Often activities begin by trying to address a national development priority for Tonga and aim to achieve measurable results. What is fundamentally lost is the disparity from where each start. This 'start' point referred to here is about the misconception of where each initiative begins and how Australia, New Zealand, and Tonga all do not know have a full comprehension of what they are doing. Some activities begin with the correct expertise, capacity and buy-in from all the stakeholders involved - Tonga Village Network Upgrade by New Zealand, the Kau Mai Netipolo by Australia (Australia Department of Foreign Affairs and Trade, 2015b) for example. Other activities begin with very limited resources, high expectations to deliver the intended outcomes, and operate within a sector that is fragmented - GroFED Activity by New Zealand and Australia's first years into the Seasonal Workers Scheme are examples in this case. Therefore, it is misleading to assume that following processes, studies, policies, translate into producing automatic and guaranteed outcomes.

The Country Programmable Aid of Australia and New Zealand still find it challenging to translate their activities into the desired national development results for Tonga. There is an imbalance at activity level and how engagement is conducted. That is, there is uncertainty not only where the activity starts but also when it continues into implementation and so forth. Institutional knowledge is important here and often activities encounter changes. The Tonga Village Network Upgrade by New Zealand is 
an example of an activity maintaining stability because of the officials involved remaining throughout the project cycle. The misconceptions may fuel misplaced claims on why the activity fell short on delivering its intended purpose.

It seems that there is very little opportunity for Tonga to voice what it perceives as results. What I mean here and interpret from the analysis thus far is that Tonga gives, due to varying reasons, little importance to the power of owning the narrative regarding results. Often the lens that dominates is that according to the two donors. Tonga does engage by initially drafting their reports on either of Australia or New Zealand's reporting templates. However, it is not clear why Tonga does not formulate its own reporting standards, though lack of resources is probably a factor. This is not to say that none exist, for example the Ministry of Finance has templates distributed to donors for reporting the volume of activities and allocation. However, to ensure managing for results is implemented effectively it is important that Tonga owns the narrative of results being used. Tonga needs to see results - in particular how well its national development priorities are being achieved - from a much higher and strategic level than just reporting on the progress of separate activities to satisfy donor requirements.

In this section the managing for results principle has presented not only the broad context but also how important it is to have a deeper appreciation of the nuances behind the activity. This is why working relationships and a collaborative approach are important. Australia and New Zealand need the insight, knowledge, and experiences from Tonga if they are to encounter success with their CPA. On the other hand, Tonga needs the CPA of Australia and New Zealand to support it achieve its national development priorities. At a broad level, there is agreement to manage for results and there are the general strategic planning and budget systems in place. However, the substance of regular and detailed reporting and monitoring appears to be lacking. Some reporting templates and routine systems are in place but these seem to be largely to satisfy donor needs. Similarly, there do seem to be some systems for donors and Tonga to discuss and review the progress of activities and having a general understanding of why activities do well or not is an achievement, but it can be concluded that much more can and should be done for Tonga to take the lead in defining assessment frameworks and indicators that are meaningful and relevant to the country's deeper development objectives.

\subsection{Mutual Accountability}

In the Paris Declaration on Aid Effectiveness mutual accountability is defined as "donors and partners are accountable for development results" (Organisation for Economic Development and Co-operation, 2005, p.8). Ostensibly the aim of the principle, so to speak, is to enhance public support for 'national policies and development assistance'. Expanded on further in the Declaration is prescribed separate 
and joint commitments for both the partner and the donor. In turn the commitments make up elements that constitute the definition of the 'mutual accountability' principle. Indeed, for these commitments they assume a perhaps unintentional naïve grasp on the reality because motivations and drivers are not always about development. For Tonga, this principle means strengthening the role of Parliament in national development priorities together with a budget and creating the appropriate multilateral engagement when assessing progress of implementation. Australia and New Zealand are expected to give timely, transparent, and comprehensive information regarding their aid flow. The reason is so Tonga can present foreign aid allocation reports to the legislature and grants wider accessibility to the public. Lastly, both partner and donor are jointly committed to "assess through existing and increasingly objective country level mechanisms mutual progress in implementing agreed commitments on aid effectiveness, including the Partnership Commitments." (Organisation for Economic Development and Co-operation, 2008, p.8).

The Kingdom of Tonga has two commitments under the Paris Declaration Principle of mutual accountability:

- Strengthen as appropriate the parliamentary role in national development strategies and/or budgets.

- Reinforce participatory approaches by systematically involving a broad range of development partners when formulating and assessing progress in implementing national development strategies. (Organisation for Economic Development and Co-operation, 2008, p.8)

When analysing the first partner commitments within the principle, the Kingdom of Tonga encounters several constraints. The most obvious is the constant state of change in personnel at the highest level in the Legislative Assembly, as demonstrated in the chapter four. The change in turn is often a result of political manoeuvring due to the leadership style and acts to reinforce the idea the changes, to an extent, are not out of necessity but self-inflicted. Inferred in the commitment is that Parliament members know their duties relative to their role. It is not entirely inaccurate to argue that together with the constant state of flux of personnel, and the reasons behind it, exists a general lack of knowledge, and gaps in expertise. Another theme, but interconnected with the previous two, is maintaining relationships which often is the central driver. Putting into place 'participatory approaches' requires reliance on nurturing or strengthening working relationships. The goal by Tonga therefore is not on the long-term outcome but on short- term gain due to the political context. Accountability for Tonga thus proved problematic in 2013-17 with political upheavals meaning that 
the sort of public participation envisaged in the Paris Declaration principle could not be effectively conducted through a pre-occupied parliamentary system.

Mutual accountability also involves donors. Australia and New Zealand are encouraged to commit towards providing Tonga with:

- timely, transparent and comprehensive information on aid flows so as to enable partner authorities to present comprehensive budget reports to their legislatures and citizens. (Organisation for Economic Development and Co-operation, 2005, p.8)

When taking into consideration the Country Programmable Aid of both Australia and New Zealand between 2013 to 2017 the commitment is not as straightforward as it would appear. This is for different but overlapping reasons. One is that 'aid flow' is dependent on a system in place which accommodates factors such as financial expertise and more importantly understanding the principles that might guide it, foreign exchange fluctuations between the Australian, New Zealand dollar and Tongan Pa'anga, and record keeping tracking allocation and expenditure, just to name a few.

Another factor is the lack of continuity in donor policies and systems. As indicated earlier, Australia went through change in its government during the period (from the Labor Gillard government to the Abbot (in 2013) then Turnbull Liberal-led governments in 2015) and this caused shifts in aid policy. New Zealand had a more stable government over the period, though its relations with Tonga was affected by the Chinese aircraft issue (see chapter six). Also it is important to acknowledge the context of New Zealand's aid policy prior to 2008. New Zealand emphasized in their aid programme at the time priorities more focused on poverty alleviation and, from an operational perspective, semi automatous with the establishment of 'NZAID' (Banks et al 2012, pp. 175-175). Then with the election of the National Government in 2008 the shift in policy and operational structure, as discussed earlier, built in more activities but change of priorities with a focus on energy and agriculture that is 'aid for economic development' (Spratt and Wood, 2018, p.27). So New Zealand aid was still in a process of transition even in 2013, moving from poverty-related priorities to more projects/activities in the economic sector. In addition to these political and policy changes, donor ways of operating experienced change over the period. Both donors struggled to implement multi-year aid commitments and forward planning. So there was not the desired level of certainty or predictability in the information on future aid flows they could provide.

Donor priorities may not always align with the stipulated commitment in the Paris Declaration as well. Here the Country Programmable Aid might experience internal movement in priorities, through change in Government for example, and by extension resources are mobilised to suit incoming 
political directives. However, aid flows do still occur and information has been provided by donors. This is reflected by Tonga being able to accommodate, tailor, and incorporate the information into the annual Budget Statement and Estimates. Tonga has been required to do this due to their own domestic legislation. The donor commitment acts more as a multilateral reinforcement of shared and agreed best practices. What is more of a problem is the efficiency, quality, and accuracy of the aid flow data reported by Tonga, though for no fault of their own. Chapter four illustrated many of the problems in providing accurate data about CPA given the complexity of the timing of allocations and disbursements and problems of definition.

Both donor and partner are asked in the Paris Declaration principle of mutual accountability to:

- Jointly assess through existing and increasingly objective country level mechanisms mutual progress in implementing agreed commitments on aid effectiveness, including the Partnership Commitments (Organisation for Economic Development and Cooperation, 2005, p.8)

As we have come to understand perhaps that essential groundwork needed to already exist here is mutual clarity on alignment - the Country Programmable Aid with the National Development Priorities - and harmonisation. These principles are multi-layered and are arbitrary in application by both donor and partner throughout the whole lifecycle. This arbitrary application is both intentional, being the strategic impetus of parties, and a cumulation, due to the by-product of intricate 'country level mechanisms'. Under that context this mutual accountability commitment is a work in progress between donor and partner.

\subsection{Conclusions}

At the beginning of this thesis I introduced the metaphor of Siutakahe'ahoafa where one is on a voyage navigating the vast ocean of international development and how at times storms are on the horizon. This chapter has navigated how aid programs such as the CPA use the five Paris declaration principles as guidance for better aid effectiveness. I have focused on assessing the principles not from the conventional donor framework but from what the reality is and what makes sense in Tonga. The Kingdom of Tonga continues to apply ownership by choosing to reconfirm its cultural values, identity is the development lens Tonga primarily uses. Despite the seeming proliferation of activities by one donor in a sector, there is still a collaborative approach to align the CPA with the national development priorities of Tonga. The features of the alignment principle are not exclusive to just the sectors or activities but to strengthen Tonga's system which is challenging due to capacity, resources, and personnel. Australia and New Zealand can do better under the harmonisation principle by avoiding duplication and repetition where possible. However, the harmonisation principle still has a fair way to 
go but Tonga can take a more active role via donor coordination. Managing for results is an important principle. Results may vary and may not always produce the outcomes Australia, New Zealand, and Tonga envisage. However, this research argues that it is equally important to understand the context and appreciate the nuances of the results. Holding each other to a level of mutual accountability is a delicate principle to manage. What the section on the principle has demonstrated is that parties appreciate the existing relationship mechanisms and how important bilateral relationships are collectively. Mutual accountability may be a work in progress, but it should not be lost that there is a mutual commitment to do so by Australia, New Zealand, and Tonga. 


\section{Chapter Eight: Conclusion}

\subsection{Siutakahe'ahoafā}

This research offers an interpretation of concepts pertaining to the national development priorities of the Kingdom of Tonga, Country Programmable Aid of Australia and New Zealand, and the aid effectiveness principles. The concepts are examined in the broader context for which they exist within international development and how they are applied in the context of Tonga's development landscape. Three important Tongan concepts are introduced in the beginning of this thesis as insight into the Tongan culture - Fakatapu is an action of reverence, permission, and acknowledgement; Fakafe'iloaki is introducing yourself but relatable to the collective; and lastly Siutakahe'ahoafā which is the title of this research meaning metaphorically, or heliaki, to navigate the dynamic nature of the vast ocean which is international development.

The purpose of reflecting on these Tongan concepts is acknowledgement as a Tongan that the thesis contains cultural elements, but I alone do not hold authority on Tongan culture. It is important to build on the work of Hau'ofa (1993), Lātūkefu (1968), Taumoefolau (1996), and Thaman (2003), to name a few, who are of Tongan heritage but incorporate Tongan knowledge into research. My contribution aims to broaden the knowledge of Tongan culture in research, and in the field of international development, by way of the three concepts mentioned. The first two concepts - Fakatapu and Fakafe'iloaki - are introduced in the beginning and serve more as an introductory protocol. Siutakahe'ahoafa is the thesis itself in that $\mathrm{I}$, as a Tongan researcher, am navigating the dynamic nature of the vast ocean of international development.

This research offers a bridge of understanding between the Tongan and outside world perceptions on international development. The research questions helped navigate this journey and it was also guided by three key foci: the national development priorities of Tonga; Country Programmable Aid of Australia and New Zealand; and the aid effectiveness principles of the Paris Declaration of 2005. These gave our voyage signs so that we knew we were on the right path. The destination - what this research found - is not only a location but also a reflection on important lessons gathered along the way.

This chapter reviews the thesis briefly before addressing each of the main research questions. It then explores some key thematic findings in terms of aid effectiveness and aid relationships and before finishing by addressing underlying issues in the development of Tonga. 


\subsection{Thesis summary}

This thesis has been concerned with the question of international aid in Tonga and the extent to which aid supports Tonga's own development priorities, strategies and activities. It is located within the broad concern for aid effectiveness, especially as articulated by the OECD-promoted Paris Declaration of 2005 which established five central principles for the improvement of aid effectiveness, and which represented a consensus at the time as to what constituted good practice in aid delivery. The thesis also recognises its place alongside theories of development. Here it sees the 'neostructural' paradigm in aid and development as being of particular relevance in the way it outlines a leadership role for the state with regard to development goals such as poverty alleviation.

The research focused on the period 2013-17 in Tonga and on the two main donors - Australia and New Zealand. It involved a mixed methods approach, combining a close analysis of relevant policy documents, such as Tonga's strategic development framework and agreements between Tonga and donors, with in-depth interviews with officials from both Tongan and donor agencies. These interviews gave insights into the way aid relationships are formed and operate in practice. These approaches were complemented by analysis of statistical data on both ODA and CPA flows in Tonga.

The substantive chapters of the thesis examined each of the three main parties. Chapter four looked at Tonga. It surveyed the political environment in the years under study, noting the changes that occurred in government and it looked critically at notions on leadership in Tonga, highlighting the need to follow the Tonga National leadership code. The chapter also covered the key development planning frameworks and policies adopted by the Government of Tonga. Chapters five and six focused on Australia and New Zealand respectively. For each, we saw different political context, Australia in particular experiencing changes in administration and priorities. Aid flows were also traced for both and this revealed the relatively minor place Tonga holds in Australia's aid portfolio (though Australia is by far Tonga's largest donor), whereas, for New Zealand, Oceania and Tonga figure more prominently. Both donors also could be seen to be articulating and following their own strategic priorities through their respective aid programmes and these were critical for Tonga to read and respond to.

Chapter seven brought the three parties together and used the five Paris Declaration principles for aid effectiveness as a framework to analyse the way aid relationships and interactions occurred in Tonga over the period. Here we found that there was generally high-level support for the Paris principles and these supported the idea that the Government of Tonga should 'own' its development, by drafting and implementing its development priorities and strategies. This was supported by agreement to 
abide by the principles of alignment with Tongan systems and Harmonisation amongst donors as well as pursuing practices which enhanced results-based management and accountability. The interviews revealed that these agreements were given some substance in practices which encouraged consultation and information exchange amongst the partners. However, in the details of daily interactions and practices, we also saw how these high-level agreements were often diluted or confused. Although Tonga had its own set of priorities, donors continued to choose which of these they would fund, according to their own strategic goals and concerns. Thus, separate elements of Tonga's priorities were supported but, arguably, the totality of its holistic strategic priorities was not. In other ways also, we saw this subtle ability of donors to shape what activities were pursued and which were not. Furthermore, given significant issues of capacity to operate effectively in the aid environment, with much onus on Tongan officials and agencies to provide data, report on progress, consult with the public and engage closely with donors, we saw how Tonga often struggled to exert strong and consistent leadership and control of aid-supported development.

The thesis has attempted to contribute to our understanding of aid in Tonga. To date, literature has been limited in terms of a Tongan interpretation of national development priorities, the use of aid, and aid effectiveness. The research has drawn inspiration however from previous Tongan scholars. It recognises Fa'avae's (2019) reflections on the challenges of an indigenous researcher and themes relating to decolonisation together with positionality. Lātūkefu (1979) is also valuable in the historical insight and interpretation of events. This window into the past highlights some important threads: that contemporary challenges to the effectiveness of foreign aid to Tonga have existed for many years; there has been no clear management of institutional knowledge; and leadership in Tonga still needs to do more. From an institutional and operational lens, 'Utoikamanu (1980) highlights the historic approach to national development via the Five-Year Plans and the transition into the Tonga Strategic Development Framework. Kefu (2005), Taumoepeau (2019), and Vaea (2019) have touched on governance.

Building on this earlier work, the interviews conducted for this thesis included Tongans and their perspectives together with their insight into the concepts applied to aid and development. However, more is needed to better align these Tongan researchers' perspectives on 'development' and their work. In particular the principle of ownership needs critical analysis so that Tongans lead in the construction and interpretation of what development means for the Kingdom. This research has addressed some of these themes such as the priorities, strategies, institutions and what they mean, how they are understood, and how Tongans apply them. 
There is a philosophical basis to develop Oceanic and Tongan understandings of development aid. For example, how applicable is decolonisation to Country Programmable Aid or Aid Effectiveness in Tonga? To me, it is worth the time to continue finding strands of our past to decolonise the way we think about and practice aid. An additional endeavour is figuring out strategies to apply Tongan knowledge and ingenuity. Leadership with Tongan values is key and retaining Tongans who have confidence in the Tongan culture and work experience abroad is valued. The national creed declared in the Kingdom's coat of arms suggests the strongest foundation and strength for Tonga's development aspirations - Ko e 'Otua mo Tonga ko hoku Tofi'a - which can be translated as God and Tonga are my inheritance. Guiding and believing in the people is arguably Tonga's best long-term investment. Essentially, it is one thing to think of decolonisation but an entirely different more pressing matter altogether to apply ideas into reality. Kēpa and Manu'atu, (2008), Rutherford (1977), Thaman (2003) and Hau'ofa (1993) have all contributed and have all enriched our understanding of Tonga in this light. Hau'ofa is perhaps the most appealing and most useful to utilize in relation to the emphasis of this research, that is the ability to think independently and critically with regard to Oceania.

However, I would also argue intrinsic to development is that the likelihood of a successful and enduring outcome rests on a locally-driven exercise of ownership, instead of an intervention by an external and foreign development partner. Where foreign aid enters for the purposes of development partnerships in Tonga, this research suggests that there is an imbalance. This imbalance is one actor holding more weight to influence, due to multiple reasons, over the other. Tonga for its part attempts to exercise self-determination and sovereignty but it is finding it increasingly difficult to lead its own development within the present aid environment.

\subsection{Research questions}

Having reviewed the research in general, it is now possible to address the research questions posed at the start of this thesis. The main research question was 'To what extent are the national development priorities of Tonga shaped or supported by international aid?' Before addressing this, the six sub-questions are examined in turn to better understand the two aid programmes under the Paris Declaration on aid effectiveness. Here we explore what the data informs us about how foreign aid is applied, the nuances behind it, the national development priorities of Tonga, and more importantly focus on the aid effectiveness principles. The research sub-questions for this thesis were:

i. How does Tonga develop and articulate its development priorities? 
ii. What is the external aid environment and to what extent does it align or not with these priorities?

iii. How do donor priorities and systems help shape the way Tonga articulates its own priorities?

iv. What analytical tools do donors (and Tongan agencies) use in the aid relationship?

v. How do these systems and relationships deal with the dynamics of aid (changes in policies and personnel on each side)?

vi. How do the relationships within aid systems in Tonga accommodate differences in the definition, prioritising and evaluation of development?

\subsubsection{How does Tonga develop and articulate its development priorities? and how do donor priorities and systems help shape the way Tonga articulates its own priorities?}

Tonga plans and strategizes its national development priorities by balancing domestic needs and external requirements. The systems of government formulate the country's development plans through a process of consultation, reporting, and reviews. In this Tonga also recognises the processes of Australia and New Zealand's CPA via the working relationships, aid mechanisms, and institutions. This recognition enables Tonga to collect information and strategically apply the knowledge on why, how, and where Australia and New Zealand apply their foreign aid. However perhaps the most important aspect in this important process is that Tonga practices ownership by possessing an innate and unique understanding of the future for its people. Identity, by way of Tongan values, continues to represent the core definition of development which is aspired to by the people of Tonga.

The Kingdom of Tonga uses the conventional bilateral engagement mechanism as a communication tool to articulate the national development priorities. From this process ownership is multidimensional given it has a shared functional and operational aspect to it and is not exclusively just a 'principle'. Tonga is strongest developing and estimating a budget for the national development priorities but needs to undertake more work to guide and improve donor coordination. The latter is more a reflection of the donor landscape and Tonga being strategic where, when, and how to engage with development partners. This comes in the form of forums, meetings, and established communication lines which Tonga and its development partners mutually abide by. Tonga has attempted to address donor coordination but with little traction and mixed results. Donor coordination, according to the Tongans, exists but appears to be more compartmentalized and 
functions in silos as donors pursue their own priorities to support. Tonga does not have direct control in the total allocated amount of the Country Programmable Aid, but they can influence it more.

The ways donors operate and the need to a balanced approach to participation shape how Tonga articulates its own development priorities. Other examples of donor priorities and systems that shape how Tonga articulates its own priorities are high level mutually-agreed commitments, strategic investment plans of Australia and New Zealand that articulate the priorities of their aid programmes and the overarching documents that act as a bilateral reference point, such as the joint commitments for development. The development priorities of Tonga are influenced by the extent donors perceive a purpose for it within their investment strategies. Tonga leans towards accommodating donor foreign aid priorities and systems. During the period of 2013 to 2017 Australia, New Zealand, and Tonga all experienced a high flux of change at the political (change of governments), organisational (change of ministerial portfolios for Tonga and the reconfiguration of the aid programme for Australia and New Zealand), and personnel (constant change at senior officials) level.

Despite this Tonga still manifests an ability to manage, engage, and articulate its national development priorities and is not contingent on the changes or the outcome of those changes. Tonga continues to own its national development priorities by defining what that change is heading into the future.

\subsubsection{What is the external aid environment and to what extent does it align or not with these priorities?}

This question centres on the principle of alignment and in this research, alignment involves the degree to which donors fall in behind Tonga's systems and institutions to support them and work through them. At a higher level, however, alignment could be seen to be first manifested in the way all parties agreed to broad strategic goals, firstly in the Millennium Development Goals and, after 2015, in the Sustainable Development Goals. Both these are development frameworks that enable both donors and recipients to streamline an understanding where motivations at the global level for foreign aid programmes originate. Tonga has participated in several international meetings and agreements which have generally influenced their domestic aid environment. Participation includes being a signatory to the Millennial Development Goals (Naidu, 2009) and Sustainable Development Goals as global frameworks. Tonga, as part of the Pacific Islands Forum, also agreed to the Koror Pacific Aid Effectiveness Principles at regional level which were derived from the Paris Aid Effectiveness principles. These gave further shape to the aid framework and relations between Tonga and donors. Finally, and crucially, the Government of Tonga developed the Tonga Strategic Development 
Frameworks I and II at the national level. All these elements provided a clear broad framework for Tonga to state its priorities and systems and for donors to align behind them.

More generally, the external aid environment helps define and guide the degree of donor alignment. Regionally, the support provided by the Pacific Islands Forum and similar regional institutions operate in a niche way. That is, they heavily specialise providing technical assistance to the member countries including Tonga. Like the Asian Development Bank and the World Bank, the regional institutions receive funding from donor countries such as Australia and New Zealand. The technical assistance the regional institutions provide fill a gap needed often during implementation and aim to maximize the effectiveness of the funding. For Tonga, the Strategic Development Framework I and II offer a bridge where policies between levels overlap, shared, or tailored. In terms of aid effectiveness, Tonga at the global stage has commitment to both the Paris Declaration and the Global Partnerships for Effective Development Co-operation (GPEDC). However, what this means at a national level is hard to ascertain. One of the biggest challenges to Tonga at times is translating the relevance of global commitments to the national level. Despite this, the national development priorities of Tonga are still invested in by development partners as exemplified by the aid programmes of Australia and New Zealand.

Although we see donors generally following the broad development priorities of Tonga (albeit with a degree of selective support), one of the challenges with alignment in practice concerns the more operational elements. The Paris Declaration called for the alignment principle to involve donors using partner country systems and build their capacity. Yet there has been a high influx of development aid with an increase in the types of donors, more bilateral projects, more private sector partnerships, and a growing need to address issues that cross borders and require a multilateral approach. This proliferation of aid activities and agencies, and increases in volumes and scope has stretched the capacity of Tongan systems to cope. In practice, donors have often used their own mechanisms, such as the use of consultants and out-sourcing, rather than relying on Tongan institutions and personnel - or investing substantially in building the capability of such institutions.

\subsubsection{What analytical tools do donors (and Tongan agencies) use in the aid relationship?}

Aid relationships require parties to adopt shared and effective tools for implementing and monitoring aid programmes and projects. Perhaps the most important set of tools are those used by the Tongan Ministry of Finance. The budget to implement the development priorities is approved by Parliament but then both domestic and aid funds are disbursed through the Ministry's own financial management systems. These are subject to audit and donor scrutiny so that there is reasonable confidence in the way finances are managed. 
The second element is demonstrated by analytical tools used by donors such as evaluations and reviews. Tonga participates together with other development partners separately from Australia and New Zealand. An evaluation informs us how well working relationships are operating between officials and key institutions, be it the implementing agency or the documented arrangement of parties. Foreign aid rests on different ideals such as accountability or what is the money spent on, participation including collaboration with the recipient designing the project, and effectiveness that asks what the result was. Reviews take the form of activity level progress reports, reviews of an activity and feasibility studies, and donors have undertaken such reviews on a regular basis in Tonga. They are not only analytical tools but are strategically selected, concurrently with the pre-high-level meetings, as ways donors such as Australia and New Zealand are able to exert some further influence and further their interests within the aid relationship. To do so requires information gathering and close understanding of the working environment in Tonga.

So we can see a range of such tools being used in the aid relationship but they are used and valued in different ways. To a large extent, the reviews and evaluation process is donor-driven. It is conducted largely so that donors can report to their own constituencies and auditors regarding the way aid has, ideally, been carefully spent and has achieved its objectives. This approach has put emphasis on financial management systems and accounting procedures - to show that funds have been managed well - rather than necessarily on the effectiveness of the results. This latter task would require more long-term focus on qualitative outcomes. For the Tongan side, evaluations and reviews may be taken note of - and they help keep donors involved - but ultimately evaluation of the effectiveness of aid is a much more complex process, conducted sometimes through the political sphere and linked to deeper cultural and social considerations of what constitutes good outcomes.

\subsubsection{How do these systems and relationships deal with the dynamics of aid (changes in} policies and personnel on each side)?

This research finds that working relationships between Tonga and development partners play a key role in aid delivery and how Tonga articulates its national development priorities. This relationship, because of its strategic importance, is established early amongst the actors and maintained though not without challenges. Relationships matter because for development partners, such as Australia and New Zealand, it is important for them to know who it is they are working with in Tonga and subsequently the implications. To do so requires information gathering about personnel, their placement in the intricate influential and working networks, and capacity to ensure the objectives intended by their foreign aid is achieved. 
Given the high level of turnover of personnel and governments on both sides -as we have seen - it is important that there are key elements in place which provide both a level of stability but also allow for some flexibility. In this regard, the Tonga Strategic Development Framework plays a critical role. This provides a strong and stable platform for presenting Tonga's development priorities that stayed in place, through its two iterations (TSDF I \& II) during the period under study. However, the Tonga Strategic Development Framework is not a national plan but rather more a framework. This subtle distinction is important because as the extract below emphasizes the design of the framework considers change in government:

"The Role of TSDF II: ... It is not a national plan with detailed priorities. It is a ten-year framework within which government, and other organisations in the Kingdom, can plan in a more consistent and integrated manner. Detail of the implementation of the framework will be identified in the planning and budgeting documents of sectors, districts and MDAs. There is also scope for each political administration to choose certain key areas for focus and to document them in a Priority Agenda within the framework (emphasis added)." (Ministry of Finance, 2015b, p. 48)

Having a centralised approach is another measure Tonga has in place that provides some stability in relationships and processes. The Ministry of Finance is consistently the contractual partner whereby funding is deposited to the Government Development Account. Subsequently the funding would then be allocated according to the agreement with the relevant implementing partner - Ministry of Commerce, Labour, and Tourism, Tonga Power Limited, and the Tonga Police Force. This adds a layer of stability and continuation to the changes that the working environment in Tonga is highly prone to in the years of this research.

Alongside these important elements - the strategic development framework and the financial management system- other institutional structures and processes are in place that deal with the dynamics of aid. High Level Consultations and the donor partners forum hosted by Tonga are examples. The donor partners forum is used as an opportunity, for both development partner and Tonga, to articulate Tonga's national development priorities and donor's development programmes. The forum allows for new officials to meet and get to know each other and maintain existing relationships. Engagement, often through less formal mechanisms but possible in the relatively small social environment of Nuku'alofa, is another means that Australia, New Zealand, and Tonga employ to build relationships. 
The changing aid environment in terms of policies and personnel, though, does pose particular challenges. On both sides the ability, expertise, knowledge, and technical skills are imbalanced in recognition, appreciation, and acknowledgement. A prevailing assumption with foreign aid is that the provider, having greater resources, knows more not only than the receiver but can compete (or duplicate) with other donor systems. There are grounds to this belief driven in part by the lack of due process and adequate representation pushed forward by Tonga to coordinate development partners. Nonetheless, the relationship is not entirely unilateral and has meaningful exchange in some areas.

Therefore we see that the dynamics of aid do involve considerable 'churn' in terms of changing staff and government policies and leadership. However, it can also be suggested that aid in Tonga has been able to deal with these changes reasonably well through a combination of stable strategic and operational frameworks and flexible relationships reinforced through frequent engagement. Nonetheless, a frequently changing aid environment remains an issue and is not conducive to the pursuit of long-term and consistent aid strategies and commitments.

\subsubsection{How do the relationships within aid systems in Tonga accommodate differences in the} definition, prioritising and evaluation of development?

One of the fundamental issues to be faced in the aid system in Tonga - and elsewhere - is differences in the basic conception of aid. This is where the theories of development offer not only analytical tools to us but a view into the world. What that view is depends on what the theory outlines. The indigenous epistemologies and ontologies of a Tongan have a different understanding of foreign aid and development from Australia and New Zealand. The epistemology of a Tongan, in terms of development, is that growth is what you give someone instead of what you gain (see, for examples, Gegeo 1998 and Hau'ofa 1993, and Ulu 2013 for Oceanic conceptions of development). It is bound by webs of relationships and reciprocity. For donors, development is much more a matter of a linear and material approach that seeks to achieve a range of economic and welfare improvements (for example Sachs 2005, Arndt et al 2015). Therefore, this outlook has broader implications for development at the national level and how Tonga engages with Australia and New Zealand. Looking ahead and taking that knowledge is important for the parties to strengthen the aid relationship. It enriches their understanding of where the other is coming from and is not just another policy or process to complete. Ratuva and Brady (2019), for example discuss how New Zealand sees its relationships in the Pacific as not just 'neighbourly' but also linked by genealogy.

Another way of seeing aid relationships is to appreciate differences that are evident in the range of institutions involved. The aid systems in Tonga are not only the contractual and implementing agencies such as the Tonga Ministry of Finance and other line Ministries but also other aid-related 
stakeholders and these add complexity to the definition and prioritizing of development. These stakeholders include local non-government organisations and private companies, and the range of NGO and private sector partners that come from donor countries. Hence, the volume and types of actors is a notable aspect of the aid environment in Tonga. We have seen that Tonga hosts only two residential embassies and two residential High Commissions but there was a long list of development partners between 2013 to 2017 according to the Government of Tonga Budget Estimates (see table eight). Thus, although this thesis has focused on Australia and New Zealand as the main donors, the multiplicity of other parties operating in Tonga has influenced how the definition, prioritising, and evaluation of development has to be accommodated in complex sets of relationships. This includes the monetary amount each development partner provided, the large number of development partners, and different policies that each development partner adheres to.

To accommodate this complexity and different perspectives and processes, Tonga has sometimes struggled due to limited capacity, though it has also turned to international agreements and frameworks to help. Tonga participates in several international meetings and agreements which have generally influenced the aid environment. This participation by Tonga enables it to use different platforms and institutions to convey how it perceives or interprets its development. Having the ability and access to engage on issues that are transnational is important for Tonga and assists in finding common ground, if differences arise, pertaining to foreign aid. The type of aid system is important and entails its own contribution to the working relationship. Multi-lateral institutions are also of use. For example, the regional development partners specialise in thematic areas such as climate change (SPREP) and fisheries (the Forum Fisheries Agency). As topics that require a collective effort above Tonga's national level, members of these regional/multilateral institutions develop frameworks and mechanisms to implement where otherwise this would've been a gap left unattended.

Tonga is represented by both circumstance and adaptive strategic directive and leans toward a more support and coordination role but only where they can concerning foreign aid. Local capacity to closely manage aid and its effectiveness is limited. Therefore, Australia and New Zealand carry a responsibility to measure the impact and effectiveness of their aid programmes. This difference is not a divergence without the possibility to realign but more a product of the current dynamic and circumstances.

With regard to the overall question regarding differences in the definition, prioritising and evaluation of development, it seems that very little is indicated by Tonga to voice what it perceives as 'results'. What I mean here from the analysis is that Tonga gives, due to varying reasons, little weight to the 
power of owning the 'results' narrative. Often the lens that dominates is that according to the two donors. No real straightforward indication is hinted by Tonga as to why they do not formulate their own reporting criteria or standards. It is important for Tonga to be able to tell a story of what it has achieved but together with knowing the nuances behind the activity. The reason as to why the context and nuance of an activity are important is because to understand the result fully is to appreciate the circumstances that shaped it. This is why working relationships and a collaborative approach are important. Australia and New Zealand need the insight, knowledge, and experiences from Tonga if they are to encounter success with their aid programmes. On the other hand, Tonga needs the aid from Australia and New Zealand to support it achieve its national development priorities. In practice, Tonga does not have sufficient knowledge of what the donor processes are, what their underlying motives are or how they manage their aid programming. Such knowledge is needed if Tonga is to own and lead its development strategies more effectively. Relationships within aid systems in Tonga attempt to accommodate differences in the definition, prioritising and evaluation of development through enabling access, engagement, and building on existing strengths but much can done to improve mutual understanding of these differences.

Having reviewed these specific research questions posed in this thesis, it is now possible to address some broader thematic findings. These widen the discussion and suggest that the experiences of Tonga can help inform the future of aid both globally and in Tonga itself. Here we move from global frameworks, to relationships with donors, to finish with some broad conclusions regarding development and leadership in Tonga.

\subsection{Aid Effectiveness}

This research has engaged closely with notions of aid effectiveness and, in particular, with the aid effectiveness framework established by the OECD and the set of principles put in place in the Paris Declaration of 2005. The OECD has played a key role in building and extending the aid effectiveness framework and it has clearly had an effect on the way Tonga, Australia and New Zealand practice aid delivery. Although in 2020 the aid effectiveness approach has been somewhat weakened, with no further high level forums since Busan in 2011, and a move by donors towards more self-interested and shorter-term approaches to aid (Harmon and Williams, 2014; Gulrajani, 2015; Mawdsley et al., 2018), it is possible to reflect on how aid effectiveness has played out in Tonga and what some of the lessons learned have been.

Woodward (2009) expands on the organisational establishment of the OECD and how it changed throughout the decades whereas Magid (2012) offers insight into the program that is seen as foreign 
aid and how this it came about. Linked to this is Australia and New Zealand joining the OECD around the same time in 1971 and 1973 (Organisation for Economic Co-operation and Development, 1973) respectively. Throughout the years, foreign aid has morphed and evolved into how it is today after many different types of experiences and encounters, some a success and some often proving hard to decipher. Out of that, this research reflects on the background towards how foreign aid landed on 'programming' as a modality and subsequently Country Programmable Aid. Country Programmable Aid here is an aspiring intent to achieve the elusive ultimate outcome of the practitioner to render the foreign aid effective. Programme approaches represent a high-order modality of aid delivery that involve larger volumes over longer timeframes, a scaling up of the scope and impact of aid, and strong donor support for recipient systems (Koeberle \& Stavreski, 2006; Overton \& Murray, 2020). Programme approaches align with the neostructural approach to aid and are closely linked to the OECD's aid effectiveness framework.

The aid effectiveness principles arise out of a common understanding between donor and recipient to frame the dynamic more as a partnership through shared commitments (Organisation for Economic Co-operation and Development, n.d.). This recognizes the development landscape which even today is still changing and evolving, though strong elements of the neostructural approach remain. Literature pertaining to Tonga and the subject matter of international development and aid is sparse (Needs, 1988; Campbell, 2001; 'Utoikamanu, 1980; Mountfort, 2013) or focuses more on wider cultural and social issues (Thaman, 2003; Hau'ofa, 1992; Lātūkefu, 1968; and Taumoefolau 1996). These are all important in this research for they all contribute to the understanding, and emphasized here, the context, history, and background that the way the global-level concepts and approaches are manifested on the ground in Tonga. We can see the way these global approaches are reflected and adapted by agencies and actors in Tonga. A few official documents are critical here. These include the Australia-Tonga Partnership for Development (Australia Department of Foreign Affairs and Trade, 2014b), the Joint Commitment for Development between Tonga and New Zealand (New Zealand Ministry of Foreign Affairs and Trade, 2016c), and Tonga's Strategic Development Framework I and II (Tonga Ministry of Finance and National Planning, 2015b). This research has seen how this mix of global-level understandings and agreements, particularly the OECD's aid effectiveness framework, and local and regional contexts and concerns has combined to produce a particular form of aid environment.

Modernisation, neoliberalism, and neostructualism, as theories of development, are shown to have one fundamental limitation here in this research. That is, their conceptual frameworks is based on how a western world view perceives reality. Modernisation is constrained by the reality whereby not all nations, and therefore the development of each country, propel the same cultural, historical, and 
economic trajectory. Modernisation offers a limited interpretation of development that is foreign to Oceania in many aspects. Most obvious is the way the introduction of external concepts, many of which (such as individualism) are alien to indigenous cultures but at times force a way into the community. Neoliberalism, on the other hand, imposes a market-oriented view of economic organisation and development as the sole focus of all national development priorities.

Neostructualism appears at first to offer a more pragmatic and flexible approach, mixing state- and market-led approaches. However, this can be problematic when the onus falls on the ability and capacity of the state to act rationally and knowingly. In the case of Tonga, the state has often struggled to do so effectively and meaningfully. As a theory, neostructualism should open the door for more local, in this case Tongan/Oceanic, ways of driving development. Local ownership should really allow opportunity for these grounded ways of operating to take the lead. In the case of Tonga and articulated in the Tonga Strategic Development Frameworks I and II, there is emphasis on advancing cultural values but parallel to economic growth. However, for Tonga achieving the balance between effectively identifying its place in the world under its right to self-determination and finding a sustainable viable economic option is proving elusive. This research shows that the realities of operational aspects of foreign aid such as policies, documents, reporting - coupled with issues of local capacity - mean that this possibility is compromised. Tongan views are supposed to be at the forefront but they struggle to be heard or miss those opportunities. Perhaps the 'culture' of the foreign aid world, its ways of operating, language, procedures, override the cultures where it operates. This is similar to the arguments highlighted by Overton et al (2019). They argue ownership is limited by the operation of aid and designate this as the 'inverse sovereignty' effect - ownership is promoted in principle but undermined through new conditionalities in practice. However, they do suggest that there are some opportunities under the Paris Declaration on aid effectiveness where local ownership could be asserted more in Oceania $(2019$, p. 185).

The importance of aid effectiveness to the international community is equally relevant in this research alongside how the term is framed from the point of view of Tonga, especially the Tongan community. Tonga views foreign aid effectiveness from the indigenous framework of Siutakahe'ahoafā. This indigenous framework is one example. Siutakahe'ahoafā in this sense acknowledges that at the community level, aid for them has many aspects and components to it. While aid does have a significant impact in Tonga it is subject to Tonga's own objectives and networks of relationships and power.

The Paris Declaration can reasonably be argued as step in the right direction for the effectiveness of foreign aid. However, what determines or ensures the likelihood of effectiveness is multi-layered and 
multifaceted, dependent on will, need, and perhaps more importantly leadership. The Paris Declaration on Aid Effectiveness should also be interpreted as for what they are - principles. They are not legally binding statues for which donor or recipient are to abide by concerning foreign aid together with national development priorities. The Paris Declaration on Aid Effectiveness are principles and the appreciation, the adherence, the agreement to them are first and foremost demonstrated by the willingness of both donor and recipient. This is commended for both and by all indicators the closer collaboration is evident under the principles for aid effectiveness. As we have seen, the principles are important and have had some useful impacts but they are often undermined or complicated in practice.

In this light, and reflecting on the operation of the aid effectiveness principles in Tonga (chapter seven), it can be suggested that the principles have had some positive effects in Tonga. None of the five principles have been completely followed in practice and results in terms of effectiveness have been mixed. Yet the fact that the principles exist, and the parties subscribe to them at a high level at least, does provide Tonga with more leverage and ownership that it might otherwise have had. Even if the daily realities of practice mean that ownership, alignment and Harmonisation are not fully achieved, they do provide agreed foundations for aid relationships. To return to the overall research question of this thesis - 'To what extent are the national development priorities of Tonga shaped or supported by international aid?' - it can be suggested that, at the least, the aid effectiveness principles do provide a means to keep donors in line with such priorities as defined by Tonga and to actively support them. Under alternative development paradigms such as modernization or neoliberalism, there was little or no such concern for local ownership or for the contextualizing of development.

However, as a final observation here, we can see a weakening of the neostructural approach used by Australia and New Zealand in recent years. The high-level modality of foreign aid support, namely Country Programmable Aid, is still in operation but is being diverted from in some ways. At the ground level, by championing international private sector engagement, new forms of the neo-liberal paradigm are being re-introduced. The renewed focus on the private sector, together with the sectors that both donors are supporting - energy, agriculture, fisheries, and tourism - suit this new approach that opens opportunities for the private sector from donor countries to operate in Tonga. Given these recent shifts and a weaker adherence to the ownership principle, it is important to re-emphasise the need for Tonga, despite ongoing forms of a push towards economic development, to maintain a strong lead to ensure culture-oriented or culturally appropriate forms of development. 


\subsection{Aid Relationships}

With this understanding of the complexities of applying international principles and agreements regarding aid to countries such as Tonga, we now turn to considering how relationships between Tonga and donors has played out. This research has focused on Country Programmable Aid as one area of Official Development Assistance. Australia and New Zealand were chosen together with Tonga to unpack the dynamics between aid and national development priorities. What this research points out is that aid programming encounters different context and scenarios that shape or support national development priorities. It is possible to make some observations from the research with regard to the way aid relationships work in complex ways to produce diverse aid and development outcomes.

Determining the exact extent to which foreign aid shapes and supports national development priorities is guided by the agreements, common policies, and partnership arrangement documents. What I mean here is that both donors, Australia and New Zealand, together with the recipient, Tonga, have systems and structures in place. The systems and structures do not guarantee the desired result or objective, but they do make it more probable. They help provide some guiding objectives and processes but they are open to negotiation and change in practice. The 'extent' of shaping or supporting development is not controlled but it also is not clear whether the intention is to do so. This is because the intended results for each party are not always toward development per se but at times a different underlying interest - political, strategic, or economic. Achieving these wider objectives and interests involves using aid and development as a flexible policy tool. This is particularly more apparent with Australian Country Programmable Aid than New Zealand Country Programmable Aid. Australia engages in a more prescribed manner with their aid program and delivery, with strategic and security concerns prominent (Fry 1997, Hamieri 2008) whereas New Zealand aims to leverage themselves as being part of Oceania (Ratuva, 2019). This is not saying either is correct or wrong but rather it is important to keep in mind how they understand the purpose of their respective aid strategies. Development through foreign aid to another country is positioned to the overarching national interests of the donor. As its most basic expression, Australia and New Zealand do not have Country Programmable Aid in Tonga solely or even primarily to achieve Tonga's national development priorities. Rather, they support these priorities as a means of achieving wider objectives, largely political stability and diplomatic alignment. Country Programmable Aid by its creation and origin thus is an extension of the underlying interests of the donor which then seeks to work through mutual and collective interests.

Tonga exhibits ownership by articulating its national development priorities but it does have potential to be more active. The focus for Country Programmable Aid and the tendency to be donor-oriented and supply-driven (Wood 2015; Overton et al, 2019, pp. 66-68) shape and limit the form of ownership 
Tonga exhibits. This observation is to discredit the attempts at partnership, but this research points to an imbalance. There are multifaceted reasons to why this is so and it is not entirely due to the donor side. Tonga does at times lack the capacity, resources, will power, and technical knowledge to strongly drive its ownership. In addition to those reasons Tonga does not intentionally or purposefully do so but appears to be more of an unintentional by-product from being preoccupied with domestic priorities. The development landscape in Tonga is complex and involves many development partners, resulting in proliferation and fragmentation of activities. Within such an environment, aid in practice is still predominately donor-driven, especially at the operational level. This is not in the best development interest of Tonga and the national development priorities do not assume the prime position they should. This argument is not implying that Tonga should fully control all Country Programmable Aid. Rather, it is indicated from the research that the two sides are not collaborative enough. Going further it can be argued that it is important for Tonga to own the space of donor coordination. We need a situation where donors know clearly the policy and operational details of their aid programme in country and the recipient knows the development context and landscape of donors. The potential for Tonga lies in applying a collective and more united front, especially at the leadership level, being clear and assertive in articulating what it perceives as the best interests of Tonga for the future.

Information is key to the national development priorities. This research strongly indicates that better more meaningful development outcomes are potentially achievable for Tonga, but the wealth of knowledge that exists is not effectively used. The argument here is that Tongan leadership can do better with the resources available. The issue appears to be the management of that information, specifically who generates the information about development and how the actors use that knowledge. Many of the informants echoed a common view that the donor process is duplicated and repetitive. This carries weight when looking at multiple donors following the same project management cycle norms - concept notes, design, implementation, review, and evaluation - for many activities. What is perhaps 'lost in translation' so to speak is the linkages and rationality that connects it all. This concerns the due process mechanisms in place and why they are in place, the lessons learned incorporated into the process, the decisions to proceed or not and the manner the decisions are communicated. They are linked to arguably a lack of transparency, communication, and applied strategies. The reality of the harmonisation principle is that the large number of different donors continue to use different templates and processes. Tonga may have the same meeting with different development partners asking almost word for word the same question. These practices are acting both to strain Tonga's limited resources but also weaken its ability to lead the development process. 
Tonga continues to define and move forward on self-determination regarding the interests of the Kingdom. Challenges have arisen, for example during 2013 to 2017 when there was much ministerial turnover. I would also argue that the ability, capability, and general capacity of those in influential and leadership positions of Tonga require adherence to the national leadership codes. Opportunities to maximise the effectiveness of aid have presented themselves to Tonga but not been taken. Missed opportunities for Tonga pertaining to the five Paris Declaration aid effectiveness principles (as argued in chapter seven) include stronger alignment, active ownership, harmonisation and donor coordination, being accountable, and delivering more realistic and grounded results. To achieve a more effective management of foreign aid Tonga needs to apply more continuity and apply their capability to the expertise that exists. This argument is referencing the Executive branch but does note the influence of the other branches that make up Governance in Tonga. Culture and traditional values still play a huge role in the development of Tonga. Furthermore, while the depth of expertise with knowledge and skills regarding these aspects in Tonga in donor aid programmes is rotational and limited, engagement and leadership from the Tonga side, especially at Ministerial level, has tended to be limited and variable in nature.

The motivational focus for Tonga appears hinged on short term, often political, outcomes instead of consistent commitment to long-term development goals. For example, we might ask what does Tonga want in terms of an educated population or sustainable energy in coming generations rather than just focus on how much money can Australia give Tonga for education in the next budget or how much can New Zealand give to the energy sector. At the political level, the shift to emphasize long term outcomes needs to be highlighted at the very least if Tonga wishes to have a credible and robust system. Important elements have been put in place, such as the TSDF I and II documents, but aid relationships in practice have proved to be much more operational and opportunistic than strategic. Under the current democratic system, arguably in all the three countries, the ability to be elected does not automatically translate into an effective, coherent, and competent outcomes as desired. Effective leadership in development demands the ability to set a long-term course and navigate the 'storms' along the way in ways which keep the development destinations as consistent guiding navigation points.

\subsection{Tonga's National Development Priorities}

Having examined the issues regarding global aid effectiveness agendas and the complex interplay between donors and Tonga as a recipient, this thesis finishes by addressing the challenges for Tonga. These challenges focus on how it can better articulate and drive its development priorities through the aid environment. 
The national development priorities of Tonga are captured, acknowledged, and articulated through the Tonga Strategic Development Framework I and II. Australia, New Zealand, and Tonga have each engaged with this framework, and in doing so, they have interpreted the TSDF I and II but some key differences. Mainly, Australia and New Zealand engage with the TSDF at a high level but from the perspective of how it aligns with their own aid priorities and strategies. The Tonga Strategic Development Framework is the main document which the Kingdom uses as a framework for a collective and cohesive approach towards development. Tonga encounters unique challenges at a national level pertaining to foreign aid being an effective development tool. The research suggests this is something that both Tonga and donors do not fully appreciate. Tonga has outlined many aspirations in the Tonga Strategic Development Frameworks I and II for the years 2011 -2014 and 2015 -2025. The two documents are the official Government of Tonga's framework for the Kingdom's national development and there are many important priorities laid out that will enhance Tonga's independence and well-being. However, when the national development priorities are examined under the Government of Tonga Budget between 2013 to 2017, we observe it indicates that they are dependent upon a high volume of foreign aid and, as argued earlier, such aid is not well aligned or harmonised in practice as it is swayed by the changing specific policies and objectives of the donor. When we examine the high-level agreement between the two donors and Tonga, Australia's Tonga-Australia Partnership and New Zealand's Joint Commitment for Development, I suggest these are essentially what donors think of Tonga's national development priorities, and select from them, rather than a strong and comprehensive adherence to what Tonga sees as its priorities. So, Australia and New Zealand do support the national development priorities of Tonga but only selectively and pragmatically.

Multiple visions of what the Tonga national development priorities are, or should be, exist. Indeed, the overarching Tonga Strategic Development Framework I and II exist and went through a centralised government consultation process. However, the level of buy-in towards the framework and its content are relatively weak. The national development priorities of Tonga exist in competing interpretations of priorities, allocation of resources, and which priority holds precedence over the other. There are limited channels whereby other stakeholders, except for the Government, can engage. Even so, the nature of that engagement is problematic as it leans more prominently towards the Government as a financial provider or broker to development partners. There is little space or reason for these other stakeholders to find their own core funding. This flags a by-product of the development environment Tonga currently exists under, one of heavy reliance on foreign aid (as demonstrated in chapter four). We can see this as a characteristic of the neostructural aid regime where the key relationships are between governments and higher aid volumes, ideally, are transacted through recipient governments' 
own systems and strategic plans. This heavy reliance on aid and state systems and the lack of opportunity for other stakeholders to venture out independently creates an environment where foreign aid donors can shape how and what the national development priorities of Tonga are. After all, the Tonga Strategic Development Framework I and II are only aspirations by the Tongan Government. Putting that into action is completely different and dependent on the limited and selective nature of aid funding. Attempts have been made by Tonga to be more strategic toward thematic areas such as the Agriculture Sector Plans and the Tonga Energy Road Map. These are useful and important steps to take. Thus, there is a need for a centralised mechanism that has an overview and can ensure more concerted and harmonised development activities through aid. This would need the ability to see the 'bigger picture' together with being able to function strategically.

An often overlooked and under acknowledged operational aspect of the national development priorities is personnel. This was touched in earlier chapters whereby Government of Tonga employees are tasked to manage the bilateral activity on top of their core responsibilities in their job descriptions. For the two development partners examined in this thesis, the sectors they are most apparent in carrying this out are the Ministry of Education and the Ministry of Health and these are under considerable pressure. Once the bilateral agreement is decided at a high level - involving the Minister and Chief Executive Officer - it is then passed down to staff to implement. Several activities have encountered significant limitations of such an operational approach with one donor implementing seven different activities at once within the Ministry. A troubling aspect regarding this issue is the attitude expressed when it is highlighted: one of very little change or recognition. Often, the donor perceives this as being the Government of Tonga's issue to handle given, the donors, are 'the ones offering the money'. Therefore, the issue of capacity is acute and there is a serious need for donors to be aware of this and provide resources to alleviate it, perhaps through augmented salaries and longerterm training, as well as being much better attuned to the need to co-ordinate and limit their demands on Tongan institutions and staff.

An activity should have an adequate operational and administrational costs together with an adequate governance structure. The issue is not as straightforward as increasing the salary of those tasked with managing the activity, hiring local personnel, or designing the activity as being semi-automatous. Many activities, and administrations on both sides, have tried to find the right mixture of local expertise, salary caps, and operational budgets but have landed only mixed results. Part of the reason this aspect is so hard to figure out is because of the development environment and context the activity operates under. 
Tonga encounters unique challenges. This is not to say that the challenges are only found or experienced in Tonga, but that the nature of the unique challenges is what distinguishes them from other development contexts. In addressing this claim, maintaining institutional knowledge would be an immediate and sensible remedy. If that were the case, we are likely talking about hiring, at least within the local context, personnel near retirement. If one observes the average age of those in leadership positions in Tonga within the Government, Legislative Assembly, and other important national development bodies, the majority are late in their careers, born in the 1950s and 1960s. This generation has a completely different and at times outdated perspective on so many of Tonga's national development priorities and it shows in the approach, nature of their engagement with external actors, and policies. Yet they also have experience and wisdom that should be better utilised and tapped by new generations of leaders.

More local knowledge and expertise should either be developed or appreciated together with the appropriate human resources. The current model of whereby an outside 'expert' is procured but then mines local knowledge and reports it back as official documentation of the donors is flawed. This is a model that presents a dilemma that is subjective and difficult to find an adequate solution. In the spirit of what foreign aid encapsulates then development under the ownership principle perpetuates a sense of responsibility. In Tongan, responsibility and the act of responsibility is translated as fatongia. Two references have been made earlier in this thesis to this, first by Ka'ili who translates it as social duties (2008) and the other by Lātūkefu as obligation (1980). My interpretation of the word fatongia is responsibility which includes in Tongan culture your obligations to fulfil your social duties accordingly. This act of responsibility is characterised by the courage to serving with humility and without expectations. Meeting this requires mateaki and mamahi'i me'a which are Tongan leadership values. These are values that ask us to work towards an agreed common vision and outcomes. Tongan personnel will need to be more active in this space to effectively articulate what works.

The most fundamental and unique challenge but also a strength for Tonga is the enduring resilience of our culture. This aspect is given some acknowledgement by the two donors and ironically, they emphasize in contrast their national 'expertise'. This is true to an extent from a technical perspective - Tonga at times requires technical experts in many, but not all, of the fields or sectors required. Even with the technical expertise that Tonga does have, it often encounters further auxiliary issues such as the adequate value to local knowledge to maintain it. The Tongan culture is a strength in many aspects but most relevant here are the leadership code. They are Mo'ui Faka-e-'Otua (Piety), 'Ofa (Love), Faitotonu (Honesty), Faka'apa'apa (Respect), Mamahi'i Me'a (Commitment/Loyalty), Tauhi Vā (Reciprocal Relationships), Vahevahe Tatau (Equity), Fa'a Kataki (Patience), Tali Ui (Accountability), 'Ata ki Tu'a (Transparency), Falala'anga (Integrity), Ngāue'i Kaha'u (Visionary), Fakatokilalo 
(Humility), and Mo'ui Lelei Fakaesino (Healthy). The leadership code is fundamental to Tongans together with the Tongan culture and if adhered to in action especially under the context of the national development priorities, more meaningful collective achievements can eventuate. 


\section{Reference:}

Acharya, A., Fuzzo de Lima, A., and Moore, M. (2004). Aid proliferation: how responsible are the donors? Institute of Development Studies Working Paper Series, 214. Retrieved from:

https://opendocs.ids.ac.uk/opendocs/handle/20.500.12413/4009 (12 October 2019)

Alesina, A., Dollar, D. (2000). Who Gives Foreign Aid to Whom and Why?. Journal of Economic Growth 5(1), pp. 33-63.

Anae, M. (2016). Teu Le Va: Samoan Relational Ethics. Knowledge Cultures, 4(3), pp. 117-130.

Anderson, T. (2011). Aid: is it worth it?. Timor Leste Studies Association. Retrieved from: http://tlstudies.org/pdfs/TLSA\%20Conf\%202011/chp 20.pdf ( $4^{\text {th }}$ September 2019)

Armytage, L. (2011). Evaluating aid: An adolescent domain of practice. Evaluation: The International Journal of Theory, Research and Practice, 17(3), pp. 261-276. doi: 10.1177/1356389011410518

Arndt, C., Jones, S. and Tarp, F. (2015). Assessing foreign aid's long-run contribution to growth and development. World Development 69, pp. 6-18.

Asian Development Bank. (2009). Pacific Private Sector Development Initiative Phase II. Retrieved from: https://www.adb.org/projects/43048-012/main\#project-pds (2 May 2019)

Asian Development Bank. (2013a). Grant Agreement for Outer Islands Renewable Energy Project. Retrieved from: https://www.adb.org/sites/default/files/project-document/81156/43452-022-grj0348.pdf (7 August 2019)

Asian Development Bank. (2013b). Grant Agreement (Special Operations) for Strengthening Public Financial Management Program. Retrieved from: https://www.adb.org/projects/documents/grantagreement-special-operations-strengthening-public-financial-management-program (18 August 2020)

Asian Development Bank. (2013c). Strengthening Public Financial Management Program: Report and Recommendation of the President. Retrieved from 
https://www.adb.org/projects/documents/strengthening-public-financial-management-program-rrp (8 August 2019)

Asian Development Bank. (2015). Nuku'alofa Urban Development Sector Project: Project Administration Manual. Retrieved from: https://www.adb.org/projects/documents/nukualofaurban-development-sector-project-pam (12 August 2019)

Asian Development Bank. (2017). Building Macroeconomic Resilience - Subprogram 2: Report and Recommendation of the President: Joint Policy Reform Matrix, FY2016-FY2018. Retrieved from https://www.adb.org/projects/documents/ton-48361-002-rrp (2 September 2019)

Asian Development Bank. (2018). Private Sector Development Initiative 2007 - 2017 Evaluation Report. Retrieved from: https://www.adb.org/documents/pacific-private-sector-developmentinitiative (15 August 2019)

Aurini, J. D., Heath M., and Howells, S. (2016). The How To of Qualitative Research: Strategies for Executing High Quality Projects. London: SAGE Publications Ltd.

Australia Department of Foreign Affairs and Trade. (2012). Independent Progress Review: Tonga TVET Support Program 1-Final Report. Retrieved from: https://dfat.gov.au/aboutus/publications/Pages/independent-progress-review-tonga-tvet-support-program-1-finalreport.aspx (17 July 2019)

Australia Department of Foreign Affairs and Trade. (2013a). Aid Budget Statement 2013-2014. Retrieved from: https://www.dfat.gov.au/about-us/publications/aid/australias-internationaldevelopment-assistance-program-2013-14/Pages/australia-s-international-development-assistanceprogram-2013-14 (10 December 2018)

Australia Department of Foreign Affairs and Trade. (2013b). Interim Skills Development Facility design. Retrieved from: https://dfat.gov.au/about-us/publications/Pages/tonga-interim-skilldevelopment-facility-design-document.aspx (13 August 2019) 
Australia Department of Foreign Affairs and Trade. (2014a). Australia Aid: promoting prosperity, reducing poverty, enhancing stability. Retrieved from: http://dfat.gov.au/aboutus/publications/Pages/australian-aid-promoting-prosperity-reducing-poverty-enhancingstability.aspx (26 March 2018)

Australia Department of Foreign Affairs and Trade. (2014b). Australia-Tonga Partnership for Development. Retrieved from: https://dfat.gov.au/geo/pacific/developmentassistance/partnerships/Pages/tonga.aspx\#tonga (7 August 2019)

Australia Department of Foreign Affairs and Trade. (2014c). Tonga Aid Program Performance Report 2013-14. Retrieved from: https://dfat.gov.au/about-us/publications/Pages/tonga-aid-programperformance-report-2013-14.aspx (1 August 2019)

Australia Department of Foreign Affairs and Trade. (2015a). Aid Investment Plan Tonga: 2015-16 to 2018-19. Retrieved from: https://dfat.gov.au/about-us/publications/Pages/aid-investment-plan-aiptonga-2015-16-to-2018-19.aspx (7 August 2019)

Australia Department of Foreign Affairs and Trade. (2015b). Pacific Sports Partnerships phase I: 2009-14. Retrieved from: https://dfat.gov.au/about-us/publications/Pages/pacific-sportspartnerships-phase-I-2009-14.aspx (5 August 2019)

Australia Department of Foreign Affairs and Trade. (2015c). Tonga Aid Program Performance Report 2014-15. Retrieved from: https://dfat.gov.au/about-us/publications/Pages/tonga-aid-programperformance-report-2014-15.aspx (1 August 2019)

Australia Department of Foreign Affairs and Trade. (2015d) Tonga Health Sector Support Program Phase 2: Design Document. Retrieved from: https://dfat.gov.au/about-us/publications/Pages/tongahealth-sector-support-program-phase-2-design-document.aspx (12 August 2019)

Australia Department of Foreign Affairs and Trade. (2015e). Tonga Education Sector Support Program Phase 2: Independent progress review and management response. Retrieved from: https://dfat.gov.au/about-us/publications/Pages/tonga-education-sector-support-program-phase-2ipr.aspx (13 August 2019) 
Australia Department of Foreign Affairs and Trade. (2016a). Australia-Tonga Aid Partnership Arrangement. Retrieved from: https://dfat.gov.au/about-us/publications/Pages/australia-tonga-aidpartnership-arrangement-2016-19.aspx (14 August 2019)

Australia Department of Foreign Affairs and Trade. (2016b). Tonga Aid Program Performance Report 2015-16. Retrieved from: https://dfat.gov.au/about-us/publications/Pages/tonga-aid-programperformance-report-2015-16.aspx (14 August 2019)

Australia Department of Foreign Affairs and Trade. (2016c). Tonga Interim Skills Development Facility Completion Report. Retrieved from: https://dfat.gov.au/about-us/publications/Pages/tonga-interimskills-development-facility-completion-report.aspx (15 August 2019)

Australia Department of Foreign Affairs and Trade. (2016d). Tonga Skills for Inclusive Economic Growth Program Investment Design. Retrieved from: https://dfat.gov.au/about-us/businessopportunities/Pages/investment-design-skills-for-inclusive-economic-growth-tonga.aspx (15 August 2019)

Australia Department of Foreign Affairs and Trade. (2016e). Tonga Nuku'alofa Urban Development Sector Project: Consolidated Annual Report. Retrieved from:

https://www.dfat.gov.au/geo/tonga/development-assistance/Pages/objective-2-more-effectiveefficient-and-equitable-health-system (18 August 2019)

Australia Department of Foreign Affairs and Trade. (2017). Tonga Aid Program Performance Report 2016-17. Retrieved from: https://dfat.gov.au/about-us/publications/Pages/tonga-aid-programperformance-report-2016-17.aspx (14 August 2019)

Australia Department of Foreign Affairs and Trade. (2018a). Tonga Aid Program Performance Report 2017-2018. Retrieved from: https://www.dfat.gov.au/about-us/publications/Pages/tonga-aidprogram-performance-report-2017-18 (18 August 2020)

Australia Department of Foreign Affairs and Trade. (2018b). Governance, economic and private sector development in Tonga. Retrieved from: https://dfat.gov.au/geo/tonga/developmentassistance/Pages/objective-1-governance-economic-and-private-sector-development.aspx (8 August 2019) 
Australia Department of Foreign Affairs and Trade. (2018c). Independent Evaluation of DFAT's

Economic and Public-Sector Reform Program (EPSG III) to the Kingdom of Tonga 2015/16 - 2017/18.

Retrieved from https://dfat.gov.au/about-us/publications/Pages/tonga-economic-public-sector-

reform-program-independent-evaluation.aspx (8 August 2019)

Australia Department of Foreign Affairs and Trade. (2019). Overview of Australia's aid program to

Tonga. Retrieved from: https://dfat.gov.au/geo/tonga/development-

assistance/Pages/development-assistance-in-tonga.aspx (16 July 2019)

Australia Department of Foreign Affairs and Trade. (2019). Tonga Australia Awards intake

information. Retrieved from: https://dfat.gov.au/about-us/publications/Pages/tonga-information-

for-intake.aspx (3 August 2019)

Bainbridge, T. (2000). A brief history of the OECD. OECD Observer, 111. Retrieved from

http://link.galegroup.com/apps/doc/A65862157/AONE?u=vuw\&sid=AONE\&xid=07fa6baf (9 April 2019)

Ball, R., Beacroft, L., \& Lindley, J. (2011). Australia's Pacific Seasonal Worker Pilot Scheme: Managing vulnerabilities to exploitation. Trends and Issues in Crime and Criminal Justice, (432), 1, pp. 1-8.

Banivanua-Mar, T. (2016). Decolonisation and the Pacific: Indigenous globalisation and the ends of empire. Australia: La Trobe University.

Banks, G., Murray, W., Overton, J., and Scheyvens, R. (2012). Paddling on One Side of the Canoe? The Changing Nature of New Zealand's Development Assistance Programme. Development Policy Review, 30(2), pp. 169-186. doi: 10.1111/j.1467-7679.2012.00570.x

Barbezat, D. (1997). The Marshall Plan and the Origin of the OECC. In Griffiths, R.T. (Ed), Explorations in OEEC History (pp. 33-48). Paris: OECD.

Bauer, P. T. (1976). Dissent on development. London: Weidenfield \& Nicholson. 
Benner, E. (2012). The Nation-State. In Wood, A., \& Hahn, S. (Eds.) The Cambridge History of Philosophy in the Nineteenth Century (1790-1870) (pp. 699-730). Cambridge: Cambridge University Press. doi:10.1017/CHO9780511975257

Bernstein, H. (1971). Modernization theory and the sociological study of development. Journal of Development Studies, 7(2), 141-160.

Bielschowsky, R. (2008). Sixty years of ECLAC: structuralism and neo-structuralism. Cepal Review, 97, pp. 171-192.

Bigsten, A., and Tengstam, S. (2015). International Coordination and the Effectiveness of Aid. World Development, 69, pp. 75-78.

Blampied, C. (2016). Where next for development effectiveness?. Building a renewed consensus. Conference Note 1 at the CAPE Conference. Retrieved from https://www.odi.org/sites/odi.org.uk/files/events-documents/10936.pdf (18 June 2019)

Bogle, C. (2019). Democratisation in Asia-Pacific Monarchies: Drivers and Impediments. PhD Thesis. Wellington: Victoria University of Wellington.

Booth, W. C., Colomb, G. G., \& Williams, J. M. (2008). The Craft of Research (3 ${ }^{\text {rd }}$ Edition). Chicago: University of Chicago Press.

Bott, E. (1981). Power and Rank in the Kingdom of Tonga. The Journal of the Polynesian Society, 90(1), pp. 7-81.

Brech, V. and Potrafke, N. (2014). Donor Ideology and types of foreign aid. Journal of Comparative Economics, 42, pp. 61-75.

Buchanan, A., \& Keohane, R. (2006). The Legitimacy of Global Governance Institutions. Ethics \& International Affairs, 20(4), pp. 405-437. doi: 10.1111/j.1747-7093.2006.00043.x

Buiter, W. H. (2007). 'Country ownership': a term whose time has gone. Development in Practice, 17(4), pp. $647-652$. 
Bull, B., \& Bøås, M. (2012). Between Ruptures and Continuity: Modernisation, Dependency and the Evolution of Development Theory. Forum for Development Studies: The Past, Present and Future of Development Studies, 39(3), 319-336. doi: 10.1080/08039410.2012.688860

Burk, K. (2001). The Marshall plan: Filling in some of the blanks. Contemporary European History, 10(2), 267-294.

Burr, V. (2015). Social Constructionism ( $3^{\text {rd }}$ ed). London: Routledge.

Cadogan-Cowper, Faletau, Gouy, Lemani. (2010). Public Financial Performance Report, Kingdom of Tonga. Public Expenditure and Financial Accountability Program. Retrieved from:

https://pefa.org/assessment/may10-pfmpr-public-en (5 May 2019)

Campbell, I. C. (1992). A Historical Perspective on Aid and Dependency: The example of Tonga. Pacific Studies, 15(3), pp. 59-75.

Campbell, I. C. (2001). Island kingdom: Tonga ancient and modern (2ed). Christchurch: Canterbury University Press.

Campbell I. C. (2019). Conflict Resolution and Political Change in Tonga. In: Lutmar C., Ockey J. (Eds.) Peacebuilding in the Asia-Pacific (pp. 143 -160). Cham: Palgrave Macmillan.

Cassen, R. (1994). Does Aid Work?: Report to an Intergovernmental Task Force. Oxford: Oxford University Press.

Chambers, R. (1994). The origins and practice of participatory rural appraisal. World Development, 22(7), pp. 953-969.

Collier, P.. and Dollar, D. (2002). Aid allocation and poverty reduction. European Economic Review, 46(8), pp. 1475-1500. 
Cory, K., Canavan, B., and Koenig, R. (2009). Power Purchase Agreement Checklist for State and Local Governments. United States: National Renewable Energy Lab. doi:10.2172/967194.

Cowen, M. and Shenton, R. (1996). Doctrines of development. London: Routledge.

Cracknell, B. E. (1988). Evaluating development assistance: a review of the literature. Public administration and development, 8(1), pp. 75-83.

Dabelstein, N., and Michael, Q. P. (2012). The Paris declaration on aid effectiveness: History and significance. The Canadian Journal of Program Evaluation, 27(3).

Davis, T. (2011). Foreign Aid in Australia's Relationship with the South: Institutional Narratives. The Round Table, 100(415), pp. 389-406.

Dearden, S. J. (2008). EU aid policy towards the Pacific ACPs. Journal of International Development: The Journal of the Development Studies Association, 20(2), pp. 205-217.

Denoon, D. (2012). A Trial Separation: Australia and the Decolonisation of Papua New Guinea. Canberra: ANU Press.

Deutscher, E., and Fyson, S. (2008). Improving the effectiveness of aid: A proliferation of donors and projects has made the governance of aid more problematic. Finance and Development, 45(3), pp. 1519.

Dollar, D., and Pritchett, L. (1998). Assessing aid: what works, what doesn't, and why. Oxford: Oxford University Press.

Dollar, D., and Svensson, J. (1998). What Explains the Success or Failure of Structural Adjustment Programs? The Economic Journal, 110, pp. 894-917.

Dornan, M. (2017). How new is the 'new' conditionality? Recipient perspectives on aid, country ownership and policy reform. Development Policy Review, 35, pp. 46-63. 
Dornan, M., Newton Cain, T., (2014). Regional Service Delivery among Small Island Developing States of the Pacific: An Assessment. Asia and the Pacific Policy Studies 1(3), pp. 541-560.

Dornan, M., \& Pryke, J. (2017). Foreign Aid to the Pacific: Trends and Developments in the TwentyFirst Century: Foreign Aid to the Pacific. Asia \& the Pacific Policy Studies, 4(3), pp. 386-404.

Easterly, W. (2006). The white man's burden. The Lancet, 367(9528), pp. 2060.

Easterly, E. and Pfutze, T. (2008). Where Does the Money Go? Best and Worst Practices in Foreign Aid. Journal of Economic Perspectives, 22(2), pp. 29- 52.

Ellem, E. (1989). Chief Justices of Tonga 1905-40. The Journal of Pacific History, 24(1), pp. 21-37.

Emeagwali, G. (2011). The Neo-Liberal Agenda and the IMF/World Bank Structural Adjustment Programs with Reference to Africa in Kapoor, D. (Ed.) Critical Perspectives on Neoliberal Globalization, Development and Education in Africa and Asia (pp. 3 -13). doi: 10.1007/978-94-6091$\underline{561-1}$

Eyben, R. (2007). Harmonisation: how is the orchestra conducted? Development in Practice, 17(4), pp. $640-646$.

Fa'avae, D. (2019). Tatala 'a e koloa 'o e to'utangata Tonga i Aotearoa mo Tonga : a way to disrupt and decolonise doctoral research. MAl Journal (Online), 8 (1), pp. 3-15.

Fa'avae, D., Jones, A., \& Manu'atu, L. (2016). Talanoa'i 'a e talanoa-Talking about talanoa: Some dilemmas of a novice researcher. AlterNative, 12(2), pp. 138-150.

Fairbairn, T.I. (1998). The Tonga economy: recent performance and future challenges. Pacific Economic Bulletin, 13(1), pp. 18 -35.

Feeny, S., lamsiraroj, S., and McGillivray, M. (2014). Growth and Foreign Direct Investment in the Pacific Island Countries. Economic Modelling, 37, pp. 332- 339.

Feeny, S and McGillivray, M. (2008). Do Pacific countries receive too much foreign aid? Pacific Economic Bulletin, 23(2), pp. 166-178. 
Flamez, B., Lenz, A. S., Balkin, R. S., and Smith, R.L. (2017). The Literature Review. In Brandé Flamez et al (Eds.) A Counselor's Guide to the Dissertation Process Where to Start \& How to Finish, pp. 93110. Alexandria, USA: American Counselling Association.

Fogerty, N.. (2020). Tonga's SWP earnings surpass Australian aid plus Tongan exports for first time. ABC Australia. Retrieved from: https://www.abc.net.au/radio-australia/programs/pacificbeat/tongaswp-earnings-pass-exports-australia-aid-first-time/11888494 (19 August 2020)

Forster, T., Kentikelenis, A., Reinsberg, B., Stubbs, T., \& King, L. (2019). How structural adjustment programs affect inequality: A disaggregated analysis of IMF conditionality, 1980-2014. Social Science Research, 80, pp. 83-113. doi: 10.1016/j.ssresearch.2019.01.001

Fry, G. (1997). Framing the islands: knowledge and power in changing Australian images of the South Pacific, The Contemporary Pacific, 9(2), pp. 305-44.

Fry, G., and Tarte, S., (Eds). (2015) The New Pacific Diplomacy. Canberra, ANU Press.

Fuchs, A., and Richert, K. (2018). Development minister characteristics and aid giving. European Journal of Political Economy, 53, pp. 186-204.

Fuhrer, H. (1994). The story of official development assistance: A history of the development assistance committee and the development cooperation directorate in dates, names and figures. Retrieved from: http://www.oecd.org/dac/1896816.pdf (12 June 2018)

Furukawa, M., and Takahata, Junichiro. (2017). Can GBS be a preferable aid modality under SDGs? African Journal of Economic and Management Studies, 8(2), pp.106-125.

Gegeo, D. W. (1998). Indigenous knowledge and empowerment: Rural development examined from within, The Contemporary Pacific, 10(2), pp. 289-315.

Gehring, K., Michaelowa, K., Dreher, A., and Spörri, F. (2017). Aid Fragmentation and Effectiveness: What Do We Really Know? World Development, 99, pp. 320-334. 
Gibson, J., \& McKenzie, D. (2011). Australia's PSWPS: Development impacts in the first two years. Asia Pacific Viewpoint, 52(3), pp. 361-370.

Gibson, J., \& McKenzie, D. (2014). The development impact of a best practice seasonal worker policy. Review of Economics and Statistics, 96(2), pp. 229-243.

Global Partnership for Effective Development Co-operation. (n.d.). Global Partnership Country Profiles. Retrieved from: https://www.effectivecooperation.org/landing-page/gpedc-country-profiles (17 August 2020)

Grant, J. P., Barker, J. C., \& Parry, C. (2009). Parry and grant encyclopaedic dictionary of international law. Retrieved from: https://ebookcentral.proquest.com/lib/vuw/detail.action?doclD=3054186 (17 February 2019)

Gudikunst, N., Briggs, K., Clark, T., \& Deskins, J. (2010). The social impact of the International Monetary Fund: Structural adjustment programs in Latin America from 1980-2000. Retrieved from: http://search.proquest.com/docview/748223030/ (27 May 2020)

Gulrajani, N. (2015). Dilemmas in donor design: organisational reform and the future of foreign aid agencies. Public Administration and Development, 35(2), pp.152-164.

Halapua, S. (2013). Talanoa in building democracy and governance. In Proceedings of the conference of future leaders of the Pacific, pp. 4-7. Retrieved from:

http://talanoa.org/Home files/Talanoa\%20in\%20Building\%20Democracy\%20and\%20Governance.pd f (3 June 2020)

Harman, S. and Williams, D. (2014). International development in transition. International Affairs 90(4), pp.925-941.

Harrell, M. C. and Melissa A. Bradley. (2009). Data collection methods. Semi-structured interviews and focus groups. National Defense Research Institute. Santa Monica: RAND Corporation. 
Hassall, G. (2010). Governance, Legitimacy and the Rule of Law in the South Pacific. In Jowitt A. \& Cain T. (Eds.), Passage of Change: Law, Society and Governance in the Pacific (pp. 51-70). Canberra: ANU Press.

Hasselskog, M., and Schierenbeck, I. (2017). The ownership paradox: Continuity and change. Forum for Development Studies, 44(3), pp. 323-333.

Hau'ofa, E. (1993). Our sea of islands. A new Oceania: Rediscovering our sea of islands. The Contemporary Pacific, 6(1) pp. 2-16.

Hau'ofa, 'E. (2008). We Are the Ocean: Pasts to Remember. Hawai'i: University of Hawai'i Press. Retrieved from: http://www.jstor.org/stable/j.ctt6wqzrq (10 January 2019)

Hayter, T. (1971). Aid as imperialism. England: Penguin Books Ltd.

Huffer, E. (2005). Governance, Corruption, and Ethics in the Pacific. The Contemporary Pacific, 17(1), pp. 118-140.

Hughes, H. (2003). Trade or aid? Which benefits developing countries more? Economic PapersEconomic Society of Australia, 22(3), pp. 1-19.

Infratec. (n.d.). Tongatapu Wind Energy Feasibility Study, Tonga. Retrieved from: https://www.infratec.co.nz/projects/tongatapu-wind-energy-feasibility-study,-tonga (21 August 2019)

Jelovac, I., and Vandeninden, F. (2008). How should donors give foreign aid? Project aid versus budget support. IDEAS Working Paper Series from RePEc. Retrieved from: http://search.proquest.com/docview/1698436879/ (2 September 2019)

Jones, D. (2014). Masters of the universe: Hayek, Friedman, and the birth of neoliberal politics. Princeton: Princeton University Press. 
Ka'ili, T. O. (2008). Tauhi vā: Creating beauty through the art of sociospatial relations. Unpublished PhD Thesis, University of Washington. Retrieved from:

https://search.proquest.com/docview/304439670/?pq-origsite=primo (25 January 2019)

Kaiser, K. (2012). Protecting confidentiality. In The SAGE Handbook of Interview Research: The Complexity of the Craft (pp. 457-464). doi: 10.4135/9781452218403.n32

Kay, C. (1993). For a Renewal of Development Studies: Latin American Theories and Neoliberalism in the Era of Structural Adjustment. Third World Quarterly, 14(4), pp. 691-702.

Kefu, A. A. (2005). Recent Constitutional Developments in Tonga : Where to Now?, Unpublished Thesis. Retrieved from: http://hdl.handle.net/10063/5848 (5 June 2019)

Kellow, A., and Carroll, P. (2011). Australia and the OECD. Revista De Economia Mundial, 28, pp. 93111.

Kelly, R. (2008). No 'Return to the State': Dependency and Developmentalism against NeoLiberalism. Development in Practice, 18(3), pp. 319-332.

Kēpa, M., \& Manu'atu, L. (2008). Pedagogical Decolonization: Impacts of the European/Pākehā Society on the Education of Tongan People in Aotearoa, New Zealand. American Behavioral Scientist, 51(12), pp. 1801-1816. doi: 10.1177/0002764208318932

Keohane, R. (2011). Neoliberal institutionalism. In Hughes, C. W., and Meng., L. Y., (Eds.) Security studies: A reader. New York: Routledge.

Kirby, P. (2009). Neo-structuralism and reforming the Latin American state: lessons from the Irish case. Economy and Society 38(1), pp.132-153.

Latu and Silivenusi v Lavulavu. (2015). Supreme Court of Tonga, CV 90 of 2014.

Lātūkefu, S. (1968). Oral Traditions: An Appraisal of Their Value in Historical Research in Tonga. The Journal of Pacific History, 3, pp. 135-143. 
Lātūkefu, S. (1975a). King George Tupou I of Tonga. Tonga: Tonga Traditions Committee.

Lātūkefu, S. (1975b). The Tongan Constitution. Tonga: Tonga Traditions Committee.

Lātūkefu, S. (1980). The Definition of Authentic Oceanic Cultures with Particular Reference to Tongan Culture. Pacific Studies, 4(1), pp. 60-81.

Leimgruber, M., and Schmelzer, M. (2017). The OECD and the International Political Economy Since 1948. Cham: Springer International Publishing.

Leiva, F. I. (2008). Toward a critique of Latin American neostructuralism. Latin American Politics and Society, 50(4), pp. 1-25.

Lewis, W. (1955). Theory of Economic Growth. London: Routledge, doi: 10.4324/9780203709665

Ludwig (Lu), R. (2005). Official development assistance. Headline Series, 327, pp. 7-12,2. Retrieved from: https://search.proquest.com/docview/228222759?accountid=14782 (30 April 2019)

Māhina, ‘O. (2007). Part III: In occasion for celebration: Reflections on the Tongan theories of education. In ‘O. Māhina, N. SeveWilliams, A. Faaiuaso, \& D. Hosking (Eds.), 'Ātea, Moana and Vanua: Voices from the brown edge (pp. 217-236). Auckland: O Lagi 'Ātea Moana Press.

Mailangi, A. (2017). The accountability arrangements in Tonga's Public Service Commission. Unpublished Thesis. Wellington: Victoria University of Wellington.

Magid, J. (2012). The Marshall Plan. Advances in Historical Studies, 1(1), pp. 1.

Maloney, J. (2007). A new day in Tonga: The judiciary, the reformers and the future. Journal of South Pacific Law, 11(2), pp. 151-168.

Matangi Tonga. (2013a). Chinese government gifts MA60 aircraft at Fua'amotu hand-over. Retrieved from: https://matangitonga.to/2013/07/08/chinese-government-gifts-ma60-aircraft-fuaamotuhand-over (27 August 2019) 
Matangi Tonga. (2013b). NZ suspends tourism aid to Tonga over MA60 safety concerns. Retrieved from: https://matangitonga.to/2013/07/09/nz-suspends-tourism-aid-tonga-over-ma60-safetyconcerns (27 August 2019)

Matangi Tonga. (2014). 'Akilisi Pohiva, Tonga's new Prime Minister. Retrieved from:

https://matangitonga.to/2014/12/29/akilisi-pohiva-tongas-new-prime-minister (18 May 2020)

Matangi Tonga. (2015). Finance Minister reveals twisted Forbes affair. Retrieved from:

https://matangitonga.to/2015/08/12/finance-minister-reveals-twisted-forbes-affair (18 May 2020)

Matangi Tonga. (2016a). Claude Tupou, new Education CEO. Retrieved from:

https://matangitonga.to/2016/06/07/claude-tupou-new-education-ceo (17 May 2019)

Matangi Tonga. (2016b). Lavulavu loses his seat for election bribery and campaign overspending.

Retrieved from: https://matangitonga.to/2016/01/29/lavulavu-loses-his-seat-election-bribery-andcampaign-overspending (19 May 2020)

Matangi Tonga. (2017). Cabinet decides to terminate Tonga's contract to host 2019 Pacific Games. Retrieved from: https://matangitonga.to/2017/06/10/cabinet-terminates-tongas-contract-host2019-pacific-games (19 May 2020)

Matangi Tonga. (2018). Judiciary welcomes Hon. Mr Justice Laki Niu. Retrieved from: https://matangitonga.to/2018/07/11/judiciary-welcomes-hon-mr-justice-lakiniu?fbclid=IwAR1Y3jTeTM5yvvJmimk5DVzjxD08Ye6fk69r1oH3mMabU3QU3MyjrF75Dyg (19 May 2020)

Matangi Tonga. (2020). Trial delayed for Lavulavu couple. Retrieved from:

https://matangitonga.to/2020/04/29/trial-delayed-lavulavu-couple (19 May 2020)

Mawdsley, E., Savage, L., and Kim S. (2014). A 'post-aid world'? Paradigm shift in foreign aid and development cooperation at the 2011 Busan High Level Forum. The Geographical Journal 180 (1) pp. 27-38. 
Mawdsley, E., Murray, W.E., Overton, J, Scheyvens, R. and Banks, G.A. (2018) Exporting stimulus and 'shared prosperity': Re-inventing aid for a retroliberal era. Development Policy Review, 36, 025-043. doi: $10.1111 /$ dpr.12282

Maxwell, J. A. (2013). Qualitative research design: An interactive approach. California: SAGE Publications Inc.

McGibbon, I. (2014). New Zealand's first conquest: Ian McGibbon recalls New Zealand's occupation of German Samoa just over a century ago. New Zealand International Review, 39(6), pp. 18.

McGregor, A., Challies, E. Overton, J. and Sentes, L. (2013). Developmentalities and donor-NGO relations: Contesting foreign aid policies in New Zealand / Aotearoa. Antipode, 45(5), pp. 1232-1253.

McKay, J. (2016). Competing Development Paradigms and Alternative Evaluations of Aid Effectiveness: Challenging the Dominant Neoliberal Vision. In V. Jakupec and M., Kelly (Eds), Assessing the Impact of Foreign Aid: Value for Money and Aid for Trade (pp. 31 -44). San Diego: Elsevier Science \& Technology.

Metuamate, A. (2018). Kingship and Kinship: The House of Tupou, Democracy and Transnationalism in Tonga. (Unpublished thesis). Canberra: Australia National University.

Millbank, A. (2008). Guest-Workers for Australia: Win-Win, Token Gesture or Moral Hazard? The Rudd Government's Trial Seasonal Pacific Worker Scheme. People and Place, 16(3), pp. 58-67.

Mogalakwe, M. (2006). The Use of Documentary Research Methods in Social Research. African Sociological Review, 10(1), pp. 221-230.

Moloney, K. (2019). Post-Busan partnership in the Pacific? An analysis of donor-NGO relations. Pacific Review, 33(2), pp. 1-27. doi: 10.1080/09512748.2019.1569713

Mosley, P. (2015). Fiscal Composition and Aid Effectiveness: A Political Economy Model. World Development, 69(C), pp. 106-115. 
Mountfort, H. (2013). An Analysis of the Aid Effectiveness Agenda in Tonga. Unpublished Master's thesis. Wellington: Victoria University of Wellington.

Moyo, D. (2010). Dead Aid: Why aid makes things worse and how there is another way for Africa New York: Farrar, Straus and Giroux.

Murray, W.E., and Overton, J. (2011a). The Inverse Sovereignty Effect: Aid, Scale and Neostructuralism in Oceania. Asia Pacific Viewpoint, 52(3), pp. 272-284.

Murray, W. E., \& Overton, J. D. (2011b). Neoliberalism is dead, long live neoliberalism? Neostructuralism and the international aid regime of the 2000s. Progress in Development Studies, 11(4), pp. 307-319. doi: 10.1177/146499341001100403

Murray, W. E., and Overton, J. (2016). Retroliberalism and the new aid regime of the 2010s. Progress in Development Studies, 16(3), pp. 244-260.

Nabobo-Baba, U. (2008). Decolonising Framings in Pacific Research: Indigenous Fijian Vanua Research Framework as an Organic Response. AlterNative, 4(2), pp.140-154.

Naidu, V., (2009) 'Changing gears on the Millennium development Goals in Oceania', in J. Boston (ed.), Eliminating World Poverty, Wellington, Institute of Policy Studies, pp. 103-126.

Nallari, R., Yusuf, S., Griffith, B., and Bhattacharya, R. (2011). Frontiers in Development Policy A Primer on Merging Issues. Washington DC: The International Bank for Reconstruction and Development/The World Bank.

Nederveen Pieterse, J. (2002). Development Theory Deconstructions/reconstructions. London: SAGE Publications.

Needs, A. (1988). New Zealand Aid and the Development of Class in Tonga. Palmerston North: Massey University. 
New Zealand Ministry of Foreign Affairs and Trade. (n.d.). Tools and Guides for Aid Activities.

Retrieved from: https://www.mfat.govt.nz/en/aid-and-development/working-with-us/tools-andguides-for-aid-activities/ (23 April 2019)

New Zealand Ministry of Foreign Affairs and Trade. (2011a). International Development Policy Statement: Supporting Sustainable Development. Wellington: Ministry of Foreign Affairs and Trade.

New Zealand Ministry of Foreign Affairs and Trade. (2011b). Tonga and New Zealand Joint Commitment for Development 2011 - 2013. Retrieved from: https://www.mfat.govt.nz/assets/AidProg-docs/Commitment-for-Development/Tonga/NZ-Tonga-JCD.pdf (30 August 2019)

New Zealand Ministry of Foreign Affairs and Trade. (2012). New Zealand Aid Programme Strategic Plan 2012-15. Wellington: Ministry of Foreign Affairs and Trade.

New Zealand Ministry of Foreign Affairs and Trade. (2015a). New Zealand Aid Programme Strategic Plan 2015-2019. Retrieved from: https://www.mfat.govt.nz/en/aid-and-development/our-approachto-aid/ (5 May 2019)

New Zealand Ministry of Foreign Affairs and Trade. (2015b). New Zealand Aid Programme Investment Priorities 2015-19. Wellington: Ministry of Foreign Affairs and Trade.

New Zealand Ministry of Foreign Affairs and Trade. (2015c). Tonga Education Support Programme Phase II Evaluation. Retrieved from: https://www.mfat.govt.nz/en/aid-and-development/ourapproach-to-aid/evaluation-and-research/evaluation-reports-2015/ (26 August 2019)

New Zealand Ministry of Foreign Affairs and Trade. (2016a). Activity Planning Policy. Retrieved from: https://www.mfat.govt.nz/en/aid-and-development/working-with-us/tools-and-guides-for-aidactivities/ (6 September 2019)

New Zealand Ministry of Foreign Affairs and Trade. (2016b). Pacific Energy Country Profiles. Retrieved from: https://www.mfat.govt.nz/assets/Peace-Rights-and-Security/ARCHIVE-possiblydelete/Pacific-Energy-Country-Profiles-2016.pdf (21 August 2019) 
New Zealand Ministry of Foreign Affairs and Trade. (2016c). Tonga and New Zealand Joint Commitment for Development 2016 - 2018. Retrieved from: https://www.mfat.govt.nz/assets/AidProg-docs/Commitment-for-Development/Tonga/Tonga-Joint-Commitment-for-Development-2016Signed.pdf (30 August 2019)

New Zealand Ministry of Foreign Affairs and Trade. (2016d). Tonga Programme Evaluation. Retrieved from: https://www.mfat.govt.nz/en/aid-and-development/our-approach-to-aid/evaluation-andresearch/evaluation-reports-2016/ (26 August 2019)

New Zealand Ministry of Foreign Affairs and Trade. (2017a). New Zealand Ministry of Foreign Affairs and Trade Annual Report 2016-2017. Retrieved from: https://www.mfat.govt.nz/assets/MFATCorporate-publications/MFAT-Annual-Report-2016-17.pdf (20 May 2019)

New Zealand Ministry of Foreign Affairs and Trade. (2017b). New Zealand Partnerships for International Development Fund Guidelines. Retrieved from: https://www.mfat.govt.nz/assets/AidProg-docs/Partnerships/Partnerships-Fund-Guidelines-April-2017.pdf (26 March 2018)

Nunnenkamp, P., Ohler, H., \& Thiele, R. (2013). Donor coordination and specialization: Did the Paris Declaration make a difference. Review of World Economics, 149(3), pp. 537-563. doi: $10.1007 / \mathrm{s} 10290-013-0157-2$

O'Leary, Z. (2010). The essential guide to doing your research project. London: SAGE Publications Ltd.

Oliver, H. (2006). In the Wake of Structural Adjustment Programs. Canadian Journal of Public Health, 97(3), pp. 217-221. doi: 10.1007/BF03405589

O'Neil, A. (2017). Australia and the 'Five Eyes' intelligence network: the perils of an asymmetric alliance. Australia Journal of International Affairs, 7(5), pp. 529-543.

Orams, M. (2013). Economic Activity Derived from Whale-Based Tourism in Vava'u, Tonga. Coastal Management, 41(6), pp. 481-500.

Organisation for Economic Co-operation and Development. (n.d.). History. Retrieved from: http://www.oecd.org/about/history/ (9 August 2017) 
Organisation for Economic Co-operation and Development. (n.d.). Latest Documents. Retrieved from: http://www.oecd.org/dac/effectiveness/latestdocuments/2/ (25 September 2019)

Organisation for Economic Co-operation and Development. (n.d.). Official development assistancedefinition and coverage. Retrieved from:

https://www.oecd.org/dac/stats/officialdevelopmentassistancedefinitionandcoverage.htm (14 June 2019)

Organisation for Economic Co-operation and Development. (n.d.). The DAC 50 Years 50 Highlights. Retrieved from: http://www.oecd.org/dac/developmentassistancecommitteedac.htm (22 February 2019)

Organisation for Economic Co-operation and Development. (1960). Convention on the Organisation for Economic Co-operation and Development. Retrieved from:

https://www.oecd.org/general/conventionontheorganisationforeconomiccooperationanddevelopment.htm (22 February 2019)

Organisation for Economic Co-operation and Development. (1973). New Zealand Invited to Join OECD. The OECD Observer, 64), pp. 3.

Organisation for Economic Co-operation and Development. (2005). The Paris Declaration on Aid Effectiveness and the Accra Agenda for Action. Retrieved from:

http://www.oecd.org/dac/effectiveness/34428351.pdf (19 June 2019)

Organisation for Economic Co-operation and Development. (2007a). Country Programmable Aid. Retrieved from: http://www.oecd.org/dac/aid-architecture/cpa.htm (21 June 2018)

Organisation for Economic Co-operation and Development. (2007b). The "Marshall Plan" speech at Harvard University, 5 June 1947. Retrieved from:

http://www.oecd.org/general/themarshallplanspeechatharvarduniversity5june1947.htm (29 March 2019) 
Organisation for Economic Co-operation and Development. (2012). Aid Effectiveness 2011: Progress in Implementing the Paris Declaration, Better Aid. OECD Publishing. doi: 10.1787/9789264125780-en

Organisation for Economic Co-operation and Development. (n.d.). Latest Documents. Retrieved from: http://www.oecd.org/dac/effectiveness/latestdocuments/2/ (25 September 2019)

Organisation for Economic Co-operation and Development. (2020). OECD Stat. Retrieved from: https://stats.oecd.org/ (5 September 2020)

Overton, J., Murray, W.E., Prinsen, G., Ulu, A.J., and Wrighton, N. (2019). Aid, Ownership and Development: The Inverse Sovereignty Effect in the Pacific Islands. London: Routledge

Owa, M. (2011). Revisiting the Paris declaration agenda - an inclusive, realistic orientation for aid effectiveness. Development in Practice, 21(7), pp. 987-998. doi: 10.1080/09614524.2011.590888

Pacific Centre for Renewable Energy and Energy Efficiency. (2015). Tonga Energy Road Map (TERM) Review/Implementation Report 2010 - 2014. Retrieved from: http://prdrse4all.spc.int/system/files/term review report 5th august 2015.doc final final 2.pdf (6 August 2019)

Pacific Community Pacific Agricultural Policy Programme. (n.d.). Tonga Agriculture Sector Plan 2016 2020. Retrieved from: https://pafpnet.spc.int/resources/574-tonga-agriculture-sector-plan-2016$\underline{2020}$ (30 August 2019)

Pacific Community. (2016). Tonga Fisheries Sector Plan 2016 -2020. Retrieved from: https://pafpnet.spc.int/resources/628-tonga-fisheries-sector-plan-2016-2024 (30 August 2019)

Pacific Horticultural and Agricultural Market Access Program. (n.d.). Retrieved from: http://phama.com.au/about-us/who-we-are/ (30 August 2019)

Pacific Region Infrastructure Facility. (2016). TA-8345 REG: Due Diligence of Tonga Nuku'alofa Distribution Network Upgrade Project. Retrieved from: https://www.theprif.org/documents/tonga/energy-power-generation/prif-tonga-nukualofanetwork-distribution-upgrade-project (21 August 2019) 
The Pacific Islands Forum Secretariat. (2007a). Pacific Aid Effectiveness Principles. Retrieved from: http://www.forumsec.org/wp-content/uploads/2017/11/Pacific Aid Effectiveness Principles.pdf (5 August 2019)

The Pacific Islands Forum Secretariat. (2007b) The Pacific Plan for Strengthening Regional Cooperation and Integration, (Revised Version 2007). Suva: PIFS.

The Pacific Islands Forum Secretariat. (2013). Pacific Plan Review 2013: Report to Pacific Leaders. Suva: PIFS.

Pastor, M. (1989). Latin America, the Debt Crisis, and the International Monetary Fund. Latin American Perspectives, 16(1), pp. 79-110.

Peet, R., and Hartwick, E. (2009). Theories of Development Contentions, Arguments, Alternatives. New York: The Guildford Press.

Powles, G. (2013). Political and constitutional reform opens the door: The kingdom of Tonga's path to democracy. Suva: University of the South Pacific Press.

Prebisch, R., (1949). El desarrollo económico de la América Latina y algunos de sus principales problemas/The economic development of Latin America and its principal problems. New York: United Nations.

Przeworski, A. (1996). Modernization: Theories and Facts. World Politics, 49(2), pp. 155-183.

Radio New Zealand. (2014a). Tonga Govt queries power hikes. Retrieved from:

https://www.rnz.co.nz/international/pacific-news/247336/tonga-govt-queries-power-hikes (27 August 2019)

Radio New Zealand. (2014b). World Bank to certify Tonga plane but NZ travel warning stays. Retrieved from: https://www.rnz.co.nz/news/pacific/238128/world-bank-to-certify-tonga-planebut-nz-travel-warning-stays (27 August 2019) 
Radio New Zealand. (2015). Tonga government steps away from CEDAW ratification. Retrieved from: https://www.rnz.co.nz/international/pacific-news/283057/tonga-government-steps-away-fromcedaw-ratification (19 May 2020)

Radio New Zealand. (2016). Tongan cabinet minister to resign. Retrieved from:

https://www.rnz.co.nz/international/pacific-news/313322/tongan-cabinet-minister-to-resign (19 May 2020)

Radio New Zealand. (2017). Tongan King dissolves parliament, calls fresh elections. Retrieved from: https://www.rnz.co.nz/international/pacific-news/338015/tongan-king-dissolves-parliament-callsfresh-elections (20 May 2020)

Radio New Zealand. (2019). Tonga wind turbines commissioned with help from Japan. Retrieved from: https://www.rnz.co.nz/international/pacific-news/394131/tonga-wind-turbinescommissioned-with-help-from-japan (21 August 2019)

Rajan, R., and Subramaniam, A. (2008). Aid and growth: what does the cross-country evidence really show? Review of Economics and Statistics, 90, pp. 643-665.

Ramirez, M.D., (1993). Stabilization and Adjustment in Latin America: A Neostructualist Perspective. Journal of Economic Issues, 27(4), pp.1015-1040.

Ratuva, S. (2018). Tonga. The Contemporary Pacific, 30(1), pp.204-213.

Ratuva, S, \& Brady, A-M. (2019) 'Neighbours and cousins: Aotearoa-New Zealand's relationship with the Pacific' in A.-M. Brady (ed.), Small States and the Changing Global Order, Cham: Springer, pp. $145-163$

Ratuva, S. (2019). Aid and Foreign Policy: New Zealand Development Assistance in the Pacific. In A. Brady (ed) Small States and the Changing Global Order (pp. 55-73). Switzerland: Springer.

Rebien, C. (1997). Development Assistance Evaluation and the Foundations of Program Evaluation. Evaluation Review, 21(4), pp. 438-460. 
Riddell, R.C. (2007). Does Foreign Aid Really Work? Oxford: Oxford University Press.

Ridley, D., (2012). The Literature Review A Step-by-Step Guide for Students. London: SAGE Publications Ltd.

Rist, G. (1997). The history of development. London: Zed Books.

Rostow, W., (1960). The Stages of Economic Growth A Non-Communist Manifesto ( $2^{\text {nd }}$ ed.) London: Cambridge University Press.

Rutherford, N. (1977). Friendly Islands : A history of Tonga / edited by Noel Rutherford. Melbourne: Oxford University Press.

Rutherford, N., Ve'ehala, and Fanua., T. P. (1977). Oral Tradition and Prehistory. In Rutherford, N., (Ed.) Friendly Islands A History of Tonga (pp.27-40). Melbourne: Oxford University Press.

Sachs, J. D. (2005). The End of Poverty: Economic Possibilities of Our Time. New York: Penguin.

Sanga, K. and A. Taufe'ulungaki, A (Eds.). (2005) International aid impacts on Pacific education. Wellington: He Pārekereke: Institute for Research and Development in Māori and Pacific Education, Victoria University of Wellington.

Sapere Research Group. (2018). Evaluation of New Zealand's Partnership Fund for International Development. Retrieved from - http://www.srgexpert.com/publications/evaluation-of-mfatspartnerships-fund/ (26 August 2019)

Schornig, N. (2014). Neorealism. In Schieder, S., Spindler, M., (Eds.) Theories of international relations, pp. 37-55. New York: Routledge.

Scott, J. (1990). A Matter of Record, Documentary Sources in Social Research. Cambridge: Polity Press. 
Sjöstedt, M. and Sundström, A. (2017). Donor coordination or donor confusion? How disputed facts and problem framing affect the prospects for aid harmonization. Development Policy Review, 35(S2), pp. 64-79.

Smith, K., and 'Otunuku, M. (2015). Heliaki: transforming literacy in Tonga through metaphor. The SoJo Journal: Educational Foundations and Social Justice Education, 1(1), pp. 99-112.

Soanes, C., and Stevenson, A. (Eds.). (2008). Concise Oxford English Dictionary (11 ${ }^{\text {th }}$ ed.) New York: Oxford University Press.

Spratt, J., and Wood, T. (2018). Change and resilience in New Zealand aid under Minister McCully. Policy Quarterly (Victoria University of Wellington. Institute for Governance and Policy Studies), 14(2), pp. 25-31. doi: 10.26686/pq.v14i2.5091 21 August 2020

Storey, D., and Murray, W. (2001). Dilemmas of Development in Oceania: The Political Economy of the Tongan Agro-Export Sector. The Geographical Journal, 167(4), 291-304.

Takau, Y. (2020). The Development of Planning Processes in Tonga and the Impact of the 2006 Riots. PhD Thesis. Otago: University of Otago.

Taufa, S. M. (1993). Home Abroad: Exploring Aspects of Cultural Maintenance within Tongan Families in Tonga and New Zealand. Unpublished Master's Thesis. Wellington: Victoria University of Wellington. Retrieved from:

https://viewer.waireto.victoria.ac.nz/client/viewer/IE920121/details?dps dvs=1547075614326 981 (10 January 2019)

Taufe'ulungaki, A. (2009). Tongan Values in education: Some issues and questions. In Sanga, K., and Thaman, K.H., (Eds.), Re-thinking Education Curricula in the Pacific: Challenges and Prospects (pp. 125 -136). Wellington: He Parekereke (Institute of Research and Development in Maori and Pacific Education), Victoria University Press.

Taumoefolau, M. (1996). From Sau 'Ariki to Hawaiki. The Journal of the Polynesian Society, 5(4), pp. $385-410$. 
Taumoepeau, A. H. (2019). The Ombudsman and good governance: Tonga's experience. Asia Pacific Journal of Public Administration, 41(1), pp. 33-41. doi: 10.1080/23276665.2019.1589698

Taumoepeau, S. (2016). New heights of success for Tonga's aviation and tourism. Open Journal of International Education, 1(2), pp. 67-89.

Tecun, A., Hafoka, 'Inoke, 'Ulu'ave, L., \& 'Ulu'ave-Hafoka, M. (2018). Talanoa: Tongan epistemology and Indigenous research method. AlterNative: An International Journal of Indigenous Peoples, 14(2), pp. 156-163. doi: $\underline{10.1177 / 1177180118767436}$

Thaman, K. H. (1993). Culture and the Curriculum in the South Pacific. Comparative Education, 29(3), pp. 249-260.

Thaman, K. H. (1995). Concepts of learning, knowledge and wisdom in Tonga, and their relevance to modern education. Prospects, 25(4), pp. 723-733.

Thaman, K. H. (2003). Decolonizing Pacific Studies: Indigenous Perspectives, Knowledge, and Wisdom in Higher Education. The Contemporary Pacific, 15(1), pp. 1-17.

Thaman, K. H. (2008). Nurturing Relationships and Honouring Responsibilities: A Pacific Perspective. International Review of Education, 54, pp.459-473.

Thaman, K. H. (2009). Towards cultural democracy in teaching and learning with specific references to Pacific Island Nations (PINs). International Journal for the Scholarship of Teaching and Learning 3(2), pp.6.

The George C. Marshall Foundation. (2019). Economic Cooperation Act of 1948 s.102 (US). Retrieved from: https://www.marshallfoundation.org/library/wpcontent/uploads/sites/16/2014/05/Section 04a.pdf (25 April 2019)

Tilley, H., and Tavakoli, H. (2012). Better aid modalities: are we risking real results. London: Overseas Development Institute. 
Tonga Constitutional and Electoral Commission. (2009). Tonga Constitutional and Electoral Commission Interim Report. Retrieved from - http://lists.spc.int/pipermail/ppapdfpocc/attachments/20090609/c0960b63/attachment-0001.pdf (5 August 2019)

Tonga Ministry of Finance and National Planning. n.d. Aid \& Projects. Retrieved from: http://www.finance.gov.to/aps (12 December 2019)

Tonga Ministry of Finance and National Planning. (2011). Tonga Strategic Development Framework 2011-2014. Retrieved from: http://www.finance.gov.to/tonga-strategic-developmentframework?field document list value=Tonga+Strategic+Development+Framework (12 December 2018)

Tonga Ministry of Finance and National Planning. (2015a). Tonga Millennium Development Goals Final Report. Retrieved from:

https://www.undp.org/content/dam/undp/library/MDG/english/MDG\%20Country\%20Reports/Tong a/Tonga\%203rd\%20MDG\%20Report\%20FINAL\%20COPY.pdf (17 June 2019)

Tonga Ministry of Finance and National Planning. (2015b). Tonga Strategic Development Framework 2015-2025. Retrieved from: http://www.finance.gov.to/tonga-strategic-developmentframework?field document list value=Tonga+Strategic+Development+Framework (12 December 2018)

Tonga Ministry of Finance and National Planning. (2013). Tonga - Budget Statement and Estimate 2013-2014. Retrieved from: http://www.finance.gov.to/ (12 June 2018)

Tonga Ministry of Finance and National Planning. (2014). Tonga - Budget Statement and Estimate 2014-2015. Retrieved from: http://www.finance.gov.to/ (12 June 2018)

Tonga Ministry of Finance and National Planning. (2015). Tonga - Budget Statement and Estimate 2015-2016. Retrieved from: http://www.finance.gov.to/ (12 June 2018)

Tonga Ministry of Finance and National Planning. (2016). Tonga - Budget Statement and Estimate 2016-2017. Retrieved from: http://www.finance.gov.to/ (12 June 2018) 
Tonga Ministry of Finance and National Planning. (2017). Tonga - Budget Statement and Estimate 2017-2018. Retrieved from: http://www.finance.gov.to/ (12 June 2018)

Tonga Ministry of Finance and National Planning. (2019). Press Release. Retrieved from: http://www.finance.gov.to/index.php/node/448 (17 August 2019).

Tonga Nationality Act 1959. Retrieved from:

https://ago.gov.to/cms/images/LEGISLATION/PRINCIPAL/1915/1915-

0006/NationalityAct 1.pdf?zoom highlight=Tongan+national\#search=\%22Tongan\%20national\%22 (10 January 2019)

Tonga Nationality Act 2016. Retrieved from:

https://ago.gov.to/cms/images/LEGISLATION/PRINCIPAL/1915/1915-0006/NationalityAct 2.pdf (10 January 2019)

Tonga Power Limited. (n.d.). Outer Islands Renewable Project. Retrieved from:

http://www.tongapower.to/OurBusiness/RenewableEnergy/OuterlslandsRenewableEnergyProject.a spx (19 May 2019)

Tonga Preservation of Objects of Archaeological Interest Act. (2016). Retrieved from:

https://ago.gov.to/cms/images/LEGISLATION/PRINCIPAL/1969/1969-

0015/PreservationofObjectsofArchaeologicallnterestAct 2.pdf (14 January 2019)

Tonga Tourism Authority Act 2013. Retrieved from:

https://ago.gov.to/cms/images/LEGISLATION/PRINCIPAL/2012/2012-

0025/TongaTourismAuthorityAct 2.pdf (7 April 2020)

Tu'ipulotu, S.T.T., (2013). Gospel of hope for the world of hopeless: The success of early christianity and hope for the Tongan church (Order No. 3575403). Retrieved from:

https://search.proquest.com/docview/1461390212?accountid=14782 (7 April 2020)

Tu'itahi, S. (2010). Kafataha: Strategies to preserve Pacific languages. AlterNative: An International Journal of Indigenous Peoples, 6(2), pp. 134-142. doi: 10.1177/117718011000600205 
Ulu, A. J. (2013) 'Pule: Development policy sovereignty in Samoa', unpublished Master of Development Studies thesis, Wellington, Victoria University of Wellington.

United Nations Department of Economic and Social Affairs. (2014). Small Island Developing States Accelerated Modalities of Action Pathway. Retrieved from:

https://sustainabledevelopment.un.org/samoapathway.html (17 August 2020)

United Nations. (2000). Millennium Summit. Retrieved from

http://www.un.org/en/events/pastevents/millennium summit.shtml (17 January 2019)

United Nations. (2015). Sustainable Development Goals. Retrieved from:

https://sustainabledevelopment.un.org/sdgs (17 June 2019)

'Utoikamanu, S. T. (1980) Development Planning in Tonga; A Preliminary Study. Unpublished Master's Thesis, Victoria University of Wellington, New Zealand.

'Utoikamanu, S., and Rodger, P. (2010). Taking a lead on harmonisation : the experience of Tonga. Just Change, 18, pp. 12-13.

Va'ai, U., and Casimira, A. (Eds.). (2017). Relational hermeneutics : Decolonising the mindset and the Pacific Itulagi. Fiji: University of the South Pacific.

Vaea., A., (2019). The dismissal and re-positioning of government ministers and senior administrators in Tonga: leadership and performance challenges. Asia Pacific Journal of Public Administration, 41(1), pp. 42-47. Doi: 10.1080/23276665.2019.1592844

Verschaeve, J., \& Orbie., J. (2015). The DAC is Dead, Long Live the DCF? A Comparative Analysis of the OECD Development Assistance Committee and the UN Development Cooperation Forum. European Journal of Development Research, 28(4), pp. 571-587. doi: 10.1057/ejdr.2015.27

Verschaeve, J., \& Orbie, J. (2018). Ignoring the elephant in the room? Assessing the impact of the European Union on the Development Assistance Committee's role in international development. Development Policy Review, 36(S1), 044-058. doi: 10.1111/dpr.12216 
Vaioleti, T. (2006). Talanoa Research Methodology: A Developing Position on Pacific Research. Waikato Journal of Education, 12(1), pp. 21-34.

Victoria University of Wellington. (2018). Human Ethics Guidelines. Retrieved from https://www.wgtn.ac.nz/documents/policy/research-policy/appendix-a-human-ethics-committeeguidelines.pdf (2 June 2020)

Vuki, S. K. (1995). The Impact of Westernisation on Traditions of Power in Tonga. Masters Thesis. Wellington: Victoria University of Wellington. Retrieved from:

https://viewer.waireto.victoria.ac.nz/client/viewer/IE921885/details?dps dvs=1601250285476 318 (13 May 2019)

Weissman, A. (2013). Pivotal Politics - The Marshall Plan: A Turning Point in Foreign Aid and the Struggle for Democracy. The History Teacher, 47(1), 111-129.

Wendt, A. (1992). Anarchy is what states make of it: the social construction of power politics. International Organization, 46(2), pp.391-425.

Wengraf, T. (2001). Qualitative research interviewing: Biographic narrative and semi-structured methods. California: Sage Publications Inc.

Wesley-Smith, T. (1995). Rethinking Pacific Island Studies. Pacific Studies, 18(2) pp.115-137.

Winters, M. (2010). Accountability, Participation and Foreign Aid Effectiveness. International Studies Review, 12(2), 218-243.

Wood, A.H. (1943). History and Geography of Tonga. Nuku'alofa: Government Printing Department.

Wood, T. (2015) 'The ups and downs of New Zealand aid: budget 2015', blog. Retrieved from: https://devpolicy.org/the-ups-and-downs-of-new-zealand-aid-budget-2015-20150529/ (24 September 2020)

Wood, T., Burkot, C., and Howes, S. (2017). Gauging Change in Australian Aid: Stakeholder Perceptions of the Government Aid Program. Asia \& the Pacific Policy Studies, 4(2), pp. 237-250. 
Woodward, R. (2009) The Organisation for Economic Cooperation and Development. London: Routledge.

World Bank. (1999). What Explains the Success or Failure of Structural Adjustment Programs?

Retrieved from: https://elibrary.worldbank.org/doi/abs/10.1596/1813-9450-1938 (27 May 2020)

World Bank. (2019). Tonga Transport Sector Consolidation Project - Implementation Completion and Results Report. Retrieved from:

http://documents.worldbank.org/curated/en/805111564434355734/pdf/Tonga-Transport-Sector-

Consolidation-Project.pdf (14 October 2019)

Wrighton, N., and Overton, J. (2012). Coping with participation in small island states: the case of aid in Tuvalu. Development in Practice, 22(2), pp. 244-255. doi: 10.1080/09614524.2012.640983

Zambakari, C. (2017). Modernization Theory and the Metaphor of the Development Ladder. Journal Forum for Development Studies, 39(3), pp. 319-336.

\section{Appendix One:}

\section{Coded Interview Table}

\begin{tabular}{|c|l|l|}
\hline Participant & Sector & Month and Year of Interview \\
\hline A & Development Partner & June, 2018 \\
\hline B & Tongan Official & June, 2018 \\
\hline C & Tongan Official & June, 2018 \\
\hline D & Development Partner & June, 2018 \\
\hline E & Tongan Official & June, 2018 \\
\hline F & Tongan Official & June, 2018 \\
\hline G & Development Partner & June, 2018 \\
\hline H & Tongan Official & June, 2018 \\
\hline I & Development Partner & June, 2018 \\
\hline J & Tongan Official & June, 2018 \\
\hline K & Tongan Official & June, 2018 \\
\hline L & Tongan Official & June, 2018 \\
\hline M & Tongan Official & June, 2018 \\
\hline N & Tongan Official & June, 2018 \\
\hline O & Development Partner & June, 2018 \\
\hline
\end{tabular}




\begin{tabular}{|c|l|l|}
\hline P & Development Partner & May, 2018 \\
\hline Q & Development Partner & May, 2018 \\
\hline R & Development Partner & June, 2018 \\
\hline S & Development Partner & June, 2018 \\
\hline T & Development Partner & May, 2018 \\
\hline U & Tongan Official & June 2018 \\
\hline
\end{tabular}




\section{Appendix Two:}

Consent to Interview Form

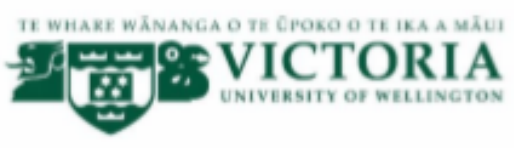

\section{Siutaka he 'aho afā: Navigating Tonga's national development priorities under international aid. \\ CONSENT TO INTERVIEW}

This consent form will be held for 5 years.

Researcher: Faka'iloatonga Taumoefolau, School of Geography, Environment and Earth Sciences, Victoria University of Wellington, New Zealand

- I have had the research explained to me clearly and understand the project. I have had the opportunity to ask questions, and any questions I had were answered to my satisfaction.

- I agree to take part in an audio recorded interview or an interview but taken with notes.

I understand that:

- I have the ability to withdrawal any information I give as long as it is prior to the completion of data collection and analysis $(20 / 01 / 2020)$.

- The information I have provided will be destroyed 5 years after the research is finished.

- I understand that during those 5 years all information will be kept securely stored by the researcher and accessible only by him.

- I understand that the information I give will be kept confidential to the researcher and their supervisor, and I will remain completely anonymous and my responses will not be attributed to me in any way unless with my consent via verbal utterance or written form.

- I understand that the only way my name will be used is if I give explicit permission for this.

- I understand that the results will be used for a PhD thesis and a summary of the results may be used in academic articles and/or presented at conferences.

- I understand that this data will remain completely confidential and will be stored in a secure manner.

- My name will not be used in reports, nor will any information that would identify me.

Signature of participant:

Name of participant:

Date:

Contact details: 
Appendix Three:

Interview information sheet for participants

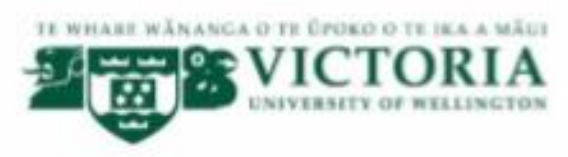

\title{
Siutaka he 'aho afā: Navigating Tonga's national development priorities under international aid.
}

\author{
INFORMATION SHEET FOR PARTICIPANTS
}

Thank you for your interest in this project. Please read this information before deciding whether or not to take part. If you decide to participate, thank you. If you decide not to take part, thank you for considering my request.

Who am I?

My name is Faka'iloatonga Taumoefolau and I am a Doctoral student in Development Studies at Victoria University of Wellington, New Zealand. This research project is work towards my thesis.

What is the aim of the project?

This project will look at how international aid shapes and supports national development, by aiming to answer the question: To what extent are national development priorities shaped and supported by international aid?

Using that overarching question, this research will focus on the Organisation for Economic Cooperation and Development 2005 Aid Effectiveness Principles and how the principles exist for Tonga's development programme provided by bilateral donors. Consequently I will also touch on whether or not a donor has adequate analytical tools in place that identifies to them the likelihood of an outcome and how or whether this informs their policies for funding.

This research has been approved by the Victoria University of Wellington Human Ethics Committee 0000024954 .

How can you help?

If you agree to take part, I will interview you where you feel most comfortable and is suitable. I will ask more or less 10 questions about your role, your responsibility, and the funding you manage. The interview will take approximately $30-40$ minutes. Where circumstances dictate 1 will record the interview and write it up later. I may just take notes during the interview. You can stop the interview at any time, without giving a reason. You can also skip any questions you do not want to answer. You can withdraw from the study prior to the completion of data collection and analysis $(20 / 01 / 20)$. If you withdraw, the information you provided will be destroyed. 


\section{What will happen to the information you give?}

This research is confidential. I will not name you in any reports, and I will not include any information that would identify you. Only my supervisors and I will read the notes or transcript of the interview. The interview transcripts, summaries and any recordings will be kept securely and destroyed 5 years after the research ends.

\section{What will the project produce?}

The information from my research will be used in my PhD thesis. You will not be identified in my report unless you explicitly state you want to be identified. I may also use the results of my research for conference presentations, and academic reports and articles. You will not be identified in any presentation or report.

\section{If you accept this invitation, what are your rights as a research participant?}

You do not have to accept this invitation if you don't want to. If you do decide to participate, you have the right to:

- choose not to answer any question;

- ask for the recorder to be turned off at any time during the interview;

- withdraw from the study prior to the completion of data collection and analysis (20/01/20);

If you have any questions or problems, who can you contact?

If you have any questions, either now or in the future, please feel free to contact either:

Student:

Faka'iloatonga Taumoefolau

Faka'iloatonga.Taumoefolau@vuw.ac.nz

\section{Supervisor:}

\author{
Professor John Overton \\ Professor \\ School of Geography. Environment and \\ Earth Sciences \\ Phone: +64-4 4635281 \\ john.overton@vuw.ac.nz
}

\section{Human Ethics Committee information}

If you have any concerns about the ethical conduct of the research you may contact the Victoria University HEC Convener: Associate Professor Susan Corbett. Email susan.corbett@vuw.ac.nz or telephone +64-4-463 5480. 


\section{MEMORANDUM \\ Phone $\quad 0-4-4635490$ \\ Email susan.corbett8vuwacnz}

\begin{tabular}{l|l}
\hline TO & Fakaïloatonga Taumoefolau \\
\hline COPY TO & Prof John Overton \\
\hline FROM & AProf Susan Corbett, Convener, Human Ethics Committee \\
\hline DATE & 12 January 2018 \\
\hline PAGES & 1 \\
\hline & $\begin{array}{l}\text { Ethics Approval: 24954 } \\
\text { SUBJECT }\end{array}$ \\
\hline
\end{tabular}

Thank you for your application for ethical approval, which has now been considered by the Standing Committee of the Human Ethics Committee.

Your application has been approved from the above date and this approval continues until 12 January 2021. If your data collection is not completed by this date you should apply to the Human Ethics Committee for an extension to this approval.

Best wishes with the research.

Kind regards
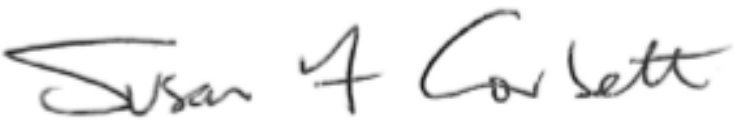

Susan Corbett

Convener, Victoria University Human Ethics Committee 
Appendix Five:

\section{Research Permit from Government of Tonga}

Prime Minister's Office Nuku'alofa, Tongatapu.

Ref: Org $1 / 8$ V.18

$29^{\text {th }}$ June, 2018

Mr. Faka'iloatonga Taumoefolau

School of Geography, Environment and Earth Sciences

Victoria University of Wellington

Wellington

NEW ZEALAND

Dear Mr. Faka'iloatonga,

\section{$\underline{\text { Re: Tonga Government Research Permit for Mr. Faka'iloatonga Taumoefolau }}$}

I am pleased to inform, that the Prime Minister's Office has approved your application to conduct your research in the Kingdom of Tonga for your $\mathrm{PhD}$ degree, namely the Siutaka, he 'aho afa: Navigating Tonga's national development priorities under International Aid.

Your proposal has compiled with all relevant requirements under the Government Research Policy as stipulated under His Majesty's Cabinet Decision No. 410 of 122 May 2011.

This permit allows you for your field work to be conducted for a period of six weeks ( $5^{\text {th }}$ June- $20^{\text {th }}$ July 2018 ) and upon request'may be extended at our discretion.

Kindly note that all relevant Government Ministries and Public Enterprises involved has granted their support to provide advice and assistance during your time here.

We wish all the best with your research during your time in the Kingdom. Should you require further assistance, please do not hesitate to contact our office.

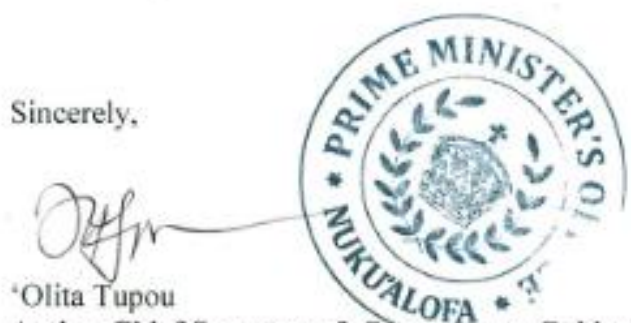

Acting Chief Secretary \& Secretary-to Cabinet. 